Aus dem Institut für Pflanzenpathologie und Pflanzenschutz der Georg-August-Universität Göttingen

\title{
Untersuchungen zum Infektionsmodus, immunologischen Nachweis und zur biologischen Bekämpfung von Leptosphaeria maculans (Desm) Ces. \& de Not., dem Erreger der Wurzelhals- und Stängelfäule an Winterraps (Brassica napus L.)
}

\author{
Dissertation \\ zur Erlangung des Doktorgrades \\ der Georg-August-Universität Göttingen \\ Fakultät für Agrarwissenschaften
}

vorgelegt von

Qinghua Zhao

aus Shaanxi, VR China

Göttingen, im Juli 2001

Gefördert durch die DFG im Graduiertenkolleg „Landwirtschaft und Umwelt“ am Forschungs- und Studienzentrum Landwirtschaft und Umwelt der Fakultät für Agrarwissenschaften 
D7

Referent: Prof. Dr. G.A. Wolf

Korreferent: Prof. Dr. U. Eberhardt

Tag der mündlichen Prüfung: 12. Juli 2001 


\section{Inhaltsverzeichnis}

\section{Abkürzungen}

1 Einleitung 1

2 Material und Methoden $\quad 8$

2.1 Chemikalien $\quad 8$

2.2 Nährmedien und Puffer $\quad 8$

2.3 Organismen 12

2.3.1 Pflanzen 12

2.3.2 Testpilze 12

2.3.3 Bakterien 12

2.4 Anzucht und Haltung der Pflanzen 13

2.5 Anzucht und Erhaltung der Mikroorganismen $\quad 14$

2.5.1 Leptosphaeria maculans 14

2.5.2 Pilzkulturen 14

$\begin{array}{lll}2.5 .3 & \text { Bakterien } & 14\end{array}$

2.6 Isolierung von Antagonisten $\quad 15$

2.7 In vitro-Screening von Antagonisten 15

2.7.1 Dualkultur-Test 15

2.7.2 Test auf antibakterielle Wirkung von Antagonistenisolaten 16

2.7.3 Nachweis der Siderophorenbildung 16

2.7.4 Nachweis flüchtiger Hemmsubstanzen 17

2.7.5 Nachweis extrazellulärer Hydrolasen 17

2.8 Charakterisierung und Identifizierung der Antagonisten 18

2.8.1 Physiologische Untersuchungen 18

2.8.1.1 Gram-Färbung 19

2.8.1.2 Nachweis der L-Alanin-Aminopeptidase 19

$\begin{array}{ll}2.8 .1 .3 & \text { Lyse durch } \mathrm{KOH} \\ & 19\end{array}$

2.8.1.4 Nachweis der Cytochrom-Oxidase 19

2.8.2 Identifizierung mit dem API-Testsystem 19

2.9 Bestimmung der Proteingehalte 21

2.10 Entwicklung und Optimierung eines DAS-ELISA zur Befallsquantifizierung 21

$\begin{array}{lll}2.10 .1 & \text { Herstellung der Antiseren } & 21\end{array}$

2.10.2 Biotinylierung der Antikörper 22

2.10.3 Optimierung des Testverfahrens 22

2.10.4 Durchführung des DAS-ELISA 22

2.10.5 Probenaufbereitung 24

2.11 ad planta Vorscreening mit Rapskeimlingen 24 
2.11.1 Besiedlung von Rapssämlingen durch Antagonisten 24

2.11.2 Hemmwirkung der Antagonisten gegen L. maculans an Rapskeimlingen 24

2.11.2.1 Inokulation der Keimblätter mit L. maculans 24

2.11.2.2 Befallsbonitur an Keimblättern 24

2.11.2.3 Durchführung des Antagonistentests 25

2.12 Inokulationsmethode für ad planta Untersuchungen in BBCH 14/15 26

2.13 Antagonistentest im BBCH 14/15 26

2.13.1 Befallsbonitur am Stängel 26

2.13.2 Durchführung des Antagonistentests 28

2.14 Versuche zum Einfluss des Früh-Stängelbefall mit L. maculans auf den $\begin{array}{ll}\text { Kornertrag } & 28\end{array}$

2.15 Untersuchungen zu den Hemmmechanismen 28

2.15.1 Bestimmung von Wachstum und Hemmstoffproduktion in Flüssigkultur 28

2.15.2 Nachweis der Bildung von Cyanwasserstoff und Ammonium 29

2.15.3 Extraktion von Hemmstoffen aus Bakterienkulturfiltraten 30

2.15.4 Plättchentest 30

2.15.5 Dünnschichtchromatographie der Extrakte 30

2.15.6 Nachweis von Bildung zweier Antimykotika mit Hilfe von HPLC 31

2.15.7 Nachweis und Quantifizierung der IAA und IAA-Derivaten- Produktion 32

2.15.8 Quantitative Aktivitätsbestimmung hydrolytischer Enzyme 32

2.16 Wachstumsbeeinflussende Eigenschaften der Antagonisten 33

2.16.1 Keimlingswachstum in Antagonistensuspensionen 33

2.16.2 Einfluss einer Wurzelbehandlung mit Antagonisten auf das Wurzelwachstum 34

2.16.3 Einfluss einer Gießbehandlung mit Antagonisten auf das Wurzelwachstum 34

2.16.4 Bestimmung der Wurzellänge 34

2.17 Untersuchungen zur Besiedlung von Rapspflanze durch Pseudomonas fluorescens RII2 bzw. Paenibacillus polymyxa HA3e anhand der CryoRasterelektronenmikroskopie (Cryo-REM) 35

2.18 Mikroskopie und Photographie $\quad 35$

2.19 Statistische Auswertung 35

3 Ergebnisse 36

3.1 Isolierung antagonistischer Mikroorganismen 36

$\begin{array}{ll}3.2 \text { in vitro-Screening antagonistischer Mikroorganismen } & 37\end{array}$

3.2.1 In vitro-Hemmung des Myzelwachstums von L. maculans und V. longisporum $\begin{array}{ll}\text { durch Antagonisten } & 37\end{array}$

3.2.2 Ermittlung des antibakteriellen Spektrums der Antagonisten 41

3.2.3 Nachweis der Siderophorenbildung 43

3.2.4 Nachweis der Bildung extrazellulärer Hydrolasen 44 
3.2.5 Überprüfung der in vitro Hemmwirkung ausgewählter Isolate auf nährstoffarmem Medium bzw. bei niedrigen Temperaturen

3.2.6 In vitro Hemmwirkung ausgewählter Isolate auf nährstoffarmem Medium bzw. bei niedrigen Temperaturen

3.2.7 Überprüfung der Hemmwirkung ausgewählter Antagonisten gegenüber verschiedenen phytopathogenen Pilzen

3.2.8 Selektion der Isolate für ad planta-Untersuchungen 50

3.3 Charakterisierung und Identifizierung von Antagonisten 52

3.3.1 Physiologische Eigenschaften der Bakterien 53

3.3.2 Identifizierung mit kommerziellen Testsystemen 53

3.3.2.1 Identifizierung der gramnegativen Bakterien 53

3.3.2.2 Identifizierung der Gram-positiven Bakterien 56

$\mathbf{3 . 4}$ ad planta Vorscreening von Antagonisten mit Rapskeimlingen $\mathbf{5 8}$

3.4.1 Besiedlung von Rapskeimlingen durch Antagonisten 58

3.4.2 Hemmwirkung gegen L. maculans an Rapskeimlingen durch die Antagonisten 59

3.4.2.1 Optimierung der Infektionsmethode 59

3.4.2.2 Verringerung des L. maculans-Befalls durch den Einsatz von Antagonisten 60

3.5 Entwicklung einer Methode zur Inokulation von Raps mit L. maculans $\quad 61$

3.6 Optimierung des ELISA zur Befallsquantifizierung mit $L$. maculans $\quad 66$

3.6.1 Ermittlung der optimalen Konzentrationen der Reagenzien im ELISA 66

3.6.2 Nachweisgrenze des Antigens und Erstellung eines internen Proteinstandards 67

3.6.3 Spezifität der Antikörper gegenüber L. maculans 68

3.7 Ausbreitung von L. maculans nach Infektion am Wurzelhals bzw. an der $\begin{array}{ll}\text { Stengelbasis von Rapspflanzen } & \mathbf{7 0}\end{array}$

3.8 Einfluß des frühen Befalles mit L. maculans auf die Kornertragsbildung $\quad 71$

3.9 Biologische Bekämpfung von L. maculans an Rapspflanzen im Entwicklungsstadium BBCH 14/15

3.9.1 Hemmwirkung der ausgewählten Antagonisten ad planta 73

3.9.2 Verbesserung der Wirksamkeit einer biologischen Bekämpfungsmaßnahme durch eine kombinierte Anwendung bakterieller Antagonisten

3.10 Einfluss der bakteriellen Antagonisten auf das Rapspflanzenwachstum $\quad 76$

3.11 In vitro Untersuchungen zu den Hemmmechanismen der Antagonisten $\quad 77$

3.11.1 Bildung von Cyanwasserstoff durch Ps. fluorescens RII2 und Paenibacillus polymyxa HA3e 
3.11.2 Bildung von Indolessigsäure (IAA) bzw. IAA-Derivaten durch

Ps. fluorescens RII2 und Paenibacillus polymyxa HA3e

3.11.3 Fungizide Wirkung von Pyrrolnitrin auf das Wachstum von L. maculans $\quad 80$

3.11.4 Nachweis der Bildung von DAPG und Pyrrolnitrin durch Ps. fluorescens RII2 und Gö2l in TSB durch DC und HPLC

3.11.4 Quantitativer Nachweis extrazellulärer Hydrolasen von Ps. fluorescens RII2 und Paenibacillus polymyxa HA3e

3.12 Untersuchungen zur Besiedlung von Rapspflanze durch Pseudomonas fluorescens RII2 bzw. Paenibacillus polymyxa HA3e 86

4 Diskussion $\quad 92$

4.1 Isolierung von Antagonisten 92

4.2 In vitro-Screening $\quad 95$

4.3 Ad planta Screening an Rapskeimlingen $\quad 100$

4.4 Verminderung des Wurzelhals- und Stängelbasisbefall durch antagonistische $\begin{array}{ll}\text { Mikroorganismen } & 102\end{array}$

4.5 Etablierung von Antagonisten am Wurzelhals der Rapspflanzen 106

4.6 Wirkmechanismen 110

$\begin{array}{ll}4.7 \text { Ausblick } & 117\end{array}$

5 Zusammenfassung $\quad 121$

6 Literatur 123 


\section{Abkürzungsverzeichnis}

\begin{tabular}{|c|c|}
\hline $\mathrm{A} 1 / \mathrm{A} 2$ & aggressive Stämme von Leptosphaeria maculans \\
\hline Abb. & Abbildung \\
\hline AG & Antigen \\
\hline AK & Antikörper \\
\hline Aqua bidest. & bidestilliertes Wasser \\
\hline $\mathrm{BBCH}$ & Rapsentwicklungsstadium (Bayer BASF Ciba-Geigy Höchst) \\
\hline BEA & Bodenextrakt-Agar \\
\hline Bis & $\mathrm{N}, \mathrm{N}^{\prime}$-Methylen-bis-acrylamid \\
\hline CAS & Chromazurol S \\
\hline CDA & Czapek-Dox-Agar, modifiziert \\
\hline cfu & colony forming units \\
\hline CM & Carboxymethyl \\
\hline DAPG/Phl & 2,4-Diacetylphloroglucinol \\
\hline DC & Dünnschichtchromatographie \\
\hline DMAPN & 3-Dimethylaminopropionitril \\
\hline DRMO & deleterious rhizosphere microorganisms \\
\hline DTT & Dithiotreithol \\
\hline $\mathrm{E}_{405}$ & Extinktion bei einer Wellenlänge von $405 \mathrm{~nm}$ \\
\hline$E_{592}$ & Extinktion bei einer Wellenlänge von 592 nm \\
\hline EDTA & Ethylendiamintetraessigsäure Dinatriumsalz-Dihydrat \\
\hline ELISA & Enzyme-linked immunosorbent assay \\
\hline Fa. & Firma \\
\hline$g$ & Erdbeschleunigung \\
\hline $\mathrm{h}$ & Stunde(n) \\
\hline $\mathrm{HCN}$ & Cyanwasserstoff \\
\hline HDTMA & Hexadecyltrimethylammoniumbromid \\
\hline HEPES & N-2-Hydroxyethylpiperazin-N'-2-ethansulfonsäure \\
\hline HPLC & high performance (pressure) liquid chromatography \\
\hline IBCN & the International Blackleg of Crucifers Network \\
\hline IAA & Indolessigsäure \\
\hline $\lg G$ & Immunoglobin G \\
\hline K & Kontrolle \\
\hline $\min$ & Minute(n) \\
\hline MsA & Messisae Agar \\
\hline NA & nicht aggressive Stämme von L. maculans \\
\hline$\varnothing$ & Durchmesser \\
\hline OD & optische Dichte \\
\hline p. a. & pro analysi \\
\hline PDA & Potato-Dextrose-Agar \\
\hline PGPR & plant growth promoting rhizobacteria \\
\hline PIPES & Piperazine-N,N"'-bis-2-ethansulfonsäure \\
\hline pNPP & para-Nitrophenylphosphat \\
\hline
\end{tabular}




$\begin{array}{ll}\text { ppm } & \text { parts per million } \\ \text { PVP } & \text { Polyvinylpyrrolidon } \\ \text { PLT } & \text { Pyoluteorin } \\ \text { RBB } & \text { Remazol Brilliant Blue } \\ \text { RSA } & \text { Rinderserumalbumin } \\ \text { S } & \text { Sekunde(n) } \\ \text { StrAP } & \text { Streptavidin-alkalische-Phosphatase-Konjugat } \\ \text { Tab. } & \text { Tabelle } \\ \text { Tris } & \text { Tris-hydroxymethyl-aminomethan } \\ \text { TSA/B } & \text { Tryptic-Soy-Agar/Broth } \\ \text { U } & \text { unit } \\ \text { v/v } & \text { Volumen pro Volumen } \\ \bar{x} & \text { Mittelwert }\end{array}$




\section{Einleitung}

Raps, der die Pflanzenarten Brassica carinata, B. juncea, B. rapa und B. napus umfasst, ist die Ölfrucht mit der größten Verbreitung in der gemäßigten Klimazone u. a. in Nord- und Zentraleuropa, Kanada, China und Indien. In Mitteleuropa wird vornehmlich der leistungsfähige und ertragreiche Winterraps (B. napus L.) angebaut.

In der Hauptnutzung als Nahrungsöl liefert der Raps den Grundstoff für Margarine, Backfett, Mayonaise und Speiseöl. Der Eiweißrückstand, der nach der Ölextraktion anfällt, stellt ein wertvolles Futtermittel dar. Das Raps-Speiseöl hat ein für die menschliche Ernährung hervorragendes Fettsäuremuster und weist im Hinblick auf Herzinfarkt und Kreislauf günstige Wirkungen auf (REUTER 1999). Im 'Non-Food' Bereich wird das Öl als Rohstoff für Spezialöle wie Schmier-, Hydraulik-, Sägeketten- und Schalungsöle sowie für die Erzeugung von Biodiesel und Tensiden genutzt (BERTRAM 1996, FochEM 1996, REMMELE \& WIDMANN 1998).

Dank der züchterischen Erfolge bei der Entwicklung von Rapssorten mit einem hohen Ölsäuregehalt in den frühen 70er Jahren erlebte der Rapsanbau einen dramatischen Aufschwung in der EU. So stieg die Anbaufläche in der Bundesrepublik Deutschland von 1974 bis 1991 von 103000 auf 933000 ha an. Seit der EU-Agrarreform 1992 bleibt diese Kulturpflanze aufgrund der guten Ertragswettbewerbsfähigkeit, der ausgezeichneten Vorfruchtwirkung und der gewährten Ölsaatprämie eine bedeutende Frucht in Deutschland. Im Jahr 1998 belief sich die Anbaufläche für Winterraps auf 1 Mio. ha und hatte somit einen Anteil von 8,4\% an der gesamten Ackerfläche in allen Regionen Deutschlands (BSA 2000). Mit dem Bevölkerungswachstum und dem daraus resultierenden Konsumzuwachs an pflanzlichen Ölen weltweit wird u. a. die Rapsproduktion ein immer größeres Gewicht gewinnen. Diese Tendenz erfordert eine verbesserte Bewirtschaftung, insbesondere einen effektiveren Pflanzenschutz vor Schädlingen und Krankheiten.

Der Erreger der Wurzelhals- und Stengelfäule, Leptosphaeria maculans (Desm) Ces. \& de Not. [anamorph Phoma lingam (Tode ex Fr.) Desm.], welcher überall in den gemäßigten Zonen verbreitet und ein bekannter Pathogen verschiedener Pflanzenarten der Familie Brassicaceae ist, gehört neben den Pilzen Sclerotinia sclerotiorum, Cylindrosporium concentricum und Verticillium longisporum zu den im Raps wirtschaftlich bedeutendsten Krankheitserregern.

Der Pilz wurde erstmals 1791 von TODE beschrieben. Da er in vertrockneten Stängeln von Brassica oleracea rubra gefunden wurde, ordnete inn TODE zu den Saprophyten und nannte inn Sphaeria lingam. 1849 isolierte DESMAZIERE den gleichen Pilz von lebenden Pflanzen der Gattung Brassica und benannte inn Phoma lingam (Tode) Desm. (zit. HENDERSON 1918). 
Das zugehörige Perfektstadium zu Phoma lingam wurde von MüLLER \& TOMASEVIC (1957) erkannt. Zuvor hatte SMITH (1956) die Hauptfruchtform entdeckt, aber als Leptosphaeria napi (Fuckel) Sacc. bezeichnet. SMITH \& SUTTON (1964) sowie BOEREMA \& VAN KESTEREN (1964) gaben inm schließlich den Namen L. maculans.

Beim Raps befällt dieser Erreger sämtliche Pflanzenteile in allen Entwicklungsstadien. In der Auflaufphase kann eine Infektion zum Umfallen der Sämlinge führen (CUNNINGHAM 1972, NDIMANDE 1976). Auf den Laubblättern entstehen zunächst Chlorosen, die dann in graue runde bis ovale Nekrosen übergehen. Diese sind meist von einem dunklen Rand umgeben und vom gesunden Gewebe deutlich abgegrenzt. Auf diesen Nekrosen entstehen zahlreiche schwarze Pyknidien, deren Pyknosporen mit Regenspritzen auf andere Blätter und Stengel verbreitet werden (BOKOR ET AL. 1975, PETRIE 1979). Läsionen am Stängel, die gewöhnlich im Juni/Juli auftreten, ähneln denen am Laubblatt. Sie sind meist an Blattansatzstellen zu finden, aber auch Wundstellen (verursacht durch Schädlingsfraß von Psylloides chrysocephalus, Ceuthorhynchus napi usw.) sind ideal für die Infektion (NDIMANDE 1976). Befallene Blütenstände und Hülsen bringen infizierte, meist geschrumpfte Samen hervor, die nicht auskeimen (BOKOR et al. 1975). Der für den Ertragsverlust zuständige Wurzelhals- und Stängelbasisbefall führt meistens zur Schwärzung des Gewebes und schließlich zur Trockenfäule. Zusammen mit Sclerotinia sclerotiorum und Verticillium longisporum verursacht der Schaderreger den Komplex der sog. "Krankhaften Abreife" (DAVIES 1986, HORNig 1986, Frauen 1992, Amelung et al. 1996, HePpNer \& Heitfuss 1996). Oft sind es starke Einschnürungen am Stängelgrund, die schließlich zum Umknicken der Pflanzen führen. Bei einem starken Befall kann es aufgrund des geringen Tausendkorngewichtes und der unterschiedlichen Abreife zu Ertragseinbußen von 20-30\% kommen (BuSCH 1987, KAHRBANDA et al. 1989, GLADDERS 1995).

Zahlreiche Berichte verdeutlichen die hohen Ertragsverluste in Befallsjahren. Hohe Ertragsausfälle in Australien führten von 1972-1974 zu einem Rückgang des Rapsanbaus von 49.000 ha auf 2000 ha (BOKOR et al. 1975). In der Region Cher/Frankreich fielen die Durchschnittserträge von 21,9 dt/ha (1964) auf $13 \mathrm{dt} /$ ha (1966) (ALABOUVETTE \& BRUNIN 1970). Besonders schwere Epidemien durch $L$. maculans sind nach der Intensivierung des Rapsanbaus (GLADDERS \& MUSA 1979, RAWLINSON \& MUTHYALU 1979, HUMPHERSON-JONES 1983) in Frankreich (LACOSTA et al. 1969), Deutschland (KRÜGER 1979) und England (GLADDERS \& SYMONDS 1995, FITT et al. 1997) aufgetreten. Mit der Einführung des Rapsanbaus in Australien wurde innerhalb weniger Jahre auch die Krankheit eingeschleppt (MCGEe \& EMMETT 1977, WoOd \& BARBETTI 1977). In Kanada hat L. maculans seit den späten siebziger Jahren schwerwiegenden Einfluss den Ertrag, besonders in den Regionen Saskatchewan und Manitoba (PETRIE et al. 1985, PETRIE 1993b). 
Die enorme Ausweitung des Winterrapsanbaus und der daraus resultierenden Tendenz zu engeren Fruchtfolgen, die ungünstigen Boden- und schlechten Auflaufbedingungen seit den 90er Jahren führten zum verstärkten Auftreten von Schädlingen und Krankheitserregern (AMELUNG et al. 1996, GARBE 1996). Die Ergebnisse der jüngsten Monitorings mit Hilfe eines für L. maculans entwickelten ELISA zeigten, dass der Pilz nach wie vor der am häufigsten vorkommende Erreger in Winterraps in Deutschland ist (CERNUSKO et al. 2000).

Die Fähigkeit des Pilzes sich sowohl asexuell über Pyknidiosporen als auch sexuell über Ascosporen zu vermehren, stellt ein großes Verbreitungspotential dar. Nach der Ernte bildet der Pilz saprophytisch auf abgestorbenen Pflanzenmaterial Pseudothezien, in denen Ascosporen heranreifen, die mit dem Wind über größere Entfernung verfrachtet werden (Alabouvette \& Brunin 1970, Petrie 1978, Gladders \& Musa 1980), als wichtiges Primärinokulum dienen und einen frühen Herbstbefall an Blätter und an Wurzelhals auslösen können (WoOd \& BARBetTI 1977, Mc Gee \& Petrie 1979, Gladders \& MusA 1980). Die asexuell gebildeten Pyknidiosporen, die durch Regen die Blattetagen und den Wurzelhals benachbarter Pflanzen besiedeln (BARBETTI 1976, EVANS 1988), werden sowohl mit der frühen Wurzelhalsinfektion als auch mit der sekundären Verbreitung in Verbindung gebracht (FESER 1992). In Gegensatz dazu spielt Myzel sehr wohl eine untergeordnete Rolle für die Primärinfektion. Nach einer erfolgten Primärinfektion an den Blättern kann der Pilz systemisch in den Stengel vordringen, wo es zu Vermorschungen kommt (GABRIELSON 1983, HAMMOND 1985, HILL \& WILLIAMS 1988, WILLIAMS 1992). Jedoch wäre eine solche Infektion von geringerer Ertragsrelevanz, als eine frühe Primärinfektion am Wurzelhals bzw. an der Stängelbasis (SCHRAMM 1989).

Nach DUAMKHANMANEE (1996) liegen Hinweise auf bodenbürtige Erstinfektionen vor, die von befallenen Stoppelresten ausgehen, solange infektionsfähige Sporen gebildet werden. Daraus kann abgeleitet werden, dass der Pilz effektiv durch die Verhinderung der Ausbildung von Asco- und Pyknidiosporen auf befallenen Ernterückständen bekämpft werden sollte. Nach der Ernte müssen dazu die Stoppelreste eingepflügt und alle ackerbaulichen Maßnahmen ergriffen werden, um eine rasche Zersetzung befallener Pflanzenteile zu fördern (GugEL \& PETRIE 1992). Die Einhaltung eines Sicherheitsabstandes zum nächsten Altraps ist eine wichtige Voraussetzung für befallensfreie Bestände (HUGES 1933, BOKOR et al 1975, NdimAnde 1976, McGee 1977). Häufig werden in Kanada, einem Land in dem Leptosphaeria maculans eine weitaus größere wirtschaftliche Bedeutung hat als in Deutschland, Anbaupausen von vier bis fünf Jahren eingehalten, weil der Abbau der Stoppeln im Feld, vor allem bei Trockenheit, bis zu fünf Jahre dauern kann. Auch durch eine Verzögerung der Aussaat kann nach NEILL (1929), BOKOR et al. (1975), BARBETTI et al. (1977), SCHUSTER et al. (1980) der Phomabefall deutlich vermindert werden. Der Nutzen für 
den Praktiker ist jedoch gering, da sich die verspätete Aussaat in der Regel negativ auf den Ertrag auswirkt.

Im Gegensatz zur Feststellung von CUNNINGGHAM (1927), der infiziertes Saatgut als Ursache für die großen Ertragsverluste im Anbau von Brassicaceae sieht, bewiesen die Untersuchungen anderer Autoren, dass die durchschnittlichen Verseuchungsgrade von Rapssaatgut sehr niedrig sind und zwischen 0,1\% bis 0,6 \% liegen (ALLEN \& SMITH 1961, BOKOR et al. 1975, NDIMANDE 1976, WINTER \& HUBER 1978, HUMPHERSON-JONES 1985, Schramm 1989).

Anstrengungen, die Wurzelhals- und Stängelfäule des Rapses chemisch zu bekämpfen, werden seit den 70er Jahren permanent unternommen.

Die Möglichkeit, mit einer Beizung den Saatgutbefall mit L. maculans zu reduzieren, wurde bereits 1927 von Cunningham erkannt und befürwortet. BRUNIN (1972) berichtete einen effektiven Schutz der Keimpflanzen vor einer L. maculans-Infektion durch Saatgutpillierung mit hohen Aufwandmengen des systemischen Wirkstoffs Benomyl. Unter Freilandbedingungen waren jedoch positive Effekte selten erkennbar (BARBETTI 1975, BROWN et al. 1976, GABRIELSON et al. 1977). FESER (1992) erzielte einen besseren Beizeffekt bei einer kombinierten Anwendung von systemischen und lokalsystemischen Wirkstoffen an der Gesamtpflanze. Allerdings konnten die Infektionen bereits eine Woche nach Feldaufgang durch Beizung nicht mehr signifikant reduziert werden.

Die Ascosporen sind als Hauptinokulum für Primärinfektionen im Herbst anzusehen. Unter Laborbedingungen konnte eine Behandlung des Rapsstrohs mit verschiedenen Fungiziden die Pseudothecienbildung fast vollständig reduzieren und eine Behandlung mit Dinosab und Harnstoff das Ausschleudern der gebildeten Ascosporen verhindern (HUMPHERSON-JONES \& BURCHILL 1982). Jedoch brachten derartige Bekämpfungsmethoden mit Fungiziden unter Feldbedingungen keine statistisch absicherbare Wirkung (RAWLINSON et al. 1984). Vor dem Hintergrund der steigenden Bedeutung von Direktsaat, vor allem in Westkanada, empfiehlt PETRIE (1995) allerdings die Applikation von Glyphosat zur Unterdrückung des Inokulums.

Fungizidapplikationen über das Blatt wurden von zahlreichen Autoren (u. a. BRowN et al. 1976, EVANS \& GLAdDERS 1981, Gladders 1988, RAWLINSON \& MUthyALU 1979, KRÜGER 1983, SCHRAMM 1989) zur Bekämpfung von L. maculans durchgeführt. Selbst die Applikation von Spezialfungiziden wie Sportak (Wirkstoff: Prochloraz) und Fungiziden mit wachstumsregulatorischem Effekt wie Folicur (Wirkstoff: Tebuconazol), Caramba (Wirkstoff: Metconazol) bei optimalen Spritzbedingungen hat nur eine begrenzte Wirkung gegenüber der Wurzelhals- und Stengelfäule (AHLERS 1991, FITT et al. 1997, STEINBACH \& BROSCHEWITZ 1997, GLADDERS et al. 1998, Garbe 2000). Die kombinierte Anwendung von 
Folicur bzw. Caramba und dem Wachstumsregler Moddus (Wirkstoff: Trinexapacethyl) führte bisher auch zu keinem überzeugenden Ergebnis (BROSCHEWITZ \& STEINBACH 1999, Lindenberg 2001). Eine chemische Behandlung bei niedrigem und mittlerem Befall ist aus ökonomischen Gesichtspunkten oftmals nicht gerechtfertigt (PAUL et al. 1991, GARBE 1994 \& 2000, THÜRWÄCHTER 1995, WÖPPEL 1995).

Die gezielteste und effizienteste Maßnahme zur Bekämpfung dieser Krankheit stellt der Anbau von resistenten bzw. toleranten Sorten dar. Als Paradebeispiel für eine weniger anfällige Sorte galt Jet Neuf, die vor der Einführung der Doppelnullsorten eine der weitverbreitetsten Sorten in Europa war. Ihre Resistenz wird polygenisch vererbt (CARGEEG \& THURLING 1980) und ist noch heute ein fester Bestandteil der Züchtung Phoma-resistenter Rapssorten mit 00-Qualität in Europa. Jedoch ist die Resistenz der auf dem Markt befindlichen 00-Sorten nur schwach ausgeprägt. Bisher sind Express, Kapitan, Licondor, Lisabeth, Mohican und Talent der Boniturnote 3 als gering anfällig in der Beschreibenden Sortenliste eingetragen (BSA 2000). Die Resistenzeinstufung des Bundessortenamtes muss jedoch kritisch gesehen werden, weil auf Grund des bisherigen Verfahren an allen Prüforten, also auch an denen mit geringem, nicht differenzierendem Krankheitsdruck, nur Bonituren nach dem Schwadlegen durchgeführt werden und daraus ein Mittelwert zur Sortenbeurteilung errechnet wurde (BUBERL 1992).

Isolate von L. maculans können hinsichtlich ihrer Virulenz anhand eines BrassicaDifferentialsortiments in die Pathogenitätsgruppen A1-A6 eingeteilt werden (KUSWINANTI et al. 1999). Durch zahlreiche Virulenzuntersuchungen wurde festgestellt, dass Isolate der Pathogenitätsgruppe A2 häufig starke Symptome an der Sorte Jet Neuf hervorrufen, die gegenüber zahlreichen anderen Pathogenitätsgruppen Resistenzen aufweist (KUSWINANTI 1996). Zwar dominierte bislang die Pathogenitätsgruppe A2 in der L. maculans-Population an Winterraps nicht (KUSWINATI 1996, 1999; VOLKE 1999), aber eine Steigerung des Anteil an A2-Isolaten in der natürlichen L. maculans-Population kann nicht ausgeschlossen werden. Daher birgt die relativ enge genetische Basis der auf dem Markt befindlichen 00Sorten die Gefahr, dass die Resistenz von der Pathogenitätsgruppe A2 bzw. neuen Erregerrassen durchbrochen werden könnte.

Eine andere Alternative zur Bekämpfung der Wurzelhals- und Stängelfäule bietet die Anwendung transgener Rapssorten mit einer Resistenz gegen L. maculans. Die Verwendung genetisch veränderter Kulturpflanzen stößt jedoch besonders in Deutschland bei weiten Teilen der Bevölkerung aufgrund mangelnder Sicherheitsabschätzung auf nur geringe Akzeptanz (LÜCHS \& FRIEDT 1997). 
In Verbindung mit dem zunehmenden ökologischen Bewusstsein in der Gesellschaft gewinnt die Suche nach alternativen umweltschonenden Bekämpfungsverfahren, bei denen durch den Einsatz antagonistischer Mikroorganismen die Pflanze vor einer Infektion geschützt und das Inokulumpotential des Erregers unterdrückt wird, ein immer größeres Gewicht. Klassische Beispiele mit nennenswertem Erfolg sind u. a. die Bekämpfung von Agrobacterium tumefaciens mit $A$. radiobacter-Isolaten sowie die Unterdrückung von Gaeumannomyces graminis var. tritici durch Einsatz von Pseudomonas spp. Zahlreiche Autoren berichten von Trichodermaarten zur Bekämpfung diverser Pilzerkrankungen sowie von Streptomyceten, Pseudomonaden und Bacilli als Antagonisten bodenbürtiger Pathogene. Mittlerweile haben ca. 40 biologische Präparate auf mikrobiologischer Basis eine Marktzulassung erlangt. Allerdings spielen Verfahren des biologischen Pflanzenschutzes in der praktischen Landwirtschaft aufgrund des eingeschränkten Wirkungsspektrums sowie der Wirkungsunsicherheit unter variierenden Freilandbedingungen einzelner Präparate nur eine marginale Rolle (POWELL \& JUTSUM 1993, KOCH 1996).

Die Nutzung antagonistischer Mikroorganismen zur Bekämpfung von Phytopathogenen hat trotz erwähnter Nachteile und potentiell unerwünschter Nebeneffekte auf Nichtzielorganismen, wie den endemischen pflanzenfördernden Mikroorganismen, nach wie vor vermehrt Beachtung gefunden. Für den ökologischen Rapsanbau wurde im Februar 1999 Contans von der Prophyta $\mathrm{GmbH}$ als das erste biologische Fungizid in Deutschland gegen Sclerotinia sclerotiorum, dem Erreger des Rapskrebs zugelassen. Das Produkt besteht aus den Sporen von Coniothyrium minitans, einem sklerotienparasitierenden Bodenpilz, der in den meisten Ackerböden natürlich vorkommt. Im Gegensatz zu den bisher üblichen Fungizideinsätzen kann dessen Anwendung sowohl das im Boden ruhende Inokulum erreichen als auch die Entstehung neuer Sklerotien von S. sclerotiorum effektiv unterbinden (von TIEDEMANN et al. 2000). Mit Contans existiert damit ein Baustein zu einer völlig neuen Strategie der nachhaltigen Pilzbekämpfung im Winterraps (von TIEDEMANN et al. 2001).

Darüber hinaus wurden von BERG (1994) und SASSE (1997) bereits Grundlagen zur biologischen Bekämpfung von Verticillium longisporum, einem der Erreger der `Krankhaften Abreife' im Winterraps, erarbeitet. Zur biologischen Bekämpfung von L. maculans liegen allerdings bisher nur unzureichende Untersuchungen vor. KHARBANDA \& DAHIYA (1990) beobachteten, das einige Stämme von Penicillium verrucosum ein für den Erreger toxisches Metabolit bilden. PETRIE (1982) verwendete schwach virulente Isolate von L. maculans zur Unterdrückung starker Symptomausprägungen.

Vor diesem Hintergrund erschien es sinnvoll, die biologische Bekämpfung der Rapswurzelhals- und Stängelfäule als eine umweltschonende Alternative verstärkt voranzutreiben. Während die oben genannten Autoren mit pilzlichen Antagonisten 
arbeiteten, sollten in der vorliegenden Arbeit vornehmlich bakterielle Antagonisten durch in vitro und in vivo Screeningverfahren selektiert und auf ihre ad planta Wirkung überprüft werden. Dazu gehörten die Entwicklung einer den natürlichen Bedingungen entsprechenden, reproduzierbaren Inokulationsmethode mit L. maculans sowie die Optimierung einer empfindlichen, zuverlässigen immunologischen Methode zur Befallsquantifizierung. Neben einer Optimierung der Bekämpfungswirkung sollten durch immunologische Methoden die Kenntnisse über die Biologie des Erregers und die Epidemiologie der Krankheit erweitert werden. Abschließende Untersuchungen, wie der Nachweis von Antibiotika oder hydrolytischen Enzymen, sollten schließlich Aufschluss über die Art des antagonistischen Wirkprinzips geben. 


\section{Material und Methoden}

\subsection{Chemikalien}

Neben den im folgenden aufgeführten Chemikalien wurden im Rahmen dieser Arbeit Produkte der Fa. Merck, Darmstadt, mit dem Reinheitsgrad p.a. verwendet.

Agar (Loewe, Sauerlach)

Chloroform (Roth, Karlsruhe)

Diacetylphloroglucinol Abt. Prof. Défago (Zürich, Schweiz)

Glycerin (Roth, Karlsruhe)

IAA (Sigma, Deisenhofen)

Kristallviolett (Serva, Heidelberg)

Natriumsulfat (Roth, Karlsruhe)

N,N,N,N -Tetramethylendiamin (Fluka, Neu-Ulm)

Paraffin (Roth, Karlsruhe)

Pepton (Difco Laboratories, Detroit, Michigan, USA)

p-Nitrophenylphosphat (Serva, Heidelberg)

Polyvinylpyrrolidone (Serva, Heidelberg)

Potato Dextrose Broth (Difco Laboratories, Detroit, Michigan, USA)

Proteose Pepton No.3 (Difco Laboratories, Detroit, Michigan, USA)

Pyrrolnitrin (Fujisawa Pharmaceutical Co. Ltd, Osaka, Japan)

Rifampicin (Serva, Heidelberg)

Rinderserumalbumin (Roche, Mannheim)

Saccharose (Roth, Karlsruhe)

Silbernitrat (Fluka, Neu-Ulm)

Streptomycinsulfat (Serva, Heidelberg)

Tryptic Soy Broth (Difco Laboratories, Detroit, Michigan, USA)

Trypton (Difco Laboratories, Detroit, Michigan, USA)

Tween 20 (Fluka, Neu-Ulm)

Xanthan (Monsanto, UK)

\subsection{Nährmedien und Puffer}

Alle Nährmedien wurden mit aqua bidest. angesetzt und 15 min bei $121^{\circ} \mathrm{C}$ und 1 bar autoklaviert. Die Einstellung des $\mathrm{pH}$-Wertes erfolgte vor dem Autoklavieren mit $1 \mathrm{~N}$ oder $2 \mathrm{~N}$ Salzsäure bzw. Natronlauge. Feste Medien wurden in Polystyrolpetrischalen $(\varnothing 90 \mathrm{~mm}$, Sarstedt, Nümbrecht) ( 90 mm, Fa. Greiner, Nürtingen) ausgegossen. 


\section{Bodenextraktagar (BEA), $\mathrm{pH} \mathrm{7,0}$}

$1.000 \mathrm{~g}$ gesiebter Feldboden wurde in $1.500 \mathrm{ml}$ Leitungswasser autoklaviert und nach dem Erkalten klarfiltriert (Faltenfilter, Fa. Schleicher \& Schuell, Dassel).

Bodenfiltrat

Agar

$16 \mathrm{~g}$

aqua bidest.

ad $1.000 \mathrm{ml}$

CAS-Medium (nach ALEXANDER \& ZUBERER, 1991)

Lösung 1: Fe-CAS-Indikatorlösung

$$
\mathrm{FeCl}_{3} \times 6 \mathrm{H}_{2} \mathrm{O}(1 \mathrm{mM}) \text { in } 10 \mathrm{mM} \mathrm{HCl} \quad 10 \mathrm{ml}
$$

CAS in Aqua bidest. $(1,21 \mathrm{mg} / \mathrm{ml}) \quad 50 \mathrm{ml}$

dazu langsam unter ständigem Rühren

HDTMA in Aqua bidest. $(1,82 \mathrm{mg} / \mathrm{ml}) \quad 40 \mathrm{ml}$

Lösung 2: Pufferlösung

$\begin{array}{ll}\mathrm{KH}_{2} \mathrm{PO}_{4} & 300 \mathrm{mg} \\ \mathrm{NaCl} & 500 \mathrm{mg} \\ \mathrm{NH}_{4} \mathrm{Cl} & 1 \mathrm{~g} \\ \text { auf } 750 \mathrm{ml} \text { mit Aqua bidest. auffüllen } & \\ \text { PIPES } & 30,24 \mathrm{~g} \\ \text { pH 6,8 mit KOH (50\%ig) einstellen } & \\ \text { Agar } & 10 \mathrm{~g} \\ \text { auf } 800 \mathrm{ml} \text { mit Aqua bidest. auffüllen } & \\ \text { Lösung 3: } & \\ \text { Glucose } & 3 \mathrm{~g} \\ \mathrm{Mannitol}^{2} & 2 \mathrm{~g} \\ \mathrm{MgSO}_{4} \times 7 \mathrm{H}_{2} \mathrm{O} & 493 \mathrm{mg} \\ \mathrm{CaCl}_{2} & 11 \mathrm{mg} \\ \mathrm{MnSO}_{4} \times \mathrm{H}_{2} \mathrm{O} & 1,17 \mathrm{mg} \\ \mathrm{H}_{3} \mathrm{BO}_{3} & 1,4 \mathrm{mg} \\ \mathrm{CuSO}_{4} \times 7 \mathrm{H}_{2} \mathrm{O} & 0,04 \mathrm{mg} \\ \mathrm{ZnSO}_{4} \times 7 \mathrm{H}_{2} \mathrm{O} & 1,2 \mathrm{mg} \\ \mathrm{Na}_{2} \mathrm{MoO}_{4} \times 2 \mathrm{H}_{2} \mathrm{O} & 1 \mathrm{mg}\end{array}$

auf $70 \mathrm{ml}$ mit Aqua bidest. auffüllen

Lösung 4:

Casamino Acids (10\%ig) $\quad 30 \mathrm{ml}(\mathrm{w} / \mathrm{v})$

Lösung wird sterilfiltriert

Lösungen 1 bis 3 werden autoklaviert.

Nach dem Abkühlen werden die Lösungen 2 bis 4 zusammengegeben, Lösung 1 wird langsam dazugegeben.

Czapek-Dox-Agar (CDA), modifiziert, pH 5,5

Czapek-Dox $25 \mathrm{~g}$

Proteose Pepton No. $3 \quad 0,1 \%$ 
Agar $\quad 16 \mathrm{~g}$

Aqua bidest. $\quad 1000 \mathrm{ml}$

Erbsenmedium (EM), $\mathrm{pH} 7,0$

$200 \mathrm{~g}$ tiefgefrorene Erbsen wurden in $1.000 \mathrm{ml}$ Leitungswasser $45 \mathrm{~min}$ gekocht und durch einen Büchnertrichter abfiltriert.

Erbsenfiltrat

Glucosemonohydrat

Leitungswasser

$6 \mathrm{~g}$ ad $1.000 \mathrm{ml}$

Hafermehl-Agar

$\mathrm{pH} 5,5$

Hafermehl

$30 \mathrm{~g}$

Agar

$15 \mathrm{~g}$

Aqua demin.

$1000 \mathrm{ml}$

King B-Agar (KBA) (nach KING et al., 1954) pH 7,2

Proteose Pepton No.3

$20 \mathrm{~g}$

$\mathrm{K}_{2} \mathrm{HPO}_{4} \times 3 \mathrm{H}_{2} \mathrm{O}$

$2 \mathrm{~g}$

$\mathrm{MgSO}_{4} \times 7 \mathrm{H}_{2} \mathrm{O}$

$1,5 \mathrm{~g}$

Glycerin

$10 \mathrm{ml}$

aqua bidest.

ad $1.000 \mathrm{ml}$

Agar

$16 \mathrm{~g}$

Messiaen Medium (MsA) $\quad \mathrm{pH} 5,5-5,7$

$\mathrm{Ca}\left(\mathrm{NO}_{3}\right)_{2} \cdot 4 \mathrm{H}_{2} \mathrm{O}$

$1,000 \mathrm{~g}$

$\mathrm{KNO}_{3}$

$0,25 \mathrm{~g}$

$\mathrm{MgSO}_{4} .7 \mathrm{H}_{2} \mathrm{O}$

$0,25 \mathrm{~g}$

$\mathrm{KH}_{2} \mathrm{PO} 4$

$0,125 \mathrm{~g}$

$\mathrm{K}_{2} \mathrm{HPO} 4$

$0,125 \mathrm{~g}$

Saccharose

$5,000 \mathrm{~g}$

Malz Extrakt

$1,000 \mathrm{~g}$

Citric acid

$0,05 \mathrm{~g}$

Agar

$16 \mathrm{~g}$

Aqua bidest

ad $1000 \mathrm{ml}$

Potato Dextrose Agar (PDA), pH 6,5

Potato Dextrose Broth

$24 \mathrm{~g}$

Agar

$16 \mathrm{~g}$

aqua bidest.

ad $1.000 \mathrm{ml}$

\section{SNA-Medium}

$\begin{array}{ll}\mathrm{KH}_{2} \mathrm{PO} 4 & 1 \mathrm{~g} \\ \mathrm{KNO}_{3} & 1 \mathrm{~g} \\ \mathrm{MgSO}_{4} \times 7 \mathrm{H}_{2} \mathrm{O} & 0,5 \mathrm{~g} \\ \mathrm{KCl} & 0,5 \mathrm{~g} \\ \text { Glucose } & 0,2 \mathrm{~g}\end{array}$


Saccharose

aqua bidest

Agar
$0,2 \mathrm{~g}$

ad $1000 \mathrm{ml}$

$16 \mathrm{~g}$

Strohextraktagar (SEA), $\mathrm{pH} \mathrm{5,5}$

$20 \mathrm{~g}$ auf $2 \mathrm{~mm}$ Größe gemahlene Rapsstängel wurde mit 1000ml aqua. demin. vermischt autoklaviert und nach dem Abkühlen abfiltriert.

Strohextrakt

aqua bidest. $\quad$ ad $1.000 \mathrm{ml}$

Agar $\quad 16 \mathrm{~g}$

Succinatagar (nach PHILSON \& LLINAS 1982) pH 7,0

$\begin{array}{ll}\mathrm{KH} 2 \mathrm{PO} 4 & 3 \mathrm{~g} \\ \mathrm{~K} 2 \mathrm{HPO} 43 \mathrm{H} 2 \mathrm{O} & 6 \mathrm{~g} \\ (\mathrm{NH} 4) 2 \mathrm{SO} 4 & 1 \mathrm{~g} \\ \mathrm{NaOH} & 0,7 \mathrm{~g}\end{array}$

(bzw. mit 4N NaOH den $\mathrm{pH}-$ Wert einstellen)

Succinat $4 \mathrm{~g}$

$\mathrm{MgSO} 47 \mathrm{H} 2 \mathrm{O} \quad 0,2 \mathrm{~g}$

$\mathrm{CaCl} 2 \mathrm{H} 2 \mathrm{O} \quad 10 \mathrm{mg}$

$\mathrm{ZnSO} 47 \mathrm{H} 2 \mathrm{O} \quad 14 \mathrm{~g}$

Oxoid Gar No.1 $16 \mathrm{~g}$

Aqua bidest.ad $\quad 1000 \mathrm{ml}$

Tryptic Soy Broth (TSB), pH 7,0

Tryptic Soy Broth $\quad 20 \mathrm{~g}$

aqua bidest. ad $1.000 \mathrm{ml}$

Tryptic Soy Agar (TSA), pH 7,0

wie oben, zusätzlich:

Agar

V8-Agar (Gemüsesaftagar), $\mathrm{pH} \mathrm{5,6}$

(modifiziert nach RIBEIRO, 1978)

aqua bidest.

$800 \mathrm{ml}$

Gemüsesaft

$200 \mathrm{ml}$

$\mathrm{CaCO}_{3}$

$2 \mathrm{~g}$

Agar

$16 \mathrm{~g}$

Wasseragar (WA), $\mathrm{pH} 7,0$

Agar

aqua bidest.
$16 \mathrm{~g}$

ad $1.000 \mathrm{ml}$ 


\subsection{Organismen}

\subsubsection{Pflanzen}

In der vorliegenden Arbeit wurden die Winterrapssorte Cobra mit starker Anfälligkeit für Leptosphaeria maculans und die geringer anfällige Sorte Express (BSA, 1997-1999) ausgewählt.

\subsubsection{Testpilze}

Folgende Isolate stammen aus der Sammlung des Instituts für Pflanzenpathologie und Pflanzenschutz, Universität Göttingen:

Leptosphaeria maculans

Pythium ultimum

Alternaria alternata

Fusarium culmorum

Fusarium oxysporum

Phoma betae

Rhizoctonia solani

Sclerotinia sclerotiorum

Saccharomyces cerevisiae

Verticillium dahliae

\subsubsection{Bakterien}

Bacillus megaterium

Escherichia coli

Agrobacterium tumefaciens

Clavibacter michiganensis ssp. Michiganensis

Erwinia amylovora

Pseudomonas phaseolicola

Folgende Isolate wurden aus Bodenproben isoliert und aus der Antagonisten-Stammsammlung der Abt. Prof. Wolf, Universität Göttingen erhalten:

Pseudomonas fluorescens

Bacillus subtilis

Erwinia herbicola
IBCN 66, R1G4, NA21

M1

Isolate A4.1 u. A4.8

$\mathrm{M} / 92$

$44 / 92$

169

107

195, CN1

V40, V543
Nr. N100

Nr. 24 
Außerdem wurden in dieser Arbeit Bakterien aus verschiedenen Bodenproben isoliert und zum Teil taxonomisch bestimmt:

Pseudomonas fluorescens

Bacillus circulans

Paenibacillus polymyxa

Serratia plymuthica
Isolate Kar 1, R21, RII-2

Isolate Kom1, Kom19

Isolate We 1, HA3e, HA6, ZU10

Isolat Zu 9

\subsection{Anzucht und Haltung der Pflanzen}

Die Aussaat erfolgte in Pikierschalen in einem von Topferde-Sand Gemisch (Verhältnis 2:1, v/v). Nach 7 Tagen wurden entweder je 4 Pflanzen in einem Viereck in 9x9 cm Töpfen oder einzeln in $9 \times 9 \mathrm{~cm}$ bzw. $13 \times 13 \mathrm{~cm}$ Töpfen umgepflanzt. Als Pflanzerde diente hierzu ein Topferde-Kompost-Sandgemisch (3:1:1, v/v/v). Die Anzucht erfolgte in einer Gewächshauskabine bei einem Tageslänge von $14 \mathrm{~h}$ bei $20 \pm 2{ }^{\circ} \mathrm{C}$ und einer relativen Luftfeuchtigkeit von 50-70\%. Nach dem Entwicklungsstadium BBCH 16 wurden die Pflanzen mit „Hakafos“ regelmäßig gedüngt. Zum Schutz vor Mehltaubefall wurden die Pflanzen ab BBCH16 einmal wöchentlich mit 0,25\% Netzschwefel (80\%ige Schwefel) gespritzt.

Ingrediens der Dünge „Hakafos“

$\begin{array}{ll}\mathrm{N} & 15 \% \\ \mathrm{P}_{2} \mathrm{O}_{5} & 11 \% \\ \mathrm{~K}_{2} \mathrm{O} & 15 \% \\ \mathrm{MgO} & 1 \% \\ \mathrm{Fe} & 0,1 \% \\ \mathrm{Mn} & 0,1 \% \\ \mathrm{Cu} & 0,04 \% \\ \mathrm{~B} & 0,025 \% \text { Bor } \\ \text { Molibdan } & 0,005 \%\end{array}$

Frei von Chlorid, Natrium, Harnstoff 


\subsection{Anzucht und Erhaltung der Mikroorganismen}

\subsubsection{Leptosphaeria maculans}

Die Isolate wurden zum Zweck der Erhaltung bei $4^{\circ} \mathrm{C}$ auf mit Paraffinöl überschichteten Hafermehlschrägröhrchen aufbewahrt.

Herstellung von Pyknidiosporen:

L. maculans-Isolate wurden auf V8-Agar für 7 Tage bei $20^{\circ} \mathrm{C}$ im Dunkeln und anschließend für 2-4 Wochen bei $18{ }^{\circ} \mathrm{C}$ unter UV-Licht mit einem Wellenlängenbereich von 350-400 nm angezogen. Zur Herstellung von Sporensuspensionen wurden Agarstücke mit hoher Pyknidiendichte in $5 \mathrm{ml}$ steriles Wasser überführt. Anschließend wurden Myzel- und Agarbruchstücke mit Hilfe eines sterilen Glaswolle-Filters abfiltriert. Nach der Ermittlung der Sporendichte mittels einer Fuchs-Rosenthal-Zählkammer wurde die Konzentration auf $1 \times 10^{7}$ Sporen/ml eingestellt. Bis zur Verwendung konnte die Sporensuspension 6 Monate bei $-20^{\circ} \mathrm{C}$ gelagert werden.

\section{Herstellung von Ascosporen:}

Die Ascosporen wurden in Anlehnung an MENGISTU et al. (1993 und 1995) angezogen.

\subsubsection{Pilzkulturen}

Die Anzucht der Testpilze Alternaria alternata, Pythium ultimum, Fusarium culmorum, F. graminearum, Phoma betae, Rhizoctonia solani, Sclerotinia sclerotiorum und Verticillium longisporum erfolgte auf PDA. Zur Erhaltung wurden die Pilze auf das Minimalmedium SNA überimpft, wozu frisches Mycel vom Kolonierand verwendet wurde. Die Platten wurden mit Parafilm zur Feuchtigkeitserhaltung dicht verschlossen. Die Inkubationszeit war bei den einzelnen Pilzen sehr unterschiedlich und bewegte sich zwischen zwei (P. ultimum) und 14 Tagen (V. longisporum). Die SNA-Platten mit den ausgewachsenen Pilzkolonien wurden bei $4^{\circ} \mathrm{C}$ gelagert und jährlich erneuert.

\subsubsection{Bakterien}

Zur Zellvermehrung wurden die Bakterien hauptsächlich auf TSA angezogen, indem einzelne, frische Kolonien mit einer Impföse auf TSA-Platten ausgestrichen und $48 \mathrm{~h}$ bei $20^{\circ} \mathrm{C}$ inkubiert wurden. Um Starterkulturen anzulegen, wurden $25 \mathrm{ml}$ TSB-Medium in einem $100 \mathrm{ml}$-Schikanekolben mit Einzelkolonien von TSA-Platten bzw. BEA-Platten (Aktinomyceten) angeimpft und $36 \mathrm{~h} \mathrm{bzw}$. 7d (Aktinomyceten) bei $20^{\circ} \mathrm{C}$ auf einem Rotationsschüttler (100 Upm) inkubiert. Gegebenenfalls wurde mit $4 \mathrm{ml}$ dieser Vorkultur eine 
Hauptkultur (250 ml TSB im $1.000 \mathrm{ml}-S c h i k a n e k o l b e n)$ beimpft und diese ebenfalls bei $20^{\circ} \mathrm{C}$ schüttelnd inkubiert.

Die Stammhaltung der Bakterien erfolgte auf dem BEA-Nährmedium. Es wurden sowohl Agarplatten- als auch Schrägröhrchenkulturen angelegt. Dazu wurden Einzelkolonien von TSA mit der Impföse auf BEA-Platten ausgestrichen bzw. in Schrägröhrchen übertragen, diese 3-4 Tage bei $20^{\circ} \mathrm{C}$ inkubiert und schließlich bei $4^{\circ} \mathrm{C}$ aufbewahrt. Die Stammkulturen wurden alle sechs Monate erneuert.

\subsection{Isolierung von Antagonisten}

Bodenproben aus der Rhizosphäre verschiedener Kulturpflanzen und aus Komposterde wurden mit der Mehrschichtagarmethode nach HERR (1959) auf Mikroorganismen untersucht, die in der Lage waren das in vitro-Wachstum von Leptosphaeria maculans zu hemmen.

Dazu wurden $10 \mathrm{~g}$ der Bodenprobe (Frischgewicht) mit $50 \mathrm{ml}$ sterilem Leitungswasser vermischt und Bodensuspension hergestellt, von der dann Verdünnungsreihen bis $10^{-6}$ erstellt wurden. $1 \mathrm{ml}$ Bodensuspension der Verdünnungsstufen $10^{-3}$ bis $10^{-6}$ wurde jeweils mit $9 \mathrm{ml}$ ca. $45^{\circ} \mathrm{C}$ warmen TSA (pH 7.0,1\% Agar) in Petrischalen vermischt. Zur Verhinderung des Oberflächenwachstums von Organismen wurde diese Agarschicht nach dem Erstarren mit 6-8 ml Wasser-Agar überschichtet und anschließend $48 \mathrm{~h}$ bei $20^{\circ} \mathrm{C}$ inkubiert. Platten mit

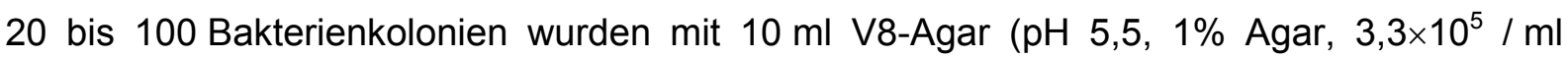
Sporen von L. maculans) überschichtet. Nach weiteren $72 \mathrm{~h}$ Inkubation bei $20^{\circ} \mathrm{C}$ wurden Kolonien, die von einem Hemmhof in der Testpilzschicht umgeben waren, isoliert. Zur Gewinnung von Reinkulturen wurden die Pilzisolate auf V8 und WA, die Bakterienisolate auf TSA und BEA überimpft. So konnten 109 Bakterienkulturen angelegt werden.

\subsection{In vitro-Screening von Antagonisten}

\subsubsection{Dualkultur-Test}

Um die in vitro-Hemmwirkung der Isolate gegenüber L. maculans und V. longisporum sowie anderen pilzlichen Phythopathogenen zu überprüfen, wurden Dualkultur-Tests mit verschiedenen Isolaten beider Pathogene auf 2 nährstoffreichen Medien durchgeführt, da die Bildung von Hemmstoffen und hydrolytischen Exoenzymen durch Bakterien stark von der Zusammensetzung des Nährmediums abhängt. Die Isolate wurden in der Mitte einer V8Platte (geeignetes Nährmedium für das Myzelwachstum von L. maculans) bzw. MsA-Platte (geeignetes Nährmedium für das Myzelwachstum von $V$. dahliae) strichförmig aufgetragen und inkubiert. Nach $48 \mathrm{~h}$ wurde rechts und links des Impfstrichs in $25 \mathrm{~mm}$ Entfernung je ein ausgestochenes Myzel-Agarblöckchen $(\varnothing 5 \mathrm{~mm})$ des Testpilzes aufgesetzt. Als Testisolate 
wurden die L. maculans-Isolate IBCN66 (aggressiv), R1G4 (mittelaggressiv) und NA21 (nicht aggressiv) und die V. longisporum-Isolate V40 und V543 verwendet. Als Kontrolle dienten Platten ohne Antagonist. Wenn die Pilzkolonien auf diesen Kontrollplatten nach ca. 10 Tagen in der Mitte zusammengewachsen waren, wurde der Hemmhof zwischen dem Antagonisten und der Koloniefront von L. maculans gemessen.

Neben 109 in der vorliegenden Arbeit gewonnenen Bodenisolaten wurden 40 bakterielle Bodenisolate, die von Dr. A. Sasse mit Verticillium lonisporum als Testpilz isoliert und auch als wirksame in vitro-Antagonisten von L. maculans charakterisiert worden waren (SASSE, 1997), auf ihre Hemmwirkung auf den zwei Medien überprüft.

Die im vorhergehenden Screening wirksameren Isolate wurden noch auf ihre Hemmwirkung gegenüber $L$. maculans bei $8^{\circ} \mathrm{C}$ und $20^{\circ} \mathrm{C}$ auf V8- und SEA-Medium überprüft. Darüber hinaus wurde die Hemmwirkung dieser Isolate gegenüber acht weiteren pilzlichen Phytopathogenen auf V8-Medium getestet.

\subsubsection{Test auf antibakterielle Wirkung von Antagonistenisolaten}

Um das antibakterielle Hemmspektrum der Antagonisten zu erfassen, wurden diese am Rande einer Petrischale mit $10 \mathrm{ml}$ TSA $(\mathrm{pH} 7,0)$ strichförmig aufgetragen. Nach $48 \mathrm{~h}$ Inkubation bei $20^{\circ} \mathrm{C}$ wurden in $1 \mathrm{~cm}$ Abstand vom Impfstrich und $90^{\circ}$ versetzt dazu sechs Testbakterien (Agrobacterium tumefaciens, Bacillus megaterium, Clavibacter michiganensis ssp. michiganensis, Erwinia amylovora, Escherichia coli, Pseudomonas phaseolicola) und eine Testhefe (Saccharomyces cerevisiae) ausgestrichen. Nach $48 \mathrm{~h}$ Inkubation bei $20^{\circ} \mathrm{C}$ wurden die Hemmhöfe der Testorganismen gemessen und nach $96 \mathrm{~h}$ weiterer Inkubation erneut überprüft und verglichen.

\subsubsection{Nachweis der Siderophorenbildung}

Die Bildung von Siderophoren durch die antagonistischen Bakterien wurde durch Ausstrich der Organismen auf dem von SCHWYN \& NEILANDS (1987) eingeführten und von BUYER et al. (1989) sowie ALEXANDER \& ZUBERER (1991) weiterentwickelten CAS-Medium getestet. In diesem Medium ist Fe III an den Farbstoff Chromazurol $S$ gebunden. Von den Bakterien ausgeschiedene Siderophoren können diesen Eisenkomplex unabhängig von ihrer chemischen Struktur lösen. Nach $24-48 \mathrm{~h}$ Inkubation bei $20^{\circ} \mathrm{C}$ wird ein Farbumschlag von Blaugrün zu orange als positiv bewertet.

Zum Nachweis von fluoreszierenden Siderophoren wurden das von KING et al. (1954) entwickelte KBA-Medium ( $\mathrm{pH} 7,2)$ verwendet. Hierbei wurde die Bildung gelber oder gelbgrüner Höfe um die Kolonien nach 24-48 h Inkubation bei $20^{\circ} \mathrm{C}$ unter UV-Licht $(254 \mathrm{~nm}$ und $360 \mathrm{~nm}$ ) überprüft. Eine zweite Überprüfung zur Bildung fluoreszierender Siderophoren 
erfolgte für die auf KBA-Medium nicht fluoreszierenden Isolate durch Kultivierung auf Succinat-Agar.

\subsubsection{Nachweis flüchtiger Hemmsubstanzen}

Zur Überprüfung der in vitro-Hemmwirkung gegenüber L. maculans durch gasförmige Substanzen wurden die Antagonisten auf einer Seite einer zweigeteilten Petrischale $(\varnothing 9 \mathrm{~cm}$ mit Nocken, Fa. Greiner, Nürtingen) auf TSA $(7 \mathrm{ml}, \mathrm{pH} 7,0)$ ausgestrichen und $48 \mathrm{~h}$ bei $20^{\circ} \mathrm{C}$ inkubiert. Anschließend wurde in die Mitte der anderen Seite auf V8 $(7 \mathrm{ml}, \mathrm{pH} 5,5)$ L. maculans als Mycelstückchen $(\varnothing 5 \mathrm{~mm})$ aufgesetzt und bei $20^{\circ} \mathrm{C}$ inkubiert, bis die Kontrollen vollständig bewachsen waren. Das Radialwachstum von L. maculans diente als Maß für die relative Hemmung des Myzelwachstums durch die von den Antagonisten abgegebenen gasförmigen Hemmstoffen.

\subsubsection{Nachweis extrazellulärer Hydrolasen}

Um die Exoenzyme nachzuweisen, wurde die Methode nach WIRTH \& WOLF (1990) angewendet. Lösliche Polysaccharid- bzw. Protein-Farbstoff-Konjugate, bei denen die Farbstoffe Remazol Brilliant Blue oder Remazol Brilliant Violett kovalent an die Substrate gebunden sind, werden dabei als Hauptkohlenstoffquellen im Nährmedien eingesetzt. Beim Abbau der Substrate bildet sich durch Diffusion der Farbstoffmoleküle eine helle Abbauzone um die Mikroorganismenkolonien.

Folgende farbstoffmarkierte Substrate wurden verwendet: CM-Cellulose-RBB (1,4-ßGlucan), CM-Chitin-RBV (1,4-ß-Poly-N-Acetylglucosamin), CM-Curdlan-RBB (1,3-ßGlucan), CM-Xylan-RBB (1,4-ß-Xylan), Gelatine-RBB (wasserlösliches Protein) und Stärke-RBB (1,6-ß-Glucan). Dabei setzte sich das Medium (WIRTH \& WOLF 1990) aus Bodenextrakt, Substratfarbstoff-Konjugat-Lösung und Agar (1,5\%) zusammen.

Zur einer optimalen Auswertung wurden die Substratfarbstoff-Konjugat-Lösungen vor dem Autoklavieren mit Aqua bidest. so eingestellt, dass die optische Dichte nach der Vermischung mit Bodenextrakt für Chitin-RBV 2,5 $\left(E_{550}\right)$, und für die weiteren Substrate 3,0 $\left(E_{592}\right)$ betrug. Das Basalmedium Bodenextrakt-Agar und die Substratfarbstoff-KonjugatLösung wurden getrennt $15 \mathrm{~min}$ bei $121^{\circ} \mathrm{C}$ autoklaviert. Nach Abkühlen auf ca. $50^{\circ} \mathrm{C}$ wurden die beiden Lösungen unter sterilen Bedingungen vermischt und $\mathrm{zu}$ je $20 \mathrm{ml}$ ausplattiert. Die Testbakterien wurden auf diesen Medien ausgestrichen, bei $20^{\circ} \mathrm{C}$ inkubiert und die Abbauzonen bis sieben Tage danach beobachtet und ausgewertet. 


\subsection{Charakterisierung und Identifizierung der Antagonisten}

Zur Charakterisierung einiger Antagonisten wurde zunächst makroskopisch das Koloniewachstum auf TSA hinsichtlich Form, Farbe und Beschaffenheit des Kolonierandes untersucht. Weiterhin konnte bei mehreren Isolaten die Bildung bakterieller Endosporen auf dem Magermedium BEA überprüft werden, da Bakterien oft nur unter Mangelbedingungen Sporen bilden. Nach viertägiger Inkubation wurden Einzelkolonien aller Isolate lichtmikroskopisch (bis zu 1.200-fache Vergrößerung, Ölimmersion) auf Zellgröße, -form, Beweglichkeit und Sporenbildung auf TSA bzw. BEA hin untersucht. Pseudomonas fluorescens B5 (Gram-negativ) und Bacillus megaterium (Gram-positiv) dienten als Referenzstämme für die Tests 1, 2 und 3.

\subsubsection{Physiologische Untersuchungen}

\subsubsection{Gram-Färbung (nach NÄVEKE \& TEPPER, 1979)}

Aus der Einzellkolonie eines Bakteriums wurde zunächst eine schwach trübe Bakteriensuspension $\left(\mathrm{OD}_{600 \mathrm{~nm}} \approx 0,06\right)$ in aqua bidest. hergestellt und ein Tropfen davon auf einem Objektträger hitzefixiert. Nach dem Abkühlen wurde der Tropfen 1 min lang mit Hucker's Kristallviolett bedeckt, anschließend $5 \mathrm{sec}$ lang in Leitungswasser gewaschen und 1 min mit Jodlösung behandelt. Nach erneutem Waschen wurde der noch feuchte Objektträger nacheinander in drei Gläser mit n-Propanol für je 1 min getaucht und wieder gewaschen. Die Gegenfärbung erfolgte für $1 \mathrm{~min}$ mit Safranin-Lösung. Nach dem Waschen mußte der Objektträger an der Luft trocknen und konnte dann mit 1200-facher Vergrößerung (Ölimmersion) mikroskopiert werden.

Gram-positive Zellen mit dickem Murein-Sacculus erscheinen dabei blau-violett, da sie sich mit n-Propanol nicht entfärben lassen. Gram-negative Zellen mit einschichtigem Murein-Netz erscheinen rosa, da sich während der Entfärbung der entstandene Jod-KristallviolettKomplex auflöst und die Zellen erst durch die Gegenfärbung mit Safraninlösung sichtbar werden.

Folgende Lösungen wurden angesetzt:

\section{Hucker's Kristallviolett}

Stammlösung 1: $10 \%$ Kristallviolett in $96 \%$ igem Ethanol

Stammlösung 2: 1 \% Ammoniumoxalat in aqua bidest.

$48 \mathrm{~h}$ vor Gebrauch $20 \mathrm{ml}$ Lösung 1 mit 80 ml Lösung 2 mischen

\section{Safranin-Lösung}

Stammlösung: 2,5 \% Safranin in $96 \%$ igem Ethanol

$10 \mathrm{ml}$ Stammlösung mit $90 \mathrm{ml}$ aqua bidest. verdünnen 


\section{Burke's Jodlösung}

$2 \mathrm{~g} \mathrm{KJ}$ in einem Mörser mit $1 \mathrm{~g}$ Jod 5-10 sec verreiben, erst $1 \mathrm{ml}$, dann $5 \mathrm{ml}$ aqua bidest. zugeben und verreiben bis alles in Lösung ist, mit aqua bidest. auf $100 \mathrm{ml}$ auffüllen

2.8.1.2 Nachweis der L-Alanin-Aminopeptidase (nach CERNY, 1978, CostIN et al., 1983)

Für den Nachweis dieses Enzyms wurde ein Schnelltest (Bactident 13301, Fa. Merck, Darmstadt) verwendet. Dazu wurde eine frische, auf TSA angezogene Einzelkolonie eines Testbakteriums in 0,2 $\mathrm{ml}$ aqua bidest. in einem E-cup suspendiert, in diese Suspension ein Teststäbchen eingetaucht und $10-30 \mathrm{~min}$ bei $37^{\circ} \mathrm{C}$ im Wasserbad inkubiert. Eine Gelbfärbung der Suspension deutete auf eine positive Reaktion hin.

\subsubsection{Lyse durch KOH (nach GREGERSEN, 1979)}

Die Zellwand eines Gram-negativen Bakteriums wird, im Gegensatz zu der eines Grampositiven Bakteriums, in Kalilauge sehr schnell zerstört. Durch die Lyse der Zellwand wird die DNA frei und ist als Schleimfaden nachweisbar. Für diesen Test wurde eine frische Kolonie mit 3 \%iger $\mathrm{KOH}$-Lösung auf einem Objektträger verrieben und mit der Impföse vorsichtig abgehoben. Eine Fadenbildung deutete auf eine Lyse der Zellen und damit auf eine positive Reaktion hin.

\subsubsection{Nachweis der Cytochrom-Oxidase (nach KovaCs, 1956)}

Mit einem Schnelltest (Bactident 13300, Fa. Merck, Darmstadt) konnte die Cytochromoxidase als das terminale Enzym der Atmungskette nachgewiesen werden. Eine frische Einzelkolonie wurde auf einem Teststreifen mit Hilfe einer Impföse verrieben. Eine Blaufärbung nach 20-60 sec deutete auf eine positive Reaktion hin. Als Referenzstämme dienten hierzu Pseudomonas fluorescens B5 (Oxidase-positiv) und Escherichia coli (Oxidase-negativ).

\subsubsection{Identifizierung mit dem API-Testsystem}

Für die taxonomische Einordnung der Gram-negativen Isolate, die nicht zur Familie der Enterobacteriaceae (NE = Non Enterics) gehören (i. d. R. Oxidase-positiv 2.8.1.4), wurde das Testsystem API 20 NE der Fa. bioMerieux, Nürtingen, verwendet. In Gegensatz dazu wurden die Isolate, die zur Familie der Enterobacteriaceae und anderer nicht anspruchsvoller Gram-negativer Stäbchen gehören, mit Hilfe des Testsystems API 20 E bestimmt (i. d. R. Oxidase-negativ 2.8.1.4). 
Für die Beimpfung der Teststreifen von API 20NE wurden 36 h-alte auf TSA gewachsene Bakterienkolonien in steriler physiologischer Kochsalzlösung suspendiert und auf einen ODWert von 0,1 bis 0,2 eingestellt. Die ersten acht Röhrchen wurden mit dieser Suspension gefüllt und zum Teil mit Paraffinöl überschichtet. Zur Überprüfung der Assimilationsreaktionen wurde die Suspension mit API AUX Medium, einem Minimalmedium, gemischt und auf die Röhrchen verteilt.

Für die Beimpfung des Streifens von API 20 E wurden ebenfalls 36h alte Bakterienkolonien in steriler physiologischer Kochsalzlösung suspendiert. Bei den Reaktionen CIT, VP und GEL wurden die Bakteriensuspensionen in die Becherchen und Röhrchen gefüllt. Für die anderen Reaktionen wurden die Bakteriensuspensionen nur in die Röhrchen gefüllt. Bei den Reaktionen $\mathrm{ADH}$, LPC, ODC, $\mathrm{H}_{2} \mathrm{~S}$ und URE wurden die Becherchen mit Paraffinöl überschichtet, so dass anaerobe Bedingungen entstanden.

Nach 24stündiger Inkubation bei $30{ }^{\circ} \mathrm{C}$ erfolgte die Zugabe verschiedener Reagenzien und anschließend wurden die Indikatorfarbumschläge und Trübungen mit der Ablesetabelle verglichen, positive und negative Reaktionen in ein numerisches Profil kodiert und die Identifizierung jeweils mit Hilfe des Analytischen-Profil-Indexes API 20 NE bzw. API 20 E vorgenommen.

Für die Identifizierung Gram-positiver, aerober Sporenbildner wurden das Testsystem API $50 \mathrm{CH}$ und das Medium API $50 \mathrm{CH} \beta$ der gleichen Firma verwendet, wobei die Verwertung von 49 Kohlenhydraten durch Mikroorganismen überprüft wird. Dadurch kann ein biochemisches Profil des Bakteriums erstellt und zur Identifizierung herangezogen werden.

Zur Beimpfung der Teststreifens wurden $36 \mathrm{~h}$ alte Kolonien in physiologischer Kochsalzlösung suspendiert (Konzentration eingestellt auf $\mathrm{OD}_{600 \mathrm{~nm}}=0,6$ ). $1 \mathrm{ml}$ dieser Suspension wurde dann mit $10 \mathrm{ml}$ API $50 \mathrm{CH} \beta$-Medium gemischt und auf die Röhrchen verteilt. Nach $24 \mathrm{~h}$ und nach $48 \mathrm{~h}$ Inkubation bei $30^{\circ} \mathrm{C}$ konnten die Farbumschläge von rot über orange nach gelb (außer bei Salicine von rot nach schwarz) ermittelt und die Ergebnisse in ein biochemisches Profil umgeschrieben werden. Zur Identifizierung wurde das computergesteuerte API-Identifizierungsprogramm der gleichen Firma eingesetzt.

Für die taxonomische Einordnung zweier Gram-positiver Isolate war die Überprüfung der Synthese 12 Stoffwechselprodukte bzw. Enzyme anhand API 20 E notwendig. Die Beimpfung, Inkubation und Auswertung der Teststreifen erfolgte wie beim API 20 NE Testsystem. 


\subsection{Bestimmung der Proteingehalte}

Die Proteinbestimmung erfolgte nach der Methode von BRADFORD (1976). Das BradfordReagenz setzt sich wie folgt zusammen:

- 100 mg Coomassie Brilliant Blue G 250 in 50 ml 96 \%igem Ethanol 2 h rühren

- $100 \mathrm{ml} 96$ \%ige Phosphorsäure zugeben und rühren

- 1:6,6 mit aqua bidest. mischen (37,5 ml Bradford-Reagenz ad $250 \mathrm{ml}$ aqua bidest.)

Das Reagenz wurde durch einen Glasfaserfilter $(\varnothing 355 \mathrm{~mm}$, Fa. Schleicher \& Schuell, Dassel) abfiltriert, in eine dunkle Dosierflasche gefüllt und bei $4{ }^{\circ} \mathrm{C}$ aufbewahrt.

Für die photometrische Bestimmung der Proteingehalte wurden sechs wäßrige Rinderserumalbuminlösungen $(0,02,0,04,0,06,0,08,0,1$ und $0,12 \mathrm{mg} / \mathrm{ml})$ als Eichreihe verwendet. $30 \mu \mathrm{l}$ der Eichlösungen, der verdünnten Proben (1:20, 1:100, $50 \mathrm{mM}$ Tris-HCl-Puffer+0,5 M Saccharose, $\mathrm{pH} 7,2)$ und aqua bidest. als Leerwert wurden in dreifacher Wiederholung in eine Mikrotiterplatte (Kavität $350 \mu$ l, Art. Nr. 3595, Fa. Costar, Cambridge, England) pipettiert und jeweils $300 \mu$ Bradford-Reagenz aus der Dosierflasche zugegeben.

Die Extinktion des Protein-Farbstoff-Komplexes wurde nach $10 \mathrm{~min}$ Inkubation bei Raumtemperatur in einem Mehrstrahlphotometer (Spectra II, Fa. Tecan) bei einer Wellenlänge von $592 \mathrm{~nm}$ und einer Referenzlänge von $492 \mathrm{~nm}$ gemessen.

Die Extinktionswerte wurden anhand der Eichreihe vom Programm (Easy Fit, Fa. Tecan) in Proteingehalte umgerechnet und so die Proteinkonzentrationen der Extrakte bestimmt.

\subsection{Entwicklung und Optimierung eines DAS-ELISA zur Befallsquantifizierung}

Das immunologische Nachweisverfahren stellt eine zuverlässige und genaue Befallsquantifizierungsmethode dar. Um den Leptosphaeria maculans-Befall der Rapspflanzen aus den ad planta-Versuchen quantitativ erfassen zu können, wurde ein direkter DAS-ELISA

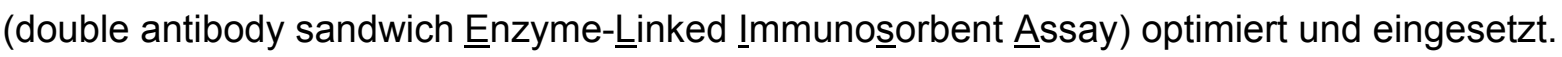

\subsubsection{Herstellung der Antiseren}

Die Herstellung des Antigens sowie die Aufreinigung des Antiserums wurde freundlicherweise von Dr. Cernusko vorgenommen (nach CERNUSKO, 1996) und zur Verfügung gestellt.

Die Pilzkultivierung zur Antigengewinnung erfolgte auf der Oberfläche von Polysulfonmembranen (HAT-200, Tuffryn, Gelman, Roßdorf). Hierzu kamen die Isolate T12aD34 und T12aC28 zur Anwendung.

Die Reinigung der Antiseren erfolgte in Anlehnung an CLARK und ADAMS (1977) mit Fractogel TSK DEAE 650 (M). 


\subsubsection{Biotinylierung der Antikörper}

Bei der Biotinylierung der gereinigten Immunoglubuline $(\lg G)$ des Antiserums wurde gegen gekühlten Kopplungspuffer dialysiert (24h, dreimaliger Pufferwechsel). Anschließend wurde $1 \mathrm{mg}$ Biotin-X-NHS in $1 \mathrm{ml}$ wasserfreiem Dimethylformamid gelöst und davon $50 \mu \mathrm{l} / \mathrm{ml} \mathrm{zu} 1 \mathrm{ml}$ IgG gegeben. Nach 30 min Inkubation bei Raumtemperatur wurde die Reaktion mit 50 l $1 \mathrm{M}$ Tris- $\mathrm{HCl}(\mathrm{pH} 7,4)$ Lösung gestoppt. Nach einer nochmaligen Dialyse $(0,85 \% \mathrm{NaCl}$ gekühlt, über Nacht; dreimaliger Pufferwechsel) wurden die biotinylierten IgG durch Zugabe von gleichem Volumen an Glycerin, $1 \%$ Ovalbumin und $0,02 \% \mathrm{NaN}_{3}$ stabilisiert und bei $-20^{\circ} \mathrm{C}$ aufbewahrt.

\subsubsection{Optimierung des Testverfahrens}

Bevor der ELISA routinemäßig zum Einsatz kam, wurde der Testablauf soweit optimiert, dass eine zuverlässige Empfindlichkeit erzielt werden konnte. Dies wurde erreichte durch die Variation der Konzentrationen der Beschichtungs- und biotinylierten Antikörper, der Probenextrakte und des Streptavidin-alkalischen Phosphotase-Konjugates.

\subsubsection{Durchführung des DAS-ELISA}

Der ELISA wurde nach folgendem Schema durchgeführt

-Beschichten mit spezifischem Antiserum (in Beschichtungspuffer, IgG-Verdünnung 1:1000), $100 \mu \mathrm{l}$ je Kavität, Inkubation bei $4^{\circ} \mathrm{C}$ über Nacht

- 3x3 min Waschen mit Waschpuffer

- Blocken zur Absättigung der noch freien Bindungsstellen (Beschichtungspuffer + 0,2\% RSA), $200 \mu \mathrm{l}$ je Kavität, 2 h bei Raumtemperatur

- $3 \times 3$ min Waschen

-Auftragen der Proben (Extraktionspuffer, Probenverdünnung 1:20 bzw. 1:1000), $100 \mu \mathrm{l}$ je Kavität, Inkubation bei $4^{\circ} \mathrm{C}$ über Nacht

- $3 \times 3$ min Waschen

-Zugabe von biotinylierten IgG (1:200 verd.), $100 \mu$ l je Kavität, Inkubation bei $4^{\circ} \mathrm{C}$ über Nacht

- 3x3 min Waschen

-Zugabe von StrAP (verd. 1:10.000), $100 \mu$ je Kavität, $1 \mathrm{~h}$ bei Raumtemperatur

- 3x3 min Waschen

-Zugabe der Substratlösung ( $1 \mathrm{mg} / \mathrm{ml}$ pNPP in Substratpuffer), $100 \mu \mathrm{l}$ je Kavität, Inkubation bei Raumtemperatur im Dunkeln für 180 min

- Messen bei 405 nm (Referenzwellenlänge 592 nm) nach 60, 120 und 180 min 
Folgende Pufferlösungen kamen zum Einsatz:

Beschichtungspuffer, $\mathrm{pH} \mathrm{9,6}$

$\begin{array}{ll}\mathrm{NaHCO}_{3} & 2,93 \mathrm{~g} \\ \mathrm{Na}_{2} \mathrm{CO}_{3} & 1,59 \mathrm{~g} \\ \text { aqua bidest. } & \text { ad } 1.000 \mathrm{ml}\end{array}$

Phosphatgepufferte physiologische Kochsalzlösung, PPK, pH 7,2 - 7,4

(nach CASPER \& MEYER, 1981)

$\mathrm{NaCl}$

$8 \mathrm{~g}$

$\mathrm{KH}_{2} \mathrm{PO}_{4}$

$0,2 \mathrm{~g}$

$\mathrm{Na}_{2} \mathrm{HPO}_{4} \times 12 \mathrm{H}_{2} \mathrm{O}$

$2,9 \mathrm{~g}$

$\mathrm{KCl}$

$0,2 \mathrm{~g}$

aqua bidest.

ad $1.000 \mathrm{ml}$

\section{PPK/Tween}

PPK $+0,05 \%$ Tween 20

\section{Extraktionspuffer}

PPK/Tween + $1 \%$ PVP + 0,02 \% $\mathrm{NaN}_{3}$

\section{Waschpuffer}

$1 / 2$ PPK/Tween

\section{Konjugatpuffer}

PPK/Tween + 0,2 \% RSA

\section{Substratpuffer, $\mathrm{pH} \mathrm{9,8}$}

$\begin{array}{ll}\text { Diethanolamin } & 97 \mathrm{ml} \\ \text { aqua bidest. } & 600 \mathrm{ml} \Rightarrow \mathrm{pH} \text { mit } 1 \mathrm{~N} \mathrm{HCl} \text { einstellen } \\ \text { aqua bidest. } & \text { ad } 1.000 \mathrm{ml}\end{array}$

Die Inkubation der Mikrotiterplatten (MaxiSorp U96, Fa. Nunc, Dänemark) erfolgte entweder bei $4^{\circ} \mathrm{C}$ im Kühlschrank oder bei $37^{\circ} \mathrm{C}$ im Wasserbad. Alle Proben wurden pro Platte in zweifacher Wiederholung eingesetzt. Die äußeren Tröge der Mikrotiterplatten wurden ausgelassen. Die Messung der OD erfolgte im ELISA-Reader mit dem Programm Easy Fit. In die Auswertung wurde der Mittelwert der zwei Wiederholungen jeder Probe nach 180 min Substratinkubation übernommen. 


\subsubsection{Probenaufbereitung}

21 Tage nach Inokulation mit den Pyknidiosporen von L. maculans wurden die Keimblätter von der Pflanze abgeschnitten und bei $-20^{\circ} \mathrm{C}$ bis zur weiteren Verwendung eingefroren. Inokulierte Stängel wurden 49 Tage nach Inokulation $5 \mathrm{~cm}$ um die sichtbare Symptome herum abgeschnitten und ebenfalls eingefroren. Zur Extraktion der Proteine bzw. Antigene von L. maculans wurde jedes Keimblatt mit $1,5 \mathrm{ml} 1 \mathrm{X}$ PPK/Tween-Puffer im Mörser homogenisiert, während das vorzerkleinerte Stängelmaterial im Verhältnis 1:20 (W:V) in Extraktionspuffer aufgenommen wurde. Die Pflanzenextrakte wurden über Nacht bei $4^{\circ} \mathrm{C}$ und 120 Upm auf einem Rotationsschüttler (Fa. Gerhardt) geschüttelt.

Danach wurden $1,5 \mathrm{ml}$ jedes Pflanzenextrakts in ein E-Cup umpipettiert und $10 \mathrm{~min}$. bei $4^{\circ} \mathrm{C}$ und $13.000 \times \mathrm{g}$ zentrifugiert. Der Überstand wurde mit Extraktionspuffer bis zur Endverdünnung 1:2.000 im ELISA weiter verdünnt.

\subsection{1 ad planta Vorscreening mit Rapskeimlingen}

\subsubsection{Besiedlung von Rapssämlingen durch Antagonisten}

Hierzu wurde das Rapsaatgut zuerst mit 3\% Natriumhypochlorit oberflächlich sterilisiert. Danach wurden das Saatgut für $1 \mathrm{~h}$ in eine 0,25\%ige Xanthan-Antagonistensuspension mit einer Konzentration von ca. $5 \times 10^{9} \mathrm{cfu} / \mathrm{ml}$ eingelegt. Nach Abtropfen der überschüssigen Flüssigkeit wurden die behandelten und nicht behandelten Rapssamen getrennt in sterilem Sand mit Bodenextrakt als Nahrungsquelle in eine Kunststoffschale (Größe: $16 \times 12 \times 6 \mathrm{~cm}$ ) ausgesät. 7 Tage nach dem Aufgang wurden die Keimlinge unter sterilen Bedingungen in eine mit TSA beschichtete Petrischale eingelegt. Nach 3 Tagen wurde die Besiedlung der Pflanzen durch die Antagonisten ermittelt.

\subsubsection{Hemmwirkung der Antagonisten gegen L. maculans an Rapskeimlingen}

\subsubsection{Inokulation der Keimblätter mit L. maculans}

Jede Keimblatthälfte wurde mit einer sterilen Nadel punktförmig verletzt, dann mit $10 \mu$ einer $10^{7}$ Sporen/ml konzentrierten Sporensuspension inokuliert. Um während des Versuchszeitraumes ein rasches Altern der Keimblätter zu verhindern, wurden die nachwachsenden Laubblätter alle 2 Tage entfernt.

\subsubsection{Befallsbonitur an Keimblättern}

In Anlehnung an VOLKE (1999) erfolgte die Keimblattbewertung 14 Tage nach einem modifizierten Schema von Delwiche (1980). indem die Boniturwerte von 0-6 verwendet wurden: 
0 keine Symptome

1 Läsionen um die Einstichstelle $<1,5 \mathrm{~mm}$

2 Läsionen um die Einstichstelle 1,5-3,5 mm

3 Läsionen um die Einstichstelle $>3,0 \mathrm{~mm}$

4 grau-grüner Gewebekollaps 3,1-5,0 mm

5 grau-grüner Gewebe-Kollaps $>5,0 \mathrm{~mm}$ ( $\leq 10$ Pyknidien)

6 grau-grüner Gewebe-Kollaps > 5,0 mm (>10 Pyknidien)

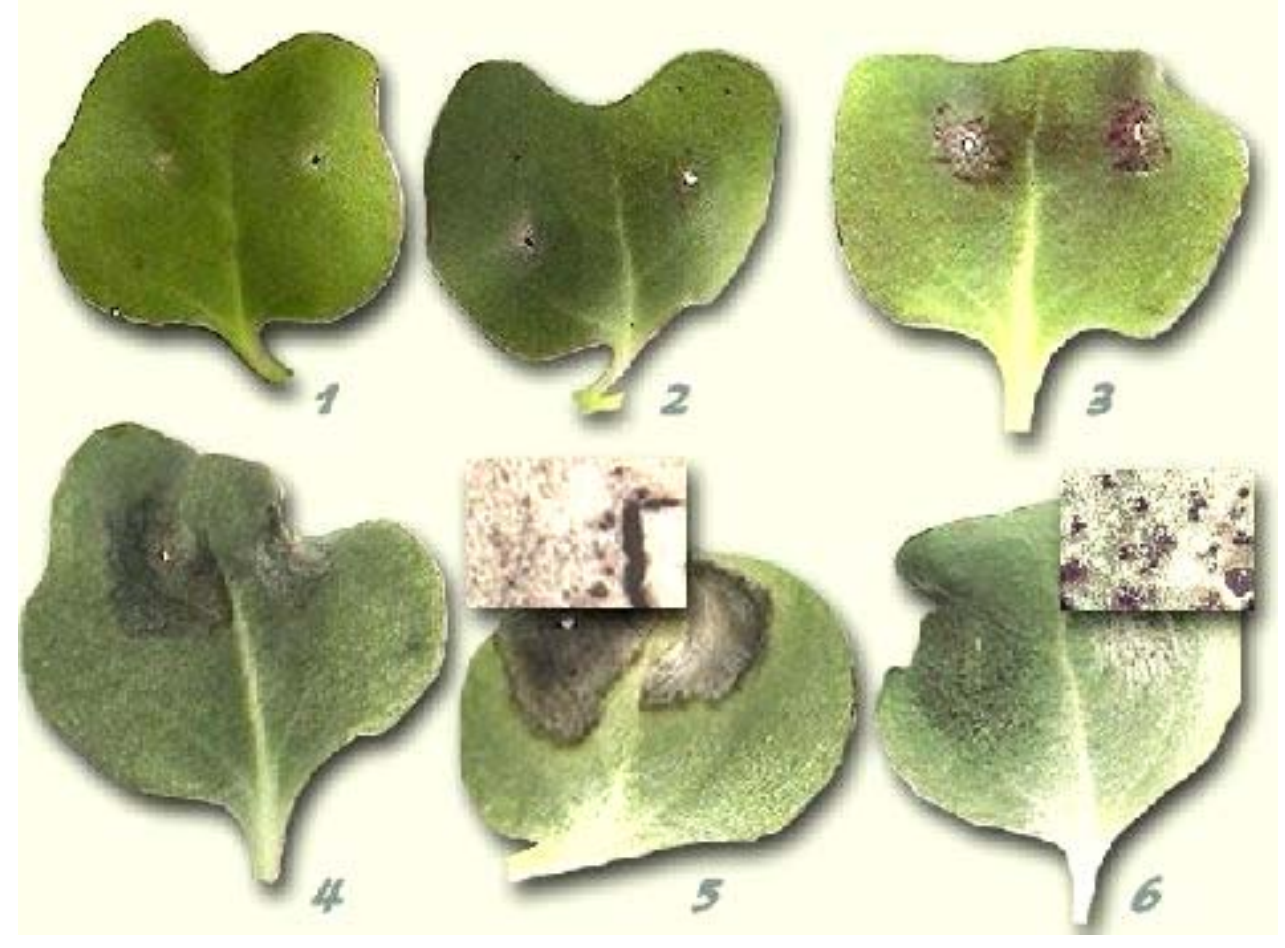

Abb. 1: Boniturschema nach der Skala 0-6

\subsubsection{Durchführung des Antagonistentests}

Hierzu erfolgte die Anzucht der Pflanzen bzw. Antagonisten wie unter 2.4 bzw. 2.5.3 beschrieben. Pro Variante wurden 32 Pflanzen in 8 Töpfen angezogen. $50 \mathrm{ml}$ einer $48 \mathrm{~h}$ alten Kultur der Antagonisten wurden durch Zentrifugation bei $20000 \mathrm{~g}, 15 \mathrm{~min}$ und $4{ }^{\circ} \mathrm{C}$ (Suprafuge 22, Heraeus Sepatech, Osterode) geerntet und das Pellet in sterilem 0,1M $\mathrm{MgSO}_{4}, 0,5 \%$ iger Carboxymethyl-Cellulose und 0,02\%iger Tween20 auf eine Konzentration von ca. $10^{9} \mathrm{cfu} / \mathrm{ml}$ resuspendiert. $15 \mathrm{ml}$ eines jeden Isolates wurde direkt nach Verletzung der Keimblätter mit einer Nadel auf insgesamt 32 Pflanzen in 8 Töpfen gesprüht. Die Inokulation von Pflanzen mit L. maculans erfolgte wie unter 2.10 .1 beschrieben, aber 6 Stunden nach Ausbringung der Antagonisten. 21 Tage später wurde der Befall nach dem Delwiche-Schema und mit Hilfe des ELISA ermittelt. 


\subsection{Inokulationsmethode für ad planta Untersuchungen in BBCH 14/15}

Für die Entwicklung einer Inokulationsmethode wurden zuerst die Pflanzen in unterschiedlichen Entwicklungsstadien sowie unterschiedliche Pflanzenteile im Entwicklungsstadium BBCH 14/15 (WEBER \& BLEIHOLDER 1990) mit myzelbewachsenen Agarstücken von V8Kulturen inokuliert. Anschließend wurden Pyknosporen und Ascosporen von L. maculans als Inokulum verglichen. Die Befallsermittlung erfolgte 49 Tage nach Inokulation mittels Sichtbonitur und ELISA.

\subsection{Antagonistentest im BBCH 14/15}

\subsubsection{Befallsbonitur am Stängel}

Für die Beurteilung der Krankheitssymptome an der Stängelbasis wurde das Boniturschema von KUTSCHER et al. (1993) verwendet. Hierbei wird sowohl die Länge (L), der Umfang als auch die Tiefe der Läsionen 49 Tage nach Inokulation berücksichtigt. Gemessene (L) und prozentuale (G.P) Werte wurden zur Erfassung des VDT-Wertes (Volume of Diseased Tissue) in Boniturklassen von 0-4 eingesetzt.

\begin{tabular}{clll}
\hline \hline Boniturstufe & Läsionslänge: $\mathbf{L}$ & Läsionsumfang: $\mathbf{~}$ & Läsionstiefe: $\mathbf{P}$ \\
\hline $\mathbf{0}$ & keine Infektion & keine Infektion & keine Infektion \\
$\mathbf{1}$ & $1-9 \mathrm{~mm}$ & $\leq 25 \%$ & $\leq 25 \%$ \\
$\mathbf{2}$ & $10-19 \mathrm{~mm}$ & $25-50 \%$ & $25-50 \%$ \\
$\mathbf{3}$ & $20-29 \mathrm{~mm}$ & $50-75 \%$ & $50-75 \%$ \\
$\mathbf{4}$ & $\geq 30 \mathrm{~mm}$ & $75-100 \%$ & $75-100 \%$ \\
\hline
\end{tabular}

$$
\text { VDT }=(1-H R 2) \times G / 4 \times L \quad \text { wobei } H R=1-P / 4
$$

Anhand der errechneten VDT-Werte ergeben sich folgende Befallsstufen: resistent: 0-0,3 intermediär: 0,4-1,5 anfällig: 1,6-4,0 

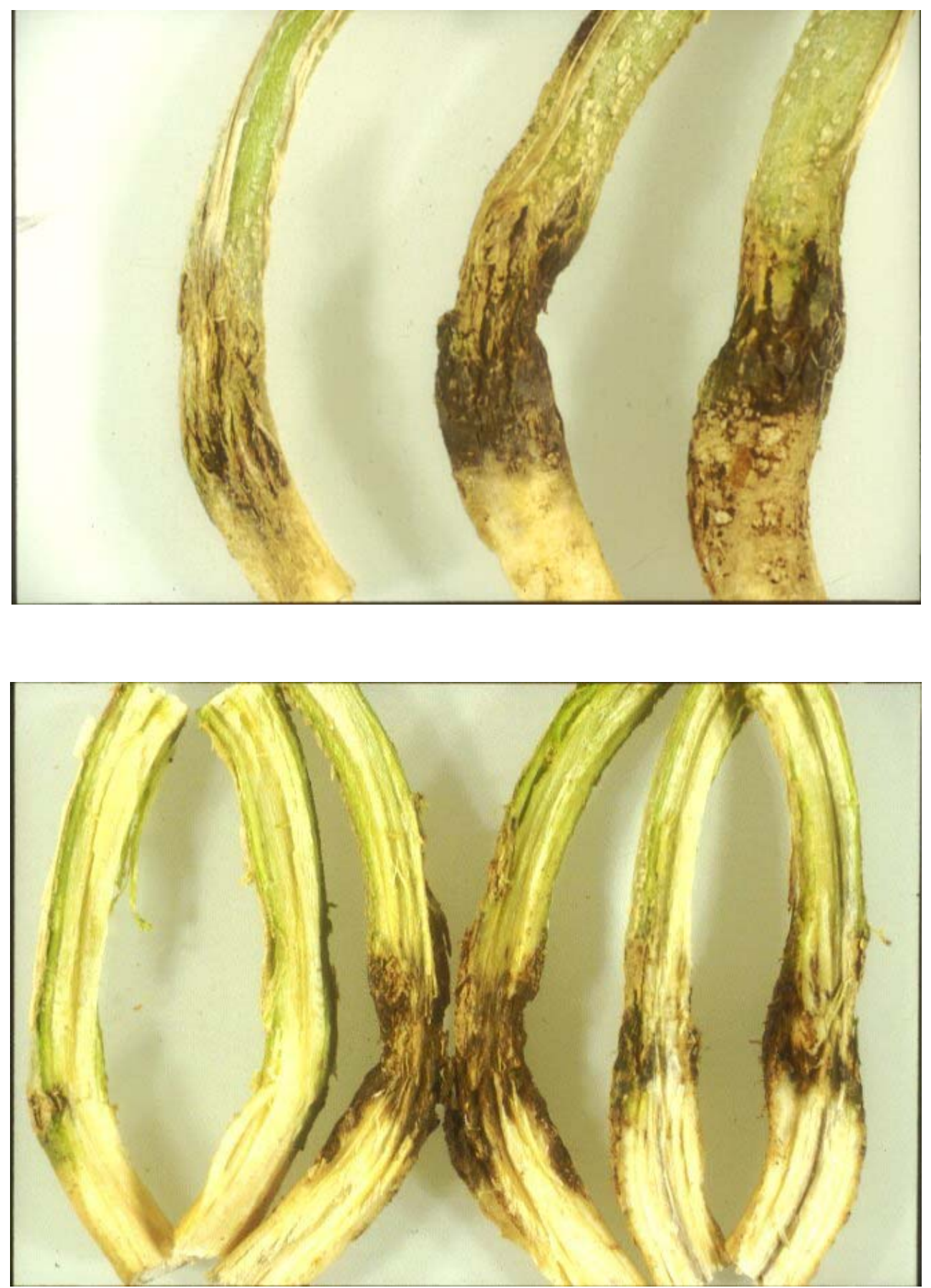

Abb. 2: Symptomausprägung an der Stängelbasis bzw. dem Wurzelhals verursacht durch Leptosphaeria maculans

Oben: Deutlich erkennbare schwarzbraune Läsionen an der Grenzstelle der oberirdischen und unterirdischen Pflanzenteile

Unten: Querschnitt der Stängel mit unterschiedlichen Läsionstiefen; 


\subsubsection{Durchführung des Antagonistentests}

Zur Ermittlung der Wirkung der Antagonisten wurden die Pflanzen und die Bakterien wie unter 2. 4 bzw. 2.5.3 beschrieben angezogen. Die Anzahl der Versuchspflanzen war 10 bzw. 20. Die Bakterien wurden im Vergleich zu 2.9.3 in 0,25\%iger Xanthan anstelle von CMCellulose auf eine Konzentration von $10^{9} \mathrm{cfu} / \mathrm{ml}\left(E_{600 \mathrm{~nm}}=1\right)$ resuspendiert. Der Wurzelhals bzw. die Stängelbasis jeder Pflanze wurde mit $3 \mathrm{ml}$ einer Antagonistensuspension behandelt. Die Inokulation der Pflanzen mit L. maculans erfolgte 2 Tage nach Ausbringung von Antagonisten mit $40 \mu \mathrm{l}$ einer $10^{7} / \mathrm{ml}$ konzentrierten Sporensuspension. Nach 49 Tagen wurde der Befall sowohl nach dem Schema von KUTSCHER et al. (1993) (siehe 2. 13. 1) als auch mit Hilfe des ELISA ermittelt.

\subsection{Versuche zum Einfluss des Früh-Stängelbefall mit L. maculans auf den}

\section{Kornertrag}

Hierzu wurde für die Anzucht der Pflanzen $13 \times 13$ Plastik Töpfe verwendet. Die Pflanzen wurden im Entwicklungsstadium BBCH 14/15 mit $40 \mu$ l einer $10^{7}$ Sporen/ml konzentrierten Sporensuspension von L. maculans inokuliert. 7 Wochen nach Symptomerscheinung wurden die Pflanzen mit unterschiedlichen Befallsstärken zum Jahresanfang 2000 in der offenen Vegetationshalle des Instituts bis zur Ernte gestellt, wo sie überwinterten und somit auch vernalisiert wurden. Ab dem Entwicklungsstadium $\mathrm{BBCH} 16$ bis zum Stadium $\mathrm{BBCH} 50$ wurden die Pflanzen alle 3 Wochen mit „Hakafos“ regelmäßig gedüngt und vor Mehltaubefall einmal in der Woche prophylaktisch mit 0,25 \% Netzschwefel gespritzt. Mitte Juni 2000 wurden die Pflanzen abgeerntet und auf Kornertrag sowie den Befall mit $L$. maculans an der Stängelbasis untersucht. Die Befallsquantifizierung erfolgte anhand des ELISA.

\subsection{Untersuchungen zu den Hemmmechanismen}

\subsubsection{Bestimmung von Wachstum und Hemmstoffproduktion in Flüssigkultur}

Vorkulturen der Isolate RII2 und HA3e wurden wie unter 2.5.3 beschrieben angelegt. Die Hauptkulturen - $250 \mathrm{ml}$ TSB in $1.000 \mathrm{ml}$-Schikanekolben - wurden mit $4 \mathrm{ml}$ Vorkultur beimpft und bei $20^{\circ} \mathrm{C}$ inkubiert (100 Upm). Pro Isolat wurden 3 Kulturen angesetzt. Die Probennahme erfolgte je nach Versuchszweck bis zu 120 Stunden. Aus jedem Kolben wurden $5 \mathrm{ml}$ Kultur entnommen, die optische Dichte bei $600 \mathrm{~nm}$ und der pH-Wert gemessen. Anschließend wurden die 3 Proben eines Isolates vereinigt, bei $20.000 \times \mathrm{g} 15 \mathrm{~min}$ zentrifugiert, das Pellet verworfen und der Überstand bei $-20^{\circ} \mathrm{C}$ eingefroren. Nach Beendigung der Inkubation der Flüssigkulturen erfolgte die Aufarbeitung aller Proben 
gemeinsam, indem die Kulturüberstände aufgetaut, sterilfiltriert und in folgenden Tests eingesetzt wurden.

\subsubsection{Nachweis der Bildung von Cyanwasserstoff und Ammonium}

Der direkte chemische Nachweis der durch die Pseudomonaden gebildeten Blausäure erfolgte mit dem Spektroquant 1417 Schnelltest von Merck. Die Bildung von Blausäure durch die Bakterien in TSB und Strohextrakt wurde getestet. Dazu wurde jeweils $10 \mathrm{ml}$ Bakterienzellkultur nach 24h, 48h, 72h Inkubation durch Zentrifugation geerntet und sterilfiltriert (Membranfilter, Porengröße 0,2 $\mu \mathrm{m}$, Fa. Sartorius, Göttingen). Der Nachweis von $\mathrm{HCN}$ in $5 \mathrm{ml}$ zellfreiem Kulturüberstand erfolgte durch die Farbreaktion nach ASMUS und GARSCHAGEN (1953). Nach Zugabe eines Chlorsalzes und Pyridin kondensiert man das sich bildende Glutacondialdehyd mit 1,3-Dimethylbarbitursäure zu einem violetten Polymethinfarbstoff (Abb.3a). Die Farbintensität ist proportional zur HCN-Menge im Kulturfiltrat und wurde in Mikotiterplatten mit dem Mehrstrahlphotometers (Fa. Tecan, Deutschland) bei 550nm gemessen.

Zum qualitativen Nachweis der Bildung von Ammoniumionen wurde die Methode von FAWCETT \& SCOTT (1960) verwendet. Dazu wurden 100 $\mu$ l zellfreier Kulturüberstand jeweils mit 2,5ml der unten aufgeführten Lösungen A und B vermischt. Nach dem Durchmischen wurde sofort bei $37^{\circ} \mathrm{C}$ im Wasserbad für 15 min. inkubiert (Abb.3b). Bevor die Messung der Extinktion bei 550nm gegen einen Blindwert mit destilliertem Wasser erfolgte, wurde weitere 15min gewartet, um die Proben auf Raumtemperatur abkühlen zu lassen.

Lösung A: 9,98 g/l Phenol und 0,05 g/l Natrium-Nitroprussid $\left[\mathrm{Na}_{2} \mathrm{Fe}(\mathrm{CN})_{5} \mathrm{NO} \cdot 2 \mathrm{H}_{2} \mathrm{O}\right]$ in dest. Wasser;

Lösung B: $1 \mathrm{~L} \quad 0,125 \mathrm{~N} \mathrm{NaOH}$ wird mit $400 \mu \mathrm{l}$ 13\%iger Natriumhypochlorid-Lösung versetzt..

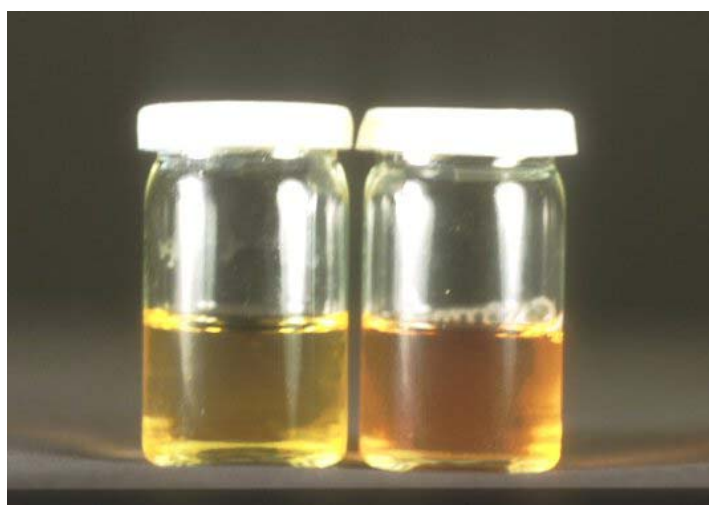

a

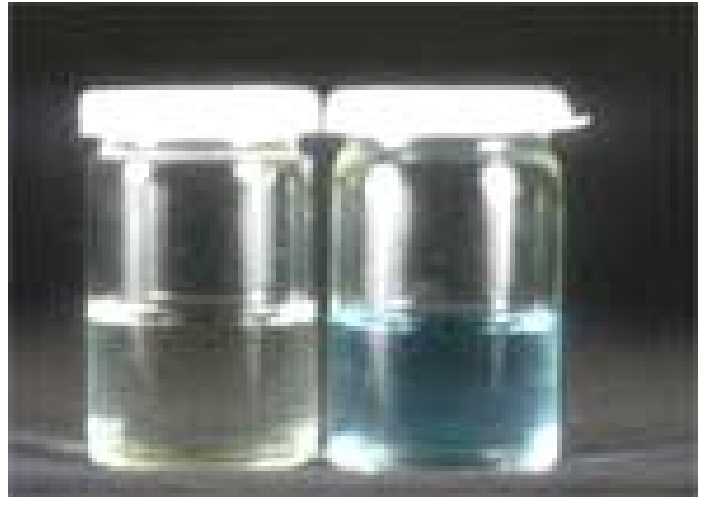

b

Abb.3: Nachweis von HCN- Bildung (a) bzw. Ammoniumbildung (b) durch Antagonisten linkes Fläschchen auf jedem Bild: negativer Nachweis rechtes Fläschchen auf jedem Bild: positiver Nachweis 


\subsubsection{Extraktion von Hemmstoffen aus Bakterienkulturfiltraten}

Die Extraktion des Hemmstoffes aus diesem Kulturfiltrat (siehe 2.15.1) erfolgte durch die Adsorption an einem XAD-Adsorberharz. Lipophile organische Substanzen werden von diesem Harz adsorptiv gebunden, nicht jedoch stark polare Verbindungen und anorganische Salze. Die Desorbtion der Moleküle erfolgt dann mit dem organischen Lösungsmittel Methanol. Vor der Anwendung mußte das XAD-4-Harz von organischen Verunreinigungen befreit werden. Dazu wurde mit $1 \%$ igem methanolischem $\mathrm{HCl}$ so lange gespült, bis die Flüssigkeit klar blieb. Danach wurde das Harz mit Chloroform, dann wieder mit Methanol und zum Schluss mit Wasser gespült.

Der Kulturüberstand (ca. $200 \mathrm{ml}$, s. o.) wurde in ein 1000-ml-Becherglas gefüllt und $50 \mathrm{~g}$ XAD-4-Adsorberharz zugegeben. Die Mischung wurde auf einem Rotationsschüttler 30 min bei $120 \mathrm{U} / \mathrm{min}$ geschüttelt. Danach wurde alles über einen Büchnertrichter gegeben und mit $1000 \mathrm{ml}$ Aqua bidest. gewaschen, um verbliebene, nicht adsorbierte organische und anorganische Substanzen zu entfernen. Anschließend wurde mit jeweils $50 \mathrm{ml}$ steigender Methanolkonzentration $(20 \%, 40 \%, 60 \%, 80 \%$ und 100\%) in Wasser eluiert, und die einzelnen Fraktionen getrennt aufgefangen. Die Lösungen wurden danach in einen Rundkolben überführt und am Rotationsdampfer eingeengt. Der Rückstand wurde mit $2 \mathrm{ml}$ Methanol aufgenommen. Diese gewonnenen methanolhaltigen Kulturfiltratextrakte wurden anschließend auf ihre Hemmaktivität gegenüber dem Mycelwachstum von L. maculans im Plättchendiffusionstest überprüft und mit Hilfe von DC bzw. HPLC auf den Gehalt an Indolessigsäure, 2,4-Diacetylphloroglucinol und Pyrrolnitrin untersucht.

\subsubsection{Plättchentest}

Sterile Antibiotika-Testplättchen (Fa. Schleicher \& Schuell, Dassel) wurden mit $50 \mu \mathrm{lder}$ sterilen methanolischen Extrakte, IAA, DAPG bzw. Pyrrolnitrin getränkt und zur schnelleren Entfernung des Lösungsmittels auf einer mit 70 \%igem Ethanol sterilisierten Heizplatte $\left(40^{\circ} \mathrm{C}\right)$ getrocknet. Als Kontrolle dienten Plättchen mit $50 \mu$ l Methanol. Jedes Plättchen wurde mittels einer sterilen Pinzette auf V8-Agarplatten aufgelegt und ein Mycel-Agarstückchen von L. maculans (Isolat IBCN66) $(\varnothing 5 \mathrm{~mm})$ in der Mitte der Platte geimpft. Der Abstand zwischen Impfstück und Plättchen betrug hierbei jeweils $35 \mathrm{~mm}$. Nach siebentägiger Inkubation bei $20^{\circ} \mathrm{C}$ wurden die Hemmhöfe um die Extraktplättchen ermittelt.

\subsubsection{Dünnschichtchromatographie der Extrakte}

Die Detektion von IAA, DAPG und Pyrrolnitrin erfolgte zunächst dünnschichtchromatographisch durch Vergleich des Laufverhaltens der Methanolextrakte mit den reinen Substanzen. Zur Auftrennung der Rohextrakte wurde eine Dünnschichtchromatographie an Kieselgel 60 durchgeführt. Dazu wurden 30-50 $\mu$ ler Extrakte mit Hilfe einer EppendorfPipette punktförmig auf die Startlinie einer Kieselgelplatte $\left(10 \times 10 \mathrm{~cm}\right.$, Kieselgel $60 \mathrm{~F}_{254}$, 
0,2 mm Schichtdicke mit Fluoreszenzindikator, Fa. Merck, Darmstadt, Nr. 5554) aufgetragen und in Chloroform/Methanol (95/5) entwickelt. Nach Abdampfen des Laufmittels wurden unter UV-Licht (254 nm bzw. $360 \mathrm{~nm}$ Wellenlänge) die UV-löschenden Zonen markiert. Anschließend wurden die Platten mit Ehrlichs Reagenz angefärbt, indem sie mit dem Reagenz besprüht und bei $100^{\circ} \mathrm{C}$ im Trockenschrank nachbehandelt wurden, bis die Banden ihre maximale Farbintensität entwickelt hatten.

$\begin{array}{ll}\text { Ehrlichs Reagenz (färbt Amine) } & \\ \begin{array}{ll}\text { 4-Dimethylaminobenzaldehyd } & 1 \mathrm{~g} \\ \text { Salzsäure (32 \%) } & \text { ad } 25 \mathrm{ml} \\ & + \\ \text { Methanol } & 75 \mathrm{ml}\end{array}\end{array}$

\subsubsection{Nachweis von Bildung zweier Antimykotika mit Hilfe von HPLC}

Im Vergleich zur Dünnschichtchromatographie (DC) stellt die Hochdruck-FlüssigkeitsChromatographie (HPLC) eine sensitivere und zuverlässigere Methode zur Detektion der Antibiotika DAPG bzw. Pyrrolnitrin dar. Die Identifizierung erfolgte durch Vergleich mit den Reinsubstanzen, die uns freundlicherweise aus der Arbeitsgruppe von Frau Prof. Défago (DAPG) und der Firma Fujisawa Pharmaceuticals (Pyrrolnitrin) zur Verfügung gestellt wurden. Für die Untersuchungen wurde eine analytische HPLC-Anlage der Fa. Kontron mit zwei Pumpen (Kontron HPLC 322) eingesetzt. Die $10 \mu \mathrm{l}$ Probe wurde mit einer Hamiltonspritze manuell injiziert. Gemessen wurde in einem Kontron UV/Vis-Detector 432 bei einer Wellenlänge von 270nm für DAPG bzw. 252nm für Pyrrolnitrin. Die stationäre Phase war eine Anionaustauschersäule (reversed-phase RP-18 Säule, 220mm*4.6 mit einem Partikeldurchmesser von $5 \mu \mathrm{m}$ ) mit Vorsäule (Spheri-5-RP-18, 30mm*4.6mm). Als mobile Phase diente ein Methanol/0,05N Phosphatsäure Gemisch mit einer Flußrate von $1 \mathrm{ml} / \mathrm{min}$. Das Lösungsmittel hatte HPLC-Qualität. Das bidestillierte Wasser wurde zuvor filtriert (Cellulose-Acetat-Filter, 0,2 $\mu \mathrm{m}$; Sartorius). Eine optimale Auftrennung der Extrakte wurde durch einen Gradienten erzielt, bei dem für DAPG die Methanolkonzentration innerhalb der ersten 10 Minuten von $25 \%$ auf $85 \%$ und in den anschließend 10 Minuten von $85 \%$ auf $100 \%$ linear anstieg, für Pyrrolnitrin die Methanolkonzentration innerhalb der ersten 25 Minuten von $75 \%$ auf $84 \%$ und in den anschließend 10 Minuten von $84 \%$ auf $100 \%$ linear anstieg. Die Retentionszeiten unter diesen Analysenbedingungen sind für DAPG .und Pyrrolnitrin jeweils 11, 85 min bzw. 5,51 min. Die Auswertung erfolgte mit der Kontron HPLC-Software Version Data System 45-MT2. 


\subsubsection{Nachweis und Quantifizierung der IAA und IAA-Derivaten- Produktion}

Die Quantifizierung der Bildung von IAA bzw. IAA-Derivaten durch Ps fluorescens RII2 und Paenibacillus polymyxa HA3e erfolgte nach der colorimetrischen Methode von PLET \& CHOLLET (1970) (Abkürzung: PC), da diese die sensitivste und spezifischste aufgrund der Salkowski-Methode darstellte (GLICKMANN \& DESAUX, 1995). $400 \mu \mathrm{l}$ eines Extraktes wurde mit $400 \mu \mathrm{l}$ der Reagenzlösung (12 $\mathrm{g} \mathrm{FeCl}_{3}$ in ein Liter 7,9 $\mathrm{M} \mathrm{H}_{2} \mathrm{SO}_{4}$ ) in einem E-cup gut vermischt und in Dunkeln für 30 min bei Raumtemperatur reagieren gelassen. Die Mischung wurden anschließend in eine Messplatte $(12 \times 8,185 \mu / /$ Trog) umpipettiert, um die Extinktion mit Hilfe eines Mehrstrahlphotometers bei $550 \mathrm{~nm} \mathrm{zu}$ messen. Die Berechnung der Konzentration erfolgte über eine mit IAA erstellte Eichgrade (Abb. 4).

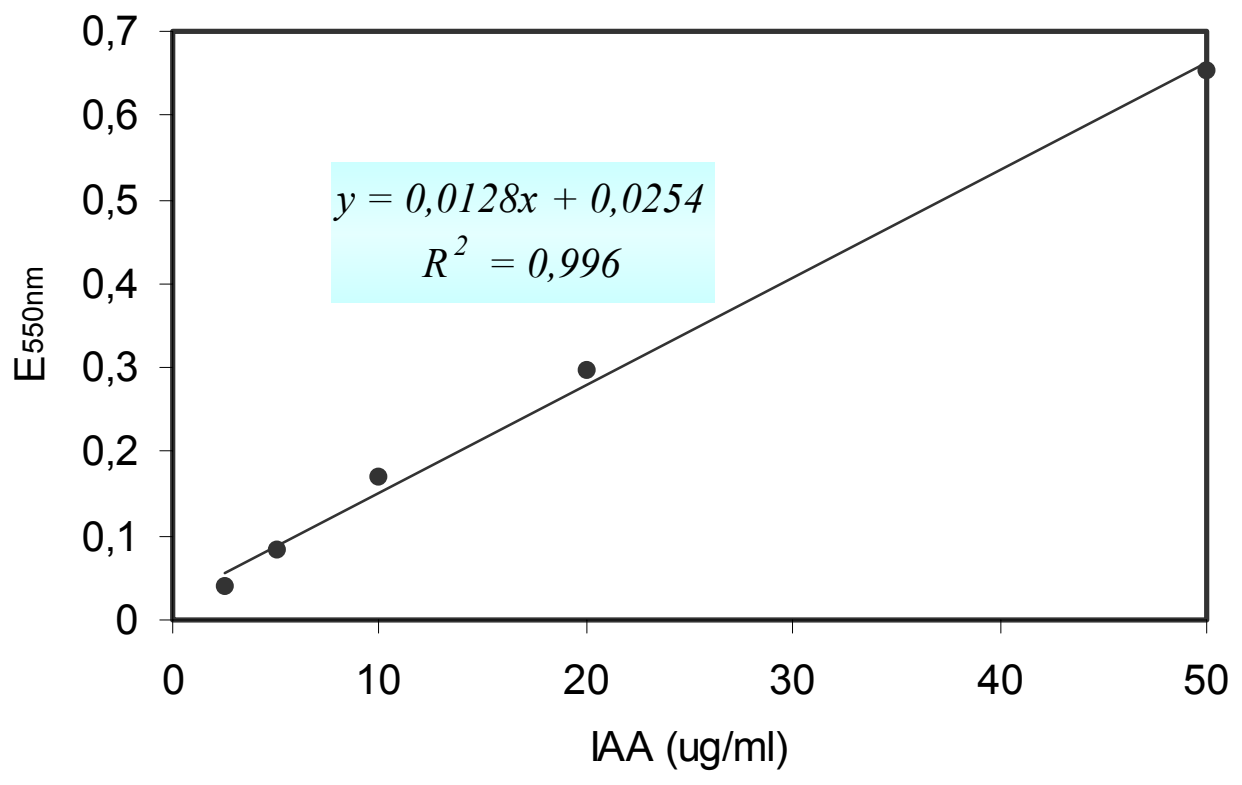

Abb. 4: Eichkurve zur IAA-Quantifizierung (Nachweisbereich: 2,5 - 50 ppm)

\subsubsection{Quantitative Aktivitätsbestimmung hydrolytischer Enzyme}

Zur quantitativen Erfassung der Produktion von extrazellulären Chitinasen, 1,3-ß-Glucanasen, Xylanasen und Cellulasen wurden Kulturfiltrate der Bakterien auf ihre Enzymaktivität getestet (WIRTH \& WOLF 1992). Bei dieser Methode dienen hochmolekulare, an die Farbstoffe RBB bzw. RBV gekoppelte, durch Carboxymethylierung wasserlösliche Polymere, hier CM-Curdlan (1,3-ß-Glucan), CM-Chitin, CM-Xylan bzw. CM-Cellulose als Substrate. Im Enzymtest werden durch Einwirkung oben genannter hydrolytischer Enzyme die Polymere in kürzere Bruchstücke gespalten. Die Zugabe von Salzsäure zum Testansatz führt zum Abstoppen der Enzymreaktion und zu einem Ausfällen der nicht gespaltenen Polymere und können abzentrifugiert werden. Die gespaltenen, kürzeren Bruchstücke verursachen eine Färbung des Überstandes. Die Intensität der Färbung ist ein Maß für die Enzymaktivität. 
Die Durchführung des Enzymtests erfolgte in Mikrotiterplatten mit $350 \mu \mathrm{l}$ Kavität. Jede Probe wurde in drei Wiederholungen mit drei zugehörigen Kontrollen (Blanks) getestet.

Zunächst wurden $100 \mu \mathrm{l}$ Substratlösung für Probe und Kontrolle vorgelegt (Tab. 1). In die Tröge für die Probe wurden gleich anschließend $100 \mu$ zellfreier Kulturüberstand pipettiert und der Ansatz $2 \mathrm{~h}$ bei $40^{\circ} \mathrm{C}$ im Wasserbad inkubiert. Nach Ablauf der Inkubationszeit wurden den Blanks ebenfalls $100 \mu$ l Kulturfiltrat zugesetzt. Durch Zusatz von $100 \mu \mathrm{l} 1 \mathrm{~N} \mathrm{HCl}$ wurde die Enzymreaktion gestoppt. Die Platten wurden $10 \mathrm{~min}$. auf Eis gelegt, wodurch die Fällung der Polymer-Farbstoff-Konjugate begünstigt wird. Anschließend erfolgte eine Zentrifugation der Mikrotiterplatten (8 min., 2800 Upm, Labofuge 400, Fa. Heraeus, Osterode). Von den Überständen wurden je $175 \mu \mathrm{l}$ in Messplatten mit $185 \mu \mathrm{l}$ Kavität (A/2, Costar) überführt. Die Extinktionen der Überstände wurden im Photometer (Spectra 2, SLT Laboratories, Crailsheim) für CM-Chitin-RBV bei $550 \mathrm{~nm}$ und für CM-Curdlan-RBB und anderen RBB-Substraten bei $592 \mathrm{~nm}$ gemessen. Aus den je drei Messwerten für die als Referenz dienenden Blanks und für die Proben wurde jeweils der Mittelwert errechnet.

Tab. 1: Pipettierschema zur Durchführung des Enzymtests

\begin{tabular}{llc}
\hline \hline \multicolumn{1}{c}{ Allgemeiner Testansatz } & \multicolumn{1}{c}{ Eingesetzte Lösung } & Eingesetztes Volumen \\
\hline & $\begin{array}{l}\text { CM-Chitin-RBV }(2 \\
\text { mg/ml), CM-Curdlan-RBB } \\
\text { bzW. andere -RBB } \\
\text { 1. Substratlösung }\end{array}$ & $100 \mu \mathrm{l}$ \\
\cline { 2 - 3 } $\begin{array}{l}\text { Substrate }(4 \mathrm{mg} / \mathrm{ml}) \\
\text { 2. Probe }\end{array}$ & Kulturfiltrat & $100 \mu \mathrm{l}$ \\
\cline { 2 - 3 } $\begin{array}{l}\text { 3. Probe } \\
\text { (nur Referenz-Tröge) }\end{array}$ & Inkubation bei $40^{\circ} \mathrm{C}$ & $100 \mu \mathrm{l}$ \\
\cline { 2 - 3 } 4. Säure & Kulturfiltrat & $100 \mu \mathrm{l}$ \\
\hline
\end{tabular}

\subsection{Wachstumsbeeinflussende Eigenschaften der Antagonisten}

\subsubsection{Keimlingswachstum in Antagonistensuspensionen}

Hierbei wurde das Rapssaatgut in Plastik-Petrischalen gefüllt $(9 \mathrm{~mm}$; die Feuchtigkeit wurde mit Hilfe von zwei auf den Boden gelegten Filterpapieren gehalten), um die Keimung zu stimulieren. Die 1 bis 2 Tage alten Keimlinge wurden einzeln in $8 \mathrm{~mm}$ breite Löcher einer schwimmfähigen, auf der Unterseite mit feinmaschiger Gaze bespannten Schaumstoffplatte ( $6 \times 6$ Bohrungen) eingelegt. Diese Schaumstoffplatte wurde in eine zu drei Vierteln mit einer Antagonistensuspension gefüllten Plastikschale gelegt. Die Platte schwimmt auf der 
Suspension und ermöglicht so ein freies Wurzelwachstum. Zur Herstellung der Antagonistensuspension wurden die Antagonisten wie unter 2.5.3 beschrieben angezogen. $250 \mathrm{ml}$ einer $48 \mathrm{~h}$ alten Kultur der Antagonisten wurden durch Zentrifugation bei $20.000 \mathrm{~g}$, $15 \mathrm{~min}$ und $4{ }^{\circ} \mathrm{C}$ (Suprafuge 22, Heraeus Sepatech, Osterode) geerntet und das Pellet in $20 \%$ igem Bodenextrakt auf eine Konzentration von ca. $10^{7} \mathrm{cfu} / \mathrm{ml}\left(\mathrm{E}_{600 \mathrm{~nm}} 0,2\right)$ resuspendiert.

\subsubsection{Einfluss einer Wurzelbehandlung mit Antagonisten auf das Wurzelwachstum}

Hierzu wurde für eine Stunde die Wurzel von 7 Tage alten intakten Keimlingen in eine ca. $5 \times 10^{9} \mathrm{cfu} / \mathrm{ml}$ konzentrierten Antagonistensuspension eingelegt und anschließend wie unter 2.4 beschrieben vereinzelt. 21 Tage nach der Inokulation wurde die Wurzellänge wie in 2.16.4 beschrieben bestimmt.

\subsubsection{Einfluss einer Gießbehandlung mit Antagonisten auf das Wurzelwachstum}

Die Behandlung der Pflanzen mit Antagonisten erfolgte wie unter 2.12.2 beschrieben, allerdings ohne Infektion mit L. maculans. 49 Tage nach der Inokulation wurde die Wurzellänge wie in 2.16 .4 beschrieben ermittelt.

\subsubsection{Bestimmung der Wurzellänge}

Nach Abtrennen des Sprosses, werden die Wurzeln der Pflanzen vorsichtig aus dem Boden ausgewaschen und danach, durch weiteres Waschen, Bodenreste und andere organische Bestandteile entfernt. Das an der Wurzel frei anhaftende Wasser wird durch Abtupfen mit Vliespapier entfernt. Danach werden die Wurzeln sofort gewogen. Nach dem Wiegen werden die Wurzeln ohne Verzögerung in 2 bis $5 \mathrm{~mm}$ lange Stücke zerschnitten und eine repräsentative Probe von 300 bis 500 mg eingewogen. Diese Probe wird entweder gleich auf einem feinmaschigen Sieb, das mit Wasser bedeckt ist, gleichmäßig verteilt oder, für die spätere Verarbeitung, in Wasser gekühlt aufbewahrt.

Die Wurzellängeermittlung erfolgte nach der Schnittpunktmethode nach TENNANT (1975). Hierzu wurden die frischen Wurzelproben in kleine Stücke geschnitten. Zwei repräsentative Unterproben von ca. 3 bis $10 \mathrm{mg}$ wurden entnommen, gewogen und danach mit etwas Leitungswasser gleichmäßig auf einer Petrischale verteilt. Auf der Petrischale befand sich ganzflächig ein quadratisches Raster von $1 / 2$ Inch Rasterabstand. Die Länge jeder Unterprobe ergab sich aus der Zählung vertikaler und horizontaler Schnittpunkte zwischen Wurzelstücken und Rasterlinien. Die Wurzellänge der Unterprobe (UWL) errechnet sich nach Formel von TENNANT (1975): UWL=11/14 * Rasterabstand. Bei einem $1 / 2$ Inch $(=1,269 \mathrm{~cm})$ Rasterabstand bedeutet jeder Schnittpunkt $1 \mathrm{~cm}$ Wurzellänge. Die Wurzellänge $(\mathrm{WL})$ der 
Gesamtprobe wurde über das Gewichtsverhältnis der Unterprobe zur Gesamtprobe errechnet.

\subsection{Untersuchungen zur Besiedlung von Rapspflanze durch Pseudomonas fluorescens RII2 bzw. Paenibacillus polymyxa HA3e anhand der Cryo- Rasterelektronenmikroskopie (Cryo-REM)}

Bei der Cryo-Rasterelektronmikroskopie wird die zu untersuchende Probe zuerst in einer Mischung vom Flüssig - und Feststickstoff innerhalb der Cryopräparationskammer bei ca. $200{ }^{\circ} \mathrm{C}$ rasch tiefgefroren, dann das auftretende Eis (Gefrierätzung) auf der Probenoberfläche durch Erhöhung der Temperatur im Probenkasten von $-150{ }^{\circ} \mathrm{C}$ auf $-90{ }^{\circ} \mathrm{C}$ sublimiert. Nach einer erneuten Temperaturreduzierung auf $-120{ }^{\circ} \mathrm{C}$ wird die Probe anschließend in den REM Kasten eingeschoben $\left(-160{ }^{\circ} \mathrm{C}\right)$. Im Vergleich zu anderen Verfahren der Elektronmikroskopie ist der Aufwand für die Probenpräparation minimal und die Möglichkeit von Präparationsartefakten nahezu ausgeschlossen. Es wurde das CryoRasterelektronenmikroskop LEO 1500 Feldemission-REM (Fa. LEO Electron Microscopy Ltd, Cambridge, England) verwendet.

Es wurden mit Antagonistensuspensionen (Pseudomonas fluorescens RII2, Paenibacillus polymyxa HA3e) standardmäßig behandelte Rapsstängel (siehe 2.13.2, 48 Stunden nach Inokulation) sowie entsprechende Kontrollen untersucht. Die technische Durchführung der Elektronenmikroskopie wurde dankenswerterweise von Herrn Dr. T. Heinrichs übernommen.

\subsection{Mikroskopie und Photographie}

Die Mikroskopischen Untersuchungen wurden mit einem Mikroskop der Fa. Leitz, Wetzlar, durchgeführt. Für die photographischen Aufnahmen wurden eine Contax Spiegelreflexkamara und Ektachrome ASA 64-Kunstlichtfilme der Fa. Kodak verwendet.

\subsection{Statistische Auswertung}

Die statistische Verrechnung erfolgte mit dem Programm Sysstat 8.0 von der Firma SPSS. Um zu prüfen, ob eine signifikante Hemmwirkung am Rapskeimblatt bzw. -stängel vorliegt, wurde der Bonferroni-Test (ANOVA: Vergleich der Befallsstärke in der Variante mit Antagonisten und der Kontrolle) verwendet. 


\section{Ergebnisse}

\subsection{Isolierung antagonistischer Mikroorganismen}

Um die Wahrscheinlichkeit eines erfolgreichen Einsatzes von mikrobiellen Antagonisten zur biologischen Bekämpfung bodenbürtiger Pathogene zu erhöhen, wird von einigen Autoren empfohlen, die Antagonisten aus dem Ziel-Habitat (Bodentyp, Pflanzenart) zu isolieren, da angenommen wird, dass es in diesen Habitaten eine Anreicherung von Antagonisten bereits stattgefunden hat. Jedoch konnte diese These widerlegt werden, da einige Bodenbakterien und -pilze erfolgreich gegen verschiedene Erreger eingesetzt werden konnten, obwohl sie aus Herkünften stammten die dem späteren Wirkort nicht entsprachen (TILCHER et al. 1994).

Um ein möglichst breites Spektrum von Antagonisten zu erhalten, wurden aus Komposterde und der Rhizosphäre verschiedener Pflanzen 109 bakterielle und 19 pilzliche Antagonisten mit einer in vitro-Hemmwirkung gegen Isolate unterschiedlicher Pathogenitätsgruppen von Leptosphaeria maculans (Isolate IBCN66, R1G4 und NA21) isoliert. In der Abb. 5 sind einige der wirksamen Antagonisten anhand der sie umgebenen Hemmhöfe im Testpilzrasen deutlich zu erkennen. Auf der unteren Hälfte der rechten Platte wird deutlich, dass mit der Dreischichtmethode nach HERR (1959) neben bakteriellen auch pilzliche Antagonisten gefunden wurden. Allerdings wird mit dieser Isolationsmethode auf dem Vollmedium Tryptic Soy bei einem pH von 7.0 nicht die ganze Bandbreite der Bodenmikroorganismen erfasst.

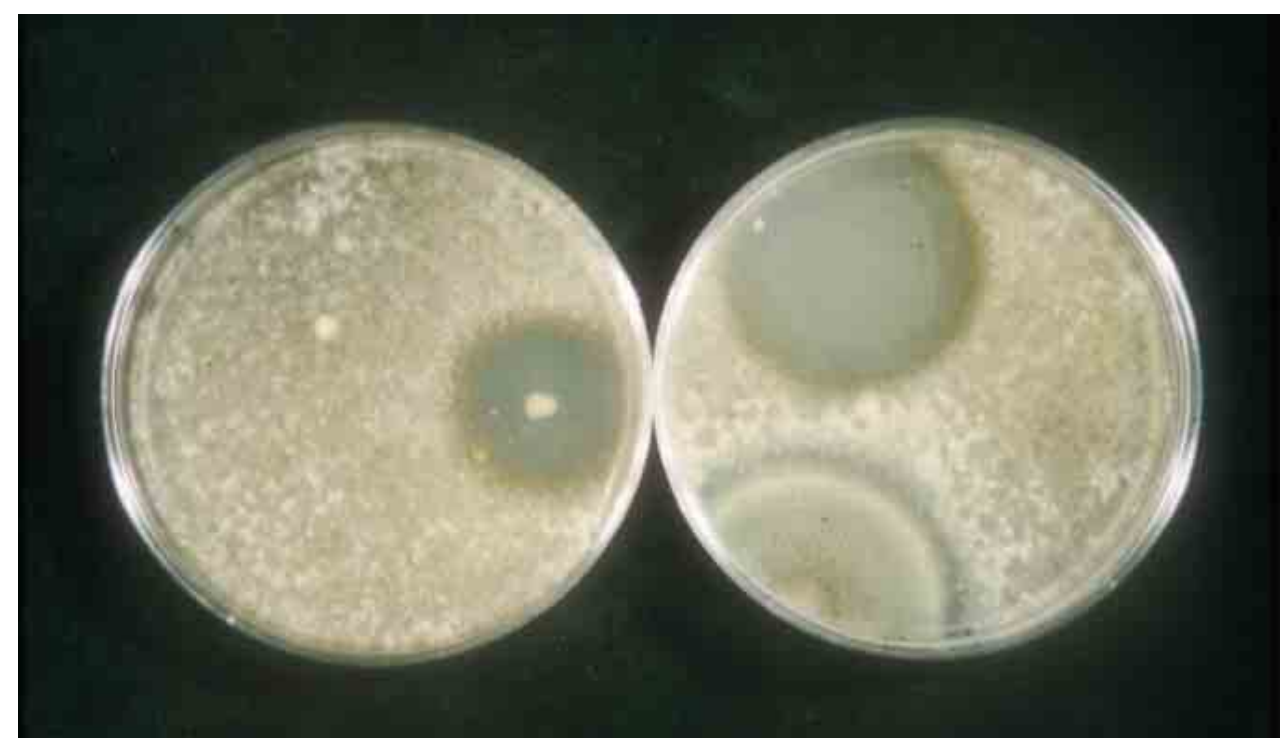

Abb. 5 Hemmhöfe im Myzelrasen von L. maculans, hervorgerufen durch die Ausscheidung von Hemmstoffen der Antagonisten 
Während aus den Bodenproben der Kulturpflanzen hauptsächlich bakterielle Antagonisten isoliert wurden, ließen sich die meisten der pilzlichen Isolate in der Bodenprobe "Wald" finden (Tab. 2). Die pilzlichen Antagonisten, von denen der größte Teil aufgrund ihrer Morphologie der Gattung Trichoderma zugeordnet werden konnten, wurden in der vorliegenden Arbeit nicht weiter berücksichtigt, da die Bakterien in ihrer Lebensweise besser an die Bedingungen in der Rhizosphäre angepaßt sind und ihre Massenkultivierung für eine Applikation einfacher und kostengünstiger durchzuführen ist (HEUPEL 1992, SASSE 1997).

Tab. 2: Anzahl der isolierten Antagonisten verschiedener Herkünfte gegen L. maculans

\begin{tabular}{llcc}
\hline \multirow{2}{*}{$\begin{array}{c}\text { Herkunft } \\
\text { der Bodenproben }\end{array}$} & Standort & \multicolumn{2}{c}{ Anzahl der Isolate } \\
\cline { 3 - 4 } Kirschplantage & Gießen & Bakterien & Pilze \\
Gerstenfeld & Gießen & 4 & 0 \\
Kartoffelfeld & Göttingen & 11 & 0 \\
Kompost & Göttingen & 18 & 1 \\
Rapsfeld 1 & Göttingen & 22 & 0 \\
Rapsfeld 2 & Göttingen & 5 & 0 \\
Wald & Göttingen & 17 & 0 \\
Weizenfeld & Göttingen & 17 & 14 \\
Zuckerrübenfeld & Göttingen & 5 & 0 \\
\hline
\end{tabular}

\section{2 In vitro- Screening antagonistischer Mikroorganismen}

\section{2.1 In vitro-Hemmung des Myzelwachstums von Leptosphaeria maculans und Verticillium Longisporum durch Anatgonisten}

Im Anschluss an die Isolierung wurde die in vitro Hemmung des Myzelwachstums der Pathogene L. maculans und V. longisporum untersucht, da dies als ein schnelles Testverfahren die Vorauswahl hemmstoffbildender Antagonisten erlaubt (FRAVEL 1988, RENWICK et al. 1991, HeUPEL 1992, ANDREWs 1992; TILCHER 1996), zumal die ad planta Hemmwirkung häufig auch eine in vitro Antibiose voraussetzt (BROADBENT et al. 1971). 


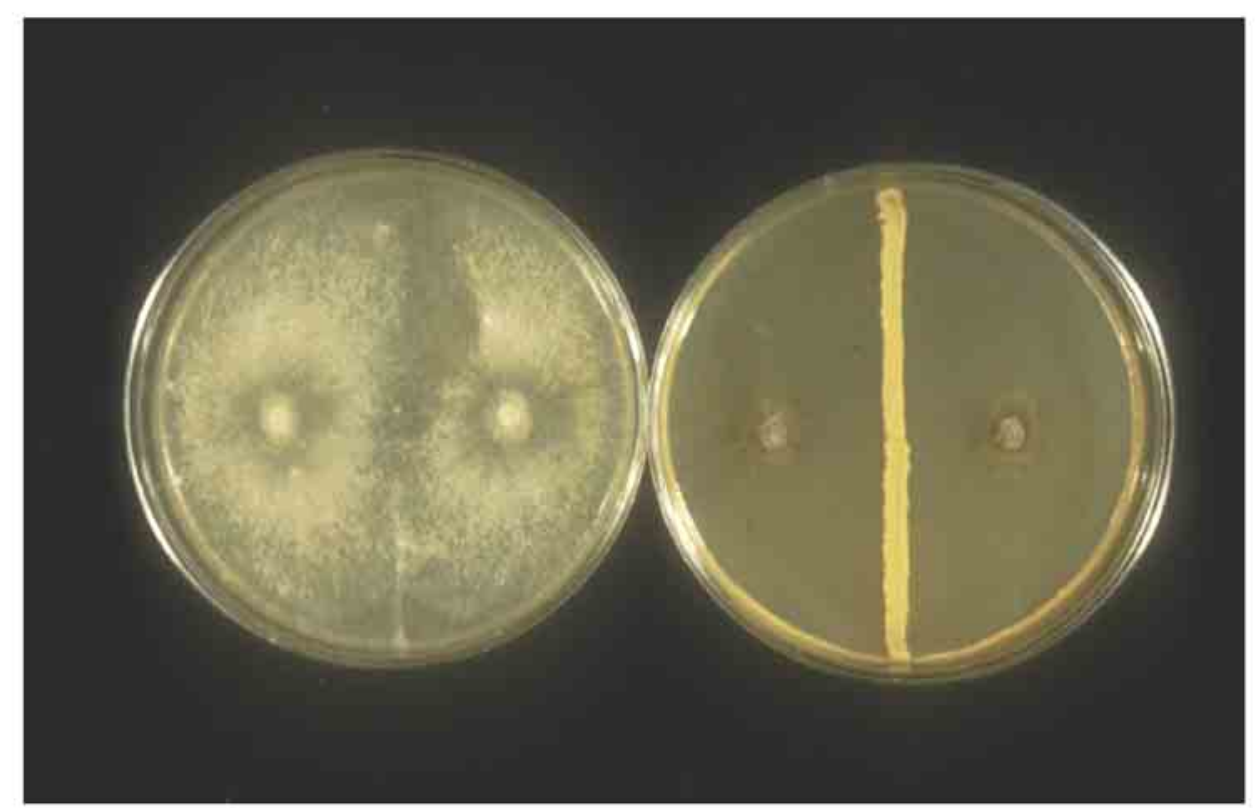

Abb. 6: Hemmung des Myzelwachstums von L. maculans Isolat R1G2 durch das antagonistische Isolat Paenibacillus polymyxa HA3e auf V8-Agar in Dualkultur. links: Kontrollplatte ohne Antagonist; rechts: Dualkultur der Mikroorganismen.

Von den 109 Isolaten erwiesen sich 58 als wirksam gegenüber dem Myzelwachstum von L. maculans sowohl auf $\mathrm{V} 8$ als auch auf MsA (Tab. 3 a und b). Alle Isolate konnten das Myzelwachstum der Pathogene unterdrücken. Bei der Hemmwirkung auf das Wachstum der drei L. maculans Isolate IBCN66 (A1), R1G4 (A2) und NA21 durch einen Antagonisten auf den entsprechenden Nährmedien konnten in den meisten Fällen keine Unterschiede festgestellt werden. Keiner der Antagonisten hat eine spezifische Hemmwirkung gegenüber einer Pathgenitätsgruppe gezeigt. Allerdings wurden Unterschiede in ihrer Wirksamkeit gegen L. maculans und V. longisporum auf V8 und MsA gefunden. Die Hemmwirkung war auf V8 meistens ausgeprägter als auf MsA. 
Tab. 3a: In vitro Hemmwirkung verschiedener Antagonisten gegen L. maculans und $V$. longisporum auf den Nährmedien V8-Agar und MsA.

\begin{tabular}{|c|c|c|c|c|c|c|c|c|c|c|}
\hline \multirow{3}{*}{ ISOLAT } & \multicolumn{6}{|c|}{ L. maculans } & \multicolumn{4}{|c|}{ V. longisporum } \\
\hline & \multicolumn{2}{|c|}{ IBCN66 } & \multicolumn{2}{|c|}{ R1G4 } & \multicolumn{2}{|c|}{ NA21 } & \multicolumn{2}{|c|}{ V543b } & \multicolumn{2}{|c|}{ V40 } \\
\hline & V8 & MsA & V8 & MsA & V8 & MsA & V8 & MsA & V8 & MsA \\
\hline HA3а & 15 & 9,5 & 11,5 & 10,5 & 12 & 10 & 12 & 6,5 & 11,5 & 5,5 \\
\hline HA3b & 15 & 6,5 & 10,5 & 5,5 & 11,5 & 6 & 11 & 8,5 & 11,5 & 6 \\
\hline HA3c & 13,5 & 7 & 10,5 & 12,5 & 13 & 8 & 12 & 4,5 & 11,5 & 7,5 \\
\hline HA3e & 15,5 & 10 & 10 & 7 & 12,5 & 2 & 12 & 5,5 & 12 & 0 \\
\hline HA6 & 13,5 & 9,5 & 11,5 & 6,5 & 11 & 0 & 12 & 6,5 & 11 & 6,5 \\
\hline HA7 & 14,5 & 4,5 & 12,5 & 5,5 & 12,5 & 12,5 & 12,5 & 9,5 & 12 & 8,5 \\
\hline KAR 1 & 2 & 16 & 0 & 8,5 & 3 & 13 & -- & -- & -- & -- \\
\hline KAR 3 & 16,5 & 0 & 7 & 0 & 10 & -- & 5 & -- & 5 & -- \\
\hline KAR 4 & 12 & 2 & 7 & 5 & -- & -- & -- & -- & -- & -- \\
\hline KAR 5 & 5 & 0 & 9,5 & 10 & 5,5 & 9 & 3,5 & 0 & 3 & 0 \\
\hline KAR 12 & 5 & 6 & 4 & 7 & 0 & 6,5 & 3 & 0 & 4 & 0 \\
\hline KOM 1 & 9 & 4 & 10 & 7,5 & 10,5 & 4,5 & 7,5 & 8 & 9,5 & 10 \\
\hline KOM 2 & 9,5 & 2 & 8 & 9 & 5 & 12,5 & 4 & 10,5 & 7 & 6,5 \\
\hline KOM 3 & 11,5 & 2,5 & 11,5 & 4,5 & 12 & 0 & 8,5 & 10,5 & 8,5 & 7,5 \\
\hline KOM 4 & 8,5 & 0 & 10 & 3,5 & 8 & 0 & 6,5 & 2 & -- & 0 \\
\hline KOM 5 & 5,5 & 0 & 14 & 0 & 10,5 & 0 & 0 & 4 & 0 & 5,5 \\
\hline KOM 6 & 8,5 & 0 & 9,5 & 0 & 8 & 8,5 & 9,5 & 8,5 & -- & 8 \\
\hline KOM 7 & 5 & 2 & 7 & 5,5 & 2,5 & 7 & 0 & 2 & 0 & 0 \\
\hline KOM 8 & -- & 5 & 4 & 1,5 & 3 & 1 & -- & 4 & -- & 3,5 \\
\hline KOM 9 & 6 & -- & 6 & 6 & 8,5 & 8,5 & 0 & -- & 0 & -- \\
\hline KOM 12 & 9 & 14,5 & 8,5 & 15 & 5 & 15 & 8 & 15 & 7 & 15 \\
\hline KOM 13 & 8 & 0 & 0 & 3 & 0 & 5 & 0 & 2 & 0 & 3 \\
\hline KOM 14 & 11,5 & 14,5 & 7 & 15 & 11,5 & 15 & 7 & 11 & 10 & 10,5 \\
\hline KOM 15 & 7,5 & 9 & 6 & 4,5 & 6,5 & 0 & 9 & 0 & 8,5 & 0 \\
\hline KOM 16 & 10,5 & 0 & 9,5 & 0 & 8 & 5,5 & 10 & 0 & 11 & 0 \\
\hline KOM 17 & 13,5 & 8,5 & 6 & 11 & 0 & 0 & 0 & 2 & 0 & 4 \\
\hline KOM 18 & 12,5 & 7 & 10,5 & 8,5 & 12,5 & 5,5 & 10,5 & 9 & 10 & 11 \\
\hline KOM 19 & 11,5 & 6,5 & 6 & 3 & 5 & 0 & 10,5 & 0 & 10 & 0 \\
\hline RI 1 & -- & 6 & 5 & 8 & 0 & 5,5 & 0 & 2,5 & 0 & 3 \\
\hline RI 2 & 11 & 0 & 10,5 & 8,5 & 12 & 4 & 9,5 & 9,5 & 8 & 7,5 \\
\hline RI 5 & 11,5 & -- & 9 & 8 & 11,5 & 11 & 9,5 & 11 & 7,5 & 7,5 \\
\hline
\end{tabular}


Tab. 3b: In vitro Hemmwirkumg verschiedener Antagonisten gegen L. maculans und V. longisporum auf den Nährmedien V8-Agar und MsA.

\begin{tabular}{|c|c|c|c|c|c|c|c|c|c|c|}
\hline \multirow{3}{*}{ ISOLAT } & \multicolumn{6}{|c|}{ L. maculans } & \multicolumn{4}{|c|}{ V. langisporum } \\
\hline & \multicolumn{2}{|c|}{ IBCN66 } & \multicolumn{2}{|c|}{ R1G4 } & \multicolumn{2}{|c|}{ NA21 } & \multicolumn{2}{|c|}{ V543b } & \multicolumn{2}{|c|}{ V40 } \\
\hline & V8 & MsA & V8 & MsA & V8 & MsA & V8 & MsA & V8 & MsA \\
\hline RI 6 & 12 & 4 & 10,5 & 4 & 10 & 5 & 10 & 8,5 & 8,5 & 7 \\
\hline RI 10 & 0 & 11 & 0 & 12 & 0 & 10 & 0 & 0 & 0 & 0 \\
\hline RI 11 & 12,5 & 4,5 & 9 & 5,5 & 12,5 & 0 & 10 & 7,5 & 8,5 & 7 \\
\hline RI 15 & 8 & 9 & 11 & 5 & & 7,5 & & 5 & & 7 \\
\hline RI 16 & 13 & 0 & 9,5 & 5 & 9,5 & 0 & 7,5 & 0 & 5,5 & 0 \\
\hline RI 18 & 12 & 12,5 & 5 & 6 & & 8,5 & & 3,5 & & 1 \\
\hline RI 21 & 14,5 & 15,5 & 14,5 & 12,5 & 11,5 & 7 & 6 & 0 & 5,5 & 0 \\
\hline RI 23 & 14 & -- & 10,5 & -- & -- & -- & -- & -- & -- & -- \\
\hline RII 1 & 13,5 & 12 & 11 & 13,5 & 13 & 14,5 & 0 & 4 & 0 & 6 \\
\hline RII 2 & 14,5 & 14 & 12 & 15 & 14,5 & 13,5 & 3,5 & 3,5 & 3 & 5 \\
\hline RII 3 & 14 & 5 & 15 & 9 & 11 & 9 & 1,5 & 5 & 0 & 5 \\
\hline RII 4 & 12 & 5 & 11,5 & 4 & 11 & 7 & 2 & 5 & 1,5 & 4 \\
\hline RII 5 & 14 & 5 & 11,5 & 10 & 10 & 9 & 0 & 4 & 0 & 2,5 \\
\hline WAL b & 11,5 & -- & 9,5 & -- & 11 & -- & 11,5 & -- & 10,5 & -- \\
\hline WAL 8 & 6,5 & 5,5 & 6,5 & 9,5 & -- & -- & -- & -- & -- & -- \\
\hline WAL 19 & 13 & 12 & 10 & 6,5 & 10 & 7 & 5 & -- & 5 & -- \\
\hline WE 1 & 14 & 14 & 11,5 & 9 & 13,5 & 5 & 12 & 7 & 12 & 8 \\
\hline WE 2 & 12 & 8 & 10 & 7 & 12 & 0 & 11 & 3,5 & 11,5 & 4,5 \\
\hline WE 5 & 14,5 & 10 & 14,5 & 9 & 2 & 2 & 0 & 5 & 0 & 0 \\
\hline WE 8 & 9 & 8 & 10 & 8 & 10 & 8 & 10 & 8,5 & 10 & 7 \\
\hline WE 12 & 12,5 & 4,5 & 12 & 3,5 & 12 & 5 & 0 & 0 & 0 & 0 \\
\hline WE 14 & 10,5 & 4 & 12,5 & 0 & 13 & 0 & 10 & 0 & 12,5 & 0 \\
\hline WE 15 & 13,5 & 10 & 10 & 13,5 & 11 & 4,5 & 11,5 & 6,5 & 10,5 & 10,5 \\
\hline WE 17 & 13 & 7 & 12 & 4 & 13 & 5 & 13 & 0 & 11 & 0 \\
\hline WE 18 & 11,5 & 13,5 & 9 & 12,5 & 11 & 0 & 11,5 & 4 & 10,5 & 5 \\
\hline ZU 9 & 12 & 3,5 & 12 & 5 & 11,5 & 4 & 6 & 5 & 5 & 5 \\
\hline ZU 10 & 15 & 7,5 & 10,5 & 11,5 & 10 & 5,5 & 13 & 9,5 & 11 & 5,5 \\
\hline
\end{tabular}




\section{2. 2 Ermittlung des antibakteriellen Spektrums der Antagonisten}

Da in Deutschland die Anwendung von Bakteriziden im Pflanzenschutz verboten ist, um einer Gefahr der Resistenzbildung humanpathogener Bakterien vorzubeugen, haben Antagonisten mit einem breiten antibakteriellen Wirkungsspektrum wenig Aussicht zur Zulassung, und sollten daher frühzeitig von weiteren Versuchen ausgeschlossen werden (WOLF et al, 1993). Zu diesem Zweck wurde die in vitro-Hemmwirkung der Antagonisten auf das Wachstum von 6 verschiedenen Testbakterien und einer Hefe ermittelt (Abb. 7, Tab. 4).

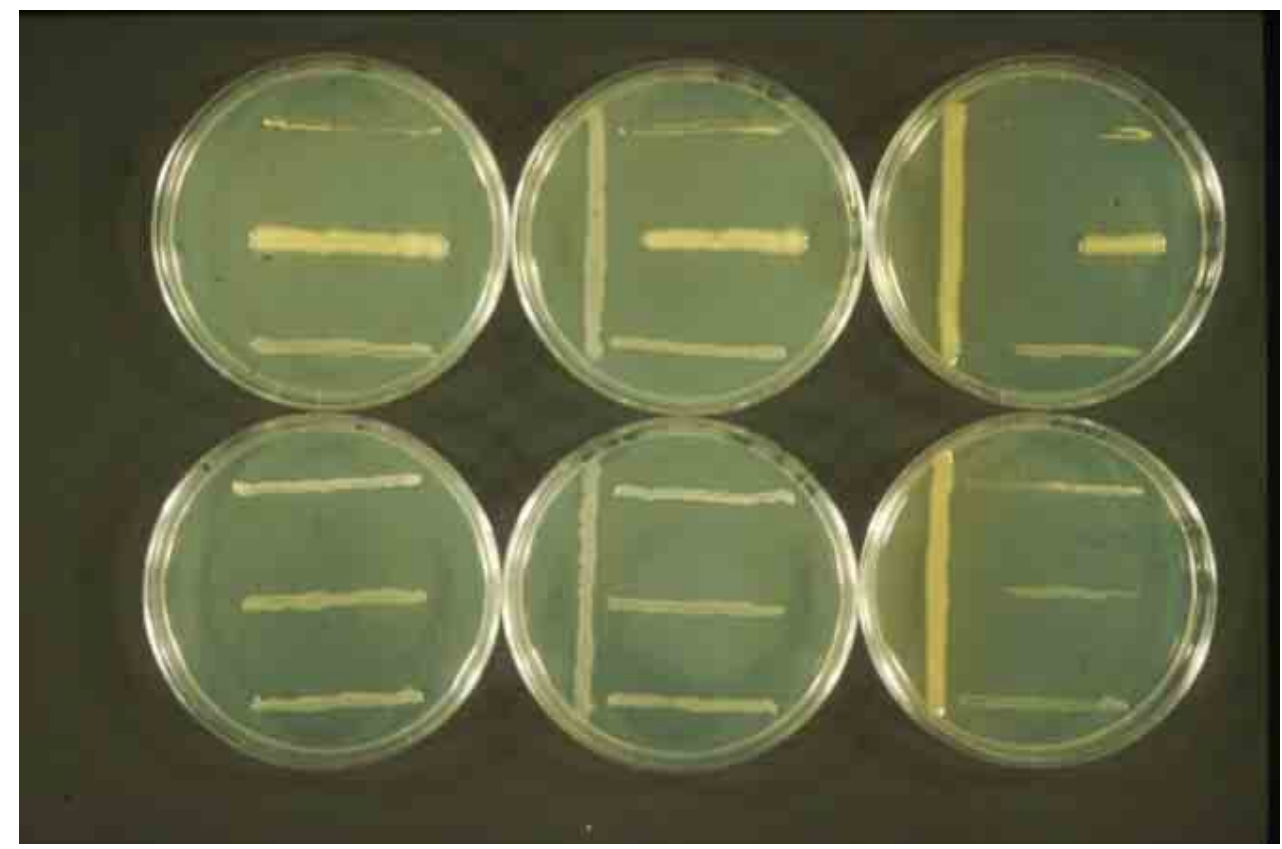

Abb. 7: Hemmwirkung der Antagonisten HA3e und KAR1 gegenüber 5 Testbakterien und einer Hefe auf TSA. Von oben nach unten: Clavibacter michiganensis ssp. michiganensis, Bacillus megaterium, Agrobacterium tumefaciens Pseudomonas phaseolicola, Escherichia coli, Sacharomyces cerevisiae.

links: Testmikroorganismen ohne Antagonist, mitte: Testmikroorganismen mit dem Isolat HA3e, rechts: Testmikroorganismen mit dem Isolat KAR1.

Das Isolat HA3e hemmte lediglich geringfügig das Wachstum von B. megaterium, während KAR1 das Wachstum von 4 der 6 Testorganismen unterdrückte (Abb. 7). Das die Antagonisten über ein zum Teil sehr unterschiedliches antibakterielles Spektrum verfügen, ist auch der Tab. 4 zu entnehmen, aus der überdies hervorgeht, dass die grampostiven Bakterien B. megaterium und C. michiganensis auf TSA sehr viel empfindlicher als die anderen Testorganismen reagierten. Die Isolate mit einer deutlichen Hemmwirkung auf mehr als 3 der Testorganismen wurden von den weiteren Untersu- 
chungen ausgeschlossen. Eine Ausnahme bildeten lediglich die Isolate KAR1 und KOM19. Sie wurden aufgrund ihrer ausgeprägten antagonistischen Wirkung in die weiteren Versuche miteinbezogen.

Tab. 4: Hemmwirkung der Antagonisten gegen 6 Bakterien und eine Hefe

A. $\mathrm{t} .=$ Agrobacterium tumefaciens; $\mathrm{B} . \mathrm{m} .=$ Bacillus megaterium; $\mathrm{C} . \mathrm{m} .=$ Clavibacter michiganensis; E. a. = Erwinia amylovora; E. c. = Escherichia coli; P. p. = Pseudomonas phaseolicola; Saccharomyces cerevisiae. (Hemmwirkung in $\mathrm{mm}$; Werte aus zwei Versuchen)

\begin{tabular}{lccccccc}
\hline \hline ISOLAT & \multicolumn{7}{c}{ Bakterien } \\
\cline { 2 - 7 } & A. t. & B. m. & C. m. & E.a. & E. c. & P.p. & S. c. \\
\hline HA3a & 0 & 11 & 11 & 0 & 0.5 & 2 & 0 \\
HA3b & 0 & 10 & 8 & 0 & 0 & 0 & 0 \\
HA3c & 0 & 8,5 & 25 & 0 & 0 & 0 & 0 \\
HA3e & 0 & 5 & 0 & 0 & 0 & 0 & 0 \\
HA6 & 0 & 10 & 6 & 0 & 1 & 0 & 0 \\
HA7 & 0 & 12 & 11 & 0 & 2,5 & 0 & 0 \\
IBAb & 0 & 14 & 11 & 1 & 0,5 & 0 & 0 \\
KAR 1 & 9 & 24 & 25 & 0 & 3 & 0 & 0 \\
KAR 3 & 0 & 0 & 0 & 0 & 0 & 0 & 0 \\
KAR 5 & 0 & 20 & 0 & 0 & 0 & 0 & 0 \\
KOM 1 & 0 & 8 & 11 & 0 & 2 & 0 & 0 \\
KOM 12 & 0 & 13 & 6 & 0 & 4 & 0 & 0 \\
KOM 14 & 8 & 13 & 11 & 0 & 3,5 & 11 & 8 \\
KOM 15 & 0 & 17 & 16 & 0 & 3,5 & 1 & 0 \\
KOM 16 & 0 & 1 & 2 & 0 & 0 & 0 & 0 \\
KOM 17 & 0 & 13 & 14 & 0 & 3 & 0 & 0 \\
KOM 18 & 0 & 11 & 15 & 0 & 1 & 1 & 0 \\
KOM 19 & 3 & 13 & 17 & 0 & 6 & 5 & 1 \\
KOM 2 & 0 & 3,5 & 12,5 & 0 & 0 & 0 & 0 \\
KOM 3 & 0 & 12,5 & 16 & 0 & 4 & 1 & 0 \\
KOM 7 & 0 & 0 & 0 & 0 & 0 & 0 & 0 \\
RI 10 & 0 & 10 & 19 & 0 & 0 & 0 & 0 \\
RI 11 & 1,5 & 13 & 14 & 0 & 6,5 & 0 & 0 \\
RI 15 & 0 & 9 & 7 & 0 & 0 & 0 & 0 \\
RI 16 & 0 & 3 & 0 & 0 & 0 & 0 & 0 \\
RI 18 & 0 & 0 & 0 & 0 & 0 & 0 & 0 \\
RI 2 & 0 & 10 & 0 & 0 & 0 & 0 & 0 \\
RI 21 & 0 & 3 & 23 & 0 & 0 & 0 & 7 \\
RI 5 & 0 & 19 & 13 & 0 & 4 & 1,5 & 0 \\
RI 6 & 0 & 18 & 16 & 0 & 4,5 & 2 & 0 \\
RI 9 & 0 & 0 & 0 & 0 & 0 & 0 & 0 \\
RII 2 & 0 & 0 & 22 & 0 & 0 & 0 & 1 \\
RII 5 & 20 & 5 & 23 & 0 & 0 & 0 & 0 \\
WAL 8 & 0 & 0 & 0 & 0 & 0 & 0 & 0 \\
WAL 9 & 0 & 0 & 0 & 0 & 0 & 0 & 0 \\
WAL 19 & 0 & 3 & 21 & 0 & 0 & 0 & 0 \\
WAL b & 0 & 2,5 & 0 & 0 & 0 & 0 & 0 \\
We1 & 0 & 10 & 10 & 0 & 0 & 0 & 0 \\
We10 & 0 & 7,5 & 21 & 0 & 0 & 0 & 0 \\
\hline I & & 0 & & & & &
\end{tabular}


Fortsetzung Tab. 14

\begin{tabular}{lcccllll}
\hline \hline We11 & 0 & 0 & 0 & 0 & 0 & 0 & 0 \\
We12 & 12,5 & 23 & 18 & 0 & 1 & 1,5 & 3,5 \\
We14 & 0 & 9,5 & 15 & 0 & 1 & 3,5 & 0 \\
We15 & 0 & 9 & 13 & 0 & 1,5 & 0 & 0 \\
We18 & 0 & 15 & 16,5 & 0 & 2 & 2 & 0 \\
We2 & 0 & 10 & 8 & 0 & 1 & 0 & 0 \\
We5 & 0 & 0 & 25 & 0 & 0 & 0 & 0 \\
We8 & 0 & 12,5 & 10,5 & 0 & 3 & 1 & 0 \\
ZU 9 & 0,5 & 2 & 3 & 0 & 0,5 & 0 & 0 \\
ZU 10 & 0 & 10 & 11 & 0 & 2 & 0 & 0 \\
\hline
\end{tabular}

\section{2. 3 Nachweis der Siderophorenbildung}

Siderophoren sind von Mikroorganismen ausgeschiedene Verbindungen, die mit Eisenionen Chelate bilden und dadurch diesen Mikroorganismen das im Boden vorliegende, schwer lösliche Eisen besser verfügbar machen. Hingegen können diese Eisenkomplexe im Normalfall nicht vom pilzlichen Pathogen aufgenommen werden, wodurch innen verfügbares Eisen entzogen wird. Da Eisen für das Pilzwachstum aber essentiell ist, wurde lange Zeit die Bildung von Siderophoren durch bakterielle Mikroorganismen als ein möglicher Mechanismus für die Unterdrückung von pathogenen Pilzen angesehen (LOPER 1988, LOPER \& BUYER 1991). So wurde die Siderophorenbildung auch mit als ein Screeningskriterium in der vorliegenden Arbeit verwendet.

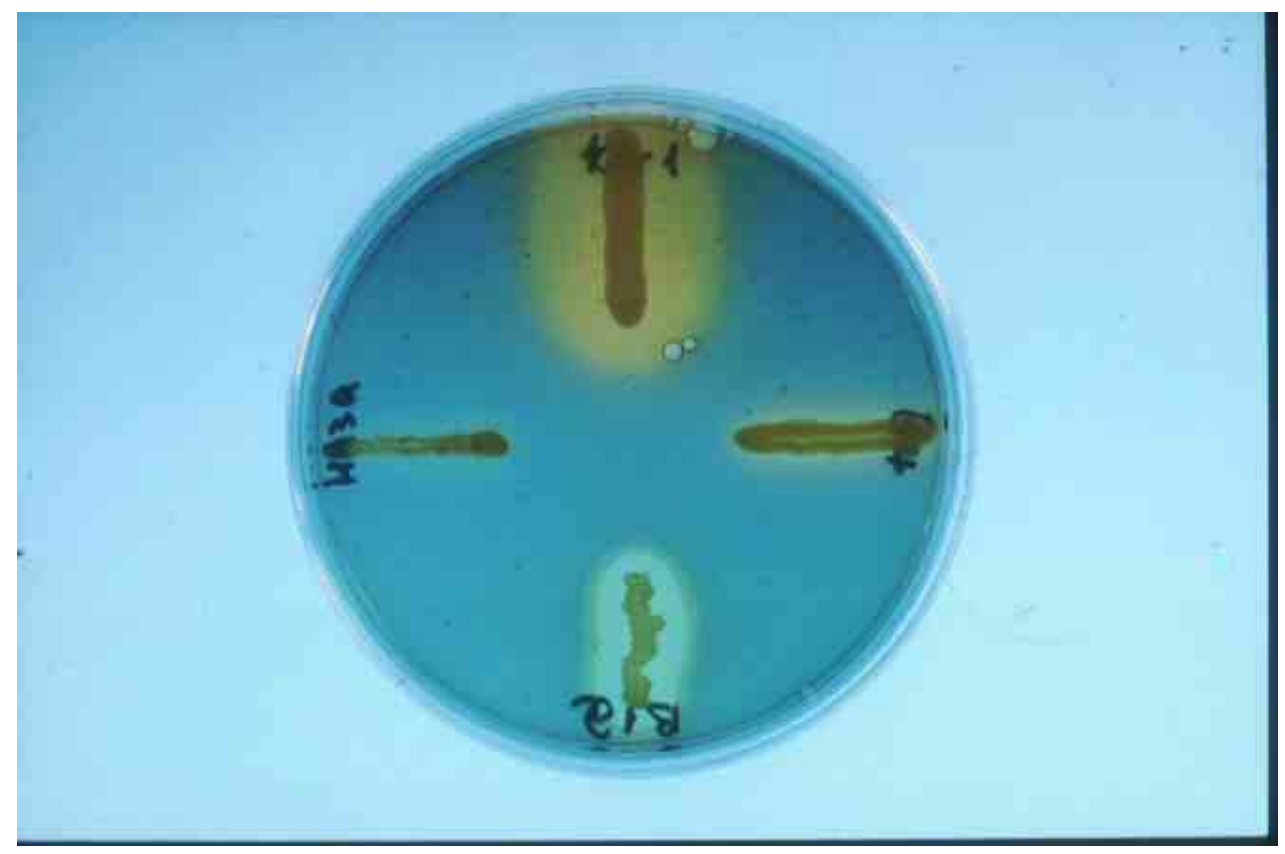

Abb. 8 Nachweis der Siderophorenbildung durch antagonistische Bakterien auf CAS-Agar. starke Siderophorenbildung: oben Ps. fluorescens KAR1, unten $B$. subtilis $\mathrm{B} 1 \alpha$; schwache Siderophorenbildung: links Paenibacillus polymyxa HA3e, rechts Pantoea agglomerans JII/E4. 
Die Tab. 5 veranschaulicht, dass die meisten Isolate in der Lage sind, auf dem CAS-Medium Siderophoren auszuscheiden. Während die Gram-negativen fluoreszierenden Pseudomonaden wie R21 oder R2II und einige nicht fluoreszierende Pseudomonaden wie KAR1 oder Serratia plymuthica ZU9 eine starke Siderophorenbildung aufwiesen, konnte u.a. Paenibacillus polymxya HA3a-e lediglich in geringem Ausmaß Siderophoren produzieren (vgl. 3.3.2).

Tab. 5: Nachweis der Siderophorenbildung durch Antagonisten auf CAS-Agar ++ = starke Siderophorenbildung; + = Siderophorenbildung; $(+)=$ schwache Siderophorenbildung; -- = keine Siderophorenbildung;

\begin{tabular}{lclclc}
\hline \hline ISOLAT & $\begin{array}{c}\text { Siderophoren- } \\
\text { bildung }\end{array}$ & ISOLAT & $\begin{array}{c}\text { Siderophoren- } \\
\text { bildung }\end{array}$ & ISOLAT & $\begin{array}{c}\text { Siderophoren- } \\
\text { bildung }\end{array}$ \\
\hline HA 3a & $(+)$ & RI 18 & -- & RII 5 & ++ \\
HA 3b & $(+)$ & RI 21 & ++ & WAL 8 & ++ \\
HA 3c & $(+)$ & KOM 12 & + & WAL19 & ++ \\
HA 3e & $(+)$ & KOM 14 & ++ & Wal b & $(+)$ \\
HA 6 & + & KOM 15 & + & We 1 & + \\
HA 7 & + & KOM 16 & + & We 2 & + \\
IBAb & $(+)$ & KOM 17 & + & We 5 & ++ \\
KAR 1 & ++ & KOM 18 & ++ & We 8 & + \\
KAR 3 & -- & KOM 19 & + & We 11 & ++ \\
KAR 5 & -- & RI 2 & $(+)$ & We 14 & + \\
KOM 1 & $(+)$ & RI 5 & $(+)$ & We 15 & ++ \\
KOM 2 & ++ & RI 6 & + & We 17 & ++ \\
KOM 3 & + & RI 10 & ++ & We 18 & $(+)$ \\
RI 15 & + & RI 11 & + & ZU 9 & ++ \\
RI 16 & -- & RII 2 & ++ & ZU 10 & + \\
\hline
\end{tabular}

\subsubsection{Nachweis der Bildung extrazellulärer Hydrolasen}

Neben den Antibiotika und Siderophoren können auch Enzyme an der Hemmung der Pilze beteiligt sein. Hierbei spielen die auf die Pilzzellwand einwirkenden Enzyme Chitinase und ß-1,3-Glucanase eine wichtige Rolle beim Angriff auf den pilzlichen Erreger. Im Gegensatz dazu sind pilzliche bzw. bakterielle Xylanasen, Amylasen, Proteasen sowie Cellulasen häufig pathogenitätsrelevante Faktoren. Daher wurde zur weiteren Selektion der antagonistischen Mikroorganismen die Fähigkeit zur Synthese von hydrolytischen Enzymen überprüft. Isolate mit einer hohen Chitinase bzw. ß-1,3Glucanase Aktivität wurden bevorzugt in die weiteren Versuche einbezogen. Hierzu wurden die von WOLF \& WIRTH (1990) entwickelten lösliche Polysaccharid- bzw. ProteinFarbstoff-Konjugaten als Substrate verwendet. Beim Abbau der Substrate bildet sich 
durch Diffusion der Farbstoffmoleküle eine helle Zone um die Mikroorganismenkolonie. Abb. 9 zeigt die Bildung von Chitinasen bzw. ß-1,3-Glucanasen durch einige Antagonisten. Die deutlich sichtbaren Aufhellungen um die Bakterienausstriche weisen auf den Abbau von CM-Chitin-RBV bzw. CM-Curdlan-RBB hin, hervorgerufen durch die Hydrolyse extrazellulärer Chitinasen bzw. ß-1,3-Glucanasen der Antagonisten.
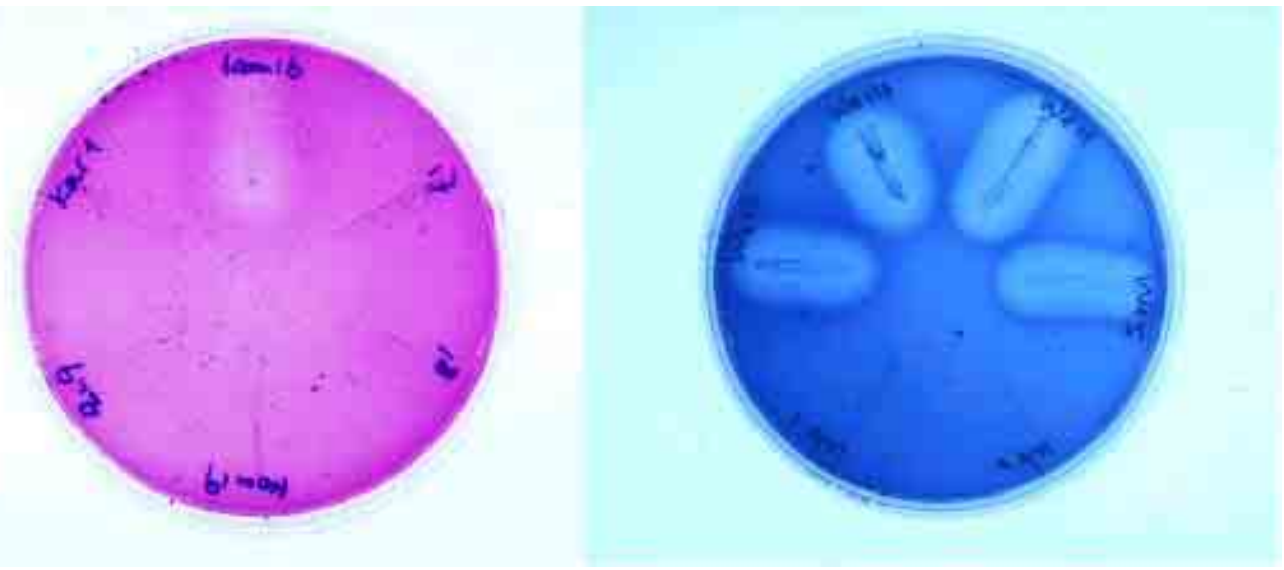

Abb. 9: Nachweis der Ausscheidung von Chitinasen auf CM-Chitin-RBV in Bodenextrakt bzw. ß-1,3-Glucanasen auf CM-Curdlan-RBB in Bodenextrakt durch Antagonisten. links: oben schwache Chitinasenbildung durch das Isolat KOM 16; rechts: starke ß-1,3- Glucanasebildung durch die Isolate WE11 und WE14.

Der Tab. 6 ist zu entnehmen, dass die meisten Gram-positiven Isolate in der Lage waren, alle der sechs getesteten Enzyme zu bilden, während die Gram-negativen Pseudomonaden (R21, RII2, RII5) und Serratia plymuthica vorwiegend Chitinasen und Proteasen auf Bodenextraktagar ausschieden. Pseudomonas fluorescens KAR1 konnte nur Proteasen, die Isolate R10 und WAL 8 sogar keines der sechs Enzyme bilden. Ebenfalls bei Streptomycetes Isolat KAR 3 war die Detektion extrazellulärer Enzyme nicht möglich, was in diesem Fall auf das unzureichende Wachstum dieses Isolats zurückgeführt wurde. 
Tab. 6: Bildung extrazellulärer Hydrolasen durch die Antagonisten von L. maculans. $+++=$ sehr starke Enzymaktivität; $++=$ starke Enzymaktivität; $+=$ schwache Enzymaktivität; -- = keine Aktivität; n. d. = schlechtes Wachstum

\begin{tabular}{|c|c|c|c|c|c|c|}
\hline ISOLAT & Chitinase & $\begin{array}{c}\text { ß-1,3- } \\
\text { Glucanase }\end{array}$ & Amylase & Cellulase & Protease & Xylanase \\
\hline HA 3a & + & + & +++ & +++ & ++ & +++ \\
\hline $\mathrm{HA} 3 \mathrm{~b}$ & + & ++ & +++ & +++ & ++ & +++ \\
\hline HA 3c & + & ++ & +++ & +++ & ++ & +++ \\
\hline HA $3 e$ & + & ++ & +++ & ++ & ++ & ++ \\
\hline HA 6 & + & +++ & +++ & +++ & ++ & +++ \\
\hline HA 7 & + & +++ & +++ & +++ & ++ & +++ \\
\hline KAR 1 & -- & -- & -- & -- & ++ & -- \\
\hline KAR 3 & n. d. & n. d. & n. d. & n. d. & n. d. & n. d. \\
\hline KAR 5 & n. d. & + & ++ & -- & -- & n. d. \\
\hline KOM 1 & -- & ++ & +++ & +++ & +++ & +++ \\
\hline KOM 2 & -- & -- & + & -- & +++ & ++ \\
\hline KOM 3 & -- & + & +++ & +++ & +++ & ++ \\
\hline KOM 12 & -- & + & +++ & +++ & ++ & +++ \\
\hline KOM 14 & -- & -- & +++ & + & ++ & ++ \\
\hline KOM 15 & -- & +++ & +++ & +++ & ++ & +++ \\
\hline KOM 16 & +++ & ++ & +++ & + & ++ & ++ \\
\hline KOM 17 & -- & -- & ++ & ++ & ++ & + \\
\hline KOM 18 & -- & ++ & +++ & +++ & ++ & +++ \\
\hline KOM 19 & -- & +++ & +++ & ++ & +++ & +++ \\
\hline RI 2 & -- & + & +++ & ++ & + & + \\
\hline RI 5 & -- & + & ++ & +++ & ++ & ++ \\
\hline RI 6 & -- & + & +++ & +++ & ++ & -- \\
\hline RI 10 & -- & -- & -- & -- & -- & -- \\
\hline RI 11 & -- & ++ & +++ & +++ & +++ & + \\
\hline RI 15 & -- & ++ & +++ & +++ & ++ & +++ \\
\hline RI 16 & ++ & ++ & +++ & +++ & ++ & +++ \\
\hline RI 18 & ++ & ++ & +++ & -- & -- & +++ \\
\hline RI 21 & ++ & -- & -- & -- & ++ & -- \\
\hline RII 2 & ++ & -- & -- & -- & + & -- \\
\hline RII 5 & ++ & -- & -- & -- & + & -- \\
\hline WAL 8 & -- & -- & -- & -- & -- & -- \\
\hline WAL19 & + & -- & +++ & -- & -- & -- \\
\hline WAL b & -- & -- & +++ & ++ & +++ & ++ \\
\hline WE 1 & -- & -- & -- & +++ & ++ & +++ \\
\hline WE 2 & -- & -- & -- & +++ & ++ & -- \\
\hline WE 5 & ++ & + & +++ & -- & ++ & -- \\
\hline WE 8 & -- & +++ & +++ & +++ & + & ++ \\
\hline WE 11 & ++ & ++ & +++ & -- & ++ & \\
\hline WE 14 & ++ & ++ & +++ & + & ++ & +++ \\
\hline WE 15 & -- & -- & +++ & + & ++ & ++ \\
\hline WE 18 & -- & ++ & +++ & +++ & + & ++ \\
\hline ZU 9 & ++ & -- & -- & -- & +++ & -- \\
\hline ZU 10 & ++ & ++ & ++ & ++ & ++ & +++ \\
\hline IBAb & -- & +++ & ++ & + & + & ++ \\
\hline
\end{tabular}




\subsubsection{In vitro-Hemmwirkung der antagonistischen Bakterien über flüchtige Hemm- stoffe}

Die mikrobielle Bildung gasförmiger Metabolite wird auch mit einer Wirkung auf phytopathogene Pilze in Verbindung gebracht (PAVLICA et al. 1978). Zu diesen Substanzen zählen insbesondere Cyanwasserstoff (KEEL et al. 1989) und Ammoniak (HowELL et al. 1988). Die Hemmung des Wachstums von L. maculans durch gasförmige Hemmstoffe wurde in zweigeteilten Petrischalen, die den physikalischen Kontakt von Antagonist und Pathogen ausschließen, überprüft (Abb. 10).

In Abb. 10 ist zu erkennen, das Paenibacillus polymyxa HAЗe keine flüchtigen Hemmubstanzen auf TSA produzierte, während die durch Pseudomonas fluorescens KAR1 gebildeten Substanzen das Wachstum von L. maculans über die Gasphase fast vollständig gehemmt haben. Offenbar schieden alle gramnegativen Bakterienstämme (KAR1, RII2, R21, ZU9 und B5) flüchtige Hemmstoffe gegen L. maculans aus (Tab. 7). Die Hemmwirkung der Isolate RII2 und B5 korrelierte mit der HCN-Bildung.

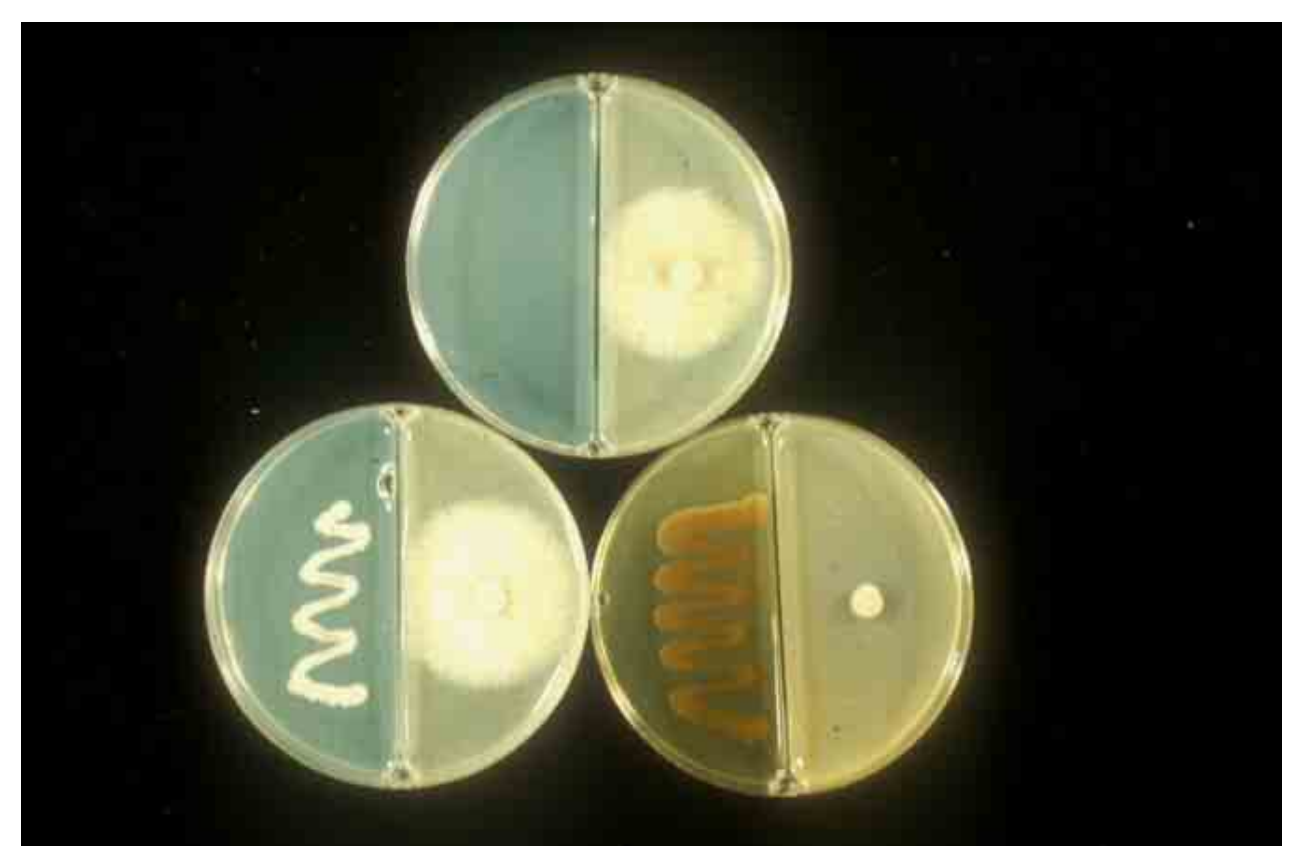

Abb. 10: In vitro Hemmung des Myzelwachstums von L. maculans durch gasförmige Hemmstoffe antagonistischer Bakterien auf TSA

oben: Kontrolle ohne Antagonist,

unten links: Paenibacillus polymyxa HA3e,

unten rechts: Pseudomonas fluorescens KAR 1. 
Tab. 7: Bildung von Cyanwasserstoff in TSB und die Hemmung des Wachstums von L. maculans über die Gasphase durch bakterielle Antagonisten

\begin{tabular}{lcccc}
\hline \hline ISOLAT & \multicolumn{3}{c}{ HCN-Produktion $\left(\right.$ OD $\left._{550 \mathrm{~nm}}\right)$} & Hemmhof \\
\cline { 2 - 4 } & $24 \mathrm{~h}$ & $48 \mathrm{~h}$ & $72 \mathrm{~h}$ & in mm \\
\hline HA3e & 0,01 & 0,00 & 0,04 & 0 \\
HA6 & 0,03 & 0,07 & 0,02 & 0 \\
KAR1 & 0,02 & 0,09 & 0,08 & 16 \\
Wal19 & 0,03 & 0,00 & 0,05 & 10 \\
KOM19 & 0,03 & 0,01 & 0,05 & n.d. \\
RII2 & 0,03 & 0,11 & 0,26 & 12 \\
R15 & 0,06 & 0,01 & 0,03 & 1 \\
R21 & 0,04 & 0,05 & 0,03 & 14 \\
Walb & 0,19 & 0,03 & 0,02 & n.d. \\
We1 & 0,06 & 0,05 & 0,04 & 0 \\
We2 & 0,04 & 0,06 & 0,02 & n.d. \\
We14 & 0,04 & 0,03 & 0,01 & 12 \\
We15 & 0,03 & 0,01 & 0,02 & 0 \\
Zu9 & 0,02 & 0,02 & 0,00 & 15 \\
Zu10 & 0,17 & 0,07 & 0,02 & 0 \\
B5 & 0,05 & 0,06 & 0,22 & 16 \\
\hline
\end{tabular}

\subsubsection{In vitro Hemmwirkung ausgewählter Isolate auf nährstoffarmem Medium bzw. bei niedrigen Temperaturen}

Vor dem Einsatz der Antagonisten gegen L. maculans ad planta, wurde ihre Hemmwirkung noch auf nährstoffarmen Strohextrakt-Medium SE und bei einer Temperatur von $8{ }^{\circ} \mathrm{C}$ überprüft, da eine Infektion mit L. maculans an Winterraps auch bei niedriger Temperatur erfolgen kann. Auch sollte die Eignung der Isolate, sich unter nährstoffarmen Bedingungen bzw. bei niedrigen Temperaturen zu vermehren und antagonistisch gegen L. maculans zu wirken, untersucht werden.

Die in vitro Hemmung des Myzelwachstums von L. maculans ist in Tab. 8 dargestellt. 15 Antagonisten, zum größten Teil Gram-positive Bacilli, hemmten das Wachstum von L. maculans auf SE bei $8{ }^{\circ} \mathrm{C}$ in starkem Ausmaß (Hemmhof $\geq 15 \mathrm{~mm}$ ). Für Serratia plymuthica ZU9 wurde sogar ein Hemmhof von $22 \mathrm{~mm}$ gemessen. Fast alle Bacillus-Isolate zeigten eine einheitliche gute Hemmwirkung bei $8{ }^{\circ} \mathrm{C}$ auf den beiden Testmedien V8- und SE-Agar. Auf V8-Medium war bei $20^{\circ} \mathrm{C}$ eine bessere Hemmung von L. maculans zu erkennen. Allerdings zeigten die Pseudomonaden Gö2l, KAR1, R21 und RII2 eine schwächere Wirkung bei $8{ }^{\circ} \mathrm{C}$ und auf SE-Agar bei $20^{\circ} \mathrm{C}$. 
Tab. 8: In vitro-Hemmwirkung ausgewählter Antagonisten gegen L. maculans bei $8^{\circ} \mathrm{C}$ bzw. $20^{\circ} \mathrm{C}$ auf Rapsstrohextrakt (SE)- bzw. V8- Agar (Hemmhöfe in mm)

\begin{tabular}{lcccc}
\hline & \multicolumn{2}{c}{$20^{\circ} \mathrm{C}$} & \multicolumn{2}{c}{$8^{\circ} \mathrm{C}$} \\
\cline { 2 - 5 } & V8 & SE & V8 & SE \\
\hline B1a & 14 & 16 & 15 & 16 \\
Gö2l & 2 & 2 & 5 & 8 \\
HA3e & 15,5 & 19 & 18 & 19 \\
HA6 & 13,5 & 19 & 15 & 16 \\
IBAb & 16 & 18 & 16 & 17 \\
KAR 1 & 2 & 3 & 5 & 10 \\
KAR 5 & 5 & $n . d$. & n. d. & n. d. \\
KOM14 & 11,5 & 18 & 14 & 16 \\
KOM19 & 11,5 & 19 & 18 & 18 \\
R15 & 8 & 18 & 14 & 18 \\
R21 & 14,5 & 1 & 0 & 10 \\
RII2 & 14,5 & 2 & 0 & 5 \\
WAL b & 11,5 & 17 & 15 & 17 \\
WAL 19 & 13 & $\mathrm{n} . \mathrm{d}$. & $\mathrm{n} . \mathrm{d}$. & $\mathrm{n} . \mathrm{d}$. \\
WE1 & 14 & 19 & 18 & 16 \\
WE2 & 12 & 18 & 14 & 16 \\
WE14 & 10,5 & 2 & 12 & 3 \\
WE15 & 13,5 & 15 & 17 & 18 \\
ZU 9 & 12 & 8 & 12 & 22 \\
ZU10 & 15 & 17 & 19 & 18 \\
\hline
\end{tabular}

\subsection{7 Überprüfung der Hemmwirkung ausgewählter Antagonisten gegenüber verschiedenen phytopathogenen Pilzen}

Um das Wirkungspotential der gegen L. maculans isolierten Antagonisten zu erfassen, wurden die Isolate auch gegen andere wichtige Krankheitserreger wie Sclerotinia sclerotiorum und Alternaria brassicae (Raps), Fusarium culmorum (Weizen) sowie Phoma betae, Pythium ultimum und Rhizoctonia solani (Zuckerrübe) überprüft.

Der Tab. 8 ist zu entnehmen, dass die meisten Isolate über ein breites antifungales Wirkungsspektrum verfügen, und fast alle Antagonisten das Wachstum von S. sclerotiorum gut hemmten. P. ultimum wurde von allen Antagonisten nur schwach gehemmt. Auffällig ist das Isolat KAR1, das gegen die 7 pilzlichen Pathogene keinerlei Hemmwirkung auf dem Testmedium V8 aufwies. 
Tab. 9: In vitro-Hemmwirkung der Antagonisten gegen verschiedene Phythopathogene auf V8-Medium (Hemmhöfe in $\mathrm{mm}$ )

A. alt. = Alternaria brassicae; $F$. cul. = Fusarium culmorum; F. oxy. $=$ Fusarium oxysporum; $P$. bet. = Phoma betae; $P$. ult. = Pythium ultimum; $R$. sol. $=$ Rhizoctonia solani; S. scl. = Sclerotinia sclerotirum $($ Hemmhöfe in $\mathrm{mm}$, Mittelwerte aus 4 Versuchen).

\begin{tabular}{lrrrrrrr}
\hline \hline ISOLAT & A. bra. & F. cul. & F. oxy. & P. bet. & P. ult & R. sol. & S. scl. \\
\hline HA3e & 13 & 14 & 12 & 15 & 5 & 8 & 16 \\
HA6 & 15 & 12 & 12 & 15 & 5 & 9 & 17 \\
IBAb & 12 & 14 & 10 & 14 & 4 & 9 & 15 \\
KAR 1 & 0 & 0 & 0 & 0 & 0 & 0 & 0 \\
KAR 5 & 6 & 8 & 6 & 8 & 5 & 3 & 9 \\
KOM 1 & 12 & 10 & 10 & 15 & 4 & 6 & 14 \\
KOM19 & 11 & 12 & 11 & 13 & 5 & 6 & 13 \\
R15 & 13 & 15 & 12 & 16 & 6 & 9 & 16 \\
R16 & 11 & 11 & 11 & 13 & 5 & 9 & 11 \\
R21 & 0 & 2 & 2 & 3 & 0 & 6 & 0 \\
RII2 & 8 & 6 & 7 & 9 & + & 5 & 8 \\
WAL b & 10 & 7 & 10 & 13 & 2 & 5 & 13 \\
WAL 19 & 13 & 5 & 5 & 11 & 11 & + & 12 \\
WE 1 & 17 & 12 & 11 & 16 & 5 & 8 & 17 \\
WE 2 & 13 & 12 & 11 & 15 & 5 & 7 & 17 \\
WE 14 & 14 & 0 & 4 & 11 & 3 & 2 & 15 \\
WE 15 & 16 & 8 & 7 & 12 & 3 & 9 & 18 \\
ZU 9 & 12 & 9 & 12 & 15 & 3 & 14 & 12 \\
ZU 10 & 18 & 12 & 11 & 16 & 5 & 9 & 17 \\
\hline
\end{tabular}

\subsubsection{Selektion der Isolate für ad planta-Untersuchungen}

Zusammenfassend wurden die wichtigsten antagonistischen Eigenschaften der Isolate in der Tab. 9 dargestellt. Um ein möglichst vielseitiges Reservoir von Antagonisten zu erhalten, galt neben der antibiotischen Wirkung gegen L. maculans auf TS-, V8- und Ms-Agar die Taxonomische Einordnung der Isolate als wichtigstes Selektionskriterium. Deshalb wurde u.a. das Isolat KAR5, welches lediglich eine ausgeprägte Wirkung auf TSA zeigte, und aufgrund morphologischer Eigenschaften zu den Streptomyceten gehört, ebenfalls selektiert. Die Isolate KAR1 und KOM19 wurden trotz ihrer breiten antibakteriellen Wirkung in die weiteren Versuche einbezogen, um eine mögliche bessere Wirkung adplanta zu Vergleichszwecken zu erzielen. Die Isolate WE14 und ZU10 wurden aufgrund ihrer Exochtinase- und Exoglucanase-Bildung ausgesucht, Isolate wie WE1 und WE2 hauptsächlich wegen ihrer einheitlichen Hemmwirkung gegen L.maculans und 
V. longisporum. HA3e und R2Il verfügten über das umfassendste Potential antagonistischer Wirkmechanismen. HA3e konnte lediglich keine Siderophoren bilden, und R2II produzierte keine Exoglucanase.

Weiterhin wurden Pseudomonas flurescens Gö2I, Bacillus subtilis B1a und Pantoea agglomerans JII/E4 (früher: Erwinia herbicola) in das ad planta Screening einbezogen, da sie sich als wirksame Antagonisten jeweils gegen den Rapswelkeerreger $V$. longisporum (SASSE 1997), den Errger der Eutypiose der Weinrebe Eutypa lata (SCHMIDT 1997) und gegen Fusarium culmorum an Winterweizen (KEMPF 1988) erwiesen hatten.

Tab. 10: Übersicht der Kriterien für das in vitro Screening der Antagonisten gegen L. maculans

\begin{tabular}{|c|c|c|c|c|c|c|c|}
\hline \multirow[b]{2}{*}{ ISOLAT } & \multirow{2}{*}{$\begin{array}{c}\text { Morphol. } \\
\text { Besonderheit }\end{array}$} & \multicolumn{2}{|c|}{ Hemmung } & \multirow{2}{*}{$\begin{array}{l}\text { Antibakt. } \\
\text { Spektrum }\end{array}$} & \multicolumn{2}{|c|}{ Exoenzymbildung } & \multirow{2}{*}{$\begin{array}{l}\text { Siderophoren- } \\
\text { bildung }\end{array}$} \\
\hline & & P. $I$. & V. $d$. & & Chitinase & $\begin{array}{c}\text { B-1, 3 - } \\
\text { Glucanase } \\
\end{array}$ & \\
\hline HA3e & $\bullet$ & $\bullet$ & $\bullet$ & $\bullet$ & $\bullet$ & $\bullet$ & \\
\hline HA6 & • & $\bullet$ & $\bullet$ & & - & $\bullet$ & \\
\hline IBAb & $\bullet$ & $\bullet$ & $\bullet$ & & & $\bullet$ & \\
\hline KAR1 & - & $\bullet$ & & & & $\bullet$ & $\bullet$ \\
\hline KAR5 & $\bullet$ & $\bullet$ & & $\bullet$ & $\bullet$ & $\bullet$ & \\
\hline KOM1 & $\bullet$ & $\bullet$ & $\bullet$ & & & $\bullet$ & \\
\hline KOM19 & $\bullet$ & $\bullet$ & $\bullet$ & & & $\bullet$ & \\
\hline RI 15 & $\bullet$ & $\bullet$ & $\bullet$ & & & $\bullet$ & \\
\hline RI 21 & - & - & - & & - & & - \\
\hline RII 2 & $\bullet$ & $\bullet$ & $\bullet$ & $\bullet$ & $\bullet$ & & $\bullet$ \\
\hline Walb & $\bullet$ & $\bullet$ & $\bullet$ & $\bullet$ & & & \\
\hline WAL19 & - & - & & & - & & - \\
\hline We1 & $\bullet$ & $\bullet$ & $\bullet$ & & & & \\
\hline We2 & - & $\bullet$ & $\bullet$ & & & & $\bullet$ \\
\hline We14 & $\bullet$ & $\bullet$ & $\bullet$ & & $\bullet$ & $\bullet$ & \\
\hline We15 & - & $\bullet$ & $\bullet$ & & & & \\
\hline ZU 9 & - & $\bullet$ & & & $\bullet$ & & $\bullet$ \\
\hline ZU 10 & $\bullet$ & $\bullet$ & $\bullet$ & & $\bullet$ & $\bullet$ & \\
\hline Gö2l & $\bullet$ & \multicolumn{6}{|c|}{ wirksamer Antagonist an Winterraps } \\
\hline $\mathrm{B} 1 \mathrm{a}$ & - & \multicolumn{6}{|c|}{ wirksamer Antagonist an Weinrebe } \\
\hline JII/E4 & $\bullet$ & \multicolumn{6}{|c|}{ wirksamer Antagonist an Winterweizen und Weinrebe } \\
\hline
\end{tabular}

- als positives Auswahlkriterium im Screening betrachtet

- geringe Ausprägung 


\subsection{Charakterisierung und Identifizierung von Antagonisten}

Parallel zum ad planta-Screening an Rapskeimlingen wurden die Isolate schon frühzeitig taxonomisch eingeordnet, um human- bzw. phytopathogene Bakterien von den folgenden Untersuchungen, insbesondere den ad planta-Versuchen, auszuschließen. Dazu wurden zunächst morphologische und physiologische Eigenschaften untersucht. Auf den Ergebnissen dieser Versuche und dem Screening mit den Rapskeimlingen beruhend, wurden mehrere Isolate mit Hilfe von kommerziellen Testsystemen bestimmt und für weitere Versuche ausgewählt.

\subsubsection{Physiologische Eigenschaften der Bakterien}

18 der Bodenbakterien zeigten auf TSA eine sehr ähnliche Kolonie- und Zellmorphologie. Sie erschienen hellbeige bis hellgelb, trüb bis schwach glänzend und glattrandig. Bei der mikroskopischen Untersuchung waren durchgehend Kurzstäbchen zu erkennen. Hier fielen die Isolate HA3e, HA6, IBAb, KOM1, KOM16, KOM19, R15, R16, WE1, WE2, WE14, WE15, ZU10 durch die Bildung von Endosporen auf BEA auf. Diese Organismen konnten zu den Gattungen Bacillus bzw. Paenibacillus gerechnet werden, da sie zu den wenigen Bakteriengattungen gehören, die aerob Endosporen bilden (HOLT et al. 1994).

Weitere wichtige physiologische Eigenschaften der Isolate sind in der Tab. 10 aufgeführt. KAR5 und WAL19 wurden von diesen Untersuchungen ausgenommen, da es sich bei ihnen um Gram-positive Actinomyceten handelt, die anhand des typischen myzelartigen Wachstums in und auf dem TSA zu erkennen waren.

Fehlende Aminopeptidase sowie ein negativer $\mathrm{KOH}$-Test weisen auf Gram-positive Mikroorganismen hin. Die positive Gram-Färbung der Isolate HA3e, HA6, IBAb, KOM1, KOM16, KOM19, R15, R16, WE1, WE2, WE14, WE15, ZU10 korrelierte mit diesen Ergebnissen und deutete im Zusammenhang mit der Sporenbildung auf die Gattung Bacillus bzw. Paenibacillus (AsH et al. 1993). Die Gram-positiven Organismen zeigten außerdem durchgehend keine Fluoreszenz auf KBA. Nur die Isolate KAR1, R21, RII2, ZU9 zeigten ein Gram-negatives Verhalten, welches mit einem positiven Aminopeptidase- und $\mathrm{KOH}$-Test korrelierte. Die Isolate R21 und RII2 zeigten eine positive Oxidase-Reaktion und Fluoreszenz auf KBA. Sie wurden schließlich in die Gruppe der fluoreszierenden Pseudomonaden eingeordnet. Das Isolat KAR1, ansonsten mit einer großen Ähnlichkeit zu Pseudomonas fluorescens Gö2I, besaß jedoch keine Oxidase-Reaktion und fluoreszierte weder auf KBA noch auf Succinat-Agar, einem Medium, was für die Prüfung der Fluoreszenz noch empfindlicher als KBA sein sollte (Schulz, persönliche Mitteilung). 
Tab. 11: Physiologische Eigenschaften 18 antagonistischer Bodenisolate. $\quad(+=$ positive Reaktion, $(+)=$ mittlere Reaktion; - = negative Reaktion; $\mathrm{n} . \mathrm{d}$. = nicht ermittelt.)

\begin{tabular}{|c|c|c|c|c|c|c|}
\hline & $\begin{array}{c}\text { Gram- } \\
\text { Verhalten }\end{array}$ & $\begin{array}{c}\text { Amino- } \\
\text { peptidase }\end{array}$ & "KOH-Test & $\begin{array}{l}\text { Sporen- } \\
\text { bildung }\end{array}$ & Oxidase & $\begin{array}{l}\text { Fluoreszenz } \\
\text { auf KBA bzw. } \\
\text { Succinat-Agar }\end{array}$ \\
\hline HA3e & + & - & - & + & n. d. & - \\
\hline HA6 & + & - & - & + & n. d. & - \\
\hline IBAb & + & - & - & + & n. d. & - \\
\hline KAR 1 & - & + & + & - & - & $-I-$ \\
\hline KOM 1 & + & - & - & + & n. d. & - \\
\hline KOM16 & + & - & $(+)$ & + & n. d. & - \\
\hline KOM19 & + & - & - & + & n. d. & - \\
\hline R15 & + & - & - & + & n. d. & - \\
\hline R16 & + & - & - & + & n. d. & - \\
\hline $\mathrm{R} 21$ & - & + & + & - & + & + \\
\hline RII2 & - & + & + & - & + & + \\
\hline WAL b & + & - & + & - & n. d. & - \\
\hline WE1 & + & - & - & + & n. d. & - \\
\hline WE2 & + & - & - & + & n. d. & - \\
\hline WE14 & + & - & - & + & n. d. & - \\
\hline WE15 & + & - & - & + & n. d. & - \\
\hline ZU9 & - & + & + & - & - & - \\
\hline ZU10 & + & - & - & + & n. d. & - \\
\hline
\end{tabular}

\subsubsection{Identifizierung mit kommerziellen Testsystemen}

10 bakterielle Isolate, die sowohl in vitro als auch an Rapskeimlingen eine hohe Wirksamkeit zeigten, wurden mit den API- bzw. Biolog- Testsystemen identifiziert (s. u.).

\subsubsection{Identifizierung der gramnegativen Bakterien}

Die Isolate R21 und RII2, die eine positive Oxidase-Reaktion und Fluoreszenz auf KBA zeigten, und das Isolat KAR1 mit einer hohen Ähnlichkeit zu Pseudomonas fluorescens Gö2I, wurden mit Hilfe des API-Testsystems 20 NE identifiziert, während die Bestimmung 
des Isolats ZU9 mit fehlender Oxidase-Reaktion anhand des API-Testsystems $20 \mathrm{E}$ erfolgte. Tabelle 12 und 13 zeigen jeweils die Ergebnisse.

Tab. 12: Ergebnisse verschiedener Nachweis- und Assimilationsreaktionen sechs Gram-negativer Bodenisolate im System API 20 NE (+ = positive Reaktion, = negative Reaktion)

\begin{tabular}{|c|c|c|c|c|}
\hline & PROFIL & KAR 1 & $\mathbf{R} 21$ & RII2 \\
\hline 1 & Nitratreduktion & - & - & - \\
\hline 2 & Indolbildung & - & - & - \\
\hline 2 & $\begin{array}{l}\text { Glucosefermentation } \\
\text { Nachweis: }\end{array}$ & - & - & - \\
\hline 4 & Arginindihydrolase & + & + & + \\
\hline 5 & Urease & + & + & + \\
\hline 6 & $\beta$-Glucosidase & - & - & - \\
\hline 7 & Protease & - & - & - \\
\hline 8 & $\begin{array}{l}\beta \text {-Galactosidase } \\
\text { Assimilation: }\end{array}$ & - & - & - \\
\hline 9 & Glucose & + & + & + \\
\hline 10 & Arabinose & + & + & + \\
\hline 11 & Mannose & + & + & + \\
\hline 12 & Mannit & + & + & + \\
\hline 13 & N-Acetylglucosamin & - & + & + \\
\hline 14 & Maltose & - & - & - \\
\hline 15 & Gluconat & + & + & + \\
\hline 16 & Caprat & + & + & + \\
\hline 17 & Adipat & - & - & - \\
\hline 18 & Malat & + & + & + \\
\hline 19 & Citrat & + & + & + \\
\hline 20 & Phenylacetat & - & - & - \\
\hline
\end{tabular}

Die Ergebnisse der Isolate R21 und RII2 sind identisch, und diese konnten mit Hilfe des Analytischen Profil Indexes 20 NE mit 99.9\% Wahrscheinlichkeit der Art Pseudomonas fluorescens zugeordnet werden. Das Isolat KAR1, welches sich bei der Verwertung von NAcetylglucosamin von den beiden anderen unterschied, konnte mit 68.5\% Wahrscheinlichkeit der Art Pseudomonas fluorescens, mit 16.8\% Wahrscheinlichkeit der Art Flavibacterium 
oryzihabitans, und mit $14.6 \%$ Wahrscheinlichkeit der Art Pseudomonas putida zugeordnet werden. Das Isolat ZU9 wurde mit Hilfe des API 20E mit 97,1\% Wahrscheinlichkeit als Serratia plymuthica bestimmt (Tab. 13). Diese Ergebnisse wurden mit dem Identifizierungssystem "Microlog GN" der Fa. Biolog bestätigt.

Tab. 13: Ergebnisse verschiedener Nachweis- und Assimilationsreaktionen eines Gram-negativen und zweier Gram-positiver Bodenisolate im System $20 \mathrm{E}$ (+ = positive Reaktion, - = negative Reaktion)

\begin{tabular}{|c|c|c|c|c|}
\hline & PROFIL & HA3e & KOM1 & Zu 9 \\
\hline 1 & $\beta$-Galactosidase & + & + & + \\
\hline 2 & Arginindihydrolase & + & - & - \\
\hline 3 & Lysindecarboxylase & - & - & - \\
\hline 4 & Ornithindecarboxylase & - & - & - \\
\hline 5 & Citratabbau & - & - & - \\
\hline 6 & $\mathrm{H}_{2} \mathrm{~S}$ & - & - & - \\
\hline 7 & Urease & - & - & - \\
\hline 8 & Tryptophandesaminase & - & - & - \\
\hline 9 & Indol & - & - & - \\
\hline 10 & Aceton & - & + & + \\
\hline 11 & Gelatinase & + & + & + \\
\hline 12 & Glucose Fermentation & - & - & + \\
\hline 13 & Mannitol & & & + \\
\hline 14 & INO & & & + \\
\hline 15 & Sorbitol & & & + \\
\hline 16 & Rhamnose & & & - \\
\hline 17 & Saccharose & & & + \\
\hline 18 & Melibiose & & & + \\
\hline 19 & Amygdaline & & & + \\
\hline 20 & Arabinose & & & + \\
\hline
\end{tabular}




\subsubsection{Identifizierung der Gram-positiven Bakterien}

Für die Artbestimmung der Gram-positiven Bacillus-Isolate wurde das Testsystem API $50 \mathrm{CH}$ mit dem Zusatzmedium API 50 CHB für aerobe Sporenbildner verwendet. Das Prinzip dieses Identifizierungssystems ist auf die unterschiedliche Verwertung von 49 Kohlenhydraten durch Bacilli zurückzuführen. Daraus ergibt sich ein Profil, welches mit Hilfe des computergesteuerten API-Identifizierungsprogrammes der Fa. bioMerieux eine Identifizierung der Isolate ermöglicht. Tab. 14 zeigt die biochemischen Profile der sechs Gram-positiven Bakterienisolate HA3e, HA6, KOM1, KOM19, R15 und WE1.

In der Tabelle symbolisiert ein gelbes bzw. schwarzes Kästchen eine positive Reaktion, ein hellrotes eine variable und ein rotes Kästchen eine negative Reaktion nach 48 Stunden Inkubation. So wurde nach dem Profil das Isolat We1 mit 95,5\% Wahrscheinlichkeit als Paenibacillus polymyxa identifiziert. Die Isolate KOM 19 und R15, die im biochemischen Profil (außer im Fall von ß-Methyl-xyloside) große Ähnlichkeiten aufwiesen, konnten mit 96,2 \% bzw. 90,4\% Wahrscheinlichkeit der Art B. circulans 1 zugeordnet werden.

Das Isolat HA3e unterschied sich im Profil deutlich von den anderen fünf Isolaten, konnte allerdings nur mit 50,0\% Wahrscheinlichkeit der Art Paenibacillus polymyxa, mit $21 \%$ Wahrscheinlichkeit der Art Bacillus licheniformis zugeordnet werden. Das Isolat KOM1 wurde mit $64,2 \%$ bzw. 10,7\% Wahrscheinlichkeit als B. circulans 1 identifiziert. Für die Isolate HA3e und KOM1 wurde zusätzlich das API 20E Testsystem benötigt. Tabelle 13 zeigt die Ergebnisse des API 20 E-Testsystems.

Die Überprüfung der 12 physiologischen Reaktionen bestätigte die Identifizierung des Isolates KOM1 als B. circulans und ließ bei dem Isolat HA3e auf die Art P. polymyxa schließen. Hier konnten allerdings keine Wahrscheinlichkeiten in Prozent angegeben werden.

Die Ergebnisse zeigen, dass weder human- noch phytopathogene Bakterien aus den Bodenproben isoliert wurden und unbedenklich ad planta eingesetzt werden können. 
Tab. 14: Biochemische Profile 6 Gram-positiver, sporenbildener Bakterien

\begin{tabular}{|c|c|c|c|c|c|c|c|}
\hline & \multirow[t]{2}{*}{$\overline{\text { PROFIL }}$} & \multicolumn{6}{|c|}{ ISOLAT } \\
\hline & & HAЗe & HA6 & KOM1 & KOM19 & R15 & WE1 \\
\hline 0 & Control & & & & & & 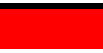 \\
\hline 1 & Glycerol & + & + & + & + & + & + \\
\hline 2 & Erythritol & & & & & & \\
\hline 3 & D-Arabinose & & & & & & \\
\hline 4 & L-Arabinose & + & + & + & + & + & + \\
\hline 5 & Ribose & + & + & + & + & + & + \\
\hline 6 & D-Xylose & + & + & + & + & + & + \\
\hline 7 & L-Xylose & & & & & & \\
\hline 8 & Adonitol & 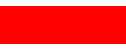 & & - & 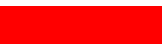 & & 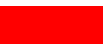 \\
\hline 9 & B Methyl-xyloside & + & 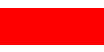 & + & + & 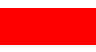 & + \\
\hline 10 & Galactose & + & + & + & + & + & + \\
\hline 11 & D-Glucose & + & + & + & + & + & + \\
\hline 12 & D-Fruchtose & + & + & + & + & + & + \\
\hline 13 & D-Mannose & + & + & + & + & + & + \\
\hline 14 & L-Sorbose & & & & & & \\
\hline 15 & Rhamnose & & & & & & \\
\hline 16 & Dulcitol & & & & & & \\
\hline 17 & Inositol & . & 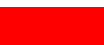 & 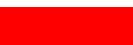 & + & + & 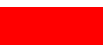 \\
\hline 18 & Mannitol & + & + & + & + & + & + \\
\hline 19 & Sorbitol & 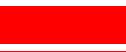 & + & 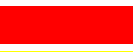 & + & + & + \\
\hline 20 & $\alpha$ Methyl-D-mannoside & & + & + & 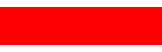 & 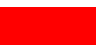 & 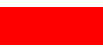 \\
\hline 21 & $\alpha$ Methyl-D-glucoside & & + & + & + & + & + \\
\hline 22 & N Acetyl glucosamine & & + & + & + & + & 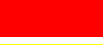 \\
\hline 23 & Amygdaline & + & + & + & + & + & + \\
\hline 24 & Arbutine & + & + & + & + & + & + \\
\hline 25 & Esculine & + & + & + & + & + & + \\
\hline 26 & Saliciline & + & + & + & + & + & + \\
\hline 27 & Cellobiose & + & + & + & + & + & + \\
\hline 28 & Maltose & + & + & + & + & + & + \\
\hline 29 & Lactose & + & + & + & + & + & + \\
\hline 30 & Melibiose & + & + & + & + & + & + \\
\hline 31 & Saccharose & + & + & + & + & + & + \\
\hline 32 & Trehalose & + & + & + & + & + & + \\
\hline 33 & Inuline & + & + & + & + & + & + \\
\hline 34 & Melezitose & + & & & + & + & \\
\hline 35 & D-Raffinose & + & + & + & + & + & + \\
\hline 36 & Amidon & + & + & + & + & + & + \\
\hline 37 & Glycogene & + & + & + & + & + & + \\
\hline 38 & Xylitol & & & & & & \\
\hline 39 & $\beta$ Gentiobiose & + & + & + & + & + & + \\
\hline 40 & D-Turanose & + & + & + & + & + & + \\
\hline 41 & D-Lyxose & & & & & & \\
\hline 42 & D-Tagatose & & & & & & \\
\hline 43 & D-Fucose & & & & & & \\
\hline 44 & L-Fucose & & & & & & \\
\hline 45 & D-Arabitol & & & & & & \\
\hline 46 & L-Arabitol & & & & & & . \\
\hline 47 & Gluconate & + & & & & & + \\
\hline 48 & 2 ceto-gluconate & & & & & & \\
\hline 49 & 5 ceto-gluconate & & & & + & + & \\
\hline
\end{tabular}




\section{4 ad planta Vorscreening von Antagonisten mit Rapskeimlingen}

\subsubsection{Besiedlung von Rapskeimlingen durch Antagonisten}

Die Besiedlung der Pflanze durch die Antagonisten wird als Voraussetzung für eine effektive Bekämpfung des Zielpathogens angesehen. Für diese Besiedlungsstudien wurden die mit Antagonisten behandelten Rapssamen in sterilem Sand mit Bodenextrakt als Nahrungsquelle in einer Plastikschale ausgesät. Nach dem Aufgang der Pflanzen, ca. 7 Tage später, wurden die Keimlinge unter sterilen Bedingungen in Petrischalen mit TSA ausgelegt. In Abb. ist das Wachstum des Antagonisten Pseudomons fluorescens RII2 auf und um den Rapskeimlingen deutlich zu erkennen. Auch weitere für ad planta Versuche ausgewählte Antagonisten waren in der Lage, die Pflanzen zu besiedeln. Allerdings war im Vergleich zu den Gram-positiven Bacilli eine bessere Besiedlungsfähigkeit der Pseudomonaden und von Serratia plymuthica zu beobachten.

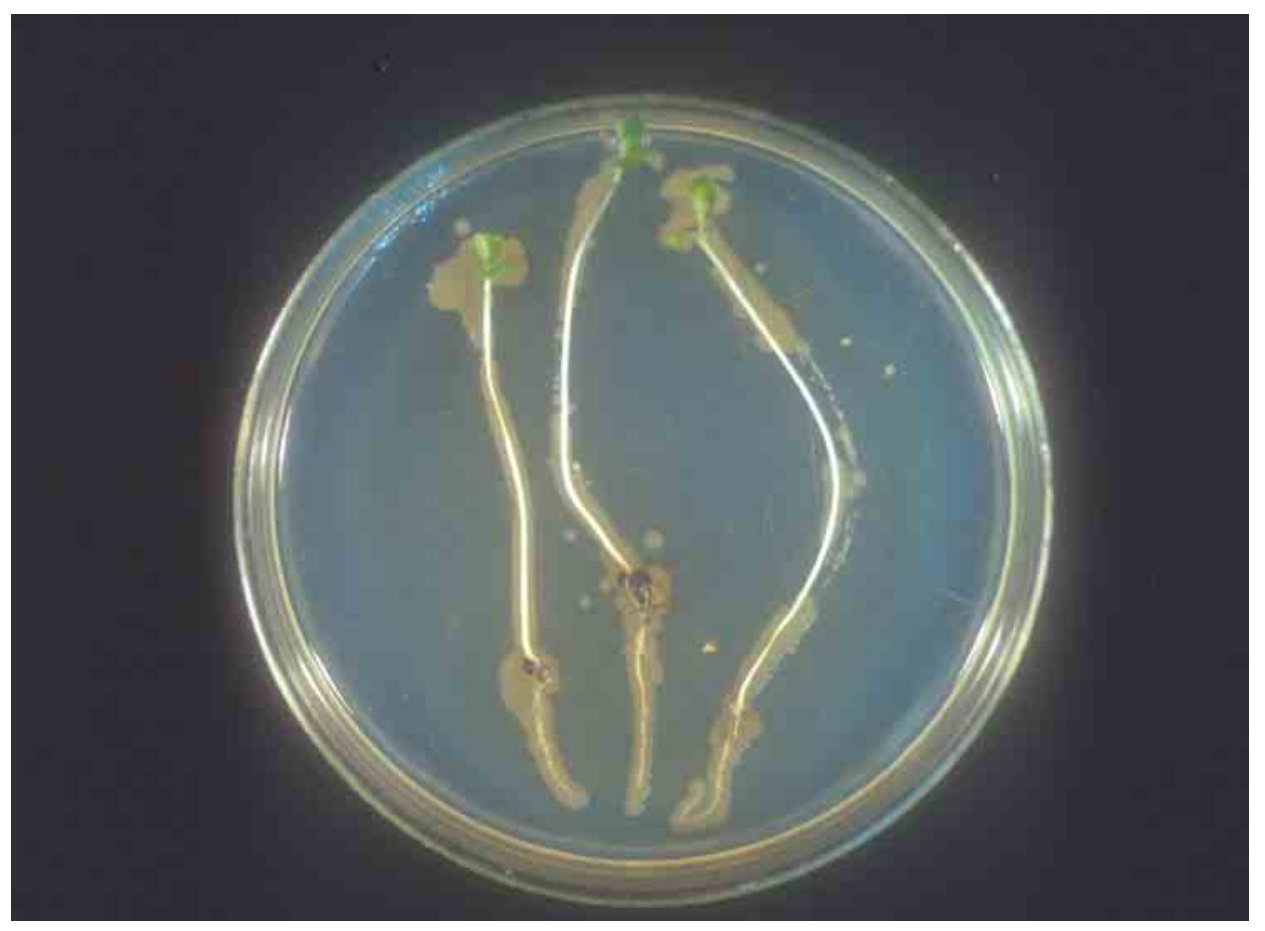

Abb. 11 Besiedlung der Rapskeimlinge durch Ps. fluorescens RII2.

Die Keimlinge wurden durch die Antagonisten von der Wurzel bis zu den Keimblättern fast lückenlos besiedelt, erkennbar auf dem Agar durch das Wachstum um die jungen Pflanzen herum. 


\subsubsection{Hemmwirkung gegen $L$. maculans an Rapskeimlingen durch die Antagonisten}

In der Literatur wird bisher keine Untersuchung beschrieben, in der eine enge Korrelation zwischen einem in vitro- und ad planta Screening festgestellt werden konnte. Um die Entdeckung wirksamer Antagonisten zu gewährleisten, war daher die Überprüfung der ad planta Hemmwirkung von möglichst vielen potentiellen Antagonisten im Rahmen der Arbeit erforderlich. Für ein schnelles Screening im Gewächshaus dienten dazu allerdings Rapskeimlinge, da deren Verwendung eine kürzere Versuchsdauer ermöglichte.

\subsubsection{Optimierung der Infektionsmethode}

Da in den Vorversuchen zunächst geprüft werden sollte, inwieweit die Antagonisten die Verletzungsstellen abdecken und somit die Keimblätter vor einer Infektion mit L. maculans schützen, wurden die Antagonisten vor der Inokulation mit der Phoma-Sporensuspension auf die Keimblätter appliziert. Um dennoch eine ausreichende Infektion der Keimblätter der Kontrollpflanzen zu gewährleisten, erschien es notwendig eine bestimmte Zeitdifferenz zwischen der Blattverletzung und der Inokulation einzuhalten. Hierzu wurden Infektionsversuche durchgeführt, um den Einfluss unterschiedlicher Zeitdifferenzen zwischen der Blattverletzung und der Inokulation mit L. maculans auf den Befall der Keimblätter der Rapspflanzen zu ermitteln. Die Ergebnisse sind in der Abb. 12 dargestellt.

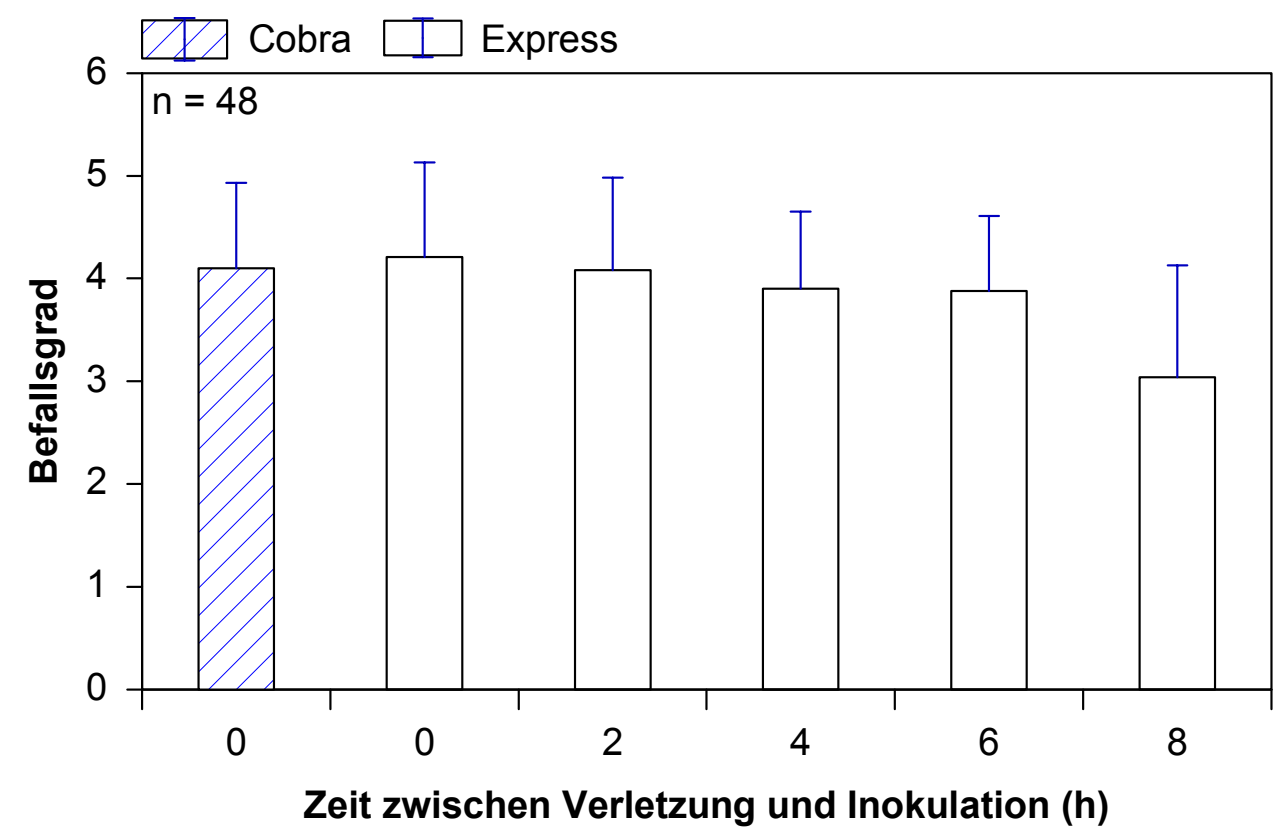

Abb. 12: Ermittlung der optimalen Zeitdifferenz zwischen der Verletzung und Inokulation für die Infektion der Rapskeimblätter mit L. maculans Sporensuspensionen. 
Da die Sorte 'Express' zur Zeit eine der anbauüblichsten Winterrapssorten ist und die Keimblattreaktion auf L. maculans im Vergleich zu der Sorte 'Cobra' kaum Unterschiede aufwies (Abb. 12), wurde die Sorte 'Express' für die weiteren Versuche mit den Rapskeimlingen ausgewählt. In der Abbildung ist auch zu sehen, dass mit zunehmender Zeitdifferenz zwischen Blattverletzung und Inokulation der Befall der Keimblätter mit L. maculans tendenziell zurückgeht. Eine statistisch signifikante Befallsrückgang wurde bei einer Inokulation von 8 Stunden nach der Verletzung erzielt. Deswegen wurden bei Screeningsversuchen die Pflanzen mit L. maculans 6 Stunden nach der Verletzung inokuliert.

\subsubsection{Verringerung des Phomabefalls durch den Einsatz von Antagonisten}

Aus technischen Gründen wurden die 21 Antagonisten in 4 Gruppen aufgeteilt, um ihre Hemmwirkung gegen L. maculans zu untersuchen. Die Befallsverminderung 21 Tage nach dem Einsatz von Antagonisten ist in der Abb. 13 dargestellt.

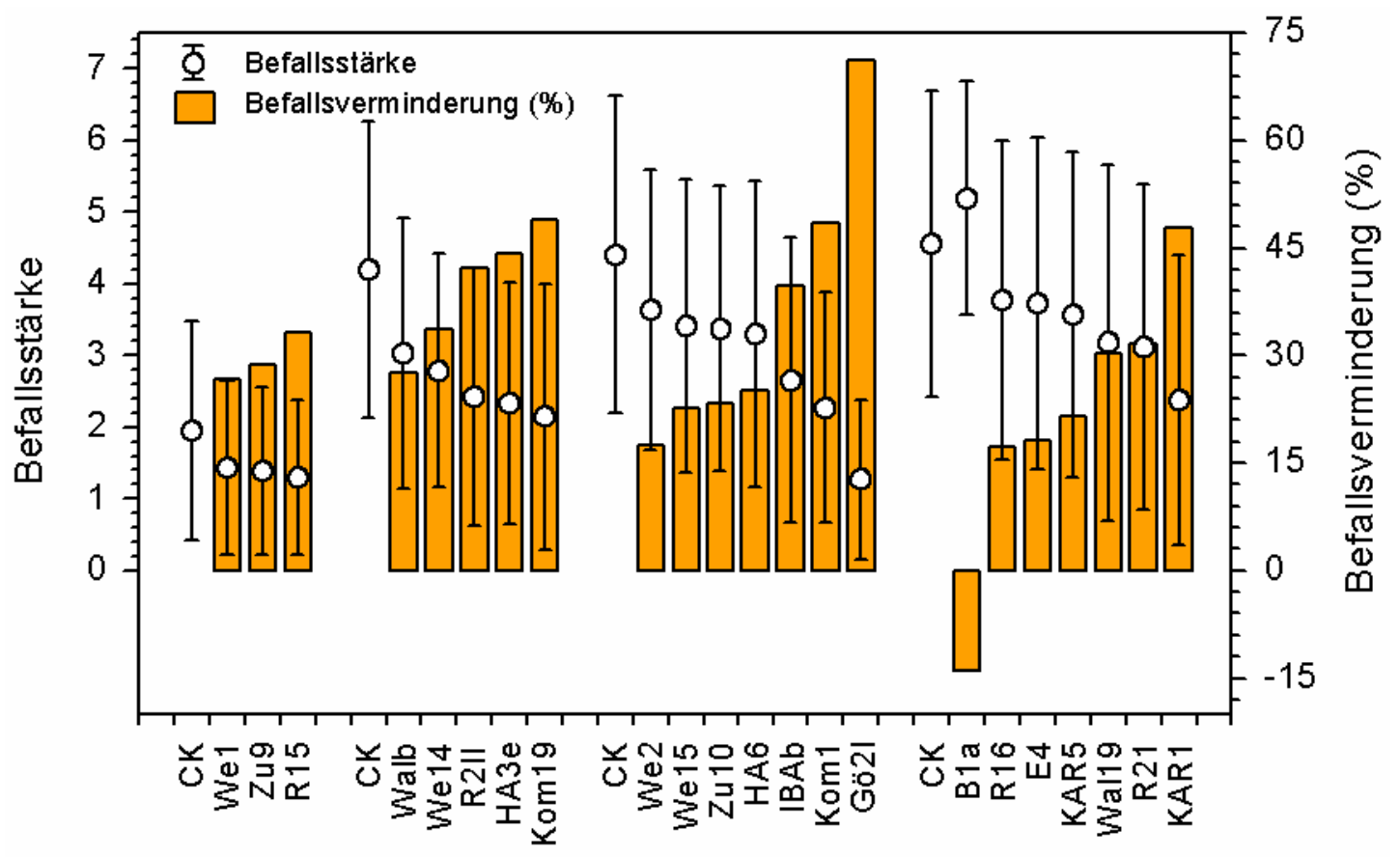

Abb. 13: Verringerung des L. maculans-Befalls an Rapskeimlingen durch die Applikation von Antagonisten

Aus der Abbildung wird deutlich, dass 20 von 21 getesteten Bakterienisolaten in der Lage waren, den Pflanzenbefall mit L. maculans bis zu 21 Tage zu unterdrücken. Am auffälligsten ist hierbei das Isolat Pseudomonas fluorescens Gö2l, welches sich bereits als wirksamster 
Antagonist von Verticillium longisporum, dem Rapswelkeerreger erwies (SASSE 1997), und auch hier einen hohen Wirkungsgrad von $73 \%$ gegenüber L. maculans erzielt. Die Verwendung der Isolate Ps. fluorescens RII2, Paenibacillus polymyxa HA3e, Ps. fluorescens KAR1, Bacillus circulans KOM1 und KOM19 führten zu deutlichen Befallreduzierungen von jeweils $42,1 \%, 44,3 \%, 47,9 \%, 48,5 \%$ und 48,9\%, während der gegen Fusarium culmorum an Winterweizen wirksame Antagonist Pantoea agglomerans E4 (KEMPF \& WOLF 1989) lediglich einen Wirkungsgrad von $18,2 \%$ erzielte. Allerdings war im Fall von B. subtilis B1a, mit einer ausgeprägten Wirkung gegen Eutypa lata, dem Erreger der Eutypiose der Weinrebe (SCHMIDT 1997), ein befallsfördernder Effekt beobachtbar.

Dass die Befallsstärke der Kontrollvarianten der Gruppe 2, 3 und 4 über 4,1 betrug und sich diese Einheitlichkeit statistisch absichern ließ, weist darauf hin, dass die Antagonisten auch bei einem höheren Befallsdruck mit L. maculans die Pflanzen schützen. In den Versuchen war noch zu beobachten, dass die Antagonisten den Befall mit L. maculans um 5 bis 7 Tage verzögern konnten.

\subsection{Entwicklung einer Methode zur Inokulation von Raps mit L. maculans}

Um erste Informationen über die ad planta Wirksamkeit der Antagonisten zu bekommen, wurden Versuche mit Rapskeimlingen den eigentlichen Versuchen mit jungen Rapspflanzen vorangestellt. Die Versuche mit den Keimlingen konnten allerdings nicht die Wirksamkeit der Antagonisten an den typischen Eintrittspforten, Wurzelhals und Stängelbasis, für L. maculans widerspiegeln. In der Regel wird der Wurzelhals der Jungpflanzen vor Inokulation mit einer Sporen- bzw. Myzelsuspension mechanisch verletzt, um eine Infektion zu erzielen. Da diese Infektionsbedingungen im Feld nicht vorliegen, erschien es sinnvoll, eine naturnahe Infektionsmethode ohne künstlich gesetzte Verletzung der Pflanze zu entwickeln, auch wenn bisherige Annahmen davon ausgingen, das eine Infektion ohne vorherige Verletzung nicht möglich sei.

Hierzu wurden in Vorversuchen myzelbewachsene Agarscheiben von V8-Kulturen auf den Wurzehals junger Rapspflanzen (BBCH 14/15) gelegt. Bereits nach wenigen Wochen waren an Geweberissen des Stängels starke Nekrosen sichtbar, in denen sich Pyknidien von L. maculans entwickelten (Abb. 15). Interessanterweise wiesen nichtinokulierte Kontrollpflanzen ebenfalls Geweberisse auf (Abb. 14). Dies führte zu der Annahme, dass der Pilz über natürliche Wunden das Stängelgewebe infiziert. Näheren Aufschluß hierzu gab ein Versuch, bei dem Rapspflanzen der Sorte Cobra im Stadium BBCH14/15 an Geweberissen des Wurzelhalses und am intakten Hypokotyl mit myzelbewachsenen Agarscheiben zweier Phoma-Isolate inokuliert wurden (Abb. 17). Hier riefen beide Isolate am Wurzelhals wesentlich häufiger Symptome als am Hypokotyl hervor. Dieser Unterschied kam auch in der 
Befallsstärke der Pflanzenorgane zum Ausdruck. Somit konnte die Annahme bestätigt werden, dass L. maculans junge Rapspflanzen vorwiegend über Geweberisse am Wurzelhals infiziert. In der Abb. 14 ist am Wurzelhals einer Rapspflanze ein Geweberiss zu erkennen, welcher als Inokulationsstelle, durch eine weiße Pfeile markiert, verwendet wurde.

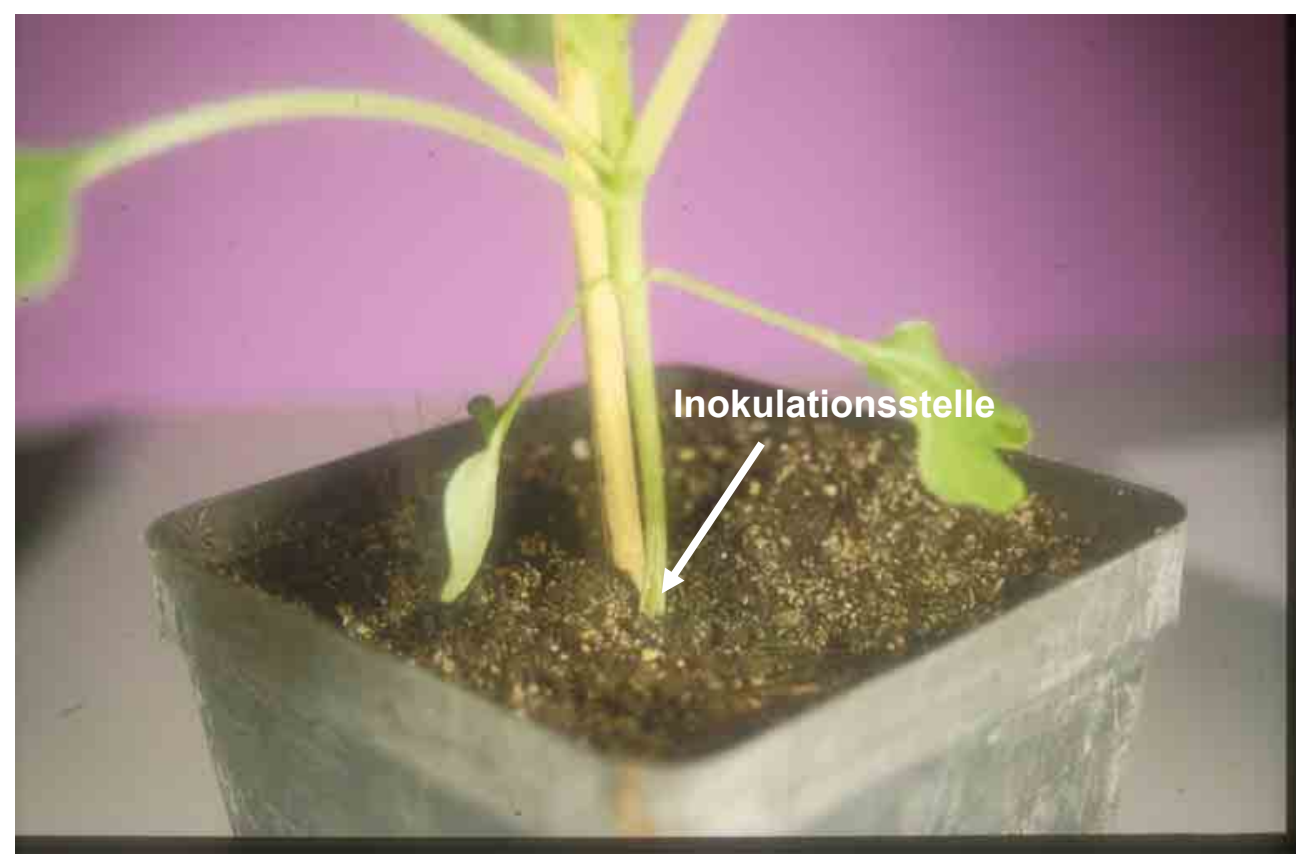

Abb. 14: Rapspflanze im Entwicklungsstadium BBCH 14/15.

In diesem Zusammenhang war zu klären, in welchem Stadium der Pflanzenentwicklung die Geweberisse entstehen, und wie groß die Anfälligkeit der Pflanzen gegenüber dem Pilz ist. Hierzu wurden in einem Gewächshausversuch Rapspflanzen der Sorte Cobra im Stadium $\mathrm{BBCH} 13, \mathrm{BBCH}$ 14/15 und $\mathrm{BBCH} 16$ mit myzelbewachsenen Agarscheiben am Wurzelhals inokuliert. Die Geweberisse traten erstmals im Entwicklungsstadium BBCH 14/15 auf. Entsprechend war im Stadium $\mathrm{BBCH} 14 / 15$ und $\mathrm{BBCH} 16$ auch die Befallshäufigkeit wesentlich höher, und in geringerem Maße die Befallsstärke der Pflanzen, als im frühen Entwicklungsstadium BBCH 13 (Abb. 16).

Auf der Basis dieser Ergebnisse wurde in einem weiteren Versuch die Anfälligkeit der Rapssorten Express und Cobra nach Inokulation im Entwicklungsstadium BBCH 14/15 untersucht. Hier wiesen nahezu sämtliche Pflanzen Symptome am Wurzelhals auf, wobei keine signifikanten Sortenunterschiede hinsichtlich der Befallshäufigkeit festzustellen waren (Abb. 18). Bezüglich der Befallsstärke jedoch waren die Symptome bei der Sorte Cobra stärker als bei der Sorte Express ausgeprägt. Die Anfälligkeit der Sorten stimmte auch mit den Angaben der Bundessortenliste gut überein. 


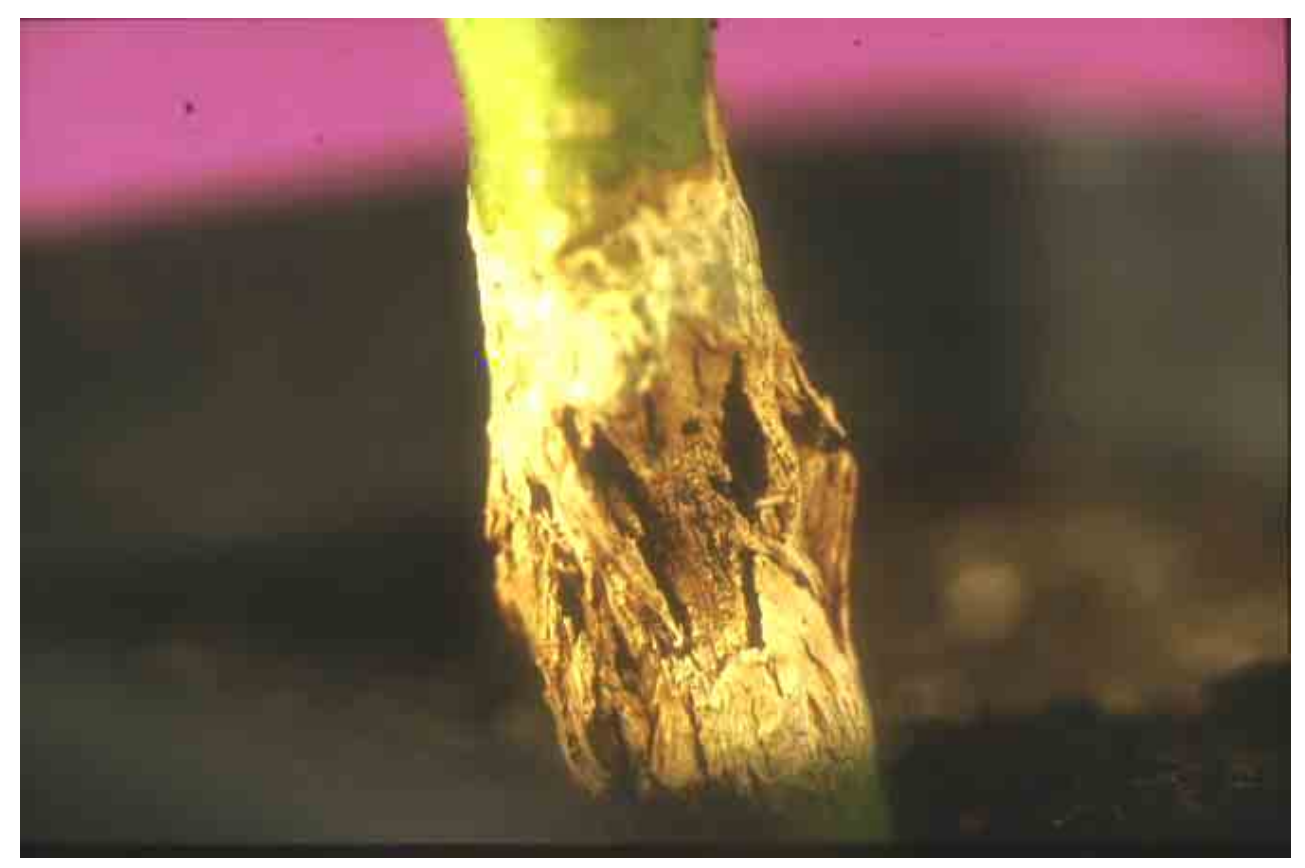

Abb. 15: Symptomausprägung an der Stängelbasis einer Rapspflanze der Sorte Express (49dpi). [Die Infektion erfolgte im Entwicklungsstadium BBCH14/15 mit einem von L. maculans bewachsenen Agarstückchen].

In den vorangehenden Gewächshausversuchen wurden die Pflanzen mit Myzel inokuliert. Da die Primärinfektion im Feld jedoch in der Regel über Sporen erfolgt, wurden Jungpflanzen im Stadium BBCH 14/15 mit einer Pyknidiosporen- bzw. Ascosporensuspension inokuliert. Dabei traten nach Applikation beider Sporensupension bei allen Pflanzen Symptome auf, wobei die Symptomausprägung nach Inokulation mit Pyknidiosporen im Vergleich zu Ascosporen deutlich stärker war (Abb. 19). Daher wurden in weiteren Versuchen Pyknidiosporen zur Inokulation eingesetzt, zumal die Gewinnung dieser Sporen im Vergleich zu Ascosporen wesentlich einfacher ist. 


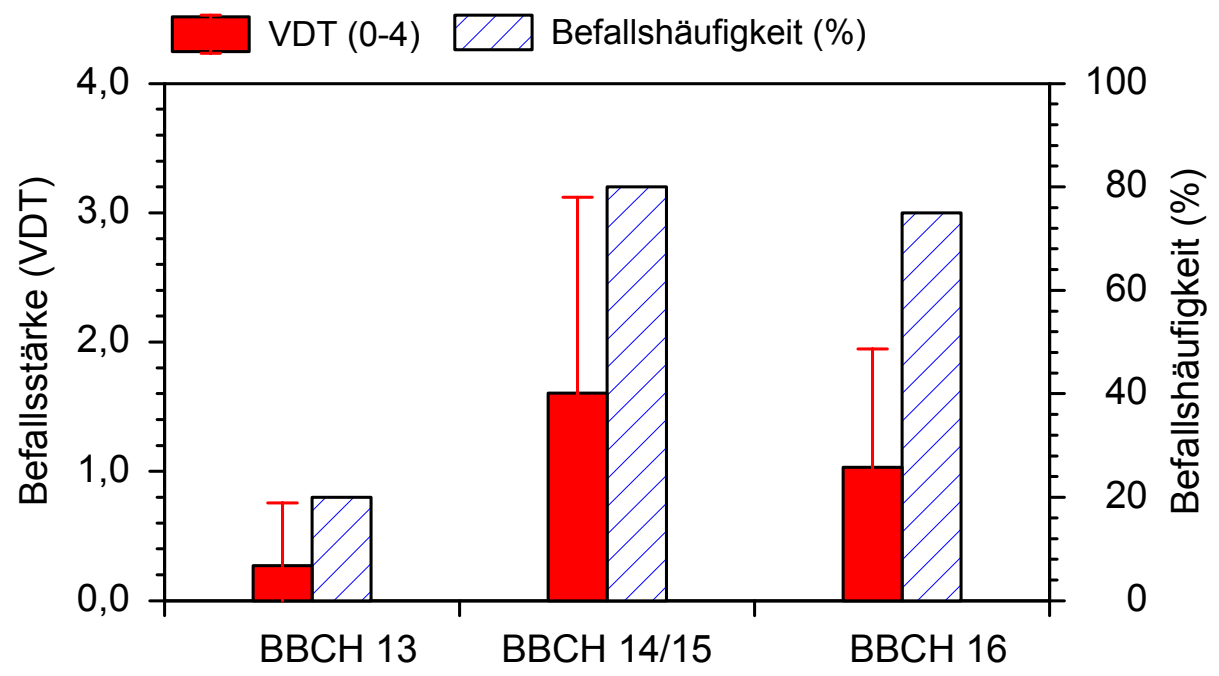

Entwicklungsstadium der Rapspflanze

Abb. 16: Infektion von Rapspflanzen der Sorte Cobra zu verschiedenen Entwicklungsstadien mit L. maculans. [Die Infektion erfolgte mit einem von $L$. maculans bewachsenen Agarstückchen. Varianzanalyse nach Bonferroni ( $p \leq$ 0,05); Varianten, die mit unterschiedlichen Buchstaben gekennzeichnet sind, unterscheiden sich signifikant voneinander].

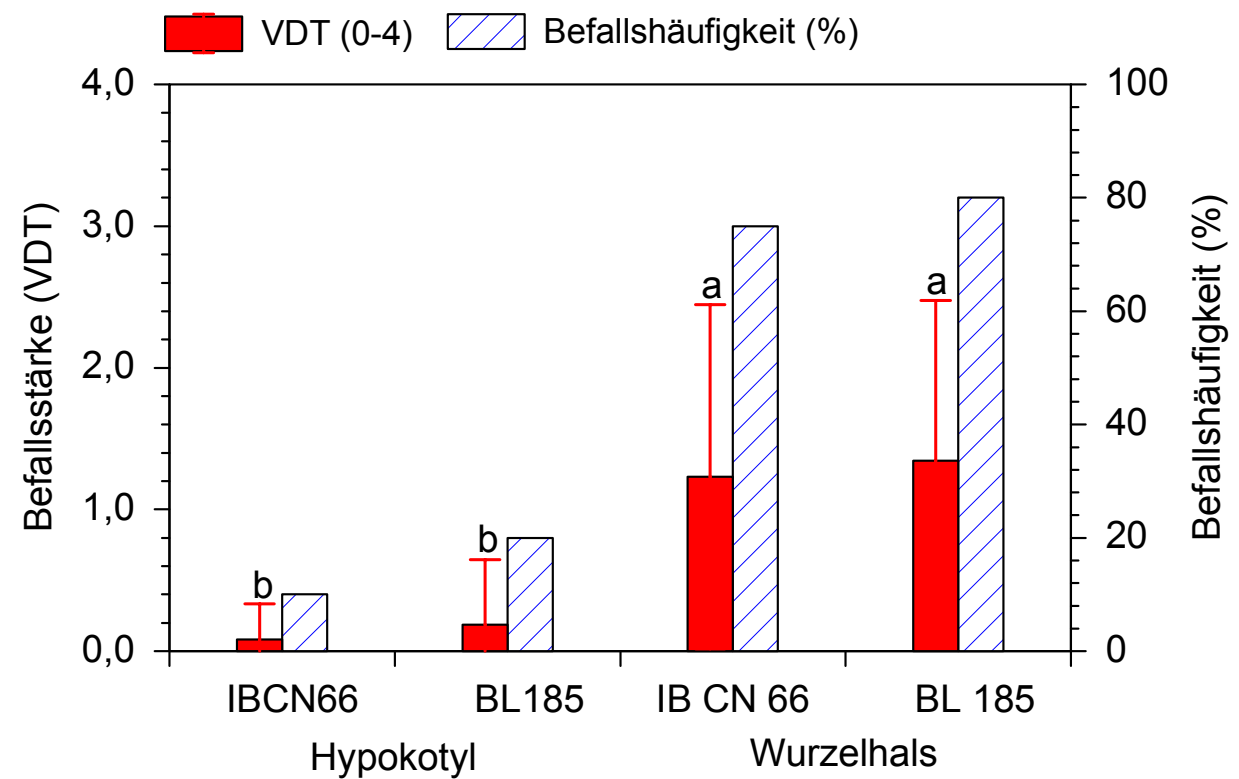

Abb. 17: Infektion von Rapspflanzen der Sorte Cobra an unterschiedlichen Stellen mit L. maculans. [Die Infektion erfolgte mit einem von L. maculans bewachsenen Agarstückchen. Varianzanalyse nach Bonferroni ( $p \leq 0,05)$; Varianten, die mit unterschiedlichen Buchstaben gekennzeichnet sind, unterscheiden sich signifikant voneinander]. 


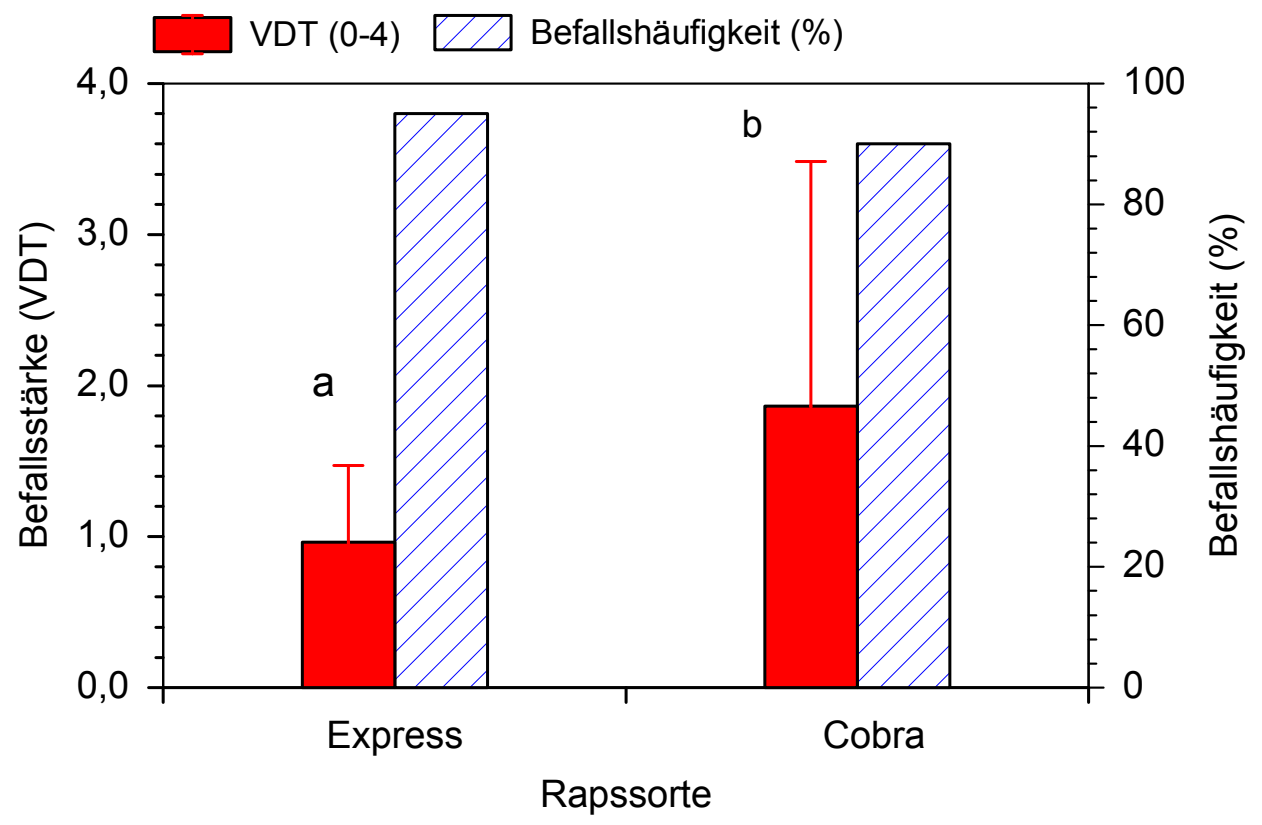

Abb. 18: Einfluss des Sortenunterschieds auf den Befall mit L. maculans IBCH66.

[Die Infektion erfolgte mit einem von L. maculans bewachsenen Agarstückchen in BBCH14/15; Varianzanalyse nach Bonferroni ( $p \leq 0,05)$; Varianten, die mit unterschiedlichen Buchstaben gekennzeichnet sind, unterscheiden sich signifikant voneinander]

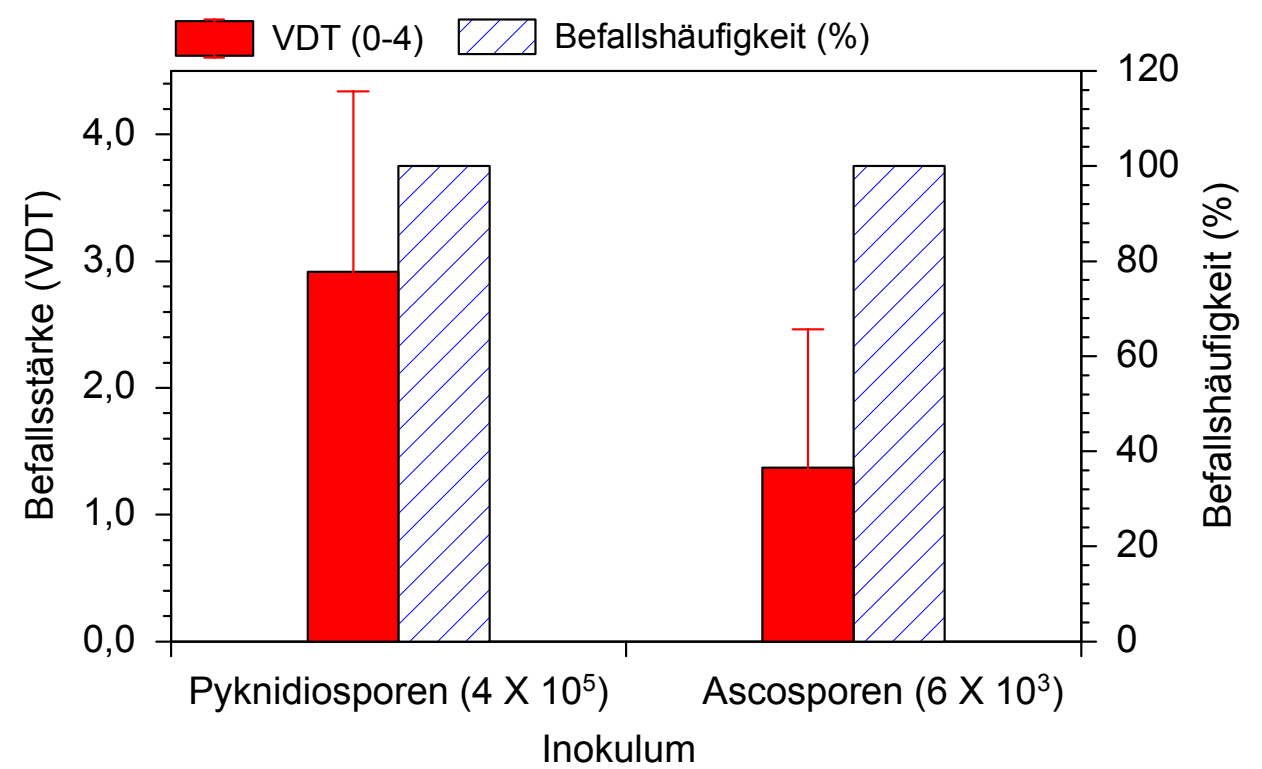

Abb. 19: Infektion von Rapspflanzen der Sorte Cobra mit unterschiedlichem Inokulum von L. maculans. [Varianzanalyse nach Bonferroni $(p \leq 0,05)$; Varianten, die mit unterschiedlichen Buchstaben gekennzeichnet sind, unterscheiden sich signifikant voneinander] 


\subsection{Optimierung des ELISA zur Befallsquantifizierung mit Leptosphaeria maculans}

Eine exakte Bestimmung der Wirksamkeit der Antagonisten ad planta, die Verringerung des L. maculans-Befalles durch die applizierten Bakterien in der Stängelbasis und am Wurzelhals, setzt nach wie vor eine zuverlässige Methode zur Befallsquantifizierung voraus. Die klassische Methode der Sichtbonitur erschien hier weniger gut geeignet, da die durch Phoma hervorgerufenen Läsionen stark variierten und die Abschätzung der Läsionslänge, der Läsionstiefe und des Läsionsumfanges zum einen sehr subjektiv ist und eine große Erfahrung voraussetzt und zum anderen keine Informationen über den tatsächlichen Pilzbefall liefert. So wurde als immunologisches Nachweisverfahren ein direkter ELISA (DAS-ELISA) entwickelt und eingesetzt.

\subsubsection{Ermittlung der optimalen Konzentrationen der Reagenzien im ELISA}

Vor dem routinemäßigen Einsatz des ELISA ist es notwendig den Testablauf soweit zu optimieren, dass eine zuverlässige Empfindlichkeit bei gleichzeitig minimalen falsch-positiven Reaktionen erzielt wird. Dies kann vor allem über eine Variation der Konzentration der Beschichtungsantikörper und der biotinylierten Antikörper erreicht werden.

Um die optimale Konzentration zu ermitteln, wurde die Stammlösung $\left(\mathrm{OD}_{280 \mathrm{~nm}}=1,45\right.$; entsprechend einer Proteinkonzentration von 1mg/ml) des Antikörper zu 50, 100, 200, 400, und 1000 fach verdünnt, und die Stammlösung biotinylierten Antikörpers (1 mg/ml) zu 500, 1000, 2000 und 4000 verdünnt. Daraus ergaben sich 20 verschiedene Kombinationen. Das Antigen wurde in einer Konzentration von $1 \mathrm{mg} / \mathrm{ml}$ eingesetzt.

Zur Auswahl der optimalen Kombination dienten zwei Kriterien. Das erste Kriterium ist, dass die optische Dichte bei $405 \mathrm{~nm}$ nach erfolgter Reaktion (bei 3 Stunden Substratinkubation) 1,5 bis 2 betragen sollte. Das zweite ist ein ökonomisches Kriterium. Damit ausreichend Antiserum für eine Vielzahl von Untersuchungen zur Verfügung steht, sollte immer die kleinste notwendige Konzentration der Immunoreagenzien verwendet werden. Aus der Tabelle geht hervor, dass die Verdünnung des biotinylierten Antikörpers die OD-Werte stärker beeinflussten, als die des nicht-derivatisierten Antikörpers. So erkennt man in dem ersten Block, dass die OD-Differenz zwischen der 50 und 100 fachen Verdünnung des biotinylierten Antikörpers ca. 1 betrug, während die Differenz zwischen der 500 und 1000 fachen Verdünnung des Antiköpers, bei der 50 fachen Verdünnung des biotinylierten Antikörpers, lediglich 0,2 betrug. Nach den o.g. Kriterien wurde die Kombination 500/100 gewählt.

Neben den Konzentrationen von Beschichtungs- und biotinylierten Antikörpern beeinflusst auch die Konjugatmenge die Empfindlichkeit und somit die Nachweisgrenze eines ELISA. So 
stieg beispielsweise bei Einsatz einer Konjugatskonzentration von 1:5000 und einer Antigenmenge von $1 \mu \mathrm{g} / \mathrm{ml}$ der Messwert von 1,32 auf 1,62.

Tab. 15 Einfluß der Konzentrationen der Immunoreagenzien auf die Reaktion im ELISA (Verdünnung des Streptavidin-alkalische Phosphtase-Konjugates: 1: 10000)

\begin{tabular}{|c|c|c|c|c|c|}
\hline \multirow{2}{*}{$\begin{array}{l}\text { Verdünnung } \\
\text { der biot.AK }\end{array}$} & \multicolumn{5}{|c|}{ Verdünnung der Beschichtungsantikörper } \\
\hline & 50 & 100 & 200 & 400 & 1000 \\
\hline \multicolumn{6}{|c|}{ Inkubationszeit: $1 \mathrm{~h}$} \\
\hline 500 & 0,694 & 0,643 & 0,522 & 0,523 & 0,340 \\
\hline 1000 & 0,421 & 0,334 & 0,270 & 0,262 & 0,160 \\
\hline 2000 & 0,237 & 0,220 & 0,163 & 0,138 & 0,093 \\
\hline 4000 & 0,113 & 0,102 & 0,084 & 0,073 & 0,076 \\
\hline \multicolumn{6}{|c|}{ Inkubationszeit: $2 \mathrm{~h}$} \\
\hline 500 & 1,433 & 1,393 & 1,152 & 1,141 & 0,736 \\
\hline 1000 & 0,852 & 0,836 & 0,657 & 0,673 & 0,405 \\
\hline 2000 & 0,463 & 0,440 & 0,368 & 0,362 & 0,295 \\
\hline 4000 & 0,243 & 0,218 & 0,173 & 0,164 & 0,168 \\
\hline \multicolumn{6}{|c|}{ Inkubationszeit: $3 \mathrm{~h}$} \\
\hline 500 & 2,674 & 2,554 & 2,215 & 2,213 & 1,442 \\
\hline 1000 & 1,709 & 1,565 & 1,321 & 1,32 & 0,853 \\
\hline 2000 & 0,960 & 0,907 & 0,722 & 0,705 & 0,609 \\
\hline 4000 & 0,497 & 0,456 & 0,361 & 0,345 & 0,36 \\
\hline
\end{tabular}

\subsubsection{Nachweisgrenze des Antigens und Erstellung eines internen Proteinstandards}

Zur Überprüfung der Nachweisgrenze des Antigens wurde eine Verdünnungsreihe der Antigenpräparation im ELISA eingesetzt. Nach Vorschlag von CLARK (1981) gelten in der Immunologie als untere Nachweisgrenze die Werte, die größer als der Mittelwert der Negativkontrolle plus seiner dreifachen Standardabweichung sind. Dementsprechend wurde in dieser Arbeit bei Werten von E 405nm > 0,1 nach einer Inkubationszeit von $3 \mathrm{~h}$ von einem sicheren Nachweis des Pilzes ausgegangen. Dies entspricht einer Nachweisgrenze von 2 $\mathrm{ng} / \mathrm{ml}$ (Abb. 20).

Zur quantitativen Erfassung des Pilzbefalls in den Pflanzenproben wurde stets ein interner Proteinstandard mitgeführt, da die Extinktionswerte verschiedener Messungen nicht direkt miteinander zu vergleichen sind. Da die Substrat-Farbentwicklung im Bereich zwischen 10 und $5000 \mathrm{ng}$ annähernd linear verlief, und ab einer Proteinkonzentration von $5000 \mathrm{ng} / \mathrm{ml}$ langsam eine Sättigung in der Bindungskapazität der beschichteten Mikrotiterplatte einsetzte, wurde für die Erstellung der Eichreihe der Standard mit Extraktionspuffer auf Proteinkonzentrationen von 5000, 1000, 500, 100, 50 und $10 \mathrm{ng}$ Protein/ml eingestellt. 


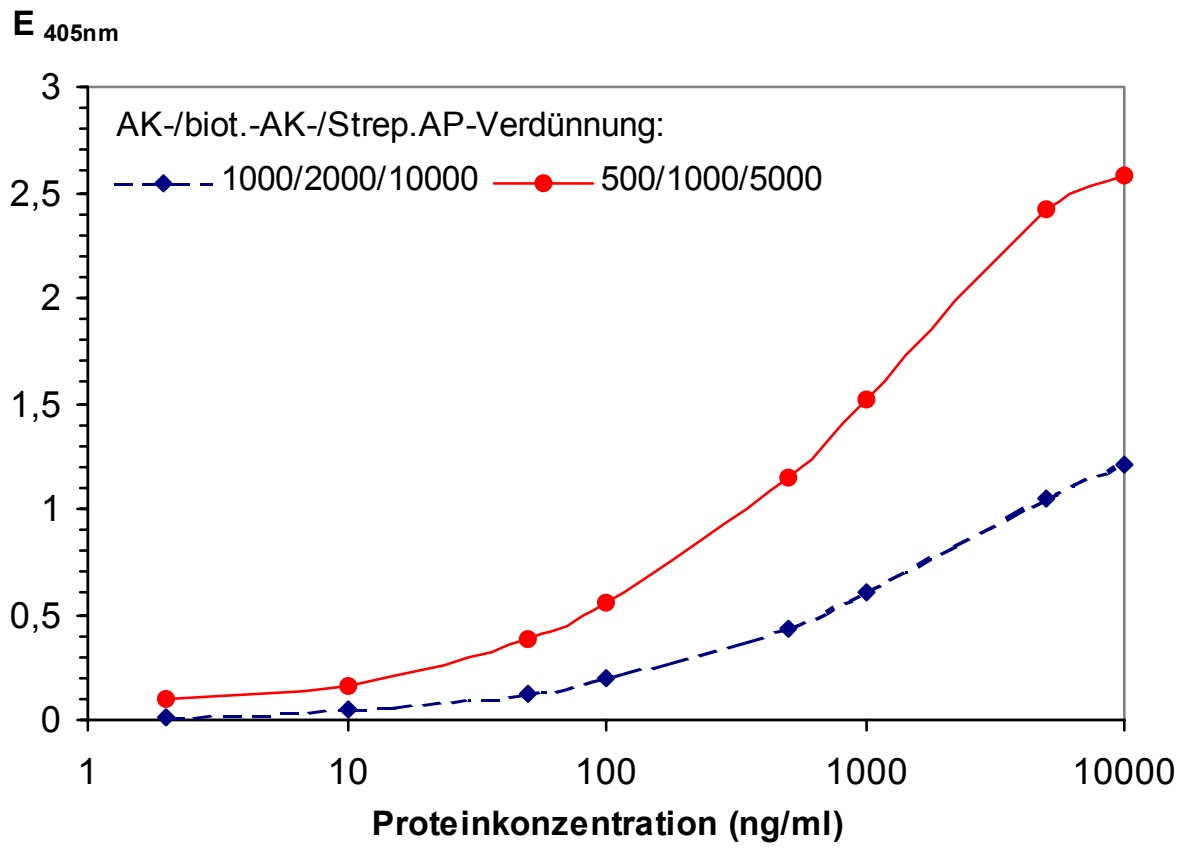

Abb. 20: Nachweis der Antigene von L. maculans im DAS-ELISA

\subsubsection{Spezifität der Antikörper gegenüber L. maculans}

Ein wesentliches Qualitätsmerkmal stellt neben der Empfindlichkeit die Spezifität eines ELISA dar. Das Immunosystem kann eine fast unbegrenzte Variabilität von Bindungsstellen am Antikörper bilden, die eine starke Affinität zum jeweiligen Epitop haben und in der Regel nur mit diesem oder strukturell eng verwandten Epitopen reagieren. Antigene Determinanten können ihrerseits bei verschiedenen Proteinen oder Polysacchariden strukturell ähnlich oder gleich sein (WALDOW 1997). Daher kann ein ursprünglich gegen eine bestimmte Antigenpräparation gebildetes Antiserum mit einem anderen Antigen mit ähnlichen antigenen Determinanten kreuzreagieren. Eine solche unerwünschte Kreuzreaktion kann ein Antiserum hinsichtlich der praktischen Anwendung unbrauchbar machen, insbesondere bei Mischinfektion.

Zunächst musste ausgeschlossen werden, dass das Antiserum weder mit der Rapspflanze oder den mit Antagonisten behandelten Rapspflanzen noch mit anderen pilzlichen Erregern kreuzreagiert (Tab. 15). Aus der Tab. 15 ist zu entnehmen, dass bei Verwendung des Antiserums 95 keine Kreuzreaktionen mit anderen pilzlichen rapspathogenen Schaderregern, insbesondere S. sclertiorum und V. longisporum, aus in vitro Kulturen auftraten, welche häufig zusammen mit L. maculans gemeinsam an Raps vorkommen und die sog. krankhafte Abreife hervorrufen. Aufgrund dieser Ergebnisse war auch keine Kreuzreaktion in planta zu erwarten. Lediglich die Isolate des saprophytischen Pilzes Alternaria altanata stellten eine Ausnahme dar, im Fall der Isolate 
A4.1 und A4.8 wurde eine relative Aktivität von $14,0 \%$ bzw. $12,4 \%$ festgestellt. Diese Kreuzreaktion konnte allerdings bei den nachfolgenden Untersuchungen durch den Einsatz verdünnter Immuno-Reagenzien (AK-/biot. AK- Verdünnung: 1:1000/1:2000 statt $1: 500 / 1: 1000)$ auf $6.3 \%$ bzw. $5.6 \%$ reduziert werden.

Tab. 15: Überprüfung der Kreuzaktivität des Antiserums 95 mit Extrakten der Rapspflanze und verschiedenen pilzlichen Pathogenen des Winterraps, des Weizens und der Zuckerrübe sowie einiger saprophytischer Pilze mittels DAS-ELISA [AKVerdünnung: 1/500, biot. AK-Verdünnung 1/1000;180 min Inkubation; AntigenKonzentration $=1 \mu \mathrm{g} / \mathrm{ml}$.

\begin{tabular}{|c|c|c|c|}
\hline Pilz & Isolat / Herkunft & $E_{405 \mathrm{~nm}}$ & rel. Aktivität (\%) \\
\hline \multicolumn{4}{|l|}{ Untersucht in der vorliegenden Arbeit: } \\
\hline Leptosphaeria maculans (A1) & IBCN66 / Raps & 1,685 & $100,0 \%$ \\
\hline L. maculans (A2) & R1G4 / Raps & 1,529 & $90,7 \%$ \\
\hline L. maculans (NA) & NA21 / Raps & 1,208 & $71,7 \%$ \\
\hline Alternaria alternata & A4.8 & 0,236 & $14,0 \%$ \\
\hline Alternaria alternata & A4.1 & 0,209 & $12,4 \%$ \\
\hline Botrytis cinerea & P229 & $\leq 0,01$ & - \\
\hline Rhizoctonia solani & Zucherrübe & $\leq 0,01$ & - \\
\hline Sclerotinia sclerotiorum & DE1 / Raps & $\leq 0,01$ & - \\
\hline Sclerotinia sclerotiorum & CN1 / Raps & $\leq 0,01$ & - \\
\hline Verticillium longisporum & V543b / Raps & $\leq 0,01$ & - \\
\hline Rapsextrakte & & $\leq 0,01$ & - \\
\hline Extrakte der mit Antagonisten behande & ten Rapspflanzen & $\leq 0,01$ & - \\
\hline \multicolumn{4}{|l|}{ Untersucht von Dr. B. Volke (1999): } \\
\hline L. maculans (A1) & IBCN 3 & 2,408 & $100 \%$ \\
\hline Alternaria alternata & $\mathrm{P} 228$ & 0,228 & $9,5 \%$ \\
\hline Sclerotinia sclerotiorum & 62/S1.1 / Raps & $\leq 0,01$ & - \\
\hline Verticillium longisporum & V40 / Raps & $\leq 0,01$ & - \\
\hline Aspergillus niger & 84 & $\leq 0,01$ & - \\
\hline Cladosporium herbarum & P226 & $\leq 0,01$ & - \\
\hline Cylindrocarpon destructans & 91 & $\leq 0,01$ & - \\
\hline Fusarium graminearum & 67639 / Weizen & $\leq 0,01$ & - \\
\hline Mucor hiemalis & 41 & $\leq 0,01$ & - \\
\hline Pseudocercosporella herpotrichoides & 4R / Weizen & $\leq 0,01$ & - \\
\hline Pythium ultimum & M1 / Zucherrübe & $\leq 0,01$ & - \\
\hline Septoria nodorum & 195 / Weizen & $\leq 0,01$ & - \\
\hline
\end{tabular}


3.7 Ausbreitung von Leptosphaeria maculans nach Infektion am Wurzelhals bzw. an der Stengelbasis von Rapspflanzen

Die gezielte Bekämpfung einer Pflanzenkrankheit setzt gute Kenntnisse über ihre Biologie voraus. Für L. maculans blieb es offen, wie der Pilz in die Pflanze eindringt und sich danach in der Pflanze entwickelt und ausbreitet. Die vertieften Kenntnisse über die Verteilung des Pilzes in der Wurzel bzw. in der Stängelbasis könnten insbesondere zu einer verbesserten Befallsermittlung beitragen, wobei die Probenahmen gezielter erfolgen können. Daher wurde die Verteilung von L. maculans in der Wurzel und in der Stängelbasis bestimmt. Die Infektion mit L. maculans dazu erfolgte in den Entwicklungsstadien BBCH14/15.

Die Pflanzen wurden im BBCH 15 Stadium an der Stängelbasis mit einem Myzelstück infiziert (vgl. 3.5). 49 Tage nach der Inokulation wurden die Pflanzen geerntet und die Blätter entfernt. Der mit sichtbaren Symptomen begrenzte Bereich der Pflanze wurde als Kernprobe genommen. Von diesem Bereich ausgehend, wurde die Pflanze nach oben und unten in jeweils $1 \mathrm{~cm}$ Abschnitte eingeteilt. Der Befall dieser Abschnitte mit $L$. maculans wurde mittels ELISA erfasst. Die Ergebnisse sind in der Abbildung 21 dargestellt.

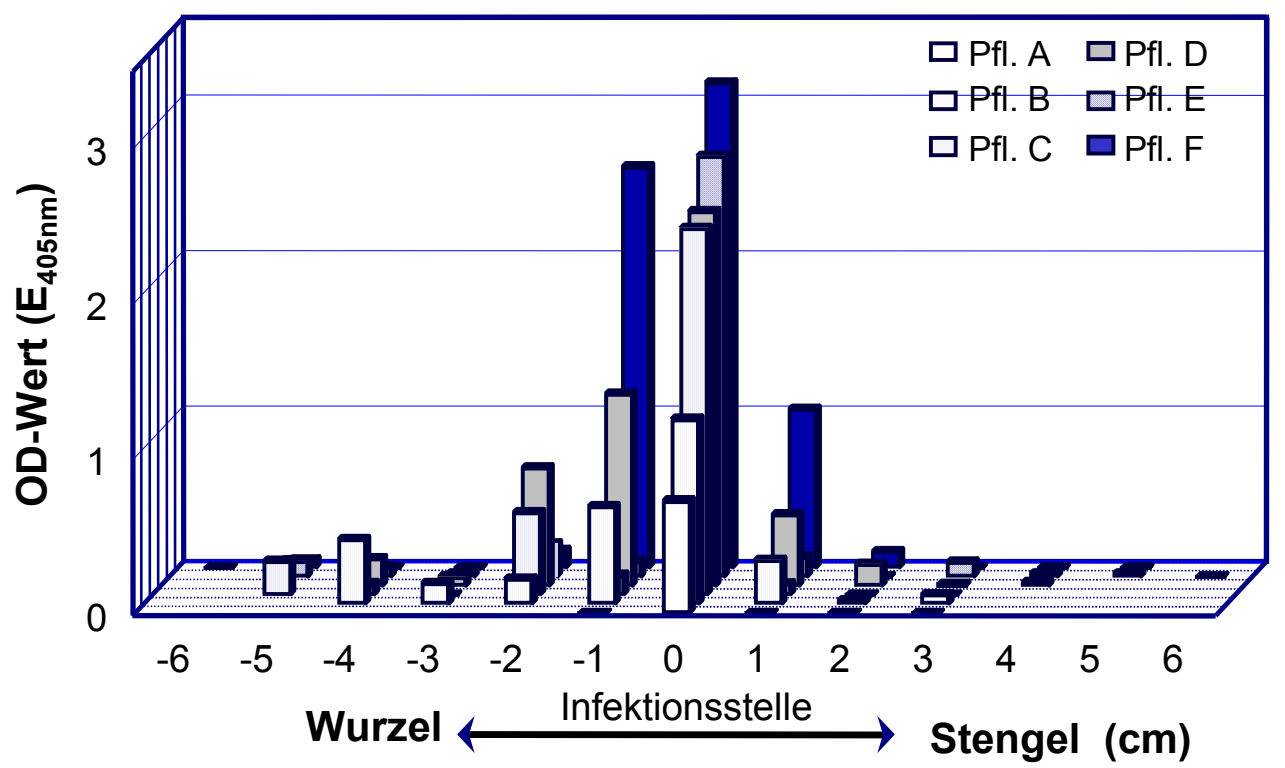

Abb. 21: Ausbreitung von L. maculans in Rapspflanzen nach der primärer Infektion an Rapswurzelhals (Die Inokulation erfolgte mit einem von L.maculans bewachsenen Agarstückchen 49 dpi)

Aus der Abbildung geht hervor, dass der Pilz sich bei einem leichten Befall auf den mit sichtbaren Symptomen begrenzten Bereich beschränkte, während beim stärkeren Befall der Pilz sich nach oben und unten ausbreiten konnte. Das Ausmaß der Ausbreitung nimmt mit Zunahme der OD-Werte des ELISA ebenfalls zu. 
Bei einem sehr starken Befall konnte sich der Pilz ca. $6 \mathrm{~cm}$ aufwärts und $5 \mathrm{~cm}$ abwärts ausbreiten. Das Maximum an Pilzprotein wurde vorwiegend im $5 \mathrm{~cm}$ Bereich um die Inokulationsstelle erfasst. Dieser Bereich wurde daher in den nachfolgenden Untersuchungen zur Befallsquantifizierung herangezogen.

\subsection{Einfluss des frühen Befalles mit L. maculans auf die Kornertragsbildung}

Die vorwinterliche vegetative und generative Entwicklung der Einzelpflanze beeinflusst das spätere Regenerations- und Kompensationsvermögen im Bestand und schließlich deren Ertrag (WU et al. 1998, DiEPENBROCH et al. 1999). Deshalb wurde untersucht, inwieweit ein früher Befall von Jungrapspflanzen mit $L$. maculans die Ertragsbildung beeinflusst.

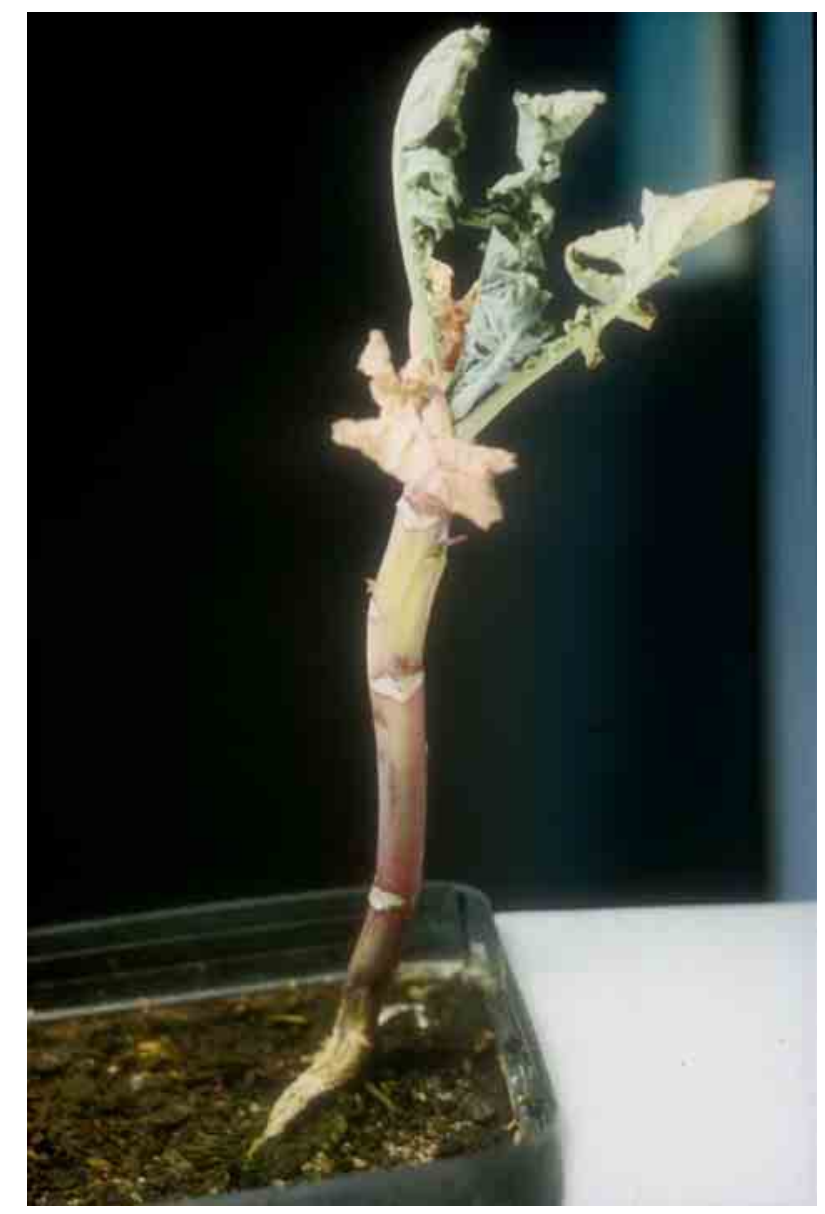

Abb. 22: Die mit L. maculans stark befallene Rapspflanze konnte nach der Vernalisation keine weiteren Blätter bzw. Triebe austreiben, was einen totalen Ertragsausfall zur Folge hatte.

Bei einem sehr starken Befall mit L. maculans wurde die Rapsentwicklung dermaßen gehemmt, dass weder neue Blätter noch neue Triebe herauswachsen konnten (Abb. 22), was zu einem totalen Ertragsverlust führt. 
Der Abb. 23 ist zu entnehmen, dass die Ertragsverminderung mit dem Phomabefall eng korrelierte $(r=-0,7159)$. Für einen starken Befall mit L. maculans wurde eine Ertragsverminderung von 28,3\% berechnet, während ein leichter Befall mit L. maculans zu einer Ertragseinbuße von lediglich 3,3\% führte. Wurde der Korrelationskoeffizient nur für die leicht befallenen Proben $\left(0,2<\mathrm{E}_{405 \mathrm{~nm}}<0,6\right)$ berechnet, konnte kein enger Zusammenhang zwischen dem Befall und der Ertragsbildung gefunden werden. Im Gegensatz dazu ging der Kornertrag bei hohen Befallsstärken $\left(1,5<\mathrm{E}_{405 \mathrm{~nm}}<3,0\right)$ deutlich zurück. Dies deutet darauf hin, dass in der Regel nur ein starker Befall mit L. maculans als ertragsrelevanter Faktor zu werten ist.

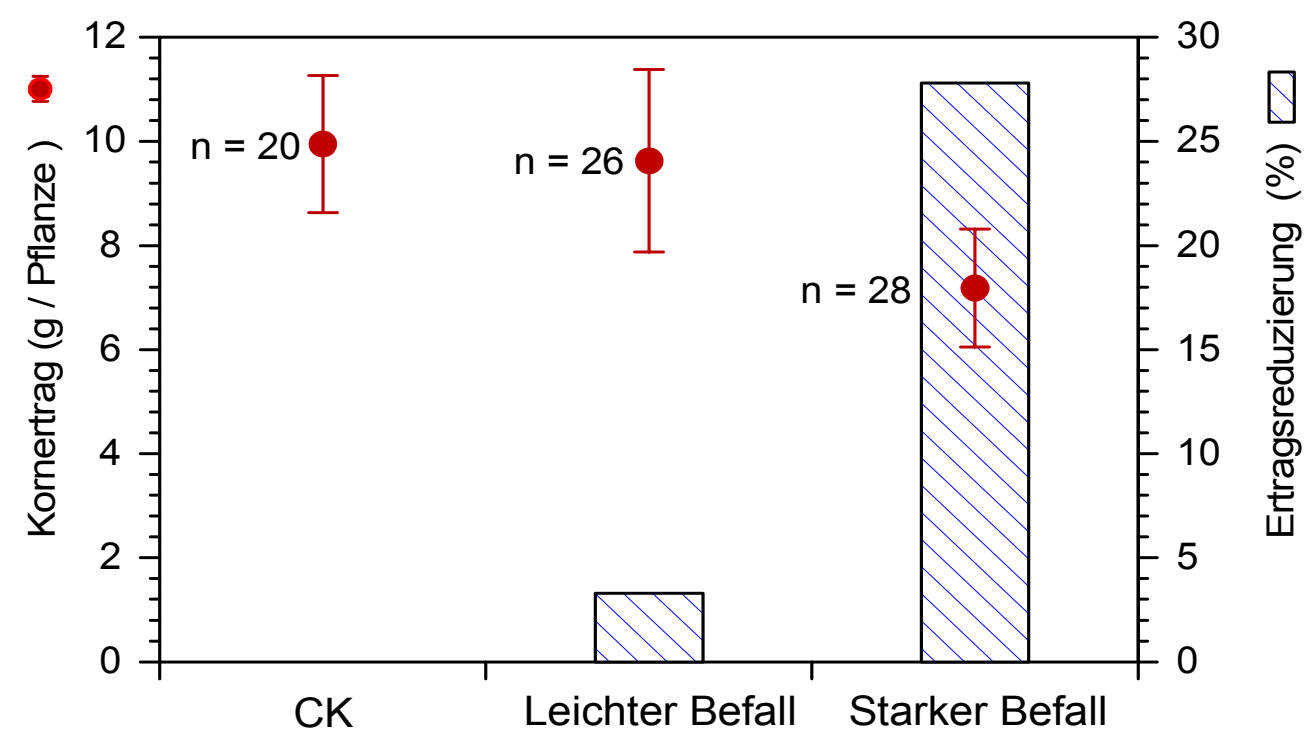

Abb. 23: Einfluss des Frühbefalles durch L. maculans auf die Kornertragsbildung des Winterraps der Sorte Cobra.

$Y_{\text {Befall-Ertrag }}=-1,4433 x+10,18(r=-0,7158 ; p=0,01)$

$Y_{\text {starker Befall -Ertrag }}=-3,1357 x+13,799(r=-0,583 ; p=0,011)$

$Y_{\text {leichter Befall -Ertrag }}=-3,6202 x+10,918(r=0,0501 ; p=0,492)$

Die Befallsquantifizierung erfolgte mit dem DAS-ELISA nach der Ernte. $X=E_{405 \mathrm{~nm}}$.

\subsection{Biologische Bekämpfung von L. maculans an Rapspflanzen im Entwicklungsstadium BBCH 14/15}

Die vorhergehenden Untersuchungen zeigten, dass die Rapspflanzen im Entwicklungsstadien BBCH 14/15 empfindlich gegen L. maculans sind und bei einem starken Befall Kornertragssverluste verursacht werden können. So war es erforderlich zu überprüfen, inwieweit durch eine Applikation von Antagonisten in diesem Entwicklungsstadium die Rapspflanzen vor einem Befall mit $L$. maculans geschützt werden können. 


\subsubsection{Hemmwirkung der ausgewählten Antagonisten ad planta}

Nach dem in vitro- und ad planta- Screening an Rapskeimlingen wurden Pseudomonas fluorescens Gö2I, KAR1 und RII2, Bacillus circulans KOM19, Serratia plymuthica ZU9, Paenibacillus polymyxa HA3e, WE1 und ZU10 ausgewählt, wobei sowohl die Wirksamkeit als auch die Herkünfte berücksichtigt wurden (vgl. 3.2.7 und 3.4.2). Die Hemmwirkung dieser Isolate gegen L.maculans wurde an Rapspflanzen im befallsempfindlichen Entwicklungsstadium BBCH14/15 im Gewächshaus überprüft. Damit diese ihr Wirkpotential möglichst vollständig entfalten konnten, wurde die Antagonistensuspension 2 Tage vor der Inokulation mit L. maculans auf die Stängelbasis und den Wurzelhals aufgebracht, so dass die Antagonisten auch genügend Vorsprung hatten sich auf der Pflanze zu etablieren, und Bindungstellen für das Pathogen zu besetzen.

In den Versuchen zur Überprüfung der Hemmaktivität ad planta wurden die Antagonisten in Kulturmedium angezogen, zentrifugiert und in 0,25\% Xanthan und 0,02\% Tween 20 auf einer Endkonzentration von ca. $1,5 \times 10^{9} \mathrm{cfu} / \mathrm{ml}\left(\mathrm{OD}_{600 \mathrm{~nm}}=1\right)$ eingestellt. Xanthan sollte aufgrund seiner Viskosität die Zahl der applizierten Bakterien auf der Pflanzenoberfläche erhöhen, während Tween für eine gleichmäßige Verteilung der Zellen auf der Oberfläche zuständig war. Im Fall von $\mathrm{HA3e}$ wurde die gesamte Flüssigkultur eingesetzt, da eine Zellabtrennung durch Zentrifugation nach der Kultivierung in Erbsenmedium schwer durchführbar war.

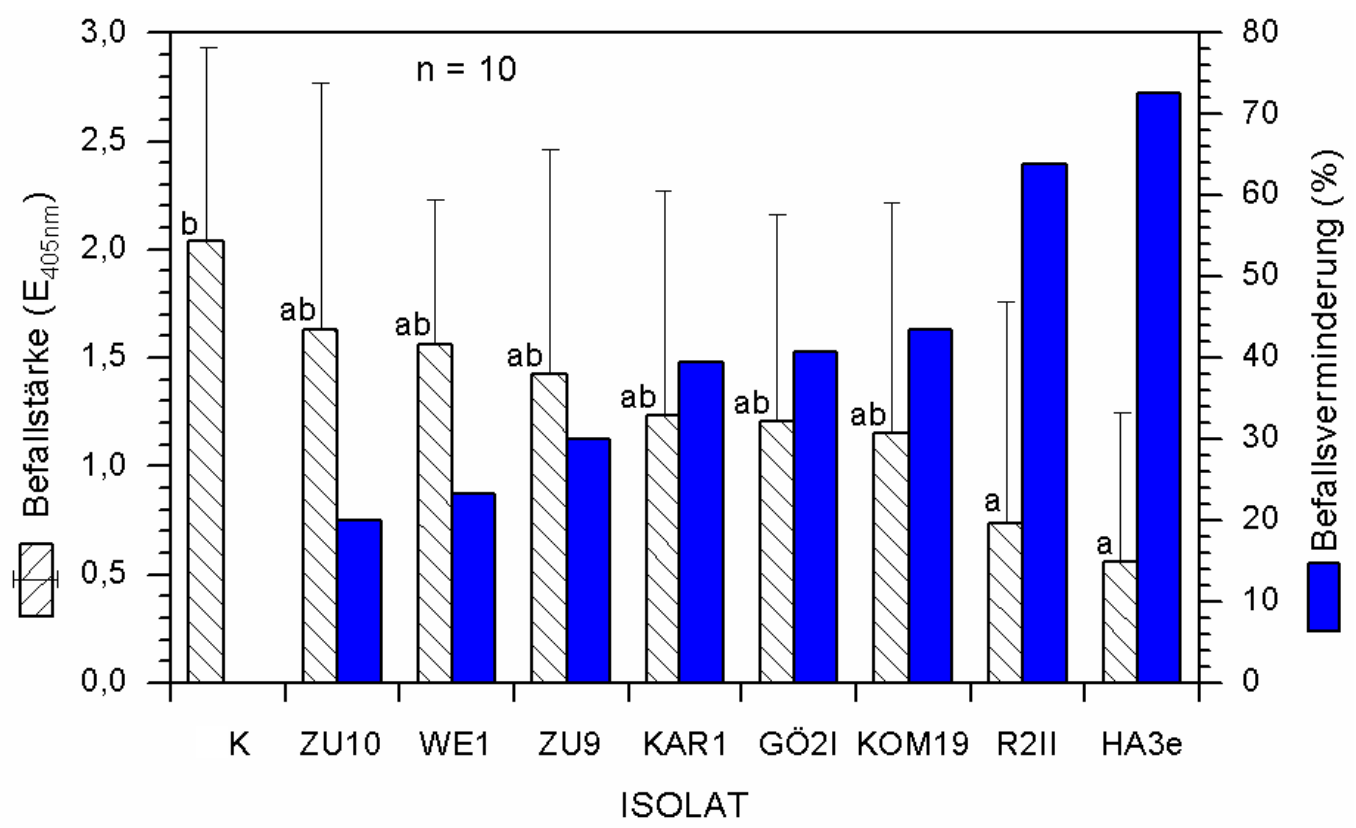

Abb. 24: Minderung des Befalls mit L. maculans an Rapspflanzen im Entwicklungsstadium BBCH 14/15 durch den Einsatz bakterieller Antagonisten.

In Abbildung 24 sind die Werte zur Befallsverminderungen durch die verschiedenen Antagonisten dargestellt. Die Isolate Pseudomonas fluorescens RII2 und Paenibacillus 
polymyxa HA3e zeigten eine ausgeprägte Wirkung von $64 \%$ bzw. $72,6 \%$, während die Befallsverminderung der Isolate Paenibacillus polymyxa ZU10 und We1 und Serratia plymuthica Zu9 unter 30\% sank. Die Isolate Ps. fluorescens KAR1 und Gö2I und B. circulans KOM19 zeigten eine mittlere, nahezu gleiche Wirksamkeit. Die relativ großen Standardabweichungen in der Befallsstärke $\left(\mathrm{E}_{405}\right)$ im Fall von HA3e und RII2 zeigen, dass die meisten Pflanzen gesund waren, aber einige der Pflanzen vor dem Befall mit $L$. maculans nicht ausreichend geschützt werden konnten, so dass Ertragsverluste auftraten (vgl. 3.6). Diese Tatsache erforderte eine Verbesserung bei der Applikation bzw. Formulierung der Antagonisten.

\subsubsection{Verbesserung der Wirksamkeit einer biologischen Bekämpfungsmaßnahme durch eine kombinierte Anwendung bakterieller Antagonisten}

Die Wirkung eines Antagonisten konnte häufig durch die Verwendung von Formulierungshilfsstoffen gefördert werden (u. a. TILCHER 1996, SCHMIDT 1997, ScHULZ \& WOLF 1998). In der vorliegenden Arbeit wurde allerdings das Hauptaugenmerk zu einer Wirkungssteigerung auf die kombinierte Anwendung von Antagonisten gelegt. Hierzu wurden die Bakteriensuspensionen von Paenibacillus polymyxa HA3e und Pseudomonas fluorescens RII2 vor der Ausbringung mit gleichem Volumen vermischt. Neben den Antagonisten HA3e und RII2 wurde auch Bacillus circulans KOM19 getestet, weil dieser in vorangegangenen Versuchen sehr gute Wirkung zeigte.

Aus den Abbildungen 25 und 26 wird deutlich, dass durch die kombinierte Anwendung von HA3e und RII2 der Bekämpfungserfolg wesentlich verbessert wurde. Der Wirkungsgrad betrug hierbei $85,9 \%$. Keine der Pflanzen wies eine Befallsstärke von über $1\left(\mathrm{OD}_{405 \mathrm{~nm}} \mathrm{im}\right.$ ELISA) auf. Die Wirksamkeit der Isolate HA3e, RII2 sowie KOM19 aus den vorhergehenden Versuchen konnten bestätigt werden. Bei ihrer Anwendung konnte der Befall mit $L$. maculans im Vergleich zur Kontrolle (0,25\%ig Xanthan) um jeweils 53,1\%, 42,3\%, bzw. 65,5\% vermindert werden. KOM19 erzielte hier eine bessere Wirkung als HA3e und RII2. Seine Anwendung in der Praxis ist aber aufgrund seiner breiten antibakteriellen Wirkung nicht empfehlenswert. Im Vergleich zur Kontrolle zeigten die Varianten HA3e + RII2 bzw. KOM19 eine signifikant geringere Befallsstärke. 


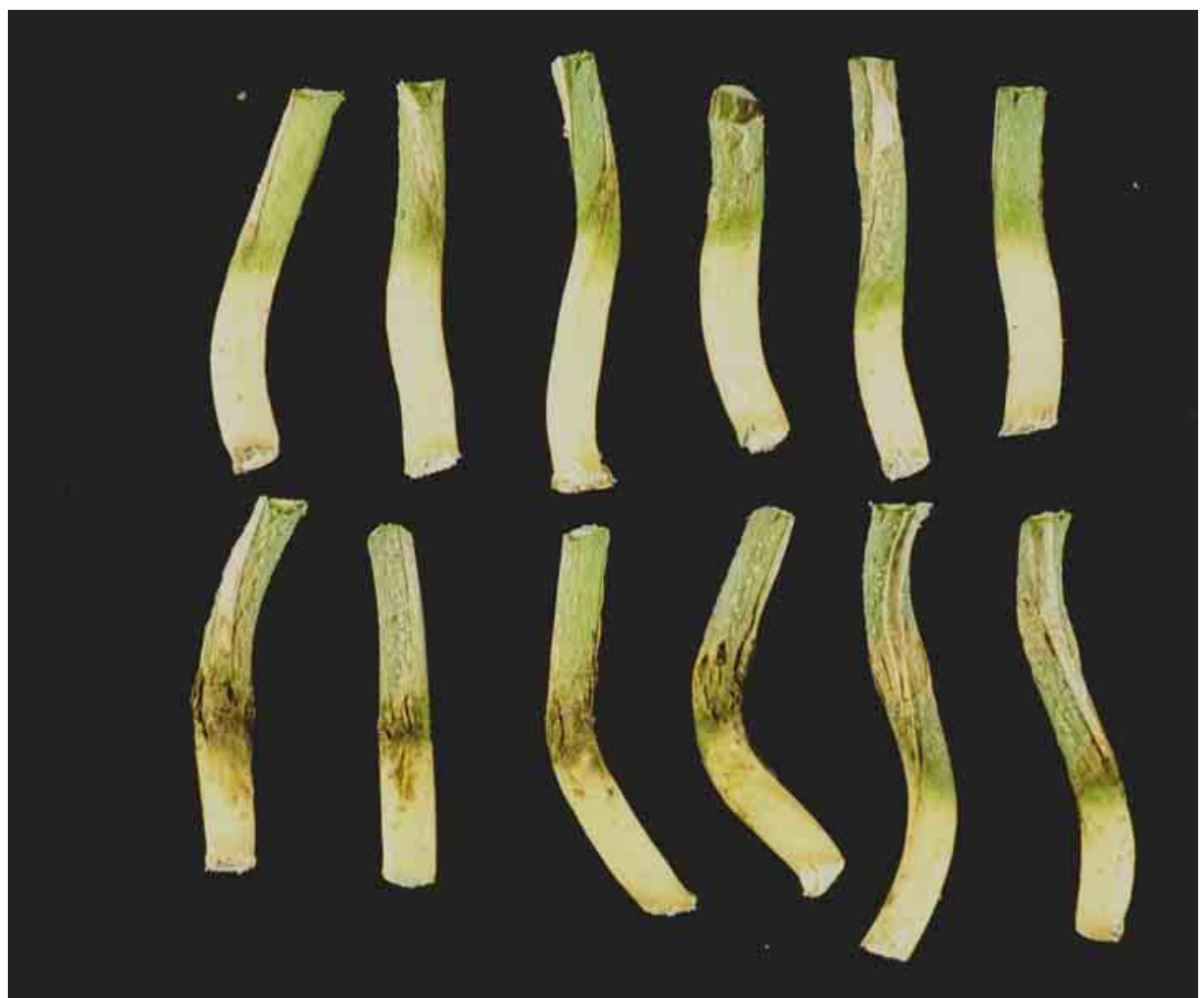

Abb. 25: Einfluss der Antagonistenbehandlung auf den Befall von Rapspflanzen mit L. maculans. Oben: mit Pseudomonas fluorescens RII2 plus Paenibacillus polymyxa HA3e behandelte Rapsstengel; Unten: inokulierte Kontrolle mit deutlich erkennbarem Symptom zwischen weißem (unterirdischem) und grünem (oberirdischem) Teil des Stengels

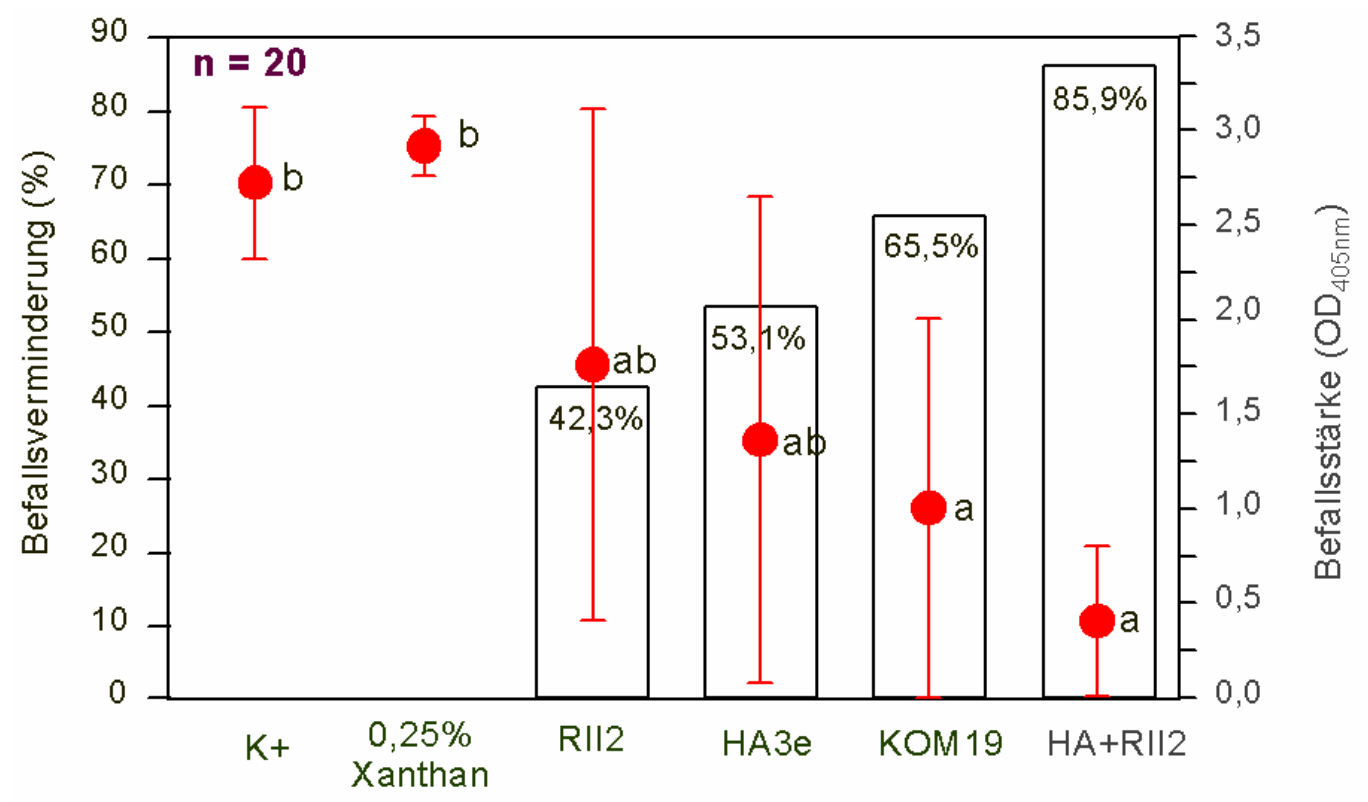

Abb. 26: Wirkung der kombinierten Anwendung von Antagonisten Paenibacillus polymyxa HA3e und Ps. fluorescens RII2 auf Phomabefall an Rapspflanzen der Sorte Cobra in Entwicklungsstadien BBCH 14/15. 


\subsection{Einfluss der bakteriellen Antagonisten auf das Rapspflanzenwachstum}

Zahlreiche Autoren berichteten in ihren Arbeiten außerdem über einen Einfluss der antagonistischen Mikroorganismen auf das Pflanzenwachstum, weshalb man diese Bakterien den PGPR (Plant Growth Promoting Rhizobacteria) zuordnet (KLOEPPER \& SCHROTH 1978, KLOEPPER et al. 1988). Da die Ertragsbildung unmittelbar mit dem Wachstum verknüpft ist, sollte ebenfalls in der vorliegenden Arbeit untersucht werden, welche Effekte die gegen L. maculans wirksamen Isolate HA3e und RII2 auf das Wachstum der Rapskeimlinge und -jungpflanzen ausüben. Darüber hinaus sollten erste Informationen für die Verwendung einer geeigneten Applikationsmethode gefunden werden.

Die Saatgutbehandlung ist eine effektive Methode zur Applikation von Antagonisten bei der biologischen Bekämpfung bodenbürtigen Erreger (SASSE 1997, SCHULZ \& Wolf 1998). Aufgrund der Biologie von L. maculans und Pathogenese der Wurzelhals- und stängelfäule wurde allerdings ein viel stärkeres Augenmerk auf die Behandlung der Rapspflanzen gelegt. Hierzu wurde der Einfluss einer Tauchbehandlung der Wurzel und einer Behandlung des Wurzelhalses bzw. der Stängelbasis auf das Wachstum geprüft. Als Parameter diente die Wurzellänge, da die vorwinterliche Wurzelentwicklung der Jungpflanzen eine entscheidende Rolle für die Weiterentwicklung der Pflanzen im kommenden Frühjahr und somit auch für die Ertragsbildung spielt (WU et al. 1998).

Während das Wachstum der Rapskeimlinge bzw. das Wurzelwachstum der Jungpflanzen nach einer Gießbehandlung mit dem Kulturfiltrat der Antagonisten kaum beeinflusst wurde (Tab. 17 und Abb. 28), konnte eine signifikante Hemmung des Wurzelwachstums 7 Tage alter Rapskeimlinge nach einer einstündigen Tauchbehandlung in einer konzentrierten Bakteriensuspension $\left(5 \times 10^{9} \mathrm{cfu} / \mathrm{ml}^{\prime} \mathrm{OD}_{600 \mathrm{~nm}}=5\right)$ nachgewiesen werden (Abb. 27). Aufgrund dieser Erfahrungen kann nur empfohlen werden, stets die Konzentration der zur biologischen Bekämpfung einzusetzenden Antagonisten in Vorversuchen zu überprüfen, um mögliche phytotoxische Wirkungen auszuschließen.

Tab. 17 Wachstum von Rapskeimlingen in Antagonistensuspensionen (7d)

Nach Vorkeimung der Samen erfolgte die Kultivierung der Keimlinge in einer Bodenextrakt-Antagonistensuspension (Konzentration: $\mathrm{OD}_{600 \mathrm{~nm}}=0,2$ )

\begin{tabular}{lccccc}
\hline \multicolumn{1}{c}{ Variante } & Anzahl der & \multicolumn{2}{c}{ Frischgewicht $(\mathrm{g})$} & Varianzanalyse \\
\cline { 3 - 4 } & Pflanzen & Mittelwert & STABW & $(\mathrm{P} \leq 0,05)$ \\
\hline $\mathrm{K}$ & 32 & 0,070 & 0,032 & $\mathrm{a}$ \\
Pseudomonas fluorescens RII2 & 26 & 0,081 & 0,038 & $\mathrm{a}$ \\
Paenibacillus polymyxa HA3e & 29 & 0,072 & 0,041 & $\mathrm{a}$ \\
\hline
\end{tabular}




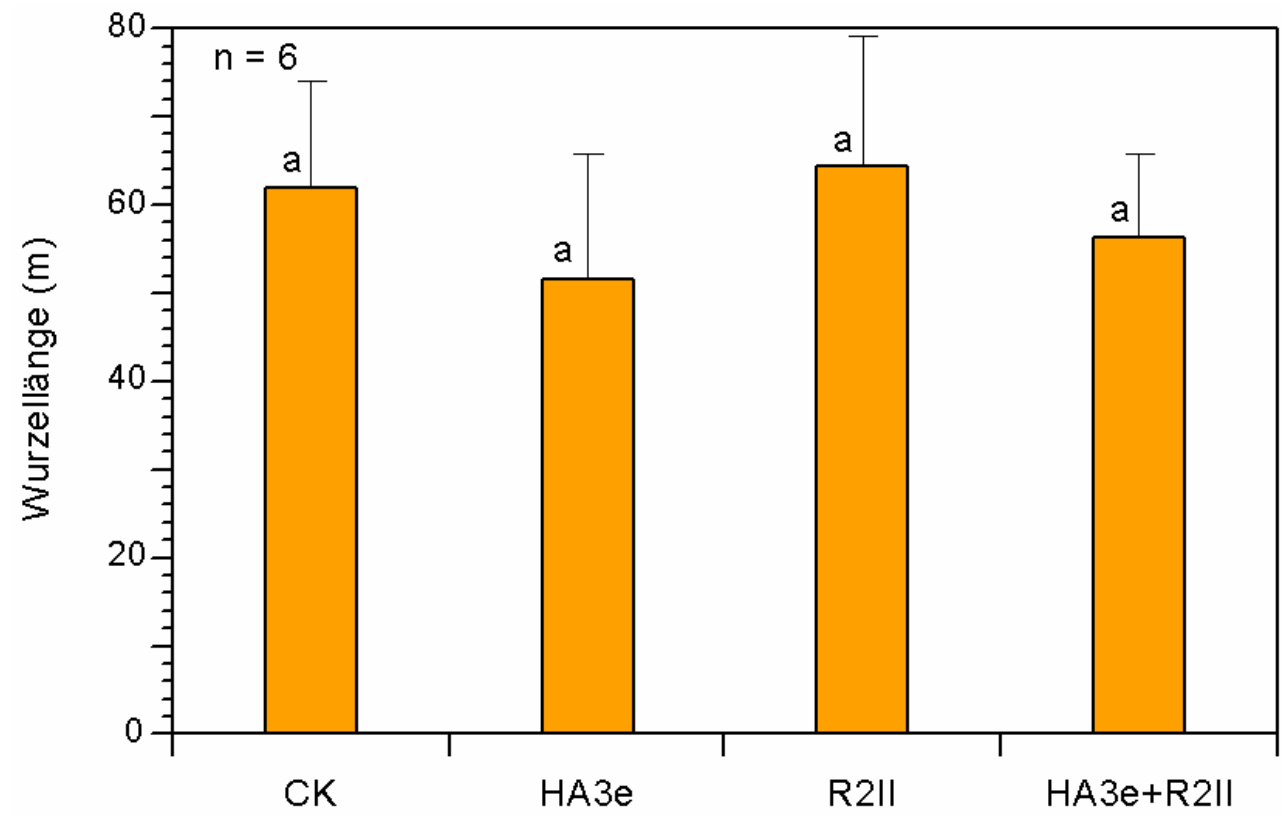

Abb. 27: Einfluss einer Gießbehandlung mit Antagonisten auf das Wurzelwachstum von Rapspflanzen in BBCH 14/15 (49 dpi)

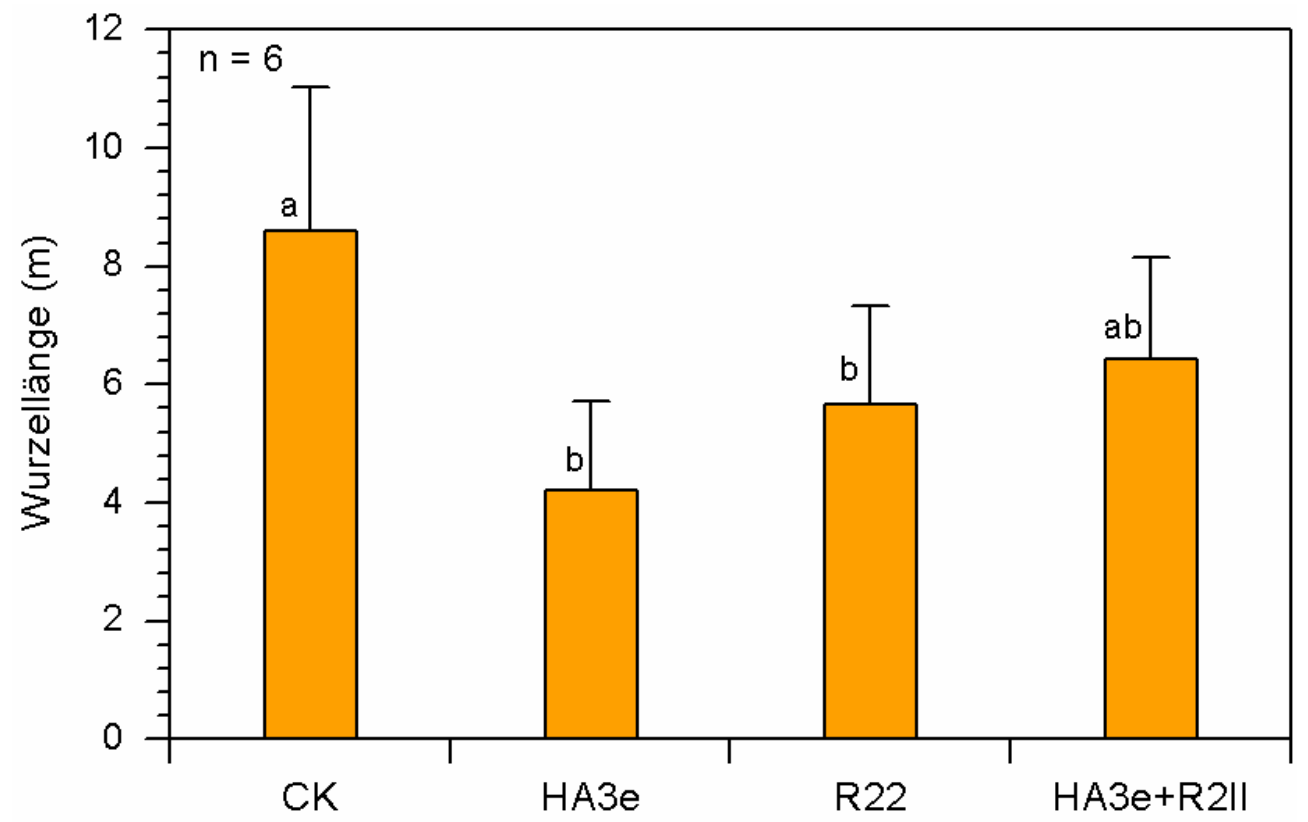

Abb. 28: Einfluss einer Tauchbehandlung mit Antagonisten auf das Wachstum von 8 Tage alten Rapskeimlingen (21 dpi)

\subsection{In vitro Untersuchungen zu den Hemmmechanismen der Antagonisten}

Die Kenntnis der Wirkmechanismen eines Antagonisten ist von großer Bedeutung für die Optimierung seiner Wirkung. Doch auch dessen Überleben und Aktivität sind mitentscheidend für den Bekämpfungserfolg und können durch Auswahl geeigneter 
Nährstoffe gezielt verbessert werden. In der Abb. 29 sind erste Ergebnisse zum in vitro Wachstum von Ps. fluorescens RII2 und Paenibacillus polymyxa HA3e in verschiedenen Nährmedien dargestellt.

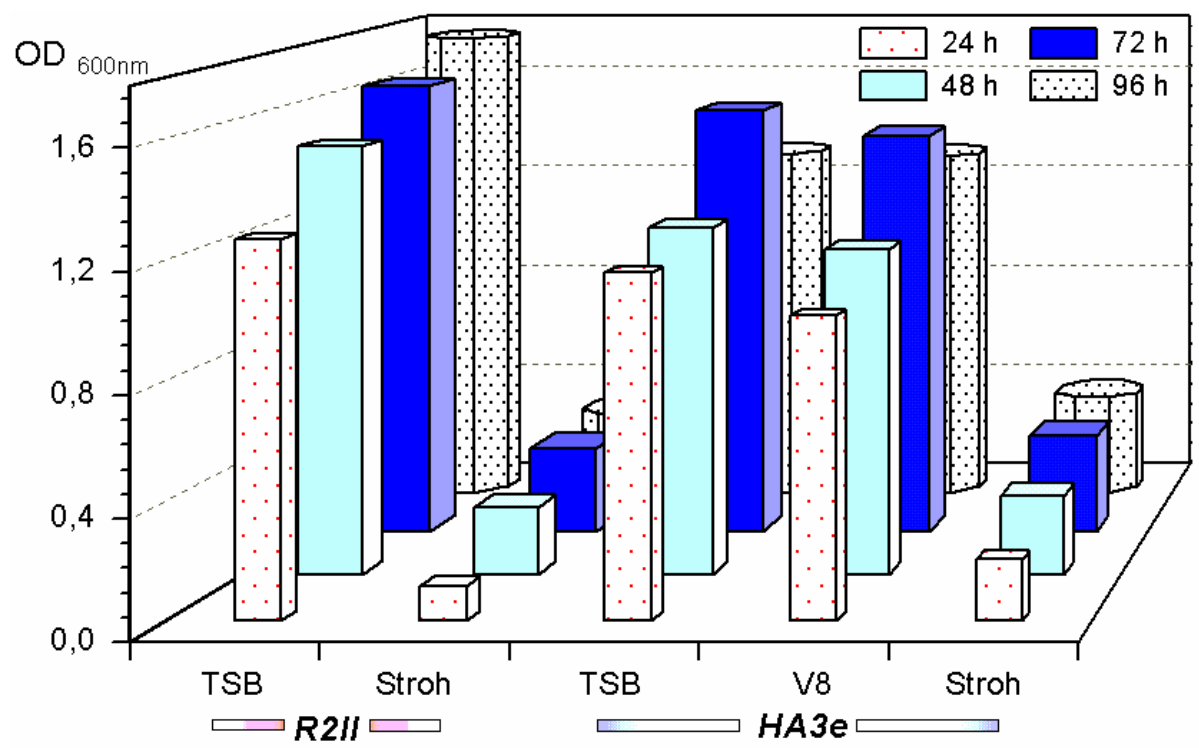

Abb. 29: Wachstum von Ps. fluorescens RII2 und Paenibacillus polymyxa HA3e in unterschiedlichen Nährmedien.

\subsubsection{Bildung von Cyanwasserstoff durch Ps. fluorescens RIl2 und Paenibacillus polymyxa HA3e}

In der Abbildung 30 wird die Bildung von Cyanwasserstoff in TSB bzw. Strohextrakt durch Ps. fluorescens R2II und durch Paenibacillus polymyxa HA3e in TSB, V8 bzw. Strohextrakt veranschaulicht. Während $\mathrm{HCN}$ nur in geringem Ausmaß $\left(\mathrm{OD}_{550 \mathrm{~nm}} \leq 0,1\right)$ im Kulturfiltrat von HA3e nachweisbar war, bildete RII2 deutlich größere Mengen an $\mathrm{HCN}$ nach einer Kultivierung von $24 \mathrm{~h}$ in TSB. Nach einer Kultivierung von $48 \mathrm{~h}$ wurde auch in Strohextrakt, einem nährstoffarmen Medium, die Produktion von HCN durch R2II ersichtlich. 


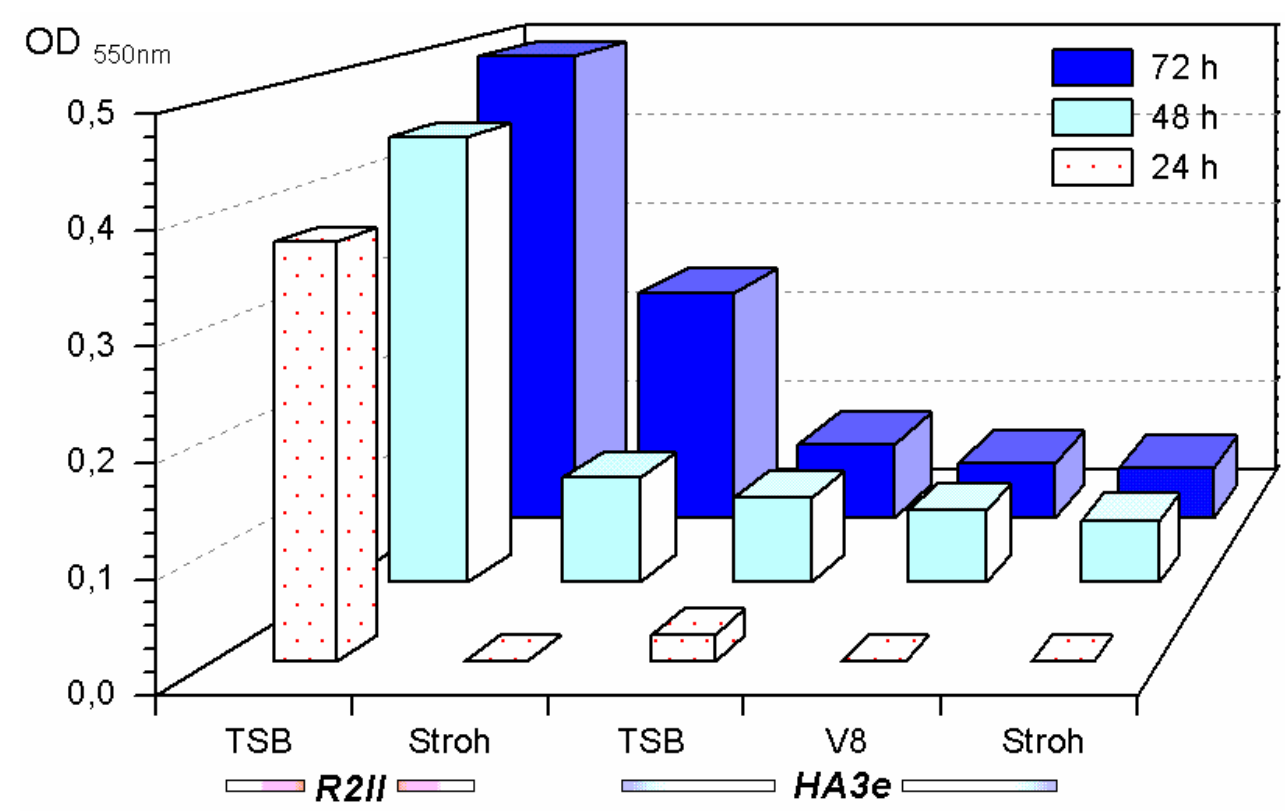

Abb. 30: HCN-Bildung durch Ps. fluorescens RII2 und Paenibacillus polymyxa HA3e auf unterschiedlichen Nährmedien

\subsubsection{Bildung von Indolessigsäure (IAA) bzw. IAA-Derivaten durch Ps. fluorescens RII2 und Paenibacillus polymyxa HA3e}

Phytohormone sind verantwortlich für die Regulation des Pflanzenwachstums. Zahlreichen Autoren berichten von einer Bildung von Phytohormonen, u.a. von IAA, durch Rhizosphärebakterien und deren direkte bzw. indirekte Wirkung auf das Pflanzenwachstum. SCHULZ et al. (1996) konnten überdies eine direkte Hemmung des Myzelwachstums von Pythium ultimum durch IAA nachweisen.

In Anlehnung an Plet \& CHOLLet (1970) wurde die Bildung von IAA bzw. IAA-Derivaten durch Paenibacillus polymyxa HA3e und Ps. fluorescens RII2 quantifiziert. Die IAA und deren Derivate reicherten sich mit zunehmender Kultivierungsdauer in TSB stets an. Im Vergleich zu RII2 produzierte HA3e die Phytohormone in deutlich geringerem Ausmaß (Abb. 31). Eine Hemmung des Myzelwachstums von L. maculans im Plättchentest war jedoch selbst mit einer 1000ppm konzentrierten IAA-Lösung nicht zu erreichen. 


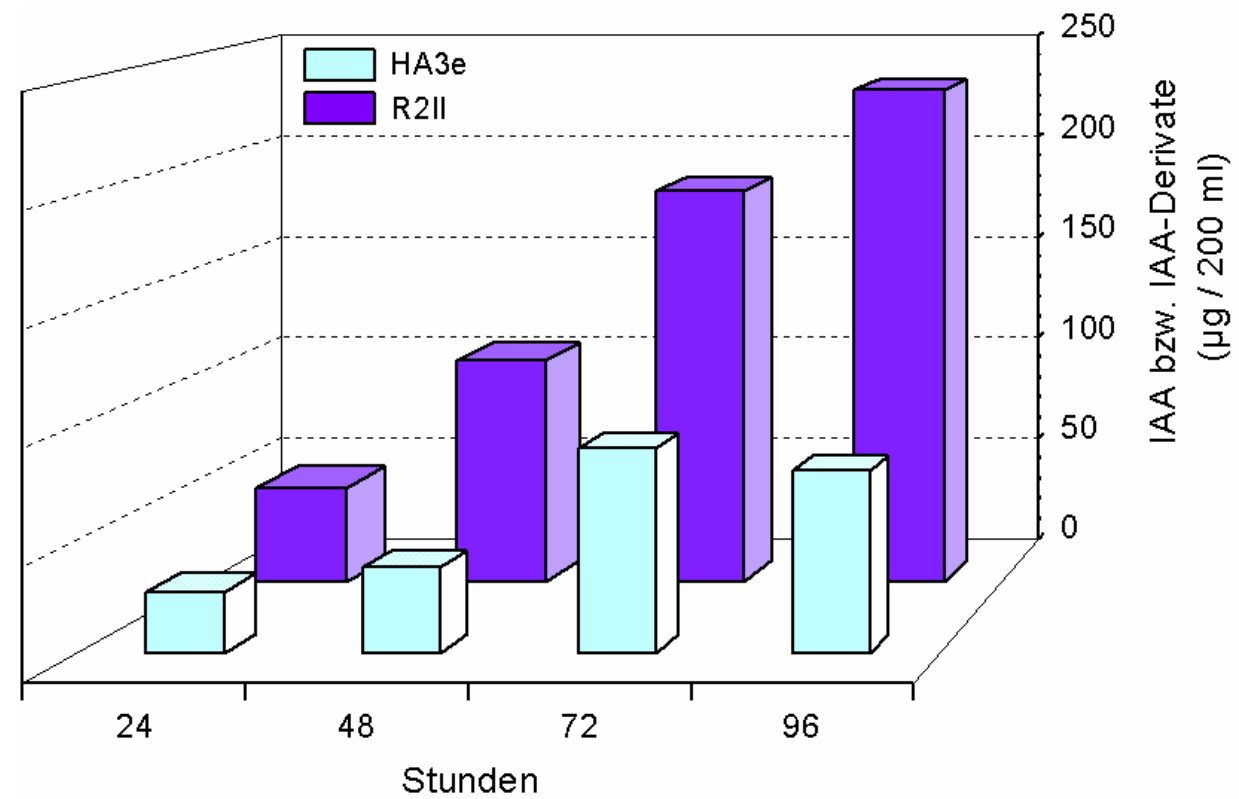

Abb. 31: Bildung von IAA bzw. IAA-Derivaten durch Ps. fluorescens RII2 und Paenibacillus polymyxa HA3e in TSB

\subsubsection{Fungizide Wirkung von Pyrrolnitrin auf das Wachstum von L. maculans}

Neben Pyoluteorin und Pyocyanin gehören 2.4-Diacetylphloroglucinol (DAPG) und Pyrrolnitrin zu den wichtigsten von Pseudomonaden gebildeten Antimykotika, die an der Hemmung bodenbürtiger Phytopathogene maßgeblich beteiligt sein können (DÉFAGO 1993, HILL et al. 1994, RAAIJMAKERS \& WELLER 1998). In der vorliegenden Arbeit wurde die Wirkung von DAPG und Pyrrolnitrin gegen L. maculans im Plättchentest untersucht. Während eine 1000 ppm konzentrierte methanolische DAPG-Lösung keine Hemmung des Wachstum von L. maculans verursachte, unterdrückte Pyrrolnitrin das Myzelwachstum von L. maculans bereits ab Konzentrationen von 2 ppm (Abb. 32).

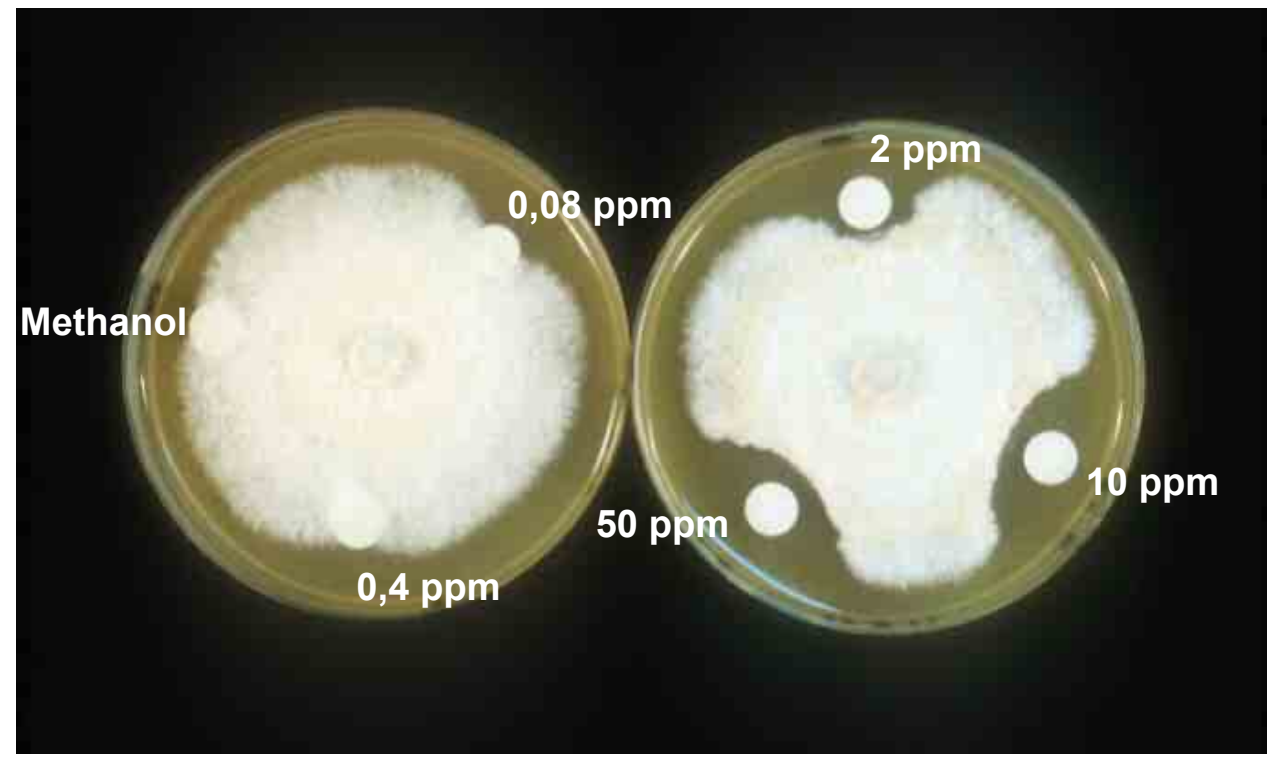

Abb. 32: Hemmung des Wachstums von L. maculans durch Pyrrolnitrin (50 $\mu \mathrm{l} /$ Plättchen). 


\subsubsection{Nachweis der Bildung von DAPG und Pyrrolnitrin durch Ps. fluorescens RII2 und Gö2I in TSB durch DC und HPLC}

Um die Bildung von Pyrrolnitrin bzw. DAPG im Kulturüberstand von Ps. fluorescens RII2 und Gö2l nachzuweisen, wurden die Überstände der Isolate nach $72 \mathrm{~h}$ und $96 \mathrm{~h}$ Wachstum in TSB mit Methanol extrahiert. Die Extrakte wurden zuerst durch Dünnschichtchromatographie aufgetrennt. Allerdings konnten hierbei nur erste Anhaltspunkte für eine Bildung der Substanzen, wie in der Abbildung 33 zu sehen, gewonnen werden. Da die Dünnschichtchromatographie zu wenig spezifisch und empfindlich ist, wurde die Bildung von DAPG und Pyrrolnitrin durch Ps. fluorescens RII2 und Gö2l auch mit Hilfe der HPLC überprüft. Die Chromatogramme zeigten eine große Übereinstimmung in den Retentionswerten mit den Referenzen DAPG und Pyrrolnitrin, so dass daraus geschlossen wurde, das beide Antibiotika von den Pseudomonaden gebildet wurden, wobei das Isolat Gö2l größere Menge an Pyrrolnitrin produzierte als das Isolat RII2 (Abb. 34 und 35).

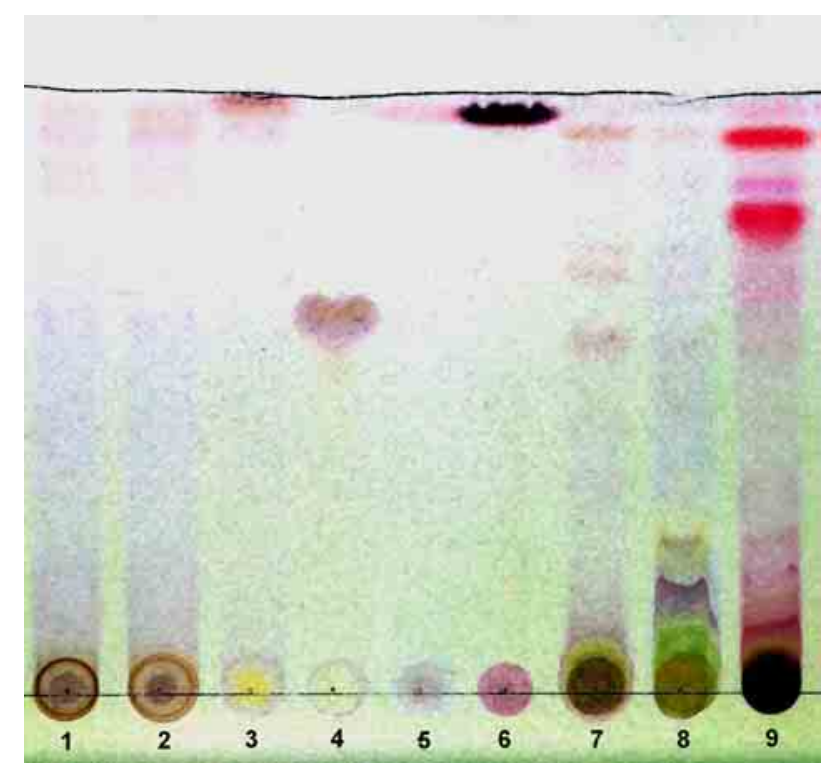

Abb. 33: Dünnschichtchromatographische Auftrennung der Kulturfiltrate von $P s$. fluorescens RII2 und Gö2l (Anfärbung mit Ehrlich-Reagenz).

1 bis 3: methanolische Extrakte aus Kulturfiltraten von Gö2I,

4 bis 6: Referenzen IAA, DAPG, Pyrrolnitrin,

7 bis 9: methanolische Extrakte aus Kulturfiltraten von RII2. 
a)

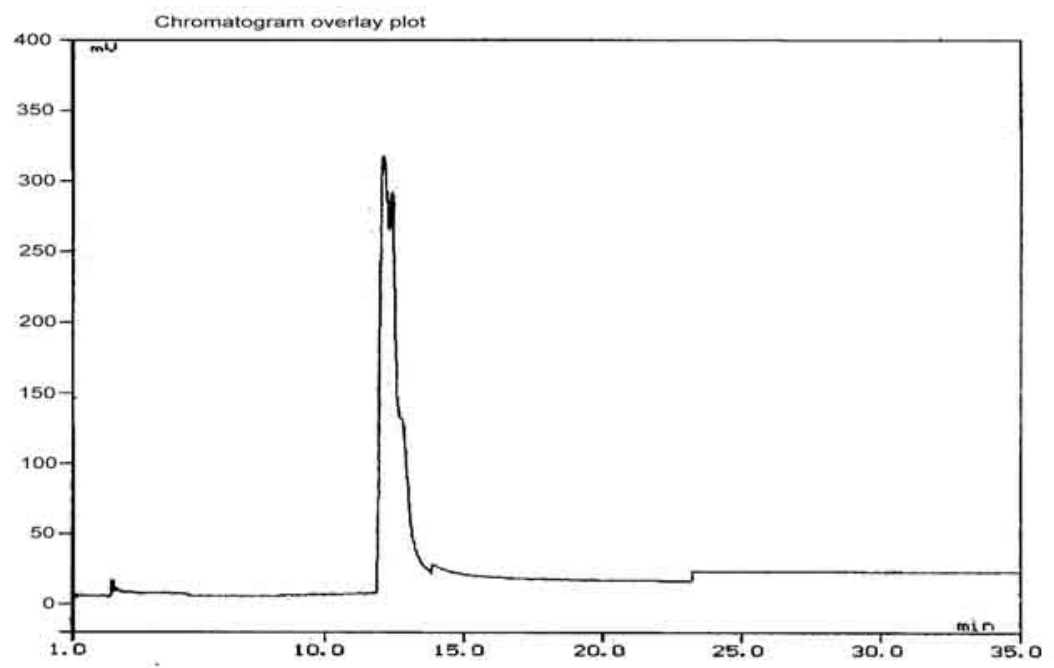

b)

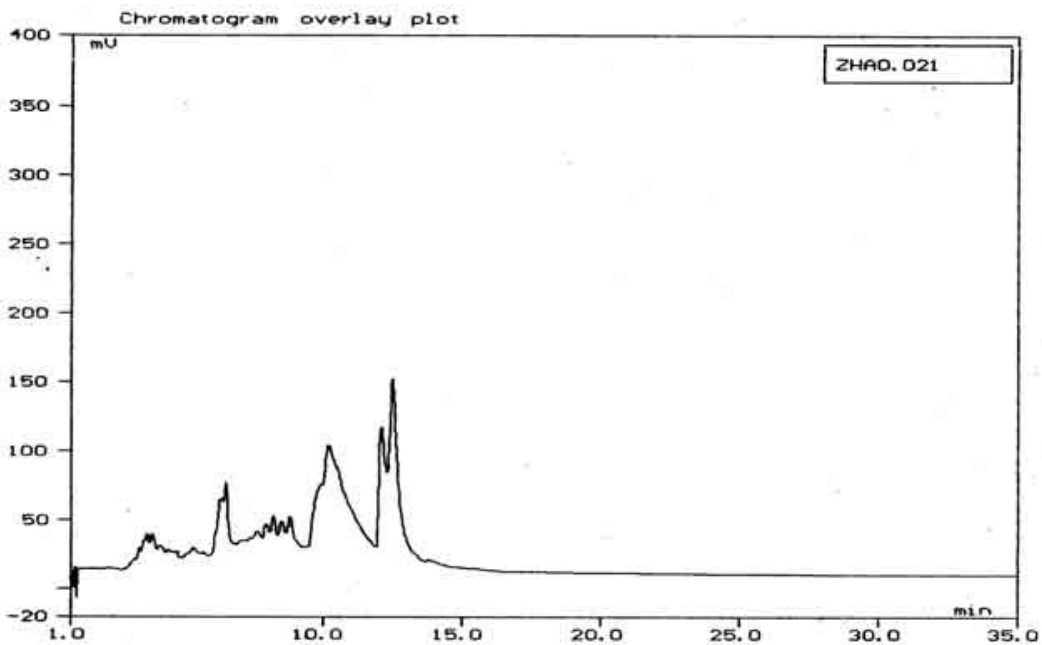

c)

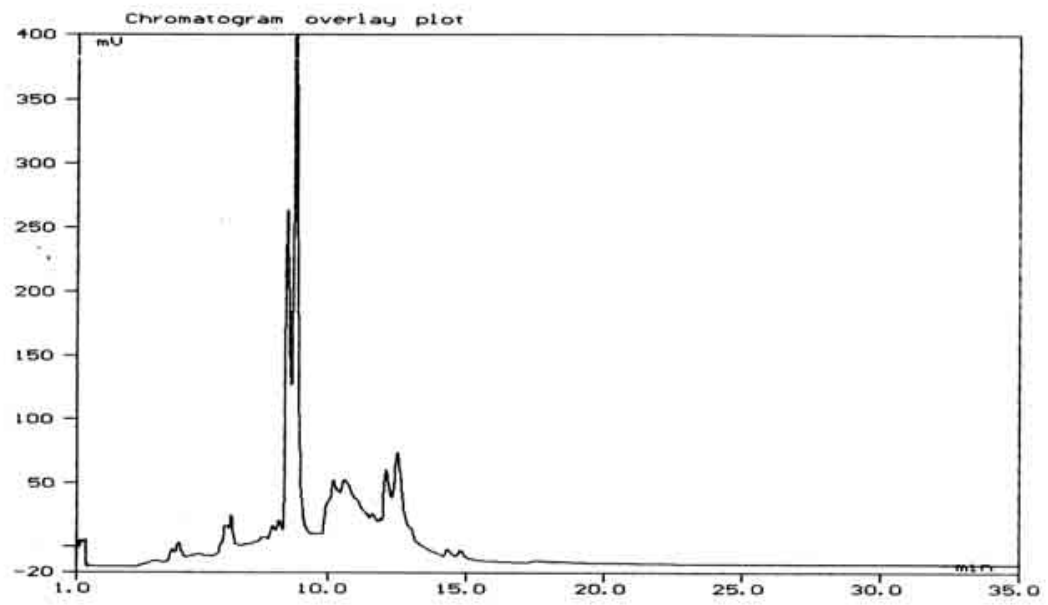

Abb. 34: Nachweis von DAPG in Kulturfiltraten von Ps. fluorescens RII2 bzw. Gö2l anhand der HPLC.

a) Chromatographie der DAPG-Referenz (Retentionszeit: 11,85 min.).

b) Chromatographie des methanolischen Extraktes des Kulturfiltrats von RII2 ( $R t=11,87$ min.)

c) Chromatographie des methanolischen Extraktes des Kulturfiltrats von Gö2l ( $R \mathrm{t}=11,89 \mathrm{~min}$ ) 
a)

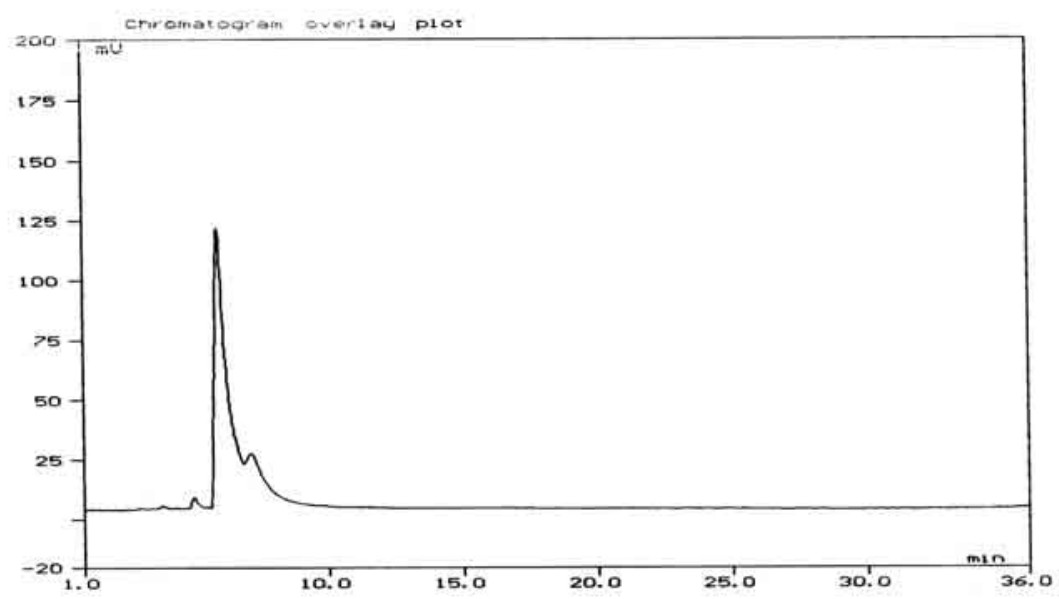

b)

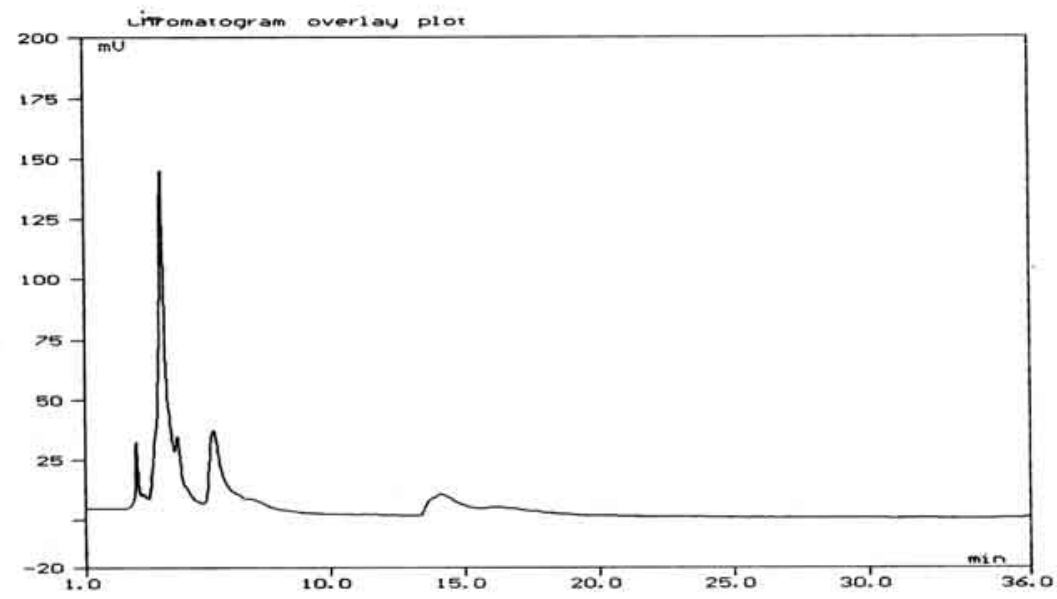

c)

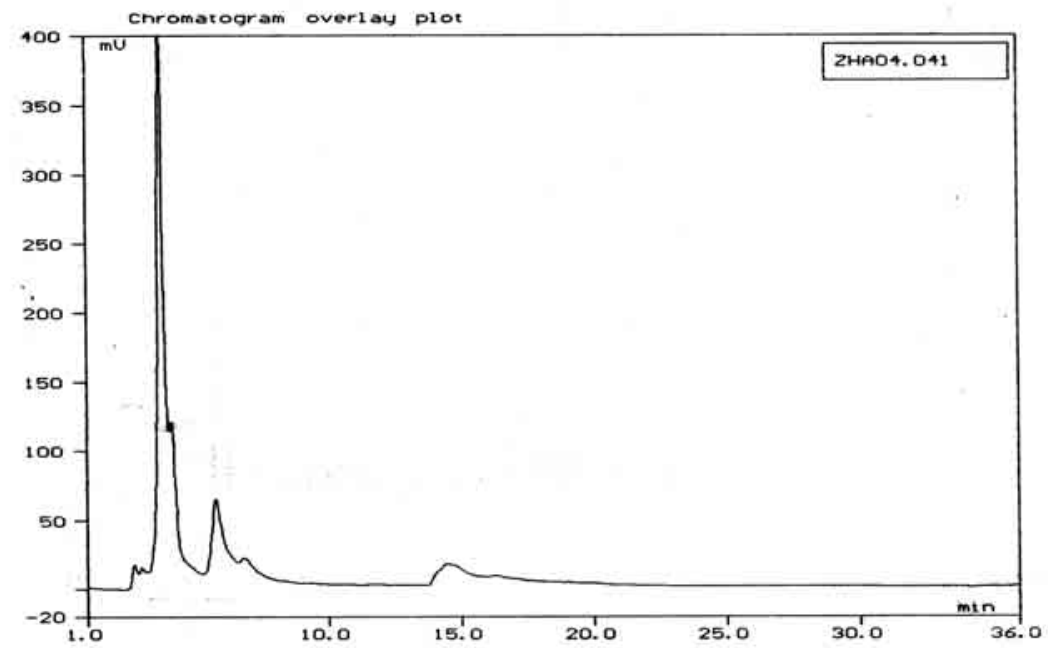

Abb. 35: Nachweis von Pyrrolnitrin in Kulturfiltraten von Ps. fluorescens RII2 bzw. Gö2l anhand HPLC.

a) Chromatographie der Pyrrolnitrin-Referenz (Retention, 5,51 min.)

b) Chromatographie des methanolischen Extraktes des Kulturfiltrats von $\mathrm{RII2}(\mathrm{Rt}=5,39 \mathrm{~min}$.)

c) Chromatographie des methanolischen Extraktes des Kulturfiltrats von Gö2l (Rt $=5,36$ min.) 


\subsubsection{Quantitativer Nachweis extrazellulärer Hydrolasen von Ps. fluorescens RII2 und Paenibacillus polymyxa HA3e}

Auf Bodenextraktagar wurde ein qualitativer Enzymnachweis für die Antagonisten bereits durchgeführt (vgl. 3.2.4). Allerdings sollte zur genaueren Beurteilung der potentiellen Hemmmechanismen die Enzymproduktion der ad planta wirksamsten Antagonisten Ps. fluorescens RII2 und Paenibacillus polymyxa HA3e genauer quantifiziert werden.

a)

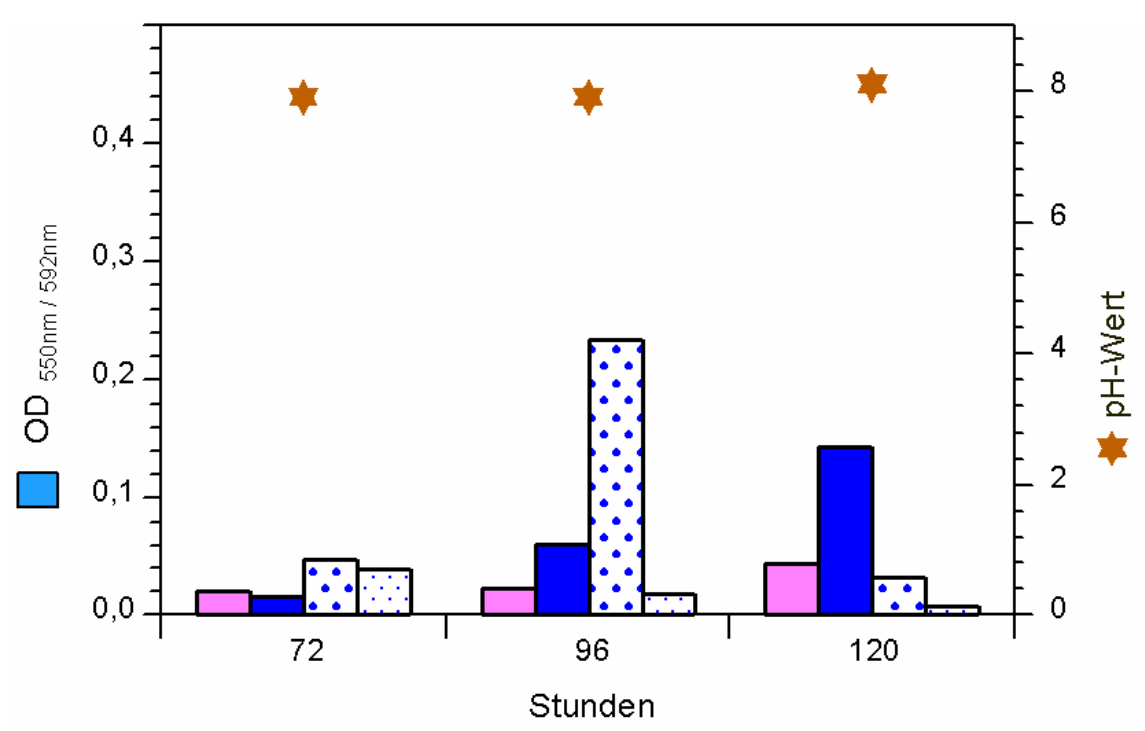

b)

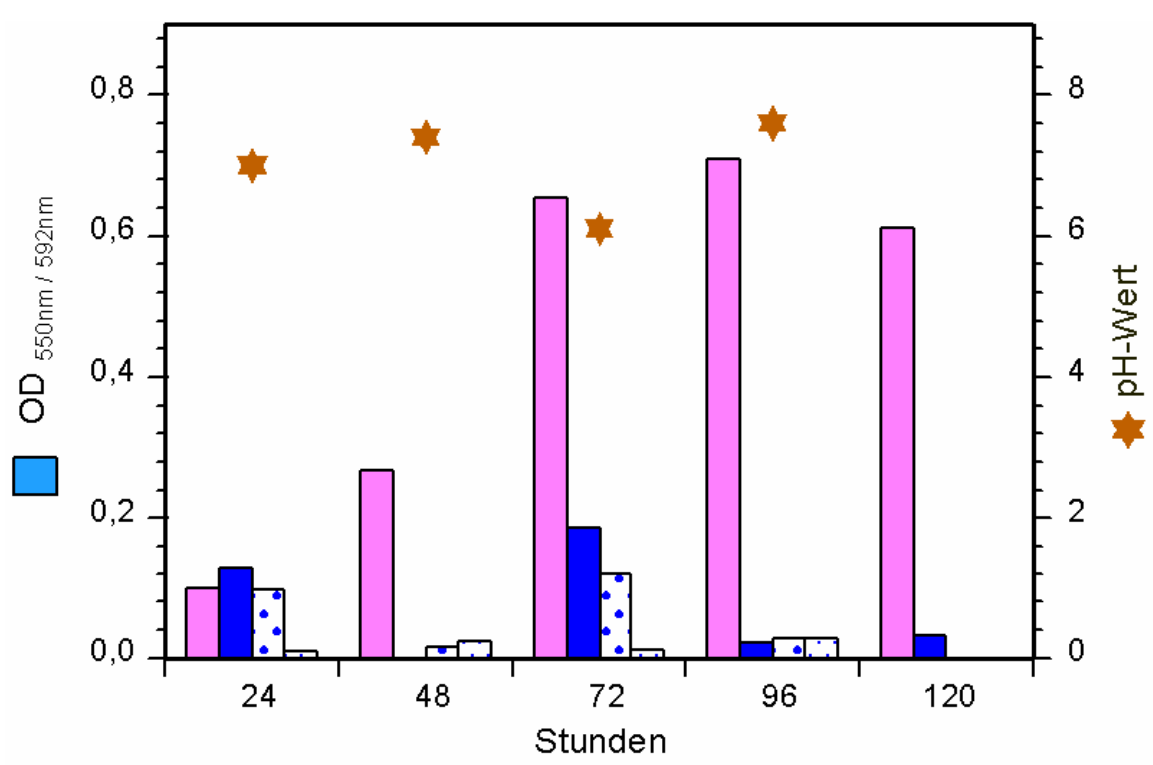

Chitinase $E_{550} \square$ 1,3-ß-Glucanase $E_{592} \quad \because \because 3$ Xylanase $E_{592} \quad \cdots$ Cellulase $E_{592}$

Abb. 36: Bildung extrazellulärer Hydrolasen durch Ps. fluorescens RII2 in unterschiedlichen Nährmedien in Rapsstrohextrakt (oben) und in TSB Medium (unten). 
Die Abbildung 36 a und b zeigen, dass in SE-Medium deutlich weniger Chitinasenaktivität gefunden wurde, als nach Wachstum der Antagonisten in TSB. Die Bildung von Chitinasen durch Ps. fluorescens RII2 hängt folglich von Nährmedien ab, was im Fall von TSB aber wohl hauptsächlich auf das gute Wachstum in dem Nährmedium zurückzuführen ist (vgl. Abb. 29).

Weder in Strohextrakt noch in TSB wurden für Paenibacillus polymyxa HA3e hohe Chitinasen- bzw. B-1,3-Glucanasenaktivitäten nachgewiesen (Abb. 37). Mit Ausnahme der Chitinasenaktivität wurden aber für $\mathrm{HA3e}$ tendenziell höhere Enzymaktivitäten als für RII2 gemessen.

a)

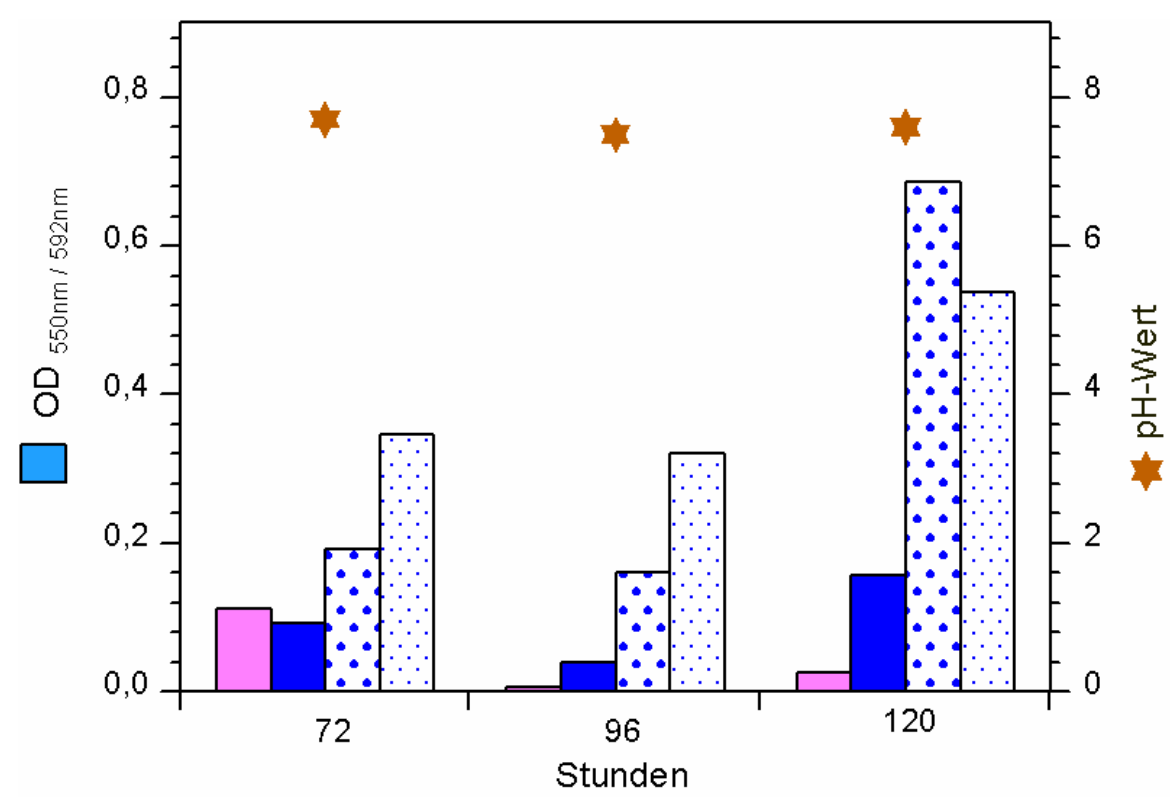

b)

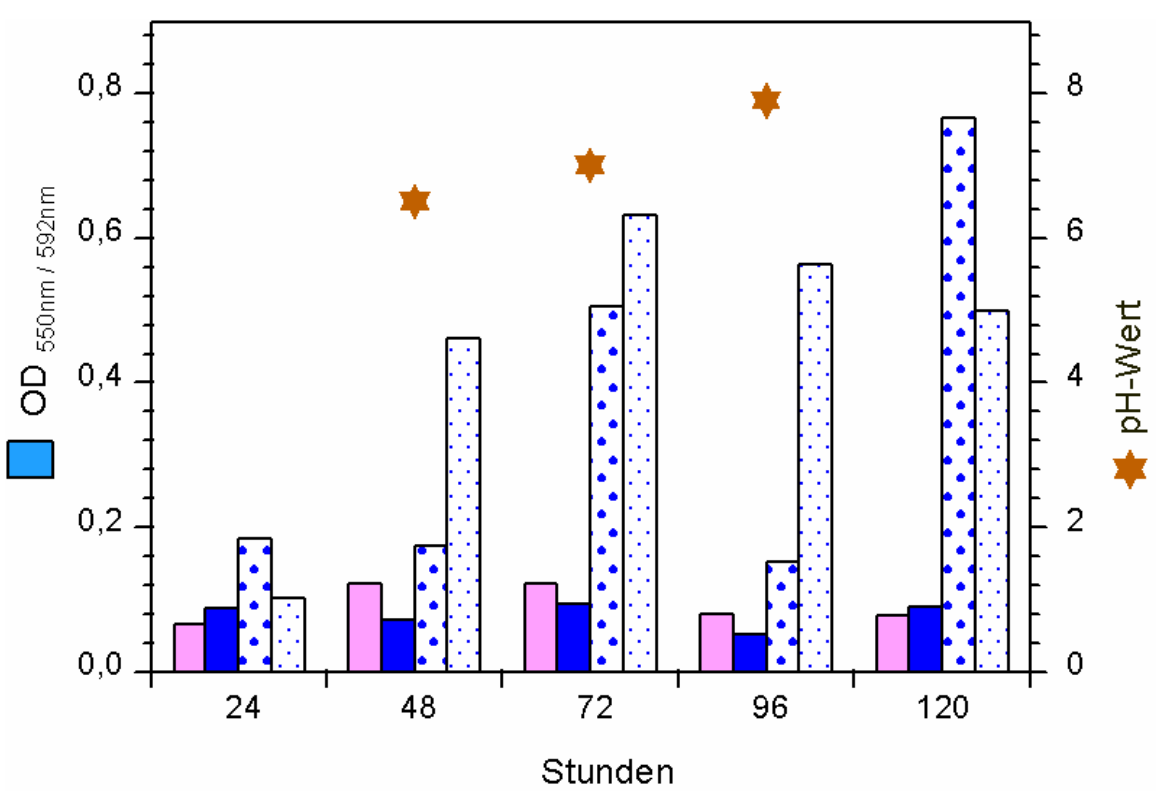

Chitinase $E_{550} \square$ 1,3-ß-Glucanase $E_{592} \quad \because \because$ Xylanase $E_{592} \quad \longrightarrow$ Cellulase $E_{592}$

Abb. 37: Bildung extrazellulärer Hydrolasen durch Paenibacillus polymyxa HA3e in unterschiedlichen Nährmedien in Rapsstrohextrakt (SE; oben) und in TSB Medium (unten). 


\subsection{Untersuchungen zur Besiedlung von Rapspflanze durch Pseudomonas fluorescens Rll2 bzw. Paenibacillus polymxa HA3e}

Die Cryo-Rasterelelektronenmikroskopie, in der Auflösungskraft zwischen der Lichtmikroskopie und der Transmissionselektronmikroskopie (TEM) angesiedelt, ermöglicht eine exakte Lokalisierung von Mikroorganismen auf der Pflanzenoberfläche (CAMPBELL \& ROVIRA 1973, RovIRA \& CAMPBELL 1975). Der Vorteil dieser Methode liegt auch darin, dass aufgrund der einfachen und schonenden Probenaufarbeitung Präparationsartefakte fast ausgeschlossen sind. Zellen die vollturgeszent und intakt erscheinen, wurden mit hoher Wahrscheinlichkeit im lebenden Zustand aufgearbeitet. Mit dieser Technik kann man daher auch das Überleben der Antagonisten am Rapsstängel und Wurzelhals nachweisen.

Durch die elektronenmikroskopischen Untersuchungen sollte vornehmlich geklärt werden, ob und inwieweit die Rapspflanzen im Normalfall durch die sogenannten Phylloplane- bzw. endophytischen Mikroorganismen besiedelt werden. Weiterhin sollten Informationen über die Struktur der Belegung mit den Antagonisten auf den behandelten Rapswurzelhals und Stängel, und über deren Besiedlung durch Paenibacillus polymxa HA3e und Ps. fluorescens RII2, gewonnen werden.

Auf der Oberfläche der Rapsblätter sind lediglich kantige Wachsstückchen zu sehen (Abb. 38 und 39). Weder im Inneren des Rapsstängels bzw. Wurzelhalses (Abb. 40) noch um die Spaltöffnungen bzw. auf Teilen des Laubblattes (Abb. 38 und 39) sind Mikroorganismen zu erkennen. Eine Besiedlung der Rapspflanze durch Endophyten bzw. Phylloplanebakterien ist daher nahezu auszuschließen. Allerdings zeigt die Abbildung 41, dass die Oberfläche des Wurzelhalses durch einige Bodenbakterien besiedelt wurde, die als einzelne kürzere Stäbchen zwischen den Bodenpartikeln zu erkennen sind.

Die Zellen von Paenibacillus polymxa HA3e präsentierten sich als Stäbchen in dem Xanthanfilm und aggregierten überwiegend in den Senken zwischen den Epidermiszellen des Stängels, von denen einige aufgrund ihrer flacheren Form wohl bereits ausgetrocknet waren (Abb. 42). Für eine detaillierte Betrachtung wurden repräsentative Bereiche (Abb. 43) der Abbildung ausgewählt. Zahlreiche Endosporen sind in der Abbildung 43a deutlich zu erkennen. In der Abbildung 39b liegen kleinere Bakterien zwischen den größeren Stäbchen dicht nebeneinander - offensichtlich eine Mikrokolonie von HA3e.

In der Abbildung 44 ist der von Pseudomonaszellen und Xanthan gebildete Film auf dem Wurzelhals- bzw. der Stängeloberfläche zu sehen. Während die Pseudomonaden auf der Oberfläche der Wurzel in voller Turgeszenz erscheinen (Abb. 45), sind die Bakterien auf dem oberirdischem Stängel flach, scheinen ausgetrocknet zu sein und sind im Xanthan-Film eingesunken (Abb. 46). 


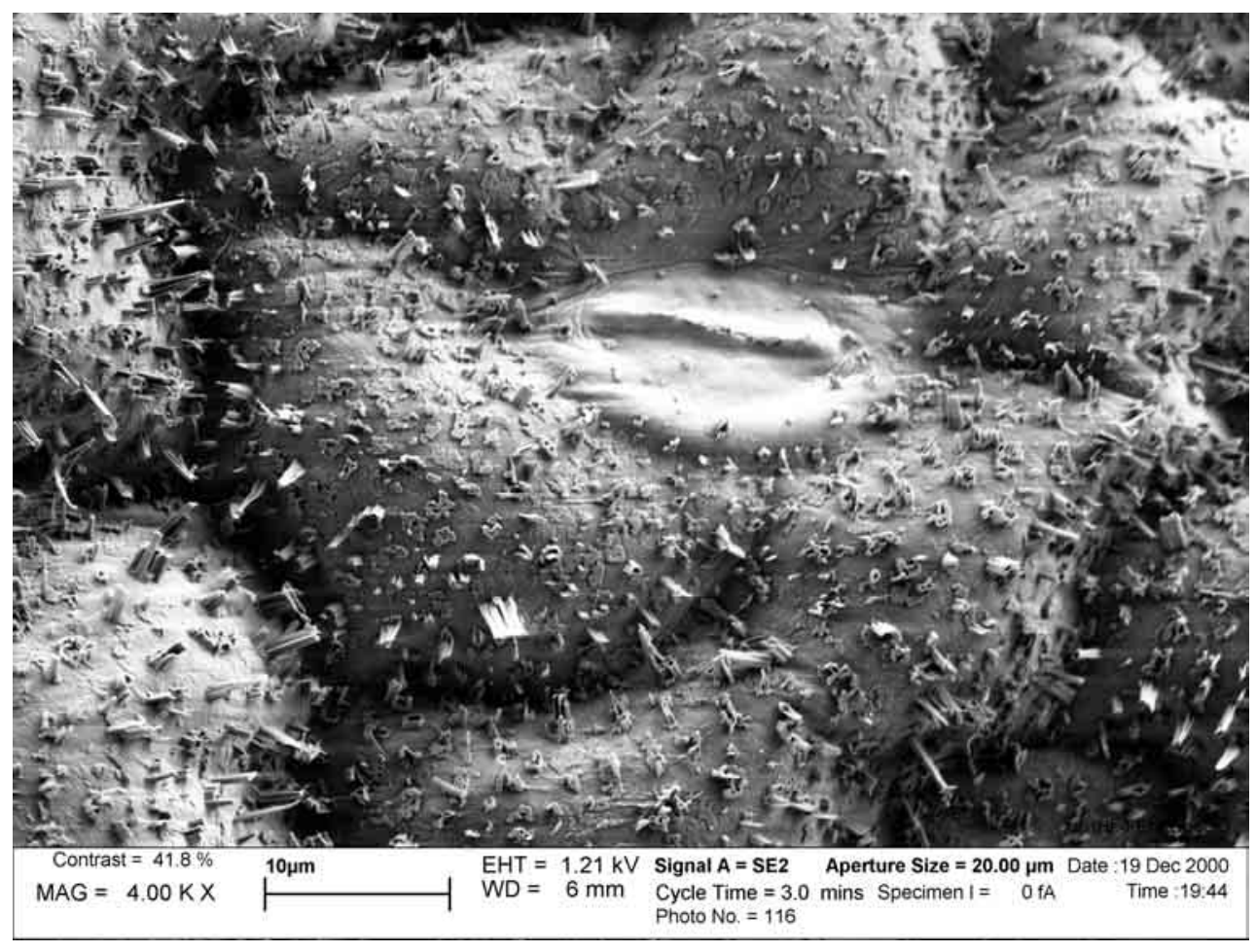

Abb. 38: Unbehandeltes Rapsblatt mit Stomata in geschlossenem Zustand; Epidermiszellen mit eckigen Blatthaaren bzw. Wachsstückchen

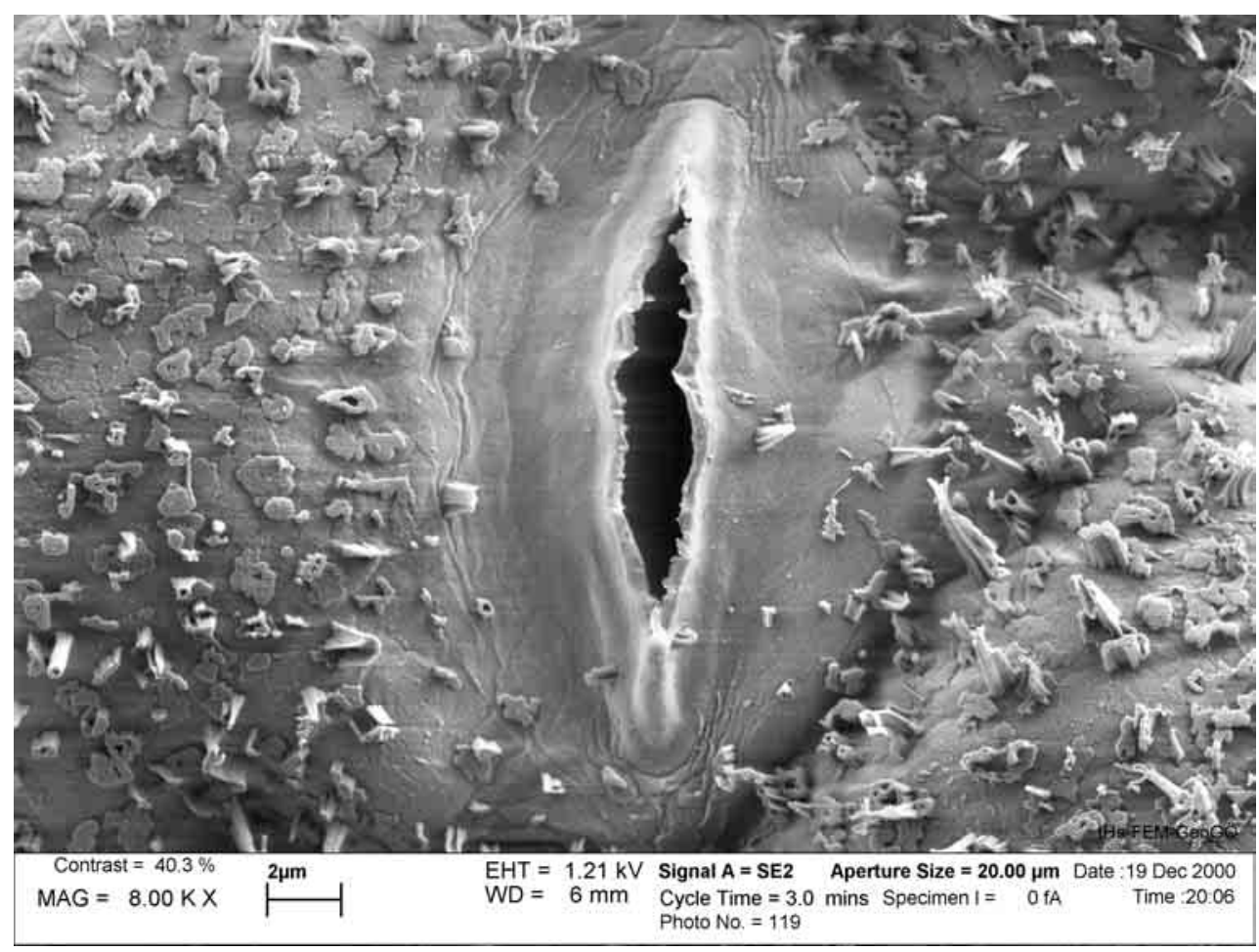

Abb. 39: Spaltöffnung in geöffnetem Zustand; eckige Blatthaare bzw. Wachsstückchen 


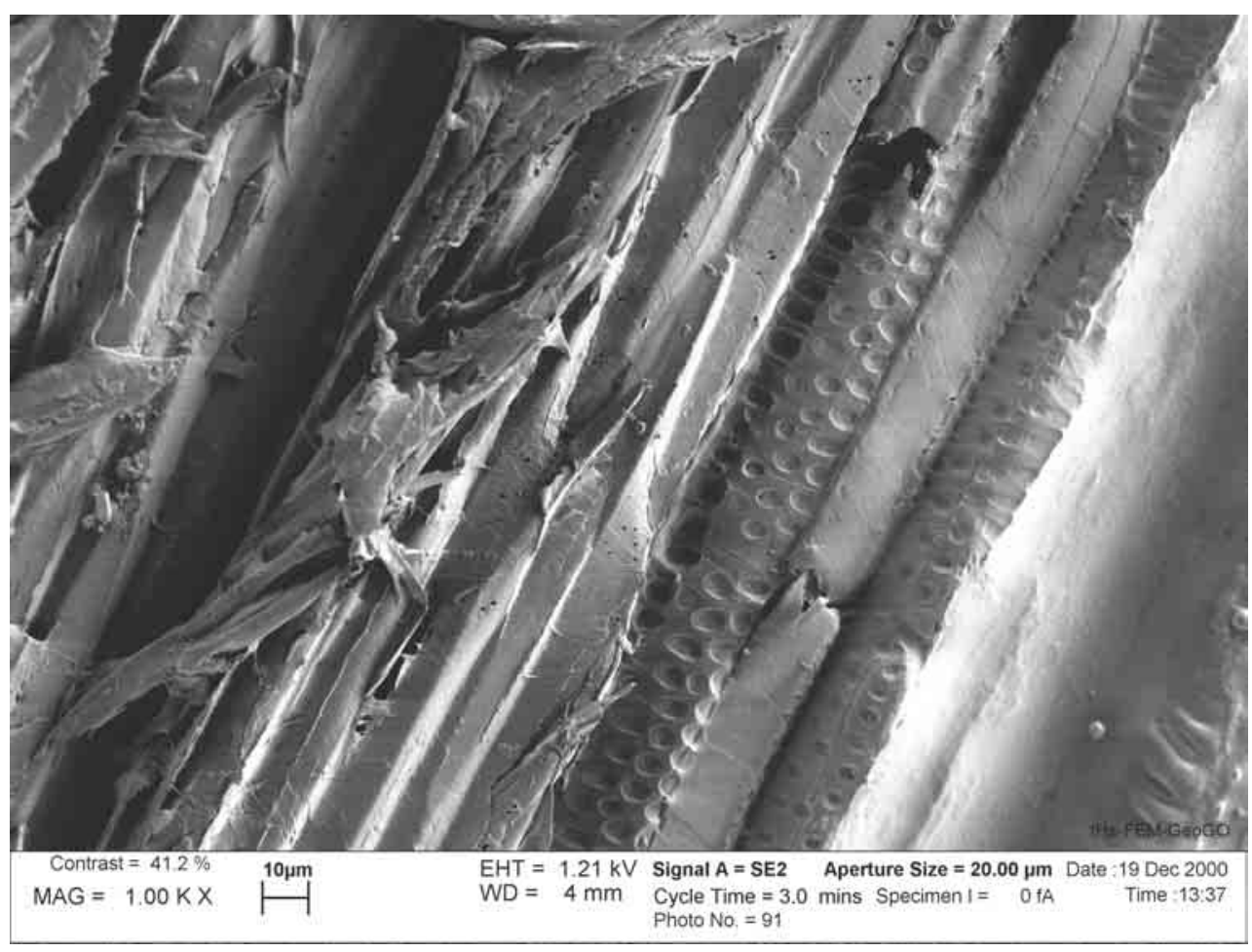

Abb.40: Innere Seite des Rapsstängels (Gefäß längs durchgeschnitten)

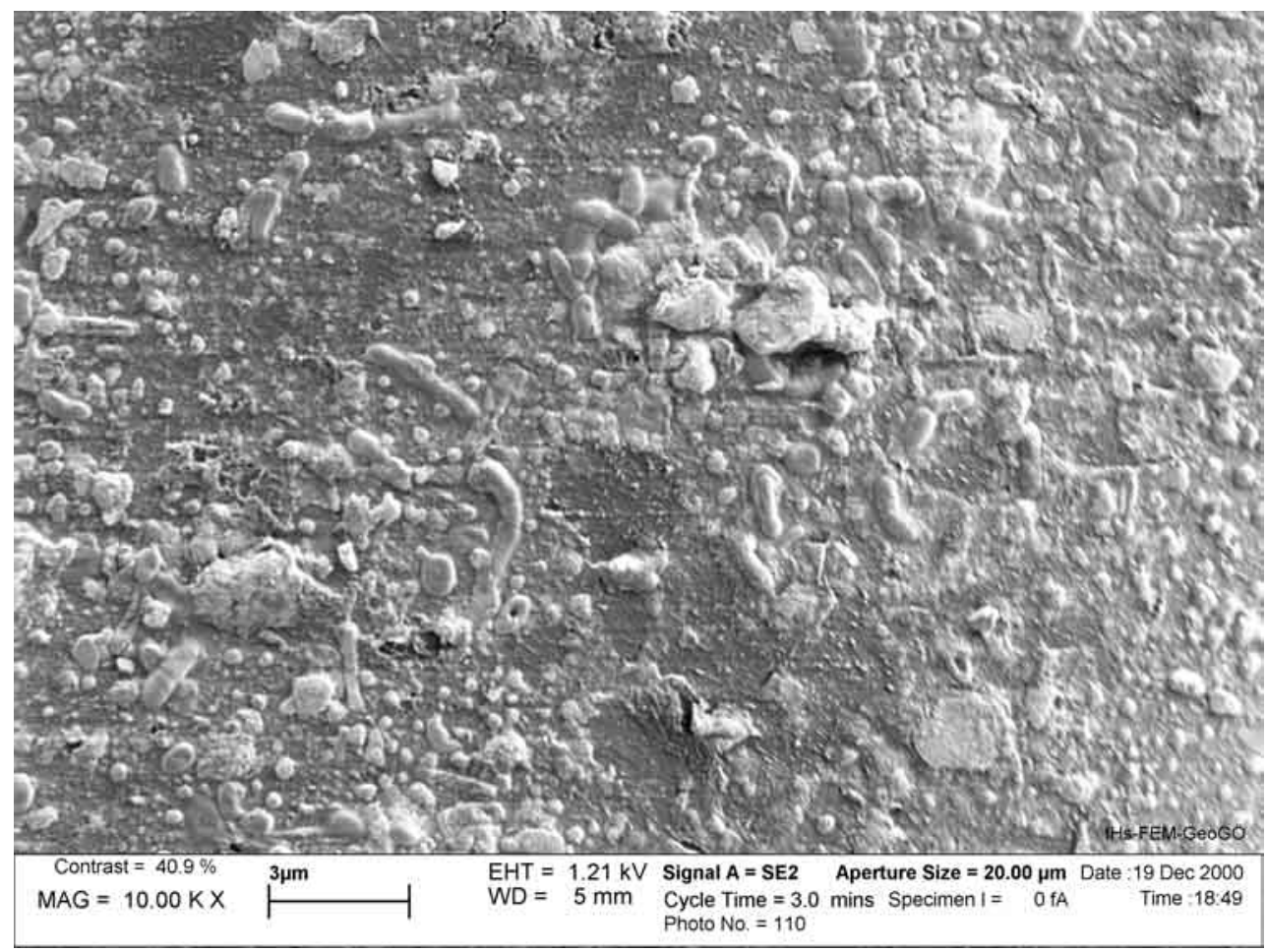

Abb. 41: Unbehandelte Wurzelhalsoberfläche; einzelne stäbchenförmige Bakterien zwischen Bodenpartikelchen erkennbar 


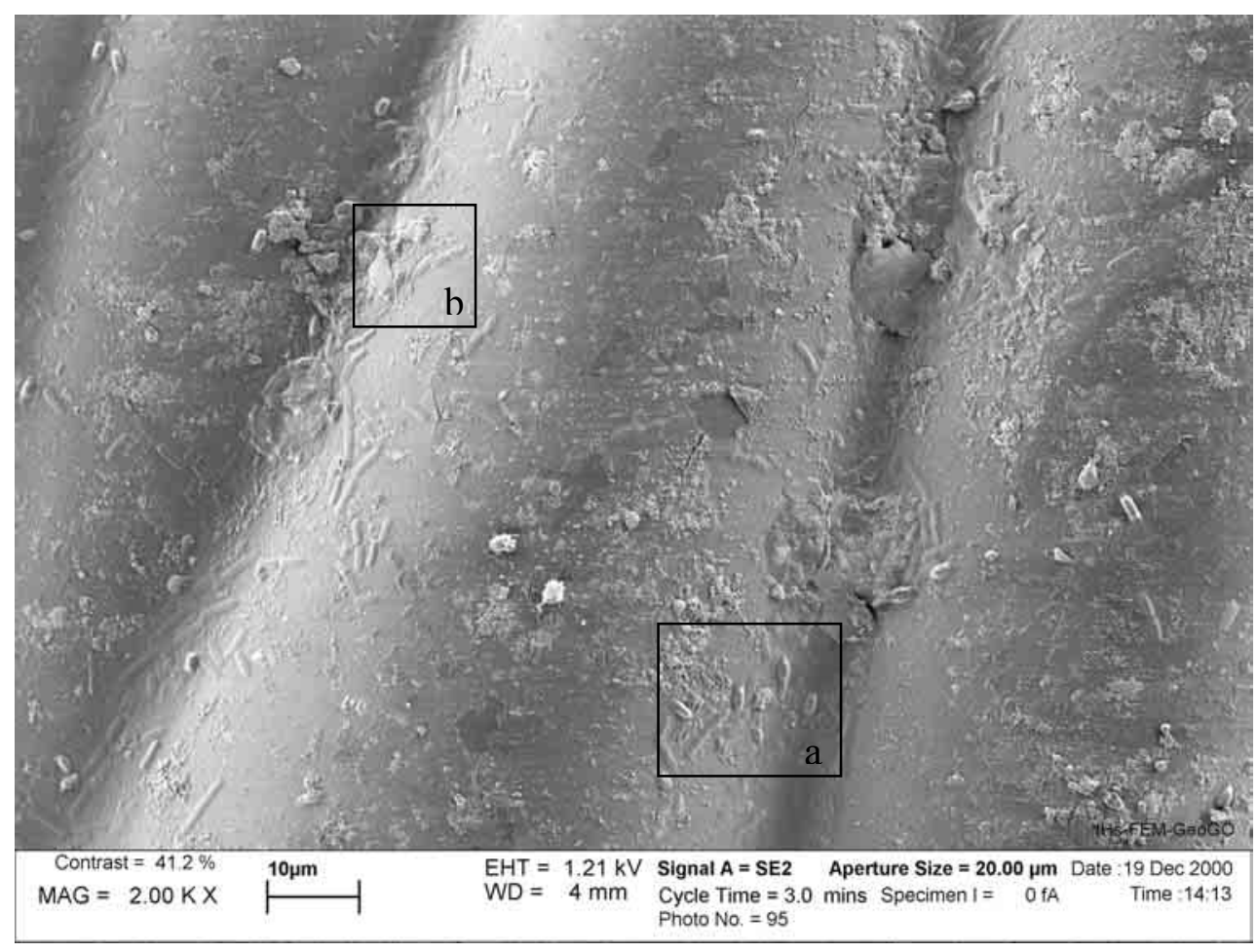

Abb. 42: Paenibacillus polymxa HA3e: Blick auf die Oberfläche des Wurzelhalses (2 dpi). Film aus $0,25 \%$ Xanthan auf der Oberfläche erkennbar; partielle Bedeckung der Oberfläche; Zellen des Antagonisten vor allem entlang der Täler zwischen den Epidermiszellen

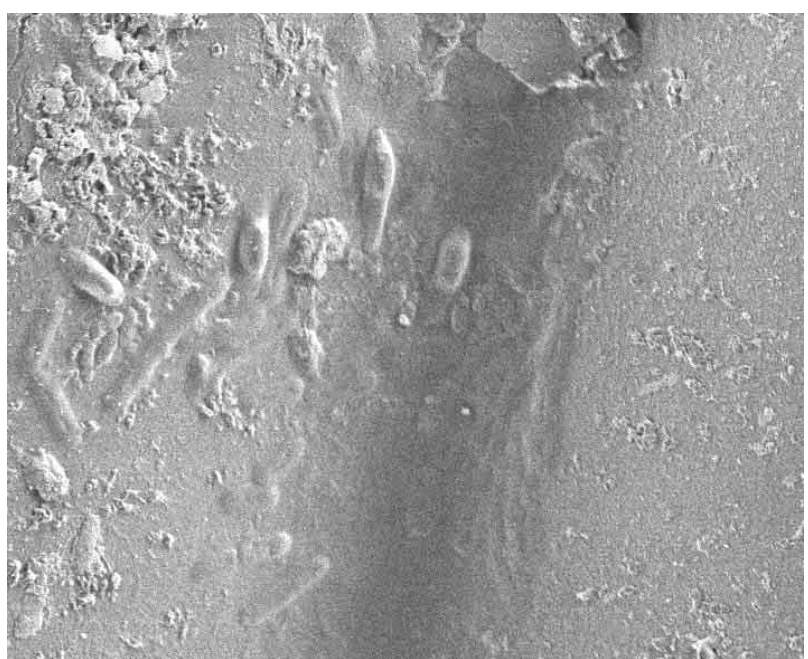

a

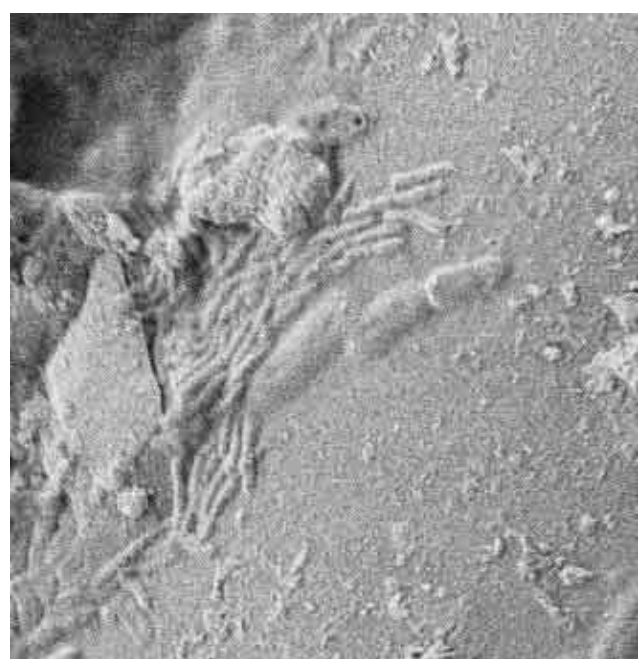

b

Abb. 43: Endosporen (a) bzw. Mikrokolonie (b) von Paenibacillus polymxa HA3e (2 dpi) Ausschnitt von Abb. 38

Die Abbildung 43 zeigt, dass die Oberfläche des Rapswurzelhalses vollständig durch Zellen von Ps. fluorescens RII2 und Paenibacillus polymxa HA3e abgedeckt wurde. Eine Differenzierung der Zellen beider Antagonisten ist allerdings anhand ihrer Größe nicht möglich, jedoch ist die Versporung einer Bacilluszelle zu erkennen. 


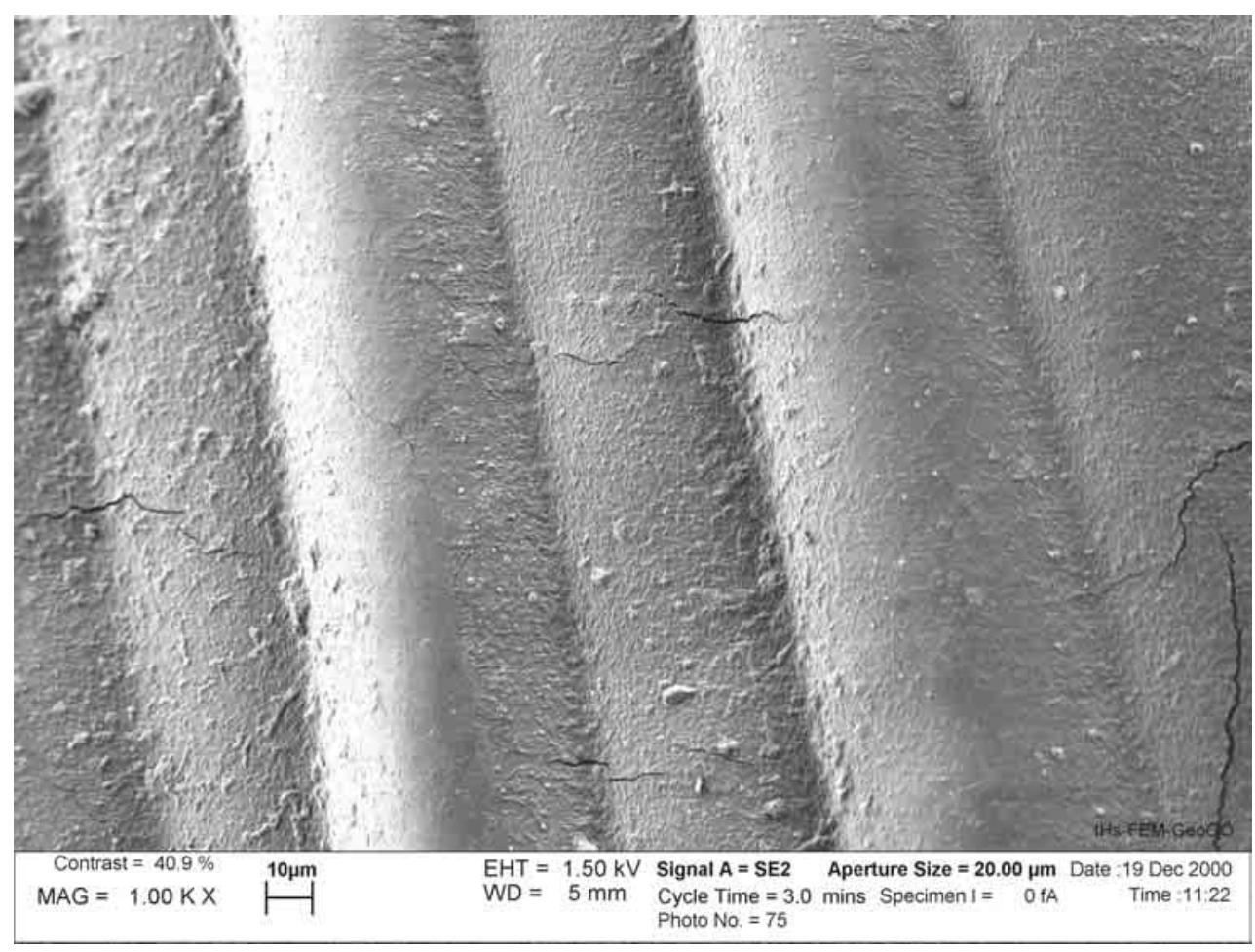

Abb. 44: Struktur des Belags auf der Oberfläche des Rapswurzelhalses nach Applikation einer Flüssigkultur des Antagonisten Ps. fluorescens RII2. Zellen in 0,25\% Xanthan formuliert; durch Abtrocknung des Films entstandene Risse erkennbar.

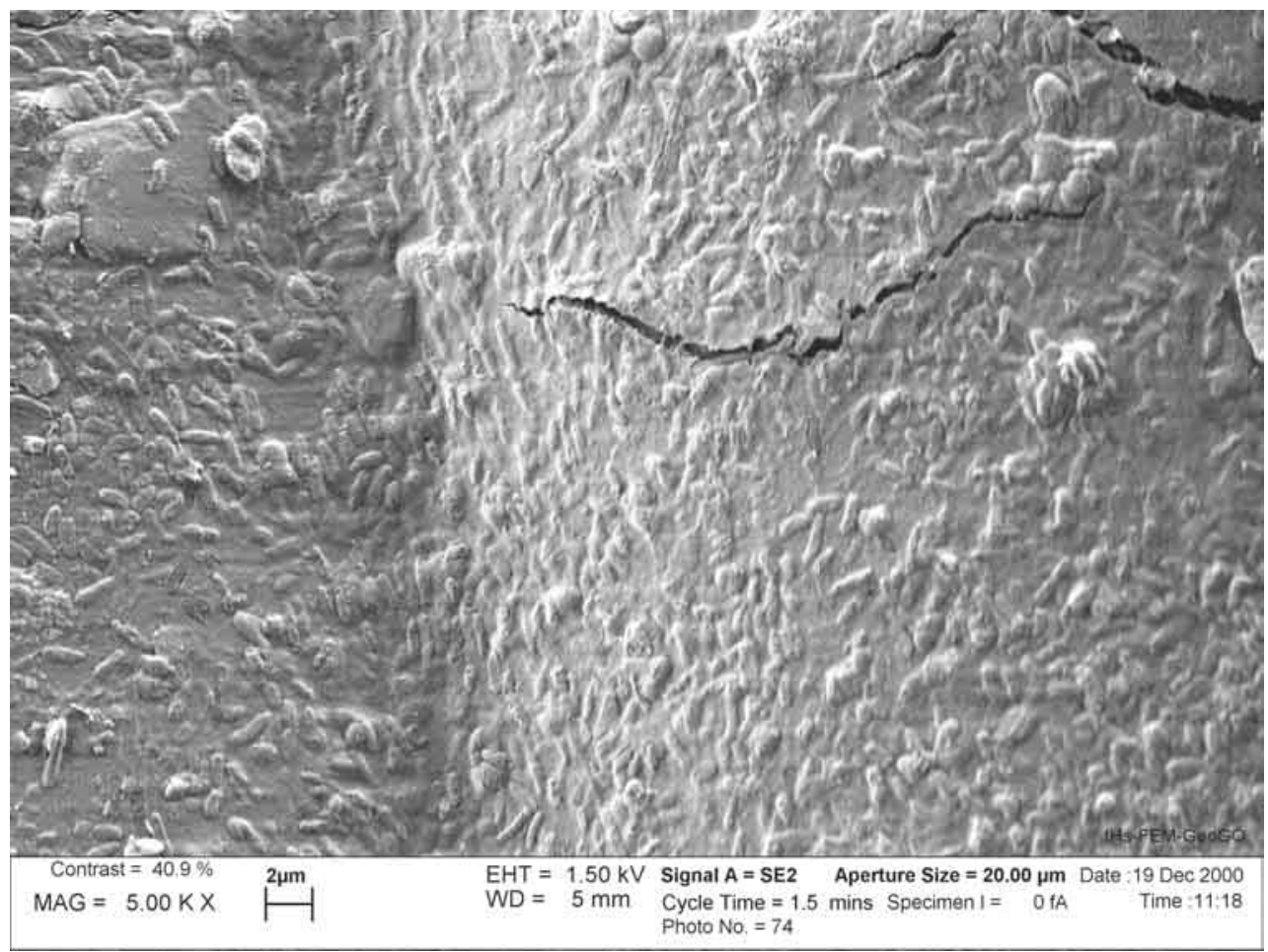

Abb. 45: Ps. fluorescens RII2 in 0,25\% Xanthan auf der Oberfläche des Rapswurzelhalses Ausschnitt von Abb. 40 


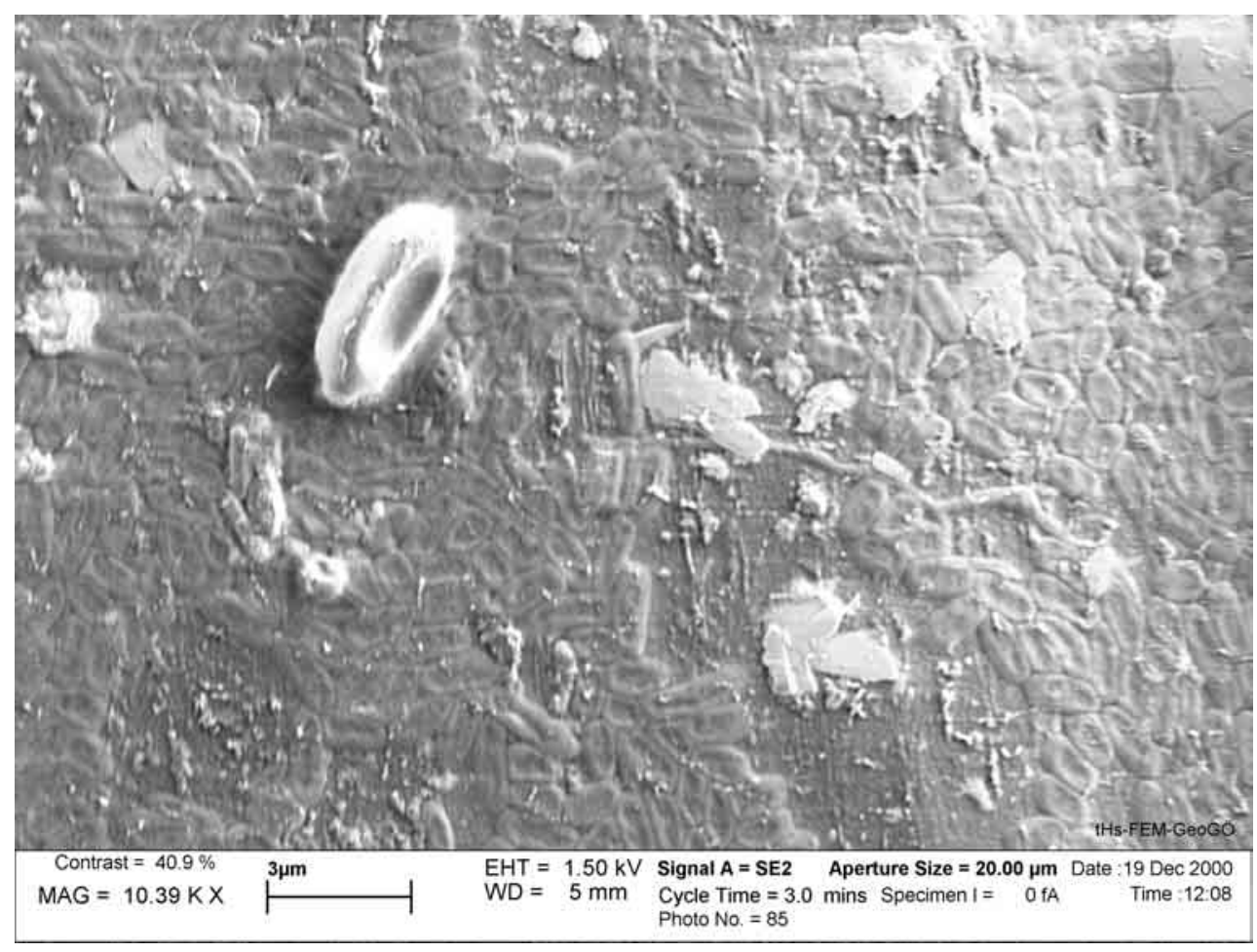

Abb. 46: Ps. fluorescens RII2 in 0,25\% Xanthan auf der Oberfläche des Rapswurzelhalses, unvollständige Bedeckung der Oberfläche

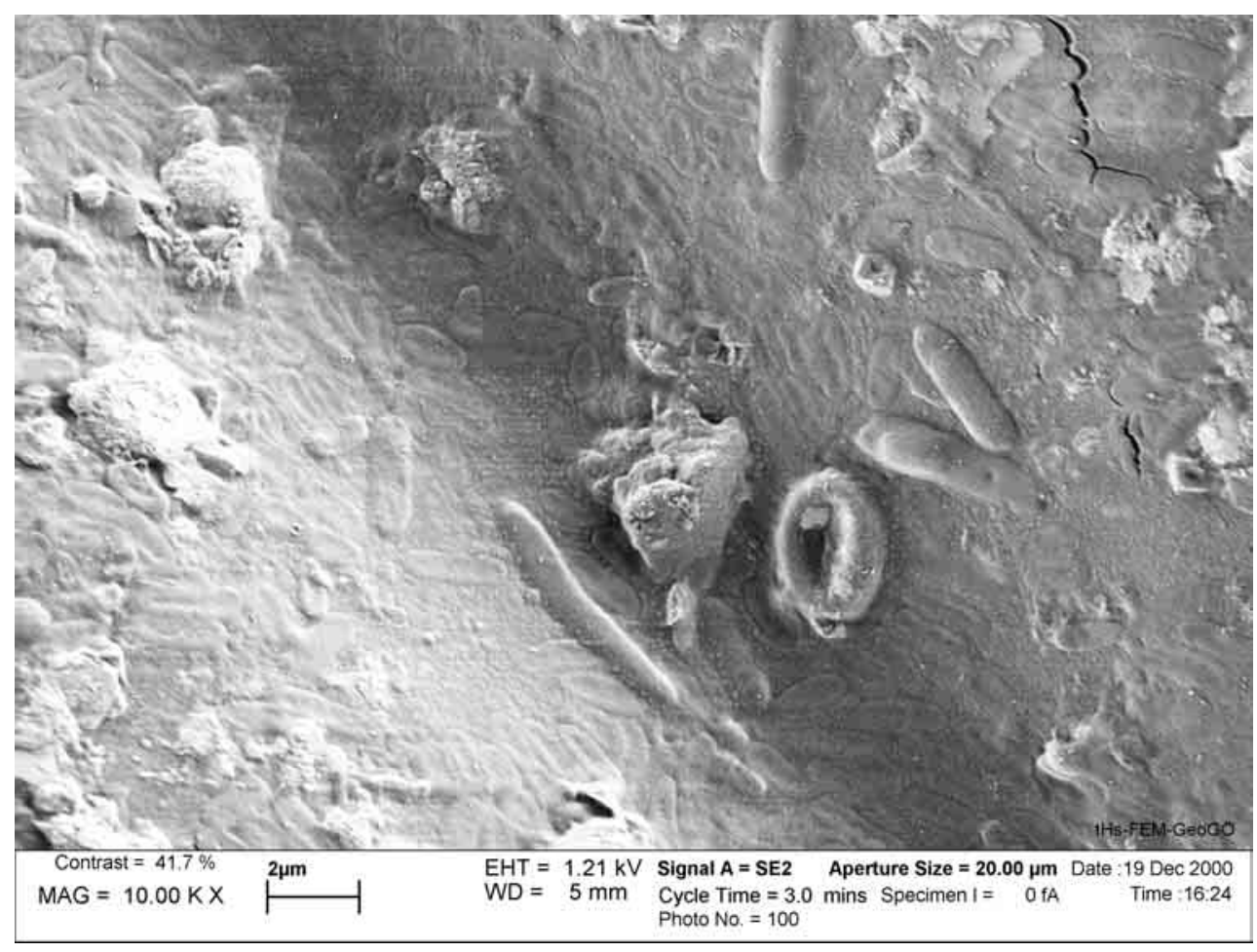

Abb. 47: Ps. fluorescens RII2 und Paenibacillus polymxa HA3e in 0,25\% Xanthan auf der Oberfläche des Rapswurzelhalses; vollständige Bedeckung der Oberfläche durch Zellen der Antagonisten; endosporenbildende Bacilluszelle erkennbar. 


\section{Diskussion}

\subsection{Isolierung von Antagonisten}

Zunehmend wurde die Meinung vertreten, dass sich mikrobielle Antagonisten gegen bodenbürtige Erreger am besten aus suppressiven Böden isolieren lassen (SCHNEIDER 1982, COOK \& BAKER 1983, RENWICK et al. 1991), nachdem der kausale Zusammenhang zwischen dem Rückgang der Schwarzbeinigkeit an Weizen nach wiederholtem Anbau und der Anreicherung antagonistischer Mikroorganismen in diesen Böden bewiesen wurde (SHIPTON 1975, CoOK \& RovIRA 1976).

Von PHILIPP (1988) wird als Suppressivität ein unter bestimmten Boden-, Klima- und Vegetationsbedingungen langfristig entstandenes antiphytopathogenes Potential mit hoher Wirksamkeit bezeichnet. Jedoch sind solche Böden sehr selten geworden, weil dieses vielfältig strukturierte System oft massiv und nachhaltig durch z. B. tiefgreifende Änderungen der Anbauverhältnisse und durch den Einsatz von chemischen Pflanzenschutzmitteln gestört wird.

Einige Autoren empfehlen, dass die Herkunft der untersuchten Antagonisten dem späteren Einsatzhabitat entsprechen sollte, um die Wahrscheinlichkeit eines erfolgreichen Einsatzes der Antagonisten zu erhöhen, insbesondere durch Verringerung des Anpassungsproblems (COOK \& BAKER 1983, KNUDSEN \& SPURR 1988, WELLER 1988 JAGNOW et al. 1991, ANDREWS 1992, COOK 1993, StABB et al. 1994). Mikroorganismen der Phylloplane sind optimal an starke klimatische Schwankungen (Temperatur, Feuchte, UV-Strahlung) und an das ständig wechselnde Nährstoffangebot auf dem Blatt angepaßt, während bodenbewohnende Organismen hier zwar überleben, sich aber nicht langfristig etablieren können (BLAKEMAN \& FOKKEMA, 1982; KNUDSEN \& SPURR, 1988; ANDREWS, 1992). So wurden zur Bekämpfung vasculärer Krankheiten vorzugsweise endophytische Isolate eingesetzt (CHEN et al. 1995, MISHAGI \& DONNDELINGER 1990, BROOKS et al. 1995), Phylloplanebakterien zur Bekämpfung von Krankheiten im Lager (FALCONI \& MENDGEN 1994, KORSTEN et al. 1995, BURR et al. 1996), aus Ackerböden gegen bodenbürtige Krankheiten (MYATT et al. 1992, BROAdBent et al, 1971, CHANG \& KOMMEDAHL 1968) und aus der Phyllosphäre gegen Blattpathogene (KEMPF \& WOLF 1989, SHARMA \& SANKARAN 1988). LIFHITZ et al. (1986) isolierten stickstofffixierende, wurzelbesiedelnde Pseudomonaden aus der kanadischen Arktis und verschafften ihnen auf diese Weise einen Wettbewerbsvorteil bei niedrigen Temperaturen. NICOLOTI \& VARESE (1996) fanden gegen holzerstörende Pilze sehr wirksame TrichodermaIsolate aus Fichtenholz. 
Bei dem bereits in der Praxis gegen Heterobasidion gigantea erfolgreich eingesetzten pilzlichen Antagonisten Peniophora gigantea (gegen Heterobasidion annosum) entsprach der Einsatzort (Kiefernstümpfe) auch dem Ursprungshabitat (GINDRAT 1978).

Jedoch gibt es mittlerweile viele Beispiele dafür, das Bodenbakterien und -pilze auch dann erfolgreich gegen verschiedenste Erreger eingesetzt werden können, wenn sie aus Herkünften stammen, die dem späteren Wirkort nicht entsprechen. So waren z. B. nur $73 \%$ der isolierten Epiphyten wirksam gegen das Blattpathogen Plasmopara viticola, jedoch $80 \%$ der aus dem Boden gewonnenen Isolate (TICHLER 1996). Als wirksamste Antagonisten zur Bekämpfung der Kraut- und Knollenfäule der Kartoffel, verursacht durch Phytophthora infestans, erwiesen sich Pseudomonas cepacia 96 bzw. 96B, ursprünglich aus dem Boden gegen den bodenbürtigen Wurzelbranderreger der Zuckerrübe Pythium ultimum isoliert, aber nicht die von Kartoffelblättern stammenden Phylloplanemikroorganismen (GOTTSCHALK 1998). Pseudomonas fluorescens Gö2l aus einem Wiesenboden, zeigte die stärkste Hemmwirkung gegenüber Verticillium longisporum an Raps (SASSE 1997). Im Falle der Eutypiose im Weinbau erwiesen sich zudem alle aus dem Einsatzhabitat gewonnenen bakteriellen Isolate, d.h. Endo- und Epiphyten des Rebholzes, im Freiland als wirkungslos (MUNKVOLD \& MARIOS 1993a). Befriedigende Ergebnisse wurden nur mit zwei Pilzen erzielt. Bei Verwendung des Bodenbakteriums Bacillus subtilis B1 konnten zumindest an Rebholzchips Wirkungsgrade bis zu 100\% erzielt werden (SCHMIDT 1997). Freilandversuche liegen hierzu leider nicht vor. Weitere Beispiele zeigten auch, dass Bodenbakterien und -pilze (u.a. Pseudomonaden, Bacilli und Actinomyceten) erfolgreich gegen Blattpathogene (LEVY et al. 1989, LEE 1991, ANDREWS 1992, JONGEBLOED et al. 1993) sowie gegen andere oberirdisch vorkommende Pathogene (MONTESINOS et al. 1996, PUSEY \& WILSON 1984, UTKHEDE \& SHOLBERG 1986, SCHMIDT 1997) eingesetzt werden konnten. TrichodermaIsolate aus dem Boden überlebten auf der Phylloplane mehr als ein Jahr (TRONSMO \& RAA 1977). In China wurden die bodenbürtigen Bacillus cereus, B. pumilus und B. firmus als ertragserhöhende Bakterien (Yield Increasing Bacteria) bezeichnet. Deren Präparate wurden von 1979 bis 1990 auf einer Ackerfläche von 26 Mio. ha mit Erfolg als Sprühmittel an oberirdischen Pflanzenteilen eingesetzt (ZHANG et al. 1996, TANG \& YANG 1997). Der Boden beinhaltet offenkundig ein bedeutsames Reservoir an Antagonisten, wie schon LEBEN (1964) bemerkte.

Bei BERG (1994) zeigten $16 \%$ der kultivierbaren Bakterien von Rapswurzeln (Brassica napus L.) eine antagonistische Wirkung gegenüber $V$. longisporum. Weiterhin stellte sie fest, daß die Dichte der Mikroorganismen und die Stärke ihrer antagonistischen Wirksamkeit in der Rhizosphäre stark variierten. NORTON \& FIRESTONE (1991) ermittelten einen wirksamen Anteil von bis zu $50 \%$ bei Kiefernsämlingen. Bei HEBBAR et al. (1992) waren 11-37\% der Gesamtbakterienflora antagonistisch wirksam. SASSE (1997) hatte daher Bodenproben aus 
der Rhizosphäre verschiedener Pflanzenarten (Raps, Gerste, Weizen, Gräsergemisch, Laubund Nadelwald sowie Wein) und aus unterschiedlichen geographischen Regionen (Niedersachsen, Schleswig-Holstein, Nordrhein-Westfalen, USA und Algerien) ausgewählt und auf den Gehalt an Antagonisten gegenüber Verticillium longisporum untersucht. Ihre wirksamsten Antagonisten jedoch stammten vornehmlich aus dem Gebiet, wo sie auch später eingesetzt werden sollten.

Beruhend auf diesen Überlegungen wurden in der vorliegenden Arbeit zur Isolierung von Antagonisten gegen L. maculans die Bodenproben vor allem aus der Rhizosphäre von Raps, Gerste, Weizen, Kartoffel, Zuckerrübe und des Laub- und Nadelwaldes aus dem Raum Göttingen bzw. Hessen entnommen, da in der Rhizosphäre hervorragende Nährstoffbedingungen durch z. B. Wurzelexsudate und abgestorbenen Wurzeln vorhanden sind (CAMPBELl \& GREAVES, 1990). Dieser Nährstoffreichtum ermöglicht den Mikroorganismen eine hohe Besiedlungsdichte des wurzelnahen Bodenraums und der Rhizoplane (CURL \& TRUELOVE 1986). Darüber hinaus wurden Mikroorganismen aus Kompostproben in das Screening einbezogen.

Die Untersuchung der Böden mit der Mehrschichtagarmethode nach HERR (1959) und der damit verbundenen Verdünnungsplattentechnik ist beim Screening von Antagonisten, ungeachtet ihrer Probleme, weit verbreitet, da sie den vermutlich bedeutsamsten Wirkmechanismus, die in vitro-Antibiose, berücksichtigt. Diese ist nicht selten die wichtigste Voraussetzung für die ad planta-Wirkung (JOHNSON 1954, BROADBENT et al. 1971). Zudem ermöglicht diese Methode eine frühzeitige und gezielte Auswahl von Antagonisten aus dem großen Reservoir - dem Boden.

Zahlreiche Autoren kritisierten allerdings, dass der Anteil der in vitro kultivierbaren und mit dieser Methode erfassbaren Bakterien in Abhängigkeit von der Zusammensetzung der Nährmedien lediglich bei maximal $10 \%$ liegt (WELLER 1988, HEMMING 1990) und das Fenster der potentiell antagonistisch wirkenden Isolate methodisch bedingt auf Hemmstoffbildner eingeengt wird (SIEDE 2000). Dennoch zeichnete sich diese Methode durch die Erfolge in zahlreichen Arbeiten (KEMPF 1989, WILLMS 1990, LEE 1991, HeUPEL 1992, GOTTSCHALK 1995, SASSE 1997) als eine der effektivsten zur Isolierung von Antagonisten aus.

Bei der Isolierung von mikrobiellen Antagonisten ist, wie bereits erwähnt, die Zusammensetzung des Nährmediums ein wichtiges Kriterium, da dieses die Hemmstoffbildung der Mikroorganismen fördernd bzw. unterdrückend beeinflussen kann (FRAVEL 1988). Die Arbeiten von Willms (1990), Heupel (1992), SASSE (1997) sowie GotTSCHALK (1998) zeigten, dass besonders das Komplexmedium TSA sehr dazu geeignet ist, hemmstoffproduzierende Mikroorganismen nachzuweisen. Diese Erfahrung wurde auch in der vor- 
liegenden Arbeit bestätigt. 109 bakterielle und 19 pilzliche Antagonisten mit einer in vitroHemmwirkung gegen L. maculans IBCN66 wurden aus Kompostproben und der Rhizosphäre unterschiedlicher Pflanzen isoliert.

Zusätzlich zu der Mehrschichtagarmethode wurden verschiedene 2-KomponentenIsolationstechniken, welche im Prinzip aus dem potentiellen Antagonisten und dem Pathogen bestehen, entwickelt und angewandt. Hierzu zählen Überschichtungstechniken, bei denen der auf dem Nährmedium wachsende Pathogen mit verdünnten Bodensuspensionen überdeckt wird, um lytische Mikroorganismen zu erkennen (CARTER \& LOCKWOOD 1957). Ähnliche Methoden wurden angewandt, um die saprophytische Konkurrenzkraft von Mirkoorganismen zu überprüfen (DAVET 1986). Verschiedene Autoren versuchten zusätzlich, die Selektivität der Verfahren zu erhöhen, um mit geringem Aufwand kompetente Antagonisten zu entdecken. MOLINE et al. (1999) isolierten und überprüften die potentiellen Biokontrollorganismen auf einem mit Zellwandfragmenten des Pathogens angereicherten Medium. Die Leistungsfähigkeit dieser Methoden spiegelte sich in der relativ guten Übereinstimmung der Screeningergebnisse mit den Bekämpfungserfolgen am tatsächlichen Einsatzort wider. Darüber hinaus gelang innen die Erstbeschreibung der antagonistischen Eigenschaften von Chryseobacterium indologenes. FRIDLENDER et al. (1993) reicherten im Rhizosphäreboden glukanasepositive Bakterien an. Diese isolierten sie auf Nährmedien, die als einzige CQuelle Laminarin enthielten.

Ungeachtet der positiven Resultate in den angeführten Beispielen haben in vitro-Untersuchungen unbestreitbar ihre Grenzen. Diese sind festgelegt durch die Testbedingungen. Art und Menge der $\mathrm{C}$ - und N-Quelle, das Fe-Angebots, die P-Verfügbarkeit, der pH-Wert, die Temperatur und das Wasserregime sind hierbei einige der wichtigsten Einflussgrößen. Folgerichtig beeinflusst die Peripherie des Testsystems das Ergebnis (SIEDE 2000).

\subsection{In vitro-Screening}

Anknüpfend an die Isolierung von potentiellen Antagonisten wurden sehr häufig in vitroScreeningmethoden aufgrund des geringen experimentellen Aufwandes angewandt (WISSING et al. 1997), wobei die Isolate in Dualkulturversuchen auf ihre Hemmwirkung gegenüber den Zielpathogenen hin überprüft wurden (JOHNSON \& CURL 1972). Da eine systematische Untersuchung einer großen Zahlen an Antagonisten nur durch eine Vorauswahl mit Hilfe schnell durchführbarer Testverfahren mit vertretbarem Aufwand zu bewältigen ist, kamen in den meisten Arbeiten entsprechende in vitro-Verfahren zum Einsatz (Broadbent et al. 1971, FRAVEL, 1988; RENWICK et al., 1991; HEUPEL, 1992; ANDREWS, 1992; TILCHER, 1996, BURR et al. 1996, SASSE 1997, SCHMIDT 1997). 
Zahlreiche Autoren kritisierten allerdings diese Vorgehensweise, da keine generelle Beziehung zwischen der Fähigkeit eines Isolates, ein Pathogen in vitro zu hemmen und der Krankheitsunterdrückung ad planta besteht (SLEESMAN \& LEBEN 1976, WebBER \& Hedger 1986, ELSHRIF \& GROSSMANN 1994, REINECKE 1981, HAGEDORN et al. 1989, HARRIS 1989, CAMPBELL, 1986; LOCKWOOD, 1986; WelLER, 1988; KLOEPPER, 1991). Demgegenüber ermittelten u. a. UTKHEDE \& RAHE (1982), FRAVEL (1988), KEMPF \& WOLF (1989), WILLMS (1990), SCHOEMANN et al. (1994), LEIFERT et al. (1993), STANLEY et al. (1994), WoDZINSKI et al. (1994), MONTESINOS et al. (1996), daß ein enger Zusammenhang zwischen der in vitroHemmwirkung und der ad planta-Wirksamkeit ihrer Antagonisten existiert, der bei KEMPF (1988) sogar hoch signifikant war. Derartige divergierende Beurteilungen sind sicherlich auf die Verschiedenartigkeit der untersuchten Systeme und Wirkmechanismen (FRAVEL 1988) und das in den einzelnen Arbeiten unterschiedliche Design der in vitro-Testvefahren zurückzuführen (WISSING et al. 1997). Kein Versuchsansteller wird jedoch bestreiten, das sich Hemmmechanismen wie die Konkurrenz um Nährstoffe sowie durch Mikroorganismen induzierte Resistenz nicht mit Hilfe von Dualkulturversuchen erfassen lassen (FOKKEMA, 1978; BLAKEMAN \& FOKKEMA, 1982).

Da die Schwächung des pilzlichen Erregers durch Hemmstoffe nach wie vor von zahlreichen Autoren (u.a. COOK \& BAKER 1983, WOLF 1994) als von zentraler Bedeutung beim Angriff nekrotropher Mycoparasiten bzw. Bakterien angesehen wird, erfolgte in der vorliegenden Arbeit die Selektion der Antagonisten zunächst anhand der Hemmwirkung auf Agarnährmedien.

Die Bildung von Antimycotika durch Antagonisten hängt überwiegend vom verwendeten Medium ab (WHIPPS 1987, BECKER \& COOK 1988). Um diesen Faktor zu berücksichtigen und möglichst die antibiotisch wirksamsten Antagonisten sicher zu erfassen, wurde das Screening in der vorliegenden Arbeit wie bei BROADBENT et al. (1971), KEMPF (1988), HEUPEL (1992), MYATT et al. (1992) und AFOUdA (1999) auf verschiedenen Medien durchgeführt. Hierzu wurden die zwei nährstoffreichen Medien V8 und MsA verwendet, welche sich in Voruntersuchungen als sehr geeignet für das Myzelwachstum von L. maculans und Vertillium longisporum erwiesen. Die Ergebnisse schließlich rechtfertigten die Verwendung der Medien; da wie in anderen Arbeiten (HEUPEL 1992, TILCHER 1995, SASSE 1997, SCHMIDT 1997) bei einigen Isolaten nur auf einem der beiden Testmedien eine antagonistische Wirkung erzielt wurde.

Analog zu der Situation bei den chemischen Fungiziden beobachteten JONES \& PETTIT (1987), dass sich Stämme verschiedener Anastomosis-Gruppen von Rhizoctonia solani unterschiedlich sensitiv gegen das Antibiotikum Gliotoxin, gebildet durch den Antagonisten Gliocladium virens, verhielten. Auch verschiedene Stämme von Gaeumannomyces graminis var. tritici variierten in ihrer Sensitivität gegen die von Pseudomonas fluorescens und 
P. chloroaphis gebildeten Antibiotika Phenazine-1-carboxylic acid (PCA) und 2,4 Diacetylphloroglucinol (Phl), was die Wirksamkeit der Antagonisten bei der Bekämpfung der Schwarzbeinigkeit an Winterweizen beeinträchtigte (MAZzOLA et al. 1994 und 1995). Deshalb wurde in den eigenen Versuchen zusätzlich geprüft, ob die Antagonisten gegen Isolate aus verschiedenen Pathogenitätsgruppen (A1, A2, NA) von L. maculans unterschiedlich wirksam waren. In den meisten Fällen wurden allerdings bei den drei Testisolaten IBCN66 (A1); R1G4 (A2) und NA21 keine Unterschiede in ihrer Hemmbarkeit durch die Antagonisten festgestellt.

FRIDLENDER et al. (1993) äußerten sich in ihrer Arbeit über die biologische Kontrolle verschiedener bodenbürtiger Schaderreger durch einen ß-1,3-Glucanase produzierenden Pseudomonas cepacia und betrachteten es als logische Schlußfolgerung, daß die effektivsten Antagonisten über mehrere Mechanismen wirken müssen.

Der Parasitismus ist ein weiterer sehr wichtiger Wirkmechanismus mikrobieller Antagonisten (PARK 1960, COOK \& BAKER 1983). Der Parasit nutzt hierbei direkt die Inhaltsstoffe des Wirtes als C- und N-Quelle. Die Voraussetzung dafür ist die Bildung von Enzymen, die in der Lage sind, die Polymere der Wirtszellwand abzubauen (MITCHELL \& ALEXANDER 1963, ELAD 1996). Als Schlüsselenzyme für den Abbau von Zellwänden höherer Pilze gelten Chitinasen und 1,3-ß-Glucanasen (MITCHELL \& ALEXANDER 1963, SKUJINS et al. 1965). Die Bildung dieser Enzyme ist ebenfalls ein wesentlicher Faktor bei der biologischen Kontrolle verschiedener Pflanzenpathogene (SNEH 1981, ELAD et al. 1982, ORDENTLICH et al. 1988, TURAN 1990, INBAR \& CHET 1991, FRIDLENDER et al. 1991, LORITO et al. 1993, CHERNIN et al. 1995, VALOIS et al. 1996). MAURER (1999) stellte fest, dass im Testsystem Rhizoctonia solani - Zuckerrübe das antagonistische Isolat C-5/8, mit geringer in vitro-Hemmwirkung auf TSA, aber mit einer starken Enzymproduktion, eine gute Wirkung ad planta zeigte. Angeregt von diesen Ergebnissen, wurden in das in vitro-Screening die Chitinase- bzw. ß-1,3-Glucanasebildung durch die Antagonisten als Selektionskriterium mit einbezogen.

Auch Nahrungskonkurrenz wie die Siderophorenbildung ist ein möglicher Mechanismus. Siderophoren sind von Mikroorganismen ausgeschiedene niedermolekulare wasserlösliche Substanzen, die Eisen- bzw. andere Metallionen mit hoher Spezifität und Affinität koordinativ binden (SCHLEGEL 1992). Dazu zählen die fluoreszierenden Verbindungen Pyoverdin bzw. Pseudobactin (BUDZIKIEWICZ 1993 und 1997, HoHNADEL \& MEYER 1988), Pyochelin (ein Salizylsäure-derivat) (Cox et al. 1981) \& Salizylsäure (MEYER et al 1992, VISCA 1993) sowie Quinolobactin (MOSSIALOS et al. 2000). Lange Zeit wurde den Siderophoren der fluoreszierenden Pseudomonaden eine große Bedeutung an der Unterdrückung pathogener Pilze zugeschrieben (LOPER 1988, LOPER \& BUYER 1991, O'SULLIVAN \& O'GARA 1992). Die Wirkung von Pyoverdin bzw. Pseudobactin beruht darauf, dass sie bei Eisenmangel- 
bedingungen in natürlichem Habitat durch ihre hohe Affinität zum dreiwertigen Eisen anderen Mikroorganismen die lebenswichtigen Eisenionen entziehen können (PHILIPP 1988, HöFTE et al. 1994, LOPER et al. 1997), während Salizylsäure zusätzlich auch lokale und systematische Wirtsresistenz induzieren können (DE MEYER \& HÖFTE 1997, LEEMANN et al. 1995, MAURHOFER et al. 1998). Darüber hinaus besteht die Möglichkeit, daß sie bei den Bakterien durch Erhöhung der Eisenverfügbarkeit die Biosynthese weiterer antifungaler Substanzen stimulieren. Im direkten Zusammenspiel zwischen Pflanze und Mikroorganismen ist HEMMING (1986) der Ansicht, daß die Siderophoren der fluoreszierenden Pseudomonaden das Eisen direkt für die Pflanzen verfügbar machen, und somit das Wachstum der Pflanzen fördern.

In den vorliegenden in vitro-Untersuchungen konnten 30 Isolate, darunter auch Grampositive Mikroorganismen, Siderophoren ausscheiden. Davon war bei 3 Pseudomonaden eine starke Bildung fluoreszierender Siderophoren auf King-B-Agar zu beobachten. LILES (2000) wies die Produktion von Siderophoren durch Bakterien von über 20 Gattungen, zu denen allerdings nicht die Gattungen Paenibacillus und Bacillus zählten, auf dem CASMedium nach. Daher wäre eine erneute Überprüfung der Siderophorenbildung durch die Bacillus Isolate erforderlich.

In der vorliegenden Arbeit erfolgte die Selektion der Antagonisten für die ad planta Prüfung vorwiegend nach den drei Kriterien in vitro-Hemmung von L. maculans auf TS-, V8- und Ms-Agar, Chitinase- bzw. B-1,3-Glucanasebildung und Siderophorenausscheidung. Um ein möglichst mannigfaltiges Reservoir von Antagonisten zu erhalten war die taxonomische Einordnung ein weiteres wichtiges Kriterium für die spätere Selektion. Schließlich wurden das Streptomyceten-Isolat KAR5 mit einer starken Wirkung auf TSA, die Isolate KAR1 und KOM19 trotz ihrer breiten antibakteriellen Wirkung, WE14 und ZU10 aufgrund ihrer Exochtinase- und Exoglucanase-Bildung, WE1 und WE2 hauptsächlich wegen ihrer einheitlichen Hemmwirkung gegen L. maculans und V. longisporum, HA3e und R2II mit dem umfassendsten Potential antagonistischer Wirkmechanismen, sowie Pseudomonas fluorescens Gö2I, Bacillus subtilis B1a und Pantoea agglomerans JII/E4, die sich als wirksame Antagonisten jeweils gegen den Rapswelkeerreger Verticillium longisporum (SASSE 1997), dem Erreger der Eutypiose der Weinrebe Eutypa lata (SCHMIDT et al. 1997) sowie gegen Fusarium culmorum an Winterweizen erwiesen (KEMPF 1988), für die ad planta Versuche ausgewählt.

Zahlreiche Autoren bezweifeln jedoch die relativ guten Erfolgsaussicht der klassischen in vitro Verfahren, da ihrer Meinung nach ein nicht zu unterschätzendes Risiko besteht, dass die ad planta wirksamsten Isolate verborgen bleiben könnten, und suchten nach einer anderen Vorgehensweise ad planta wirksame Antagonisten zu finden, deren Hemmwirkung vornehmlich auf Resistenzinduktion, Konkurrenzeffekten oder der Bildung gasförmiger 
Hemmsubstanzen und Enzymen beruhte (KOMMEDAHL \& WINDELS 1978, KNUDSEN et al. 1997, SIEDE 2000).

Einige Autoren integrierten hierzu die Wirtspflanzen in das System Antagonist-Pathogen, so dass ein 3-Komponententest für ein ad planta-Screening zur Verfügung stand: Methoden dieser Art ermöglichen die Erkennung von Gegenspielern mit direkten antifungalen Eigenschaften als auch mit indirekten suppressiven Effekten über die Pflanze auf das Pathogen. KLOEPPER (1991) etablierte das 3-Komponentensystem Antagonist-Rhizoctonia solaniBaumwolle. RANDHAWA \& SCHAAD (1985) konzipierten eine Keimkammer, die besonders gut geeignet sein soll, antagonistische Bakterien aufgrund ihrer Rhizosphärenkompetenz zu erkennen. ROSENDAL \& OLSEN (1992) entwickelten einen Schnelltest mit Kressepflanzen. Bei allen drei vorab genannten Arbeiten handelt es sich um Modelle, deren Tauglichkeit von den Autoren nicht mit den üblichen Methoden überprüft wurde. PARKE et al. (1991) fanden in einem 3-Komponententest aus einem relativ geringen Pool potentiell wirksamer Antagonisten effektive Isolate, die im Feldversuch zu reproduzierbaren und signifikanten Bekämpfungserfolgen führten. RENWICK et al. (1991) führten ein sehr umfangreiches ad planta-Primärscreening gegen Gaeumannomyces graminis durch. Ihnen gelang die Erstbeschreibung der antifungalen Eigenschaften von Rhodococcus sp., einigen Hefen und Baeuveria bassiana. Neuere Arbeiten belegen die hohe Leistungsfähigkeit, mikrobielle Antagonisten ad planta zu überprüfen. KNUDSEN et al. (1997) detektierten auf diese Weise gegenüber dem Pathogen Fusarium culmorum den Antagonisten Gliocladium roseum, der sich im Feldversuch der Fungizidkontrolle als überlegen erwies. Alle von KNUDSEN et al. (1997) gefundenen wirksamen Isolate zeigten in den klassischen Dualkulturversuchen keinerlei Wirkung. Ob hierbei allerdings der Wechsel des Testmediums zu anderen Ergebnissen führen könnte, ist nicht bekannt. Dennoch haben diese 3-Komponentensysteme immer noch ihren artifiziellen Charakter. Aussagen über die ökologische Fitness der Isolate können auf diese Weise nicht gemacht werden. Folglich stellt sich den Screeningkonzepten dieser Art immer das Problem, ein in sich kohärentes System zu entwerfen, in dem auch die Isolationsbedingungen (Zusammensetzung des Testmediums, Temperatur, pH, Wasserregime) die Situation in der Rhizosphäre simuliert. Derartige Versuche sind allerdings kaum durchgeführt worden.

CAMPBell (1986), HARMAN \& LUMSDEN (1990) sowie MERRIMAN \& RUSSEL (1990) forderten, wirksame Antagonisten in einem dem natürlichen Habitat nachgebildeten System (BodenPathogen-Pflanze) zu suchen. Derartige Versuche wurden für Weizen - Gaeumannomyces graminis (WELLER et al. 1985), Wassermelone - Fusarium oxysporum (LARKIN et al. 1996), Flachs - Fusarium spp. (SCHER \& BAKER 1980) sowie Aubergine - Rhizoctonia solani durchgeführt (BUCKI et al. 1997). Um den Antagonismus maskierende Faktoren ausschließen zu können und die Reproduzierbarkeit sicherzustellen, wurde der Boden meist gedämpft oder 
ein dem Boden ähnliches Anzuchtsubstrat verwendet. Die meisten Autoren führten keine geplante Vorselektion der Antagonisten durch. Hier fehlte es den Verfahren an Konsequenz, da bei der Isolierung aus der Rhizosphäre auf Standardmedien und Standardmethoden zurückgegriffen wurde, und nur beim Screening die natürlichen Bedingungen der Rhizosphäre simuliert wurden. SCHER \& BAKER (1980) entwickelten eine interessante Methode mit Myzel auf Nylonträgern, die im Boden eingegraben wurden. Für das Screening wurden die am Myzel haftenden Mikroorganismen verwendet.

\subsection{Ad planta Screening an Rapskeimlingen}

L. maculans kann alle Pflanzenteile anfälliger Sorten besiedeln (GUGELN \& PETRIE 1992). Ein Blattbefall im Herbst soll nach Hammond et al. (1985) das potentielle Inokulum für den späteren Befall an der Stengelbasis und dem Wurzelhals darstellen. Der Pilz kann nach dem Eindringen in die Blattstiele systemisch in den Wurzelhals und die Stengelbasis wandern und dort die typischen Symptome hervorrufen (HAMMOND et al. 1985, HAMMOND \& LEWIS 1987). Daraus resultierte die Überlegung, die Hemmwirkung der Antagonisten gegen L. maculans zunächst an Rapsblättern zu untersuchen.

Da ein in vivo-Verfahren unter normalem Testbedingungen für eine große Zahl von Antagonisten aufwendig ist, kam es für ein Screening einer großen Zahl an in vitro-wirksamen Isolaten nicht in Frage. Daher wurde ein Verfahren entwickelt, welches zwischen einem in vitro- und ad planta-Screening einzustufen ist. Versuche mit ausgestanzten Blattscheiben stellen eine gängige Methode zur Untersuchung der Wirkung von chemischen und biologischen Agenzien gegen pathogene Pilze sowie zur Resistenzprüfung dar und wurden in verschiedenen Pathosystemen verwendet, wie z. B. in Hopfen-Pseudoperonospora humili (ROYLE \& THOMAS 1973), Melone - Sphaerotheca fuliginea (COHEN 1993), Petunie B. cinerea (GoULD et al. 1993), Tomate - B. cinerea (NICOT et al. 1993), Tabak - Rhizoctonia solani (ASCHBY \& OWNLEY, 1994) und Weinrebe-Plasmopara viticola (TILCHER 1996). JONGEBLOED et al. (1993) entwickelten zur biologischen Bekämpfung von $P$. infestans ein Testverfahren, bei dem Kartoffelblätter in feuchter Atmosphäre erst mit den bakteriellen Antagonisten und später mit einer Sporangiensuspension des Erregers behandelt wurden. Nach fünf bis sieben Tagen konnte der Prozentsatz an befallener Blattfläche bonitiert werden. Ein solches Verfahren, auch als detached leaf Test bei GoTTSCHALK (1998) beschrieben, ist allerdings nur partiell als ad planta einzustufen und wurde aus diesem Grund in der vorliegenden Arbeit nicht angewendet.

Zur Überprüfung der Keimblattreaktionen auf die Infektion mit L. maculans wurde bereits eine reproduzierbare Methode etabliert (DELWICHE \& WILLIAMS 1979, KUSWINANTI 1997, VOLKE 1999), wobei Keimblätter 7 Tage alter Rapspflanzen nach mechanischer Verletzung 
mit einer sterilen Nadel mit einer Sporensuspension von L. maculans inokuliert und 14 Tage später der Befall bonitiert wurde. Die ganze Versuchsdauer betrug somit von der Aussaat bis zur Befallsbonitur lediglich drei bis vier Wochen. Unter der Berücksichtigung, dass ein Befall mit $L$. maculans eine Verletzung voraussetzt, erschien es für das ad planta-Screening in der vorliegenden Arbeit sinnvoll, ebenfalls Rapskeimlinge und den erwähnten Test einzusetzen, da er eine kürzere Versuchsdauer ermöglicht, als bei Verwendung von jungen Rapspflanzen im BBCH11-Stadium, zumal für einen Test an Laubblättern keine erprobte Infektionsmethode vorlag.

Die Fähigkeit antagonistischer Mikroorganismen Antibiotika zu produzieren oder Resistenz zu induzieren, wurde meistens nur anhand des durch Zentrifugation gewonnenen Kulturfiltrats überprüft (MAISS 1987, SCHNEIDER \& ULLRICH, 1990), während in Wasser oder physiologischen Lösungen suspendierte Mikroorganismen für Versuche zum Parasitismus und zur Konkurrenz eingesetzt wurden (LEBEN \& DAFT 1965, AKUTZSU et al. 1993, ELAD et al. 1993, JONES \& SAMMAC 1994b, SUJKOWSKI et al. 1994).

Im ad planta-Screening der vorliegenden Arbeit wurden aufgrund des Versuchsaufwands die Zellen der 21 Antagonisten eingesetzt, da das Hauptaugenmerk zunächst nur den wirksamen Organismen, aber nicht deren sekundären Metaboliten, galt.

Eine Möglichkeit, die Überlebensfähigkeit der Antagonisten auf der Pflanze zu verbessern, beschreiben SUSLOW \& SCHROTH (1981). Sie fanden, das die Verwendung des Haftmittels Methylcellulose, wahrscheinlich aufgrund der langkettigen Struktur, den Mikroorganismen einen effektiven Schutz vor einer Austrocknung gewährt.

SUSLOW \& SCHROTH (1981), WELLER \& COOK (1986), KAISER et al. (1989) sowie CALLAN et al. (1991) erhöhten die Anzahl der am Saatgut haftenden Bakterien gleichermaßen indem sie eine Bakterien-Methylcellulose-Suspension verwendeten. WILLMS (1990) verdreifachte durch eine Antagonisten-Haftmittel-Suspension die Zahl lebensfähiger Zellen am Weizensaatgut.

In der vorliegenden Arbeit wurden die Bakterienzellen nach Zentrifugation in $0,5 \%$ iger Carboxymethylcellulose und 0,02\%igem Tween 20 resuspendiert. Zur Vereinheitlichung wurden die Antagonistensuspensionen auf eine definierte optische Dichte eingestellt $\left(O D_{600 n m}=1\right)$. In den Versuchen wurde vornehmlich das Keimblatt mit den Suspensionen behandelt.

Die Zeitspanne zwischen der Applikation des Gegenspielers und der Inokulation mit dem Pathogen hat einen unmittelbaren Einfluß auf das Ergebnis der biologischen Kontrolle. HATTINGH et al. (1986), NICOT et al. (1993) und TILCHER (1996) hielten in ihren Untersuchungen eine Zeitspanne von 24 Stunden ein. Dies ist mit Bedacht auf die 
Absterberate der Antagonisten durchaus sinnvoll (MCQUILKEN et al. 1993). Aber auch die gleichzeitige Applikation (SCHMIDT 1988a, BURR et al. 1994, SCHISLER et al. 1994) bzw. eine doppelte Behandlung (24 Stunden vor dem und direkt mit dem Pathogen; BEER et al. 1984a) sind aus der Literatur bekannt. Für eine erfolgreiche Resistenzinduktion erscheint diese Zeitdifferenz jedoch zu kurz und sollte nach WALZ \& WELTZIEN (1990), die Versuche mit einem apathogenen Stamm von F. oxysporum durchführten, mindestens drei bis zu sieben Tagen betragen.

Die Inokulation mit L. maculans-Sporen erfolgte 6 Stunden nach der Verletzung, so dass die bakteriellen Antagonisten einen Vorsprung bekamen, die verletzten Stellen sowie andere Bindungsstellen des Pathogens besetzen zu können. Die Versuche zur Optimierung der Infektion zeigten allerdings, dass eine Zeitdifferenz zwischen der Applikation des Antagonisten und der Inokulation mit dem Pathogen von über 8 Stunden zu einem signifikant geringeren Befall der Pflanzen führen konnte.

20 der 21 getesteten Bakterien waren in den ad planta Versuchen mit den Rapskeimlingen auch bei einem hohen Befallsdruck antagonistisch wirksam gegen L. maculans. Serratia plymuthica Zu9 und Paenibacillus polymxya We1 und Zu10 konnten den Befall um 22 \% bis $28 \%$ vermindern. Die Verwendung der 5 selbst isolierten Stämme Pseudomonas fluorescens RII2 und KAR1, Paenibacillus polymyxa HA3e, Bacillus circulans KOM1 und KOM19 führten zu deutlichen Befallreduzierungen von über $42 \%$. Am auffälligsten zeigte sich Pseudomonas fluorescens Gö2l, der bereits bei SASSE (1997) als wirksamster Antagonist von Verticillium longisporum eingestuft wurde, und auch gegenüber L. maculans einen hohen Wirkungsgrad von $73 \%$ aufwies. Pantoea agglomerans JII/E4, ein sehr erfolgreicher Antagonist gegen Fusarium culmorum an Winterweizen (KEMPF 1988) sowie gegen Plasmopara viticola (TILCHER 1996) und Eutypa lata (SCHMIDT 1997) an der Weinrebe, war in seiner Wirkung weniger vielversprechend. Bacillus subtilis $\mathrm{B} 1 \alpha$, bei SCHMIDT (1997) gegen Eutypa lata noch sehr erfolgreich, förderte sogar den Befall durch $L$. maculans.

\section{4 Verminderung des Wurzelhals- und Stängelbasisbefall durch antagonisti- sche Mikroorganismen}

Unverzichtbar bei der Entwicklung biologischer Bekämpfungssysteme ist die Überprüfung der biologischen Agenzien ad planta in einem adäquaten und aussagekräftigen Testsystem. Die in vitro- und in vivo Untersuchungen an den Keimlingen hatten bereits die Wirksamkeit der meisten Antagonisten gegen L. maculans bewiesen. Danach wurden Pseudomonas fluorescens Gö2I, KAR1 und RII2, Bacillus circulans KOM19, Serratia plymuthica ZU9, Paenibacillus polymyxa HA3e, WE1 und ZU10 aufgrund ihrer Wirksamkeit und 
unterschiedlichen Herkünfte ausgewählt und ihre Wirkung gegen L.maculans im befallsempfindlichen Entwicklungsstadium im Gewächshaus untersucht.

Die Saatgutbehandlung, eine der gebräuchlichsten Applikationsmethoden für bakterielle Antagonisten zur biologischen Kontrolle bodenbürtiger Krankheiten, wurde u.a. angewendet bei der Bekämpfung des Wurzelbranderregers der Zuckerrübe (HEUPEL 1992), von Verticillium longisporum an Winterraps (SASSE 1997), Macrophomina phaseolina an der Augenbohne (AfOUDA 1999) und Mycosphaerella pinodes an der Erbse (SIEDE 2000). Sie vereint mehrere Vorteile. Für die Applikation der Mikroorganismen werden im Vergleich zu einer Boden- oder Pflanzenbehandlung deutlich geringere Mengen benötigt. Durch die Behandlung des Saatgutes sind die Mikroorganismen direkt am Wirkort in ausreichender Konzentration vorhanden und haben optimale Startbedingungen als Erstbesiedler des Wurzelsystems. Allerdings ist $L$. maculans kein uneingeschränkt bodenbürtiger Erreger, und nach den bisherigen Kenntnissen über die Epidemie der Wurzelhals- und Stengelfäule an Raps erschien eine Saatgutbehandlung als weniger geeignet, als eine Behandlung in späteren Entwicklungsstadien wie z.B. in BBCH 13-15 (SCHRAMM 1989) bzw. von Blattneubildung bis Sproßstreckung (STEINBACH \& BROSCHEWITZ 1997). Die Antagonisten wurden hierbei statt auf die Blätter gezielt auf die Stengelbasis und den Wurzelhals ausgebracht, so dass diese Stellen von einer Schutzschicht aus Antagonisten und Haftmittel bedeckt wurden.

Zur Überprüfung der Hemmaktivität ad planta wurden die Antagonisten in TSB angezogen und in 0,25\%igem Xanthan mit 0,02\% Tween 20 auf eine Endkonzentration von $1,5 \times 10^{9} \mathrm{cfu} / \mathrm{ml}\left(\mathrm{OD}_{600 \mathrm{~nm}}=2\right)$ resuspendiert. Xanthan kommt bei der Stabilisierung von Emulsionen und als Deckungsmittel zum Einsatz (BLITZ \& GROSCH 1982, BALTES 1983). Hier sollte es aufgrund seiner Viskosität die Zahl der applizierten Bakterien auf der Pflanzenoberfläche erhöhen, während Tween für eine gleichmäßige Verteilung der Zellen auf der Oberfläche und deren Benetzung zuständig war.

Die Pflanzen wurden zuerst mit den Zellen der Antagonisten behandelt und danach mit den Pyknosporen des Pathogens inokuliert. Abweichend vom Screening an den Keimlingen wurde hier eine Zeitspanne zwischen der Ausbringung der Antagonisten und der Inokulation mit dem Pathogen von $48 \mathrm{~h}$ eingehalten. Die Antagonisten hatten also ausreichend Zeit sich zu etablieren, mit der Hoffnung, dass die sie unter den Bedingungen ihr Wirkpotential möglichst vollständig entfalten konnten, und gegebenenfalls auch eine Resistenz der Pflanzen induzieren konnten. Hierfür wird in der Regel eine Zeitspanne von ein paar Tagen bis zu einer Woche benötigt (HAMMERSCHMIDT \& KUC 1995). P. fluorescens WCS374 benötigte mindestens einem Tag, um eine signifikante Resistenz gegen die Fusarium-Welke an Rettich zu induzieren (LEEMANN et al. 1995). 
Die 8 verwendeten Isolate waren äußerst wirksam gegen L. maculans. Serratia plymuthica zeigte erneut, vergleichbar wie im Screening an den Rapskeimlingen, ein eingeschränktes antagonistisches Potential, und dieses trotz einer ausgezeichneten Hemmwirkung und hoher Chitinaseaktivität in vitro. Ähnliches hatte SCHMIDT (1997) bei der Untersuchung zur Bekämpfung von Eutypa lata an Rebholz festgestellt.

Im Fall von Paenibacillus polymyxa We 1 und Zu10 war die Hemmwirkung weniger stark ausgeprägt als bei den anderen 6 Antagonisten. Andere Autoren haben mit Vertretern dieser Gattung in ihren Arbeiten allerdings mehr Erfolg gehabt. So wies SASSE (1997) P. polymyxa, neben einigen Pseudomonaden, als den wirksamsten Antagonisten gegen Verticillium longisporum an Winterraps aus. GOTTSCHALK (1998) ermittelte eine hervorragende in vitroHemmaktivität mehrerer Isolate von $P$. polymyxa gegenüber Phytophthora infestans, deren ad planta-Hemmwirkung allerdings nicht mehr untersucht wurde. Verschiedene P. polymyxa wurden auch als gute Wurzelbesiedler beschrieben (HWANG et al. 1996, SASSE 1997). MARKELLOU et al. (1995) fanden sehr wirksame Isolate von P. polymyxa, Bacillus subtilis, $P$. licheniformis und $P$. amyloliquefaciens gegenüber Botrytis cinerea.

Bacillus circulans KOM19, der bislang eher selten als ein Antagonist von Phytopathogenen beschrieben wurde, erwies sich in der vorliegenden Arbeit als äußerst wirksam gegen L. maculans. Paenibacillus polymyxa HA3e war von allen getesteten Isolaten der wirksamste Antagonist gegen den Erreger der Rapswurzelhals- und Stengelfäule.

In der Literatur findet man sehr häufig Bacillus subtilis als wirkungsvollen Antagonisten zahlreicher phytopathogener Pilze, u. a. an Bohne (BAKER et al. 1985, PLEBAN et al. 1995), Mais (ChANG \& KOMMEDAHL 1968), Wiesenrispe (THOMPSON et al. 1996), Erbsen (HWANG \& ChARKAVARTY 1992) und Baumwolle (PLEBAN et al. 1995) sowie als Wachstumsförderer bei Getreide (MERRIMAN et al. 1974) und Erdnuss (TURNER \& BACKMAN 1991). KNAPPE (1994) erzielte in Feldversuchen mit $B$. subtilis behandelten Rapspflanzen einen bis zu 20,5\% geringeren Befall mit $V$. longisporum. Aus der Rhizosphäre von Raps isolierten FIDDAMAN \& RosSAL (1995) das Bacillus subtilis-Isolat 205 als erfolgversprechendes Bio-Kontrollagens. Mit einer B. subtilis-Suspension von $4 \times 10^{6} \mathrm{cfu} /$ Samen erreichten sie eine in vivo-Unterdrückung von Rhizoctonia solani.

Wie in zahlreichen anderen Untersuchungen zur biologischen Bekämpfung von Pflanzenkrankheiten waren auch in der vorliegenden Arbeit die fluoreszierenden Pseudomonaden sehr effektiv. Mit den Isolaten RII2, KAR1, Gö2I konnte der Befall mit L. maculans selbst bei starkem Infektionsdruck ( $4 \times 10^{5}$ Sporen/Pflanze) noch um bis zu $64 \%$ reduziert werden.

Doch nicht alle Pflanzen waren vor dem Befall mit L. maculans ausreichend geschützt, wie die relativ hohen Standardabweichungen in der Befallsstärke zeigten, so dass immer 
noch deutliche Ertragsverluste auftraten. Zahlreiche Autoren berichten von Wirkungsverbesserungen durch verschiedene, den biologischen Präparaten beigemischten, Substanzen. Versuche an den oberirdischen Pflanzenteilen können sich dabei an den Erfahrungen bei der biologischen Bekämpfung bodenbürtiger Pathogene orientieren (WELLER 1988, CALLAN et al. 1990, LEWIS \& PAPVIZAS 1991b, MCQUILKEN et al. 1992, KHAN et al. 1994, PATEL et al. 1995). Im Bereich der Phylloplane wurden besonders Formulierungen mit pilzlichen Antagonisten (Ampelomyces quisqualis, Gliocladium spp. Trichoderma spp.), hauptsächlich Hyperparasiten durchgeführt (MiedtKe \& KenNel 1990, PhILIPP et al. 1990). Die Formulierung antagonistischer Bakterien wie Pseudomonas spp. und Pantoea agglomerans führte bei LEBEN \& DAFT (1965) sowie bei WoLF et al. (1986) zu Wirkungssteigerungen, was auch bei der Formulierung von Resistenzinduktoren sowie pilzlichen und bakteriellen Kulturfiltraten beobachtet wurde. TILCHER (1996) erhöhte sowohl die Überlebensrate als auch die Hemmwirkung von bakteriellen Antagonisten zur biologischen Bekämpfung von Plasmopara viticola an Wein durch den Zusatz der Formulierungshilfsstoffe Cellulose, Alginat und Xanthan. ScHULZ (1998) konnte sowohl eine Steigerung als auch eine Wirkungsminderung in Abhängigkeit vom zugesetzten Substrat bei der Pillierung von Zuckerrübensaatgut zur Bekämpfung von Pythium ultimum erreichen. Auch NogA et al. (1990) berichteten von Risiken des Einsatzes von Hilfsstoffen: durch Tenside kann die epikutikuläre Wachsschicht derart verändert oder gar zerstört werden, dass die Infektion durch pilzliche Pathogene wie $B$. cinerea gefördert wird.

Der kombinierte Einsatz der Antagonisten ist eine weitere Möglichkeit zur Verbesserung der Bekämpfung. Hierzu wurde in der vorliegenden Arbeit Pseudomonas fluorescens RII2 und Paenibacillus polymyxa HA3e ausgewählt, die über verschiedene, sich vielleicht ergänzende Wirkungsmechanismen verfügen, wie der Erfolg vermuten läßt, da durch die Mischung der beiden Bakterien ein synergistischer Effekt erzielt wurde. Durch die kombinierte Bekämpfung konnte der Wirkungsgrad auf $86 \%$ gesteigert werden. Im Fall der Einzelanwendung von Paenibacillus polymyxa HA3e und Ps. fluorescens RII2 waren es nur 53\% bzw. 42\%. Die antagonistische Wirkung konnte bei KLOEPPER (1983), MAZzOLA et al. (1994) sowie bei PIERSON \& WeLLER $(1993,1994)$ durch die Kombination verschiedener Isolate von Ps. fluorescens, und bei MEW et al. (1994) durch den Einsatz von Pseudomonas cepacia und Bacillus sp. gesteigert werden. TILCHER (1996) hatte Erfolg mit der Kombination Actinomycet A238 / Pantoea agglomerans, JANISIEWICZ \& BORS (1995) mit Pseudomonas syringae und der Hefe Sporobolomyces roseus. PAULITZ (1990) erreichte schließlich durch eine Mischung aus pilzlichen Antagonisten die besten Resultate. Durch die Kombination zweier einzeln nicht wirksamer Organismen, ein Ps. fluorescens und ein apathogener Stamm von F. oxysporum, konnten LEMANCEAU \& ALABOUVETTE (1991) einen signifikanten Bekämpfungserfolg gegenüber $F$. oxysporum erzielen. $B$. cinerea, $F$. solani und Uncinula nector wurden durch 
Enterobacter cloacae in Verbindung mit Chitinasen aus Trichoderma harzianum erfolgreich gehemmt (LORITO et al. 1993).

Andererseits können sich auch Antagonisten in ihrer Wirkung gegenseitig beeinträchtigen. BIN et al. (1991) berichten davon, dass in eisenarmen Böden die Wirkung von Trichoderma spp. durch fluoreszierende Pseudomonaden abgeschwächt werden kann. Und bei TILCHER (1996) verursachte die gleichzeitige Anwendung des Bakteriums B2 mit Pantoea agglomerans eine Befallszunahme durch Plasmopara viticola an der Weinrebe.

Eine weitere Möglichkeit zur Verbesserung der Bekämpfung stellt der gemeinsame Einsatz eines biologischen Kontrollagens mit einem chemischen Fungizid dar, wodurch gleichzeitig die Umwelt entlastet wird und die Resistenzentwicklung des Pathogens gegenüber den hochwirksamen systemischen Fungiziden verzögert werden kann. In Untersuchungen zur integrierten Bekämpfung von P. infestans konnte der Befallsverlauf der Krautfäule durch Bacillus subtilis-Stämme in Kombination mit Ridomil MZ-Super länger verzögert werden, als durch das Fungizid allein (SCHMIEDEKNECHT et al. 1996).

\subsection{Etablierung von Antagonisten am Wurzelhals der Rapspflanzen}

Eine wesentliche Voraussetzung zur biologischen Bekämpfung von Pflanzenpathogenen ist die Fähigkeit der Antagonisten, sich am Wirkort zu etablieren (LEBEN 1965, SCHIPPERS et al. 1987, WELLER 1988, SPURR 1990). Etablierung und Vermehrung der Antagonisten am Einsatzort werden als entscheidende Vorteile gegenüber chemischen Agenzien angesehen (WOLF et al. 1993). Bekanntermaßen sind einige Bakteriengattungen, darunter v. a. Pseudomonaden und Serratia spp., sehr effizient in der Besiedlung des Wurzelsystems der Pflanzen (u.a. ChIN-A-WoENG et al. 1997). Im Gegensatz dazu ist ein Überleben auf der Blattoberfläche mit einigen Risiken verbunden. Die größte Gefahr für Bakterien stellt neben dem Nährstoffmangel die Austrocknung dar. Auch die UV-Strahlung des Sonnenlichts ist ein großer Stressfaktor. Vor der Photooxidation sind nur pigmentierte Zellen durch Einlagerung von Carotinoiden in der Cytoplasmamembran geschützt. Über das Verhalten der Bakterien an der Grenzschicht oberirdisch/unterirdisch zwischen Stengel und Wurzel der Rapspflanzen, dem Infektionsort von L. maculans, lagen bislang keine detaillierten Informationen vor. In dieser Arbeit wurde daher das Überleben von Pseudomonas fluorescen RII2 und Paenibacillus polymyxa HA3e am Wurzelhals 48 Stunden nach deren Applikation, direkt vor der geplanten Inokulation mit den Sporen von L. maculans, ermittelt.

In den Untersuchungen zur Populationsdynamik wurden häufig Streptomycin- und Rifampicin-resistente Mutanten (u. a. HEUPEL 1992, SASSE 1997, GotTSCHALK 1998, AfOUDA 1999) bzW. Gentamycin- und Rifampicin-resistente Mutanten (GHIGLIONE et al, 2000) der Stämme hergestellt und eingesetzt. Die Markierung der Pseudomonaden mit der Resistenz 
gegen das Antibiotikum Rifampicin ist eine klassische und gängige Methode in den Untersuchungen zum Überleben und zur Besiedlungsfähigkeit antagonistischer Mikroorganismen auf Pflanzenoberflächen und in der Rhizosphäre, da die Resistenz stabil ist und nicht an andere Stämme weitergegeben werden kann (HEBBAR et al. 1992, KING \& PARKE 1996, HeSSENMÜLLER \& ZeLLER, 1996). Eine zusätzliche zweite Antibiotika-Resistenz vermindert die Gefahr, die markierten Bakterien durch spontane Rückmutation. nicht mehr erfassen zu können, und verringert gleichzeitig die Detektion spontaner Rifampicin resistenter Bakterien. Aber durch die Resistenzmarkierung, was eine Manipulation des Bakteriengenoms bedeutet, kann auch die Vitalität, Vermehrungs- und Besiedlungsfähigkeit der Antagonisten beeinträchtigt werden. Die Veränderung eines einzelnen Gens kann bereits zum Verlust der Besiedlungsfähigkeit führen. Bei Pseudomonas fluorescens Pf0-1 ist das Gen AdnA (Transkriptionsaktivator) verantwortlich für die Beweglichkeit und die Adhäsion (CASAZ et al. 2001). GHIGLIONE et al. (2000) fanden, dass die Besiedlung der Rhizosphäre von Maispflanzen durch Pseudomonas fluorescens YT1 von den funktionellen und strukturellen Genen der Atmungsnitratreduktase beeinflusst wird.

Mittlerweile werden zur Untersuchung der Populationsdynamik, Besiedlungsdichte und Verteilung von Mikroorganismen immunologische- und Immunofluoreszenztechniken in Verbindung mit dem konfokalen Lasermikroskop (NORMANDER et al. 1999), molekularbiologische Methoden wie die kompetitive PCR, die Markierung mit dem gfp Protein von Aquorea victoria (BLOEMBERG et al. 1997) oder dem lux-Gen von Vibrio fischeri herangezogen (MARSCHNER \& CROWLEY 1996, HANSEN et al. 1997).

In der vorliegenden Arbeit wurde die Cryo-Rasterelektronenmikroskopie (Cryo-REM) verwendet, um das Überleben der Antagonisten am Rapsstängel und dem Wurzelhals zu untersuchen. Die Cryo-REM, in der Auflösungskraft zwischen der Lichtmikroskopie und der Transmissionselektronmikroskopie (TEM) angesiedelt, ermöglicht eine exakte Lokalisierung der Mikroorganismen auf der Pflanzenoberfläche (CAMPBELL \& ROVIRA 1973, ROVIRA \& CAMPBELL 1975). Der Vorteil dieser Methode liegt auch darin, dass aufgrund der einfachen und schonenden Probenaufarbeitung Präparationsartefakte fast ausgeschlossen sind. Zellen die vollturgeszent und intakt erscheinen, wurden mit hoher Wahrscheinlichkeit im lebenden Zustand aufgearbeitet.

48 Stunden nach der Ausbringung waren auf der oberirdischen Stengelbasis nur sehr flach aussehende Zellen von Pseudomonas fluorescens R2II zu erkennen, während die Form der Zellen auf dem unterirdischen Wurzelhals kräftiger erschien. Im Gegensatz zu Ps. fluorescens R2Il waren von Paenibacillus polymyxa HA3e junge Mikrokolonien zu sehen, und zahlreiche Zellen dieses Antagonisten versporulierten unter den gegebenen Versuchsbedingungen. Die Bildung von Endosporen verhilft dem Bakterium auch ungünstige Bedingungen wie Nährstoffmangel und Trockenheit ohne Beeinträchtigungen zu überstehen. 
Diese Beobachtung korrielierte mit der tendenziell besseren Hemmwirkung von HAЗe ad planta.

Die Feuchtigkeit am Ort der Inokulation hat einen entscheidenden Einfluß auf das Überleben von Gram-negativen Bakterien. SLEESMAN \& LEBEN erwähnten 1976 erstmals einen Stamm von Ps. cepacia, ein Antagonist des Maispathogens Bipolaris maydis. Er hemmt dessen Konidienkeimung und das Wachstum der Keimschläuche in vitro und auf dem Blatt, aber sein Nachteil war, daß er die Abtrocknung der Blätter nicht überlebte. GoTTSCHALK (1998) beobachtete bereits im detached leaf-Test in einer Feuchtkammer ein drastisches Absinken der Populationsgröße in den ersten 24 Stunden nach der Applikation von Ps. cepacia auf Kartoffelblättern, was bei den Versuchen an ganzen Pflanzen noch deutlicher hervortrat. Auch bei KNUDSEN \& SPURR (1987) starben die meisten der Ps. cepacia-Zellen schon kurz nach deren Applikation ab. Die Mortalität am ersten Tag lag zum Teil bei $95 \%$. Unter feuchten Bedingungen stabilisierte sich die Zahl mehrere Tage später, stieg danach wieder etwas an, erreichte aber nicht mehr das Ausgangsniveau - vergleichbar dem Ergebnis von GOTTSCHALK (1998). Bei Feldversuchen wurden $10^{9} \mathrm{cfu} / \mathrm{ml}$ eines Antagonisten auf Erdnußblätter appliziert, von denen lediglich $10^{3}-10^{4}$ cfu pro Blatt reisoliert werden konnten. SLEESMAN \& LEBEN (1976) untersuchten die Lebensfähigkeit von Ps. cepacia auf Maisblättern in feuchten Kammern und stellten schon bei einer einstündigen Abtrocknung Mortalitätsraten von 96-99 \% fest. TILCHER (1996) konnte zeigen, dass die Population des Bakteriums B2 bei trockenen Bedingungen innerhalb von 24 Stunden zusammenbrach. Durch die fehlende Feuchtigkeit wurde auch die Population von Pantoea agglomerans dezimiert.

Einige Autoren führten unter gut kontrollierten Laborbedingungen die Besiedlungsstudien durch, und bekamen beeindruckende bodenpartikelfreie elektronenmikroskopische Aufnahmen. SIMONS et al. (1996) entwickelten für Untersuchungen in der Tomatenrhizosphäre ein gnotobiotisches System mit Pseudomonaden, wobei die mit Antagonisten inokulierten Keimlinge in mit sterilem Quarzsand gefüllten Glasröhrchen angezogen wurden. Die bei CHIN-A-WOENG et al. (1996) beschriebene ausgezeichnete Besiedlungsfähigkeit von Pseudomonas fluorescens WCS365 in der Tomatenrhizosphäre stützt sich letzlich auf dieses System in Verbindung mit der Scanning-Elektronenmikroskopie. SCHMIDT (1997) untersuchte die Besiedlung von Rebholz durch Bacillus subtilis bzw. Pantoea agglomerans anhand der Cryo-REM. Die Proben befanden sich vor der Präparation in mit Paraffin verschlossenen Petrischalen. Die das Überleben limitierenden Faktoren wie Austrocknung, UV-Strahlung und Konkurrenz wurde unter diesen Versuchsbedingungen ausgeschlossen. Es ist eher wahrscheinlich, daß sich die Bakterien unter Feldbedingungen weit weniger gut auf den Pflanzen etablieren. 
JONGEBLOED et al. (1993) und KESSEL et al. (1995) setzten Bacillus sp.- und Ps. fluorescensIsolate zur Bekämpfung von P. infestans ein und konnten im Gewächshausversuch bei beiden Antagonisten eine gute Etablierung auf der Phylloplane nachweisen. Darüber hinaus zeigte sich eine strenge Korrelation zwischen der Befallsverminderung und der Besiedlung der Blätter. Allerdings brach unter Feldbedingungen die Population beider Antagonisten zusammen und damit auch die antagonistische Wirkung gegen den Erreger. TROXLER et al. (1997) behandelten Weizen mit dem Antagonisten Pseudomonas fluorescens CHAO und fanden nach 8 Monaten, dass weniger als $2 \%$ der Bakterienzellen noch kultivierbar waren und nur ca. $25 \%$ als lebensfähig (Nalidixinsäuretest nach KOGURE et al. 1979) eingestuft werden konnten.

NORMANDER et al. (1999) untersuchten die Lokalisation, Vitalität und Aktivität des gfpmarkierten Pseudomonas fluorescens DR54-BN14 bis auf die Ebene einer einzelnen Zelle in der Rhizosphäre der Gerste unter natürlichen Bedingungen 3 bis 14 Tage nach der Applikation. Im Konfokalen Lasermikroskop waren auf den 3 bis 14 Tage alten Wurzeln Mikrokolonien dicht neben den endemischen Bakterien zu erkennen, wobei die meisten Zellen des Isolats DR54-BN14 klein und nahezu coccoid aussahen. Mit einem MikrokolonieTest konnten Information über die Vitalität des Inokulums gewonnen werden, wobei das Zellvolumen, die Intensität der Fluoreszenz, und der Anteil der sich teilenden Zellen als Indikator der Zellaktivität genommen wurden. Unter Bedingungen nahe der maximalen Wasserkapazität des Boden sahen die meisten Zellen in der Rhizosphäre klein und coccoid aus, so als ob sie "hungerten". Dennoch war fast $80 \%$ der Popopulation kultivierbar bzw. bis zu 14 Tagen in der Rhizosphäre lebensfähig. Danach erst brach die Population zusammen. Es war kein Unterschied in der Lebensfähigkeit, Aktivität bzw. Vitalität der Zellen in den unterschiedlichen Bereichen der Wurzel erkennbar. Allerdings waren Zellen aus sehr trockenem Boden nicht mehr lebensfähig - die Verfügbarkeit von Wasser ist ein bestimmender abiotischer Regulator, nicht nur im Boden.

Die Versuchsbedingungen in der vorliegenden Arbeit waren bereits denen im Freiland angepasst. Die mäßige Besiedlung der Stengelbasis durch die Antagonisten zwingt zu weiteren Verbesserungen in der Applikation. Ein effektiver Schutz vor Austrocknung und eine Förderung des Wachstums der Bakterien können durch die Zugabe von Formulierungshilfsstoffen und Nährstoffen erreicht werden. Besonders die Art der Applikation spielt eine wichtige Rolle. Nach FOKKEMA (1978) und BLAKEMAN \& FOKKEMA (1982) müssen bei der Etablierung einer antagonistischen Mikroflora unbedingt Nährstoffe wie Saccharose und Hefeextrakt zugesetzt werden, um die Entwicklung der Population zu gewährleisten. Auch bei JONGEBLOED et al. (1993) stimulierte die Zugabe von TSB das Wachstum von Ps. fluorescens auf Kartoffelblättern. In Feldversuchen stieg die Population 
innerhalb eines Monats von $2 \times 10^{4} \mathrm{cfu} / \mathrm{cm}^{2}$ auf $10^{5} \mathrm{cfu} / \mathrm{cm}^{2}$ an. Selbstverständlich immer im Hinblick darauf, nicht versehentlich das Pathogen zu fördern.

Die Besiedlung der Pflanzen durch Rhizobakterien wird häufig vom Sortenunterschied beeinflusst. So unterschieden sich die Besiedlung der Rapswurzel verschiedener Sorten aufgrund unterschiedlichem Gehalt an Glucosinolate and Flavonoide durch Azorhizobium caulinodans ORS571 (O'CALLAGHAN et al, 2000). Der Einfluss der Wirtspflanze auf die Population und Aktivität von Antagonisten wurde wenig beachtet. Nach EMMERT et al. (1998) hemmt Canavanine aus Luzernesaatgut das Populationswachstum von Bacillus cereus UW85, dem Antagonist von Pythium torulosum. In Abhängigkeit von der Tomatensorten wurde die Wirkung von Bacillus cereus gegen Pythium torulosum gefördert bzw. gehemmt (SMITH et al. 1999). Diese Untersuchungen konnten Im Rahmen der vorliegenden Arbeit nicht durchgeführt werden.

\subsection{Wirkmechanismen}

Antagonisten können durch die Bildung antibiotischer Substanzen, durch Parasitierung und durch Konkurrenz um Nährstoffe und Lebensraum auf der Pflanze bzw. in der Rhizosphäre direkt auf die Schaderreger einwirken. Zu den indirekten Wirkungen zählen die Induzierung von Resistenzreaktionen der Pflanze oder die Förderung des allgemeinen Pflanzenwachstums wodurch die Widerstandsfähigkeit der Pflanze verbessert wird. Die Aufklärung der Wirkmechanismen eines Antagonisten sollten vor allem auch Anhaltspunkte zur Verbesserung seines Bekämpfungserfolgs liefern.

Die Antibiose ist nach BAKER (1968) und COOK \& BAKER (1983) der wichtigste Schlüsselmechanismus und daher von fundamentaler Bedeutung bei der Hemmung phytopathogener Pilze durch mikrobielle Antagonisten. In den frühen 50er Jahren des letzten Jahrhunderts, dem Beginn des "Zeitalters der Antibiotika", wurde bereits nach Substanzen gesucht, welche für die Wechselwirkung zwischen phytopathogenen und antagonistischen Bodenmikroorganismen maßgeblich verantwortlich sind (GOTTLIEB 1976). So wurde eine Fülle von Antibiotika entdeckt, die zum größten Teil von Organismen der Gattungen Penicillium, Streptomyces und Bacillus gebildet wurden (BROCK \& MADIGAN, 1991).

Antimykotische Sekundärmetaboliten diverser Pseudomonas fluorescens-Stämme wurden erst relativ spät beschrieben. ELANDER at al. (1968) fanden verschiedene pyrrolnitrinbildende Stämme. Etwa zehn Jahre später entdeckten HOWELL \& STIPANOVIC (1979 und 1980) die Bedeutung von Pyrrolnitrin (PRN) und Pyoluteorin (PLT) für antagonistische Interaktionen. Mittlerweile wurden noch Tropolon (LINDBERG et al. 1980), Phenazincarboxylsäure (PCA; GURUSIDDAIAH et al. 1986, BRISBANE et al. 1987), Pyocyanin (DAHIYA et al. 1988), Oomycin A 
(HOWIE \& SUSLOW 1991), Hydrophenazin und Chlororapin (LEVY et al 1991), 2,4Diacetylphloroglucinol (PHL bzw. DAPG; KEEL et al. 1990, SHANAHAN et al. 1992), Dihydroaeruginolsäure (CARMI \& CAMELI 1994) sowie 2-Hexyl-5-Propyl Resorcinol (GAFFNEY et al. 1994) isoliert, die zumindest zum Teil in den jeweiligen Testsystemen für die biologische Kontrolle verantwortlich sein sollen. Darüber hinaus wurden weitere in vitrowirkende Antimykotika von verschiedenen fluoreszierenden Pseudomonaden charakterisiert (LEISINGER \& MARGRAFF 1979, DÉFAGO \& HAAS 1990), besonders DAPG, PLT, PRN und PCA waren wegen ihrer ausgeprägten Hemmwirkung Bestandteil intensiver Forschungen.

Pyrrolnitrin wurde 1964 erstmals als Sekundärmetabolit von Pseudomonas pyrrocinia beschrieben. Bislang wurde dessen Hemmwirkung gegen zahlreiche Pathogene nachgewiesen: Rhizoctonia solani, Verticillium dahliae und Pyricularia oryzae (HOMMA et al. 1989); Botrytis cinerea und Penicillium expansum an Apfel und Birnen (JANISIEWICZ et al. 1991); Sclerotinia sclerotiorum an Sonnenblumen (MC LOUGHLIN et al. 1992); Fusarium sambucinum, F. roseum, Macrophomina phaseolina, Helminthosporium maydis und Phytophthora megasperma var. sojae (JAYASWAL et al., 1993; BURKHEAD et al., 1994), Phymatotrichum omnivorum an Baumwolle (CAMPBELL 1994). Pyrenophora triticirepentis (PFENDER et al. 1993); F. culmorum und F. graminearum (LAMBERT et al. 1987), Microdochium nivale an Weizen. Allerdings kann es aufgrund seiner hohen Lichtempfindlichkeit nicht als Fungizid im Pflanzenschutzbereich eingesetzt werden. Dennoch diente es als Vorbild zur Entwicklung der zwei stabilen Fungizide Fenpiclonil (NEVILL et al. 1988) und Fludioxonil (GEHMANN et al. 1990).

Mehrere Stämme von Pseudomonas fluorescens können das breitwirksame Antibiotikum DAPG synthesieren, welches sich als besonders wirksam gegen Thielaviopsis basicola (KEEL et al. 1990), Pythium ultimum (FENTON et al. 1992) und Gaumannomyces graminis var. tritici (VINVENT et al. 1991) erwiesen hat.

Pyoluteorin, ursprünglich 1958 aus Pseudomonas aeruginosa isoliert, hemmt sowohl das Wachstum von Bakterien als auch von Pilzen (TAKEDA 1958) und wird von mehreren Pseudomonaden gebildet. Allerdings wurde bislang nur von einer Hemmwirkung gegen Pythium ultimum berichtet (HOWELL \& STIPANOVIC 1980, MAURHOFER et al. 1992).

Phenazine werden von Bakterien der Gattungen Pseudomonas, Burkholderia, Brevibacterium und Streptomyces synthetisiert (TURNER \& MESSENGER 1986). Fast alle Phenazine zeigen ein breites Aktivitätsspektrum gegen diverse Bakterien und Pilze (SMIRNOV \& KIPRIANOVA 1990). Die Wirkung der Phenazin-Verbindungen beruht auf der Anreicherung von toxischen Superoxid-Radikalen in den Zellen (HASSETT 1993). PCA wird unter anderen durch Pseudomonas fluorescens 2-79 und $P$. aureofaciens 30-84 gebildet, und hat einen wesentlichen Anteil bei der Bekämpfung von G. graminis, dem Erreger 
Schwarzbeinigkeit an Weizen (MAVRODI et al. 1998). Darüber hinaus ist es für die Rhizosphärenkompetenz der Bakterien mitverantwortlich (MAZzOLA et al. 1992).

Zur Aufklärung der Wirkmechanismen von Pseudomonas fluorescens RII2 wurde die Hemmung des Myzelwachstums von Leptosphaeria maculans durch Kulturfiltrate und deren methanolische Extrakte überprüft. Der dünnschichtchromatographische Nachweis und ein Biotest mit den methanolischen Extrakten ließen jedoch keine klaren Aussagen zur Antibiotikabildung zu. Anhand der sensitiven und spezifischen HPLC konnte schließlich für die Pseudomonas-Isolate RII2 und Gö2l die Bildung von DAPG und Pyrrolnitrin bewiesen werden. Allerdings konnte nur Pyrrolnitrin das Wachstum von L. maculans hemmen.

HAMmER et al. (1997) klonierten die vier für die Pyrrolnitrin-Synthese verantwortlichen Gene prnA, prnB, prnC und prnD von Pseudomonas fluorescens BL915. Eine gezielte Konstruktion PRN-defekter Mutanten von Pseudomonas fluorescens RII2 wird demnach möglich. Durch Einsatz der PRN-defekten Mutanten in Verbindung mit einer HPLC gestützten Detektion des Antibiotikums soll in Zukunft die Rolle von Pyrrolnitrin an der Hemmung von L. maculans ad planta beleuchtet werden.

Die Möglichkeit zur Verbesserung der Biokontrollaktivität durch eine vermehrte ad plantaProduktion der aktiven Substanzen wird von immer mehr Autoren erkannt. DuFFY \& DÉFAGO (1999) untersuchten den Einfluß von Spurensalzen und C-Quellen auf die Bildung von DAPG, Pyoluteorin (PLT) und Pyrrolnitrin sowie von Siderophoren Salicylsäure und Pyochelin. Die Produktion von Pyrrolnitrin wurde durch Zugabe von Fruktose, Mannitol sowie einer Mischung von $\mathrm{Zn}^{2+}$ und $\mathrm{NH}_{4} \mathrm{Mo}^{2+}$, die Bildung von DAPG durch $\mathrm{Zn}^{2+}, \mathrm{NH}_{4} \mathrm{Mo}^{2+}$ und Glukose, die Synthese von PLT durch $\mathrm{Zn} 2+, \mathrm{NH}_{4} \mathrm{Mo}^{2}$ und Glycerin stimuliert aber durch Glukose unterdrückt (DUFFY \& DÉFAGO 1999).

Darüber hinaus ist die in vitro-Phenazinbildung einiger Pseudomonas fluorescens-Isolate maßgeblich vom Angebot an Vitaminen, Spurenelementen (SLININDER \& JACKSON 1992), sowie dem $\mathrm{pH}$-Wert des Mediums, der Umgebungstemperatur und der angebotenen $\mathrm{C}$ Quelle abhängig (SLINIGER \& SHEAWILBUR 1995). So wurden mit Glucosezusatz die höchsten, mit Glycerin, Xylose und Fructose deutlich geringere Phenazinenausbeuten erhalten. Glucose ist nach DufFY \& DEFAGo (1999) ein entscheidender Parameter bei der Regulation der Antibiotikabildung. Diese Kenntnisse werden in Zukunft mit Sicherheit dazu beitragen auch in situ die biologische Kontrollaktivität der Pseudomonaden zu verbessern.

Eine ambivalente Rolle wird der von Pseudomonaden ausgeschiedenen Substanz Cyanwasserstoff zugesprochen. Im Zusammenhang mit der biologischen Bekämpfung diskutierten erstmals BAKKER \& SCHIPPERS (1987) die mikrobielle Cyanidproduktion durch 
DRMO als Ursache für den Rückgang der Kartoffelerträge in Holland bei Anbau in enger Fruchtfolge (GEELS \& SCHIPPERS 1983b, GeELS et al. 1986). Im Kontrast dazu konnte für den Antagonismus durch Pseudomonas fluorescens die Beteiligung von $\mathrm{HCN}$ an der Hemmung einiger bodenbürtigen Pathogen nachgewiesen werden.

Lediglich für das Isolat Ps. fluorescens $\mathrm{CHAO}$ wurde mit Negativmutanten eindeutig gezeigt, dass die Ausscheidung von $\mathbf{H C N}$ bei der Unterdrückung von Thielaviopsis basicola an Tabak der dominante Wirkungsfaktor ist (KEEL et al. 1989, DEFAGO et al. 1990). Die Autoren beobachteten nach dem Einsatz des Antagonisten verstärktes Wurzelwachstum bei Tabak und vermuteten, dass $\mathrm{HCN}$ in Tabak eine Resistenz gegen die Schwarze Wurzelfäule induziert. VOISARD et al. (1989) gelang es, die für die HCN-Bildung verantwortlichen Gene in nicht antagonistische wurzelbesiedelnde Pseudomonaden zu klonieren. Diese transgenen Bakterien zeigten suppressive Eigenschaften. Der HCN-Bildung konnte demnach ein Teil der antifungalen Wirkung in der Rhizosphäre zugeschrieben werden. Eisen, Glycin und Prolin fördern die HCN-Bildung (KNOWLES 1976, ASKELAND \& MORRISON 1983). Bestimmte Zucker unterdrücken die HCN-Synthese (Howell et al. 1988). BLUMER \& HAAS (2000) stellten neuerdings fest, dass der ANR (anaerober Regulator) und das GacS/GacA-System (Gac: Globaler Aktivitor; LAVILLE et al. 1992, 1998) sequentiell die Zyanogenese regulieren. Die Sauerstoff- und Eisenverfügbarkeit bestimmt dabei die Aktivität des ANR, während die Zelldichte die Aktivität des GacS/GacA-System beeinflußt.

HOWELL et al. (1988) fanden starke Indizien, dass Ammoniak zumindest teilweise für den Bekämpfungserfolg seiner Antagonisten mitverantwortlich sein dürfte. In situ wiesen PAVLICA et al. (1978) volatile Hemmsubstanzen nach, von denen Ammoniak am bedeutendsten sein sollte.

In eigenen in vitro-Untersuchungen konnte gezeigt werden, dass Ps. fluorescens RII2 durch gasförmige Substanzen das Wachstum des Zielpathogens direkt hemmte. Die HCN- und Ammoniakbildung durch das Bakterium erfolgte sowohl in TSB als auch in SE-Medium. Die Bedeutung von $\mathrm{HCN}$ an der ad planta Hemmung von L. maculans wurde nicht überprüft.

BLUMER \& HAAS (2000) zeigten in ihrem System, dass ausreichend verfügbares Eisen und ein Mangel an Sauerstoff wichtige Faktoren für die Induktion der Cyanidproduktion waren. Welche Bedeutung diese zwei Parameter für die Synthese durch Ps. fluorescens RII2 besitzen, lässt sich zum gegenwärtigen Zeitpunkt noch nicht beantworten. Ein Sauerstoffmangel lag unter den gegebenen Versuchsbedingungen sicherlich nicht vor.

Schon in seinem Artikel zu den Prinzipien des Antagonismus äußerte sich PARK (1960) kritisch darüber, nur einen Wirkmechanismus für den komplexen Vorgang der Hemmung 
bodenbürtiger Pilze verantwortlich machen zu wollen. Mikrobielle Antagonisten, die über mehrere Wirkmechanismen verfügen, sind gegenüber solchen mit nur einem Mechanismus grundsätzlich als wertvoller einzuschätzen (ELAD 1993). So geben COOK \& BAKER (1983) zu bedenken, dass biologische Bekämpfung, die nur auf Antibiose beruhen, wahrscheinlich nicht beständiger ist, als die Bekämpfung mit selektiven Fungiziden. So wurde die Ausscheidung extrazellulärer Enzyme, vor allem der pilzzellwandabbauenden Chitinase und ß-1.3-Glucanase, als möglicher Mechanismus der antagonistischen Wirkung neben der Antibiose in den letzten Jahren untersucht.

DUNNE et al. (1996) demonstrierten durch Verwendung chitinasedefekter Transposonmutanten von Stenotrophomonas maltophilia die Beteiligung von Chitinasen an der Hemmung von Pythium ultimum an der Zuckerrübe. In den Versuchen von CHERNIN et al. (1995) wurde die chitinolytische Aktivität des Rhizosphärenbakteriums Enterobacter agglomerans als die hauptsächliche Ursache für die gute befallsvermindernde Wirkung im Testsystem Rhizoctonia solani-Baumwolle identifiziert. Es wurden zwei Transposon (Tn5)Mutanten des Stammes IC1270 ohne chitinolytische Aktivität, eine davon mit, die andere ohne in vitro-Hemmwirkung gegen Rhizoctonia solani und gegen einige andere phytopathogene Pilze verwendet. Im Gewächshausversuch konnte gezeigt werden, dass beide Mutanten einen signifikant schlechteren Bekämpfungserfolg aufwiesen, als Isolate mit chitinolytischer Aktivität. Die Mutante, die nur noch die in vitro-Hemmwirkung aufwies, erreichte nur eine geringe, nicht signifikant befallsvermindernde Wirkung im Gewächshausversuch. Die in vitro-Hemmwirkung wurde Pyrrolnitrin zugeschrieben, dessen Bildung von den Autoren allerdings nur als eine Art "Hilfs-Mechanismus" für die Wirkung der Chitinasen bezeichnet wurde. Dem selben Autor gelang es, die Anzahl erkrankter Pflanzen im System Rhizoctonia solani- Baumwolle durch einen gentechnisch veränderten Stamm von E. coli signifikant zu reduzieren (CHERNIN et al., 1997). In diesen Versuchen wurde das ChiAGen aus Enterobacter agglomerans, das für Endochitinase kodiert, durch Transformation auf einen E. coli übertragen. Dieser rekombinante E. coli-Stamm produzierte nur eine von drei Chitinasen, die bei Enterobacter agglomerans nachgewiesen wurden. Darin sieht auch der Autor die Ursache für dessen signifikant geringere Enzymproduktion. Eine in vitroHemmwirkung des rekombinanten E. coli-Stammes gegen Rhizoctonia solani wurde ebenfalls nachgewiesen, diese war jedoch geringer als bei Enterobacter agglomerans. Erst eine gründliche Überprüfung einer möglichen Hemmstoffbildung durch das Isolat kann zeigen, wie groß der Anteil der Chitinasen an der gezeigten in vitro-Hemmwirkung wirklich ist. Durch Vergleich von acht $P$. fluorescens Isolaten mit Chitinase- bzw. beta-1,3-Glucanase Aktivität beobachteten VELAZHAHAN et al. (1999) einen signifikanten Zusammenhang zwischen der antagonistischen Aktivität gegen Rhizoctonia solani an Reis und der Chitinasebildung. Im Gegensatz zu diesen Beispielen isolierten DE BOER et al. (1998) sowie MAURER (1999) chitinolytische Bodenbakterien (u. a. Pseudomonas spp, Xanthomonas spp, 
Cytophaga spp, Actinomyceten) und stellten fest, dass in den meisten Fällen die Aktivität der Chitinasen in vitro nicht mit dem Bekämpfungserfolg ad planta korrelierte. Auch liegt bislang noch keine Arbeit vor, die den Zusammenhang zwischen einer ß-1,3-Glucanase Aktivität in vitro und der Hemmwirkung eines Antagonisten ad planta zeigt.

In der vorliegenden Arbeit konnte eine Chitinase- bzw. ß-1,3-Glukansasebildung durch Pseudomonas fluorescens RII2 sowie Paenibacillus polymyxa HA3e in dem Komplexmedium TSB nachgewiesen werden. Allerdings war bei Verwendung des nährstoffarmen Mediums (SE), in dem die C- und N-Verfügbarkeit den Versuchsbedingungen ad planta eher entsprechen sollten, fast keine Enzymaktivitäten messbar. Damit kann aber eine Parasitierung des Zielpathogens durch RII2 bzw. HA3e noch nicht ausgeschlossen werden. Die Bedeutung der Chitinasen bzw. ß-1,3-Glucanasen bei der Hemmung von L. maculans in situ lässt sich nur durch die Verwendung von Chitinase- bzw. ß-1,3-glucanasedefekten Mutanten eindeutig klären, was im Rahmen dieser Arbeit allerdings nicht durchgeführt werden konnte. Auch sollte erwähnt werden, dass die hohen Feuchtigkeitsansprüche der Hyperparasiten für eine ausreichende Wirksamkeit, in der Praxis häufig kaum zu erfüllen sind (PHILIPP \& HELLSTERN 1986).

Konkurrenz stellt eine der häufigsten Interaktionen zwischen Mikroorganismen sowohl in der Rhizosphäre als auch auf der Phylloplane dar. Mikroorganismen konkurrieren um Nährstoffe, Vitamine, Wasser, Sauerstoff, Lebensraum und andere wachstumslimitierende Faktoren. Zahlreiche grundlegende Untersuchungen konnten die Bedeutung des C- und NHaushalts für die Suppressivität antagonistischer Organismen in der Rhizosphäre herausstellen (Review: BAKER 1968). Methodisch ist der Nachweis eines konkurrenzbedingten Antagonismus schwer zu führen. Meist wurde Konkurrenz als Wirkmechanismus angenommen, wenn keine der anderen bekannten Hemmfaktoren gefunden werden konnten (ELAD \& BAKER 1985, ELAD \& CHET 1987, KRAUS \& LOPER 1992). Räumliche Konkurrenz fußt auf der einfachen Tatsache, dass Nischen und Infektionsstellen auf der Pflanzenoberfläche, die der Antagonist besetzt, nicht mehr durch das Pathogen besiedelt werden können.

Neuere Arbeiten entwickelten Bekämpfungsstrategien der durch Fusarium oxysporum verursachten Welkekrankheiten (ALABOUVETTE et al. 1993). Als Antagonisten wurden apathogene F. oxysporum-Stämme verwendet. Konkurrenz um Nährstoffe und zu besiedelnde Oberfläche zwischen den pathogenen und apathogenen Stämmen gilt als essentielles Wirkprinzip (EPARVIER \& ALABOUVETTE 1994). Das Prinzip erwies sich als so erfolgreich, dass ein $F$. oxysporum-Präparat in verschiedenen Ländern kommerzialisiert wurde (LUMSDEN 1995). Auch die klassische Bekämpfung von Agrobacterium tumefaciens mit apathogenen $A$. radiobacter-Stämmen beruht auf der Konkurrenz bei der Besiedlung der 
Wurzeloberfläche sowie auf der Fähigkeit von Agrobacterium radiobacter K84, die Antibiotika Agrocin 84 und 434 zu bilden (MCCLURE et al. 1998)

Um Erkenntnisse zur Konkurrenz um Raum und Bindungsstellen auf der Pflanzenoberfläche zu erhalten, wurde in der vorliegenden Arbeit die Oberfläche des Wurzelhalses und der Stengelbasis nach Aufbringung von Ps. fluorescens RII2 und Paenibacillus polymyxa HA3e rasterelektronenmikroskopisch untersucht. Anhand der mikroskopischen Aufnahmen wurde deutlich, dass im Fall von Ps.fluorescens RIl2 die Stängelbasis- bzw. die Wurzelhalsoberfläche fast gänzlich und im Fall von Paenibacillus polymyxa HA3e vor allem die Nischen des Stengels in den Furchen zwischen den Epidermiszellen von Bakterienzellen besiedelt wurden, an denen sich auch Wasser und damit sehr wahrscheinlich auch die Sporen von L. maculans ansammeln.

Seit dem Ende der 80er Jahre des letzen Jahrhunderts setzen zahlreiche Autoren große Hoffnung in die Nutzung der induzierten Resistenz zur biologischen Bekämpfung (Reviews: STICHER et al. 1997, VAN LOON et al. 1998). Anders als die SAR (Systemic Acquired Resistance), die durch das Pathogen induziert wird, gruppierten VAN LOON et al. (1998) die durch Rhizobakterien hervorgerufene Resistenz in die ISR (Induced Systemic Resistance) ein. Gegen Pilze, Bakterien und Viren in Arabidopsis (PIETERSE et al. 1996), Gartennelke (VAN PEer 1991), Bohnen (Alström 1991, Chang et al. 1993, BIRGIRIMANA1997,), Gurke (KLOEPER et al. 1993, LIU et al. 1995, RAUPACH et al. 1996, WASTERNACK \& PARTHIER 1997, Wel et al. 1991, ZHOU \& PAULITZ 1994, ZEHNDER et al. 1997,), Rettich (HOFFLAND et al. 1995 und 1996, LeEMAN 1996), Tabak (MAURHOFER et al. 1994, De MeYER \& HÖFTE 1997, PRESS et al. 1997, TROXLER et al. 1997) und Tomaten (DUIJFF et al. 1996, RAUPACH et al. 1996) konnte Resistenz unter Bedingungen erzeugt werden, in denen die induzierenden Bakterien und die aggressiven Pathogene räumlich voneinander getrennt waren.

Gereinigte Lipopolysaccharide (LPS) der bakteriellen Außenmembran von P. fluorescens WCS417 waren ebenso effektiv wie lebende Zellen, um bei der Gartennelke Resistenz gegen die Fusarium-Welke auszulösen. Den gleichen Effekt erzielte man mit gereinigten Siderophoren von Pseudomonas fluorescens WCS374 (VAN PEER \& SCHIPPERS 1992). Die Siderophoren von Pseudomonas fluorescens CHA0, Pyoverdin und Salizylsäure, wurden von MEYER et al. (1992) als Resistenzinduktoren beschrieben. Während die SAR mit der Expression von PR-Proteinen in der Pflanze häufig korreliert, ist die ISR generell nicht damit verknüpft (VAN LOON et al. 1998). Allerdings bestätigten MAUERHOFER et al. (1994) eine enge Beziehung zwischen der Bildung von PR-Proteinen und der durch Pseudomonas fluorescens $\mathrm{CHAO}$ induzierten Resistenz gegen TMV in Tabak. 
Im Gegensatz zu den anerkannten Resistenzinduktoren, wie z. B. Ethylen (BOLLER 1982) und Acetylsalicylsäure (MILLS \& WOOD 1984), sind bei der Anwendung von Mikroorganismen indirekte Effekte (Organismus-Pflanze) nicht immer deutlich von direkten Effekten (Organismus-Pathogen) zu trennen (BLAKEMAN \& FOKKEMA 1982). So ist der Nachweis induzierter Resistenz erheblich schwerer zu führen, als z. B. die Wirkung eines Fungizides (SCHÖNBECK et al. 1993). Gesonderte Untersuchungen zum Vorliegen induzierter Resistenz wurden daher im Rahmen dieser Arbeit nicht durchgeführt. Die Ergebnisse der Besiedlungsversuche geben allerdings Hinweise darauf, dass eine lokale bzw. systemische Resistenzinduktion durch Pseudomonas fluorescens RII2 bzw. Paenibacillus polymyxa HA3e möglich ist.

Nachdem 1996 (GöRLACH et al.) der chemische Resistenzinduktor Benzothiadiazole (BTH, BION) gegen u. a. Mehltau an Weizen kommerzialisiert wurde, wird die Entdeckung von Substanzen mit ähnlicher Funktion immer reizvoller. Um eine permanente Immunisierung zu gewährleisten, stehen die Pflanzen nach Behandlung mit solchen Substanzen häufig unter Dauerstress. Darüber hinaus bestehen noch erhebliche Unklarheiten bezüglich der zugrundeliegenden Mechanismen und möglichen Folgen.

Nach neuen Berichten erscheint es durchaus möglich, dass die Anwendung von Bion auch phythotoxische Effekte an Weizen hervorruft, die zu einem Minderertrag führen. Somit scheint auch die Anwendung permanenter Resistenzinduktoren mit negativen Effekten verbunden zu sein. Aus diesem Grund wäre es sinnvoll, nach Substanzen zu suchen, die eine Resistenz in der Pflanze lediglich für die empfindlichen Befallsstadien auslösen.

\subsection{Ausblick}

Während die biologische Bekämpfung tierischer Schädlinge weltweit breiten Einzug in die landwirtschaftliche Praxis gefunden hat, vor allem mit Präparaten auf der Basis von $B$. thuringiensis, ist die Umsetzung der Forschungsergebnisse in praxisreife Präparate und Verfahren bei der Bekämpfung von Pflanzenkrankheiten mit mikrobiellen Antagonisten in der Vergangenheit oft hinter den Erwartungen zurückgeblieben. Vor allem spielt der wirtschaftliche Aspekt hier eine Rolle. Die Diskrepanz zwischen der Profitabilität der Produkte und den Kosten der Registrierung wird als eine wichtige Ursache für die langsame Umsetzung in die Praxis angesehen.

Mittlerweile haben ca. 40 biologische Präparate auf der Basis antagonistischer Bakterien und Pilze eine Marktzulassung erhalten (LUMSDEN et al. 1995, KOCH 1996, JAHN 1998) und wurden erfolgreich auf dem Markt eingeführt. Oft handelt es sich allerdings um „Nischenprodukte“ mit begrenztem Anwendungsgebiet und Marktpotential. Derzeit 
beschränkt sich die Anwendung biologischer Präparate zur Bekämpfung von Pathogenen vornehmlich auf hochwertige Kulturen (Zierpflanzen, Obst und Gemüse etc.) und Bodenpathogenen, bei denen Bekämpfungslücken oder -beschränkungen (z. B. Wasserschutzauflagen) bestehen, bzw. der Einsatz unter kontrollierten Bedingungen stattfindet, und sie in definierten Umgebungen der Gewebekulturlaboratorien (BERGER et al. 1996), Gewächshäuser (KOCH 1996, BUCHENAUER 1998) oder hydroponischen Kulturen (KOCH 1996a) dem chemischen Pflanzenschutz überlegen sind.

Dass Biokontrollorganismen häufig ihre antagonistischen Wirkungen nur unter genau definierten Umweltbedingungen in ganz bestimmten Wirt-Pathogen Systemen entfalten, führt unter Praxisbedingungen zu gravierenden Problemen. Die mangelnde Wirkungssicherheit ist unter anderem einer der wesentlichen Gründe für das Nischendasein biologischer Pflanzenschutzverfahren (WELLER et al. 1995). Die zu hohe Wirkungsunsicherheit biologischer Präparate führt auch dazu, dass sowohl die Industrie als auch der Landwirt eine abwartende Zurückhaltung einnehmen (TILCHER 1996).

Mangelnde Wirkungssicherheit basiert neben der unzureichenden Erprobung unter Freilandbedingungen auf noch immer nicht vollständig verstandenen Mechanismen. Die den Effekten mikrobieller Antagonisten zugrundeliegenden Mechanismen setzen aber ein ausgiebiges Wissen um die Interaktion zwischen Mikroorganismen, Wirtspflanze und Umwelt im Boden oder auf der Pflanzenoberfläche voraus. Darüber hinaus sollten zur gezielten und verbesserten Bekämpfung die Kenntnisse über die Biologie des Pathogens und die Epidemie der Krankheit vertieft werden.

Nach Ansicht verschiedener Forscher eröffnen sich der biologischen Bekämpfung neue interessante Perspektiven mit der Entwicklung gentechnischer Verfahren. MAURHOFER et al. (1992) sowie LIGON et al. (1996) konnten durch gezielte Mutation des Antagonistengenoms die Bildung von Antimykotika verstärken. Nach VAN OVERBEEK \& ELSAS (1995) könnte die Antibiotikaproduktion durch die Verwendung von geeigneten, auf Wurzelexsudate reagierenden Promotoren zielgenau am Einsatzort ausgelöst werden. Diese transgenen Antagonisten werden im Vergleich zu dem kontinuierlich Hemmstoff-synthesierenden Wildtyp weniger durch die eigenen Metabolite gestresst. Nebeneffekte auf Nichtzielorganismen können dadurch verringert werden. Das Bekämpfungspotential der gesteuerten Antibiotikabildung soll beachtlich sein. Schon seit längerer Zeit wird daran gedacht, Gene, die antagonistische Faktoren kodieren, über Artgrenzen hinweg zu transferieren, und somit maßgeschneiderte mikrobielle Gegenspieler zu erschaffen (DEFAGO \& HAAS 1990, GLICK 1995). DoWLING et al. (1995) versuchten in fluoreszierende Pseudomonaden artfremde Siderophorenrezeptoren einzubauen. Trotzdem ist es noch niemandem gelungen, die für unterschiedliche antifungale Mechanismen verantwortlichen Gene aus verschiedenen Arten 
in einem Antagonistenstamm zu kombinieren und zur Expression zu bringen. Das Interesse nimmt merklich zu, allein durch die Gentechnologie potente Antagonisten zu kreieren. Als Beispiele hierfür steht die Konstruktion von Mikroorganismen mit der Fähigkeit Pflanzenoberflächen sehr schnell zu besiedeln, die Umwandlung von Epiphyten in wirksame Antagonisten oder nützliche Hypoparasiten, die Veränderung eines Pathogens in ein Apathogen. Erfahrungen liegen dazu allerdings bislang noch nicht vor.

Eine reproduzierbare Wirkung der meisten Biokontrollagenzien setzt in der Regel stabile Umweltbedingungen voraus, welche im Freiland nicht zu realisieren sind. Zur Reduzierung des dramatischen Einflusses der Umweltbedingungen auf die Wirkung der Biokontrollorganismen versuchten einige Autoren nur die für die Wirkung verantwortlichen mikrobiellen Gene in die Pflanze zu transferieren und verzichteten somit auf den Einsatz der labilen Mikroorganismen. Chitinasegene sind sehr attraktiv, da Chitinasen als Teil des pflanzlichen Abwehrsystems angesehen werden und sich zudem als fungizid aber nicht toxisch für Pflanzen, Tiere und höhere Wirbeltiere erwiesen. Daher wurden Pflanzen verschiedener Kulturarten mit Chitinasegene bakterieller bzw. pilzlicher Herkunft produziert. Die mit der Erzeugung dieser transgenen Pflanzen relevanten molekularbiologischen Techniken wurden bereits patentiert. Jedoch blieb in meisten Fällen das Resistenzspektrum und -niveau transgener Pflanzen hinter den Erwartungen zurück, so dass die Technologie für die kommerzielle Landwirtschaft bzw. für die Züchtung neuer resistenten Sorten noch nicht praxisreif ist. Bislang ist es lediglich in einem Beispiel gelungen, durch Einbau eines einzigen Endochitinase-Gens aus Trichoderma harzianum, die Widerstandsfähigkeit transgener Tabak- und Kartoffelpflanzen gegen Alternaria alternata, A. solani, Botrytis cinerea sowie Rhizoctonia solani wesentlich zu erhöhen (LORITO et al. 1998). Die Expression von Chitinasen durch Genkombinationen zu verbessern ist kaum attraktiv, da ein höherer Grad an genetischer Modifikation der Pflanzen die Kosten der Produktentwicklung wesentlich erhöhen und die Registrierung in einigen Ländern erschweren und verzögern kann. Die Ergebnisse demonstrierten dennoch, dass die pilzlichen Antagonisten über eine ergiebige Quelle potentieller Resistenzgene verfügen. Die Verwendung gentechnisch veränderter Kulturpflanzen stößt dessen ungeachtet, besonders in Deutschland, bei weiten Teilen der Bevölkerung aufgrund mangelnder Sicherheitsabschätzung auf nur geringe Akzeptanz (LÜCHS \& FRIEDT 1997).

Der biologische Pflanzenschutz befindet sich im Vergleich zum chemischen Pflanzenschutz noch in einer marginalen Position (POWELL \& JUTSUM 1993). Eine intensivierte Forschung und die Forderung weiter Kreise der Bevölkerung nach einem pestizidfreien Pflanzenschutz lassen hoffen, dass in Zukunft auch in Deutschland weitere biologische Kontrollagenzien zugelassen werden und sich die Liste der vermarkteten Produkte verlängert. Mit dieser Arbeit und den dargestellten ersten Ansätzen zur biologischen Bekämpfung eines der 
wichtigsten Rapspathogene sollte ein Beitrag dazu geleistet werden. Im Zuge der Entwicklung eines biologischen Präparates gegen Leptosphaeria maculans sind indes noch entscheidende Schritte durchzuführen: unter anderem die Optimierung der Applikation, die Auswahl geeigneter Nährstoffe zur Förderung des Überlebens und der Aktivität der Antagonisten unter Freilandbedingungen, die Optimierung der Fermentations- und Formulierungsprozesse sowie Lagerungstechnik. Grundsätzlich ist auch zu bedenken, ob in künftigen Screeningsverfahren pflanzenwachstumsfördernde bzw. resistenzinduzierende Mikroorganismen bevorzugt selektiert werden sollten. 


\section{Zusammenfassung}

Aus Komposterde und der Rhizosphäre verschiedener Pflanzen wurden 109 bakterielle und 19 pilzliche Antagonisten mit einer in vitro-Hemmwirkung gegen Leptosphaeria maculans (Anamorph Phoma lingam), dem Erreger der Wurzelhals- und Stängelfäule an Winterraps isoliert. 58 der bakteriellen Isolate hemmten das Myzelwachstum von L. maculans und Verticllium longisporum auf verschiedenen Nährmedien. Viele der Antagonisten waren auch gegenüber anderen pilzlichen Krankheitserregern des Winterraps, Winterweizens sowie der Zuckerrübe wirksam. Aufgrund einer breiten antibakteriellen Wirkung wurden einige Isolate von den nachfolgenden Versuchen ausgeschlossen.

Anhand morphologischer und physiologischer Eigenschaften erfolgte frühzeitig eine taxonomische Einordnung, um human- und phytopathogene Bakterien von den ad plantaVersuchen auszuschließen. Die Bestimmung mit den kommerziellen Testsystemen API und Biolog führte zur Identifizierung von Pseudomonas fluorescens, Serratia plymuthica, Paenibacillus polymyxa und Bacillus circulans.

18 der isolierten Bakterienarten und 3 Stämme aus der Antagonisten-Sammlung wurden für das ad planta-Vorscreening im Gewächshaus ausgewählt. Dabei dienten die Siderophorenbildung auf CAS (35 positive Isolate) sowie eine hohe Chitinase- und B-1,3-Glucanaseaktivität als Kriterium. Darüber hinaus erfolgte eine Überprüfung der Hemmwirkung auf dem nährstoffarmen Strohextraktagar und bei einer niedrigen Temperatur von $8^{\circ} \mathrm{C}$. Alle ausgewählten Bakterien konnten das Wachstum von L. maculans hierbei deutlich hemmen.

In Besiedlungsstudien konnte gezeigt werden, das ausgehend von einer Samenbehandlung eine deutlich bessere Besiedlung der Rapspflanzen durch die Pseudomonaden und von Serratia plymuthica im Vergleich zu den Gram-positiven Bacilli zu beobachten war.

Den Befall der Rapscotyledonen mit L. maculans konnten 20 der getesteten 21 Bakterienstämme bis zu 21 Tage nach der Infektion von 6-8 Tage alten Keimlingen in unterschiedlichem Ausmaß vermindern. Pseudomonas fluorescens Gö2l erzielte einen Wirkungsgrad von 73\%. Die Isolate Ps. fluorescens RII2 und KAR1, Paenibacillus polymxya HA3e sowie B. circulans KOM1 und KOM19 reduzierten den L. maculans-Befall um 50\%. Basierend auf diesen Ergebnissen wurden 8 Isolate selektiert und auf ihre Hemmwirkung an Jungpflanzen im Entwicklungsstadium $\mathrm{BBCH} 14 / 15$ untersucht.

Hierzu wurde eine naturnahe Infektionsmethode, ohne vorherige künstliche Verletzung der Pflanze, unter Verwendung von Pyknidiosporen und Ascosporen entwickelt. Die Antagonisten wurden als Suspensionen $\left(10^{9} \mathrm{cfu} / \mathrm{ml}\right)$ auf den Wurzelhals und die Stengelbasis der Pflanzen 
appliziert. Zwei Tage später erfolgte die Infektion mit einer Pyknidiosporensuspension $\left(10^{7} / \mathrm{ml}\right)$. Nach weiteren 49 Tagen wurde der Befall mit Hilfe eines im Rahmen dieser Arbeit entwickelten ELISA (Enzyme-Linked Immunosorbent Assay) bestimmt. Von 8 Isolaten erwiesen sich Paenibacillus polymxya HA3e, Ps. fluorescens RII2 und B. circulans Kom19 als sehr wirksam. Die kombinierte Anwendung von HA3e und RIl2 konnte die Befallsverminderung der Pflanzen im Vergleich zu den Einzelanwendungen von 53.1 \% bzw. $42.3 \%$ auf $85.9 \%$ signifikant erhöhen.

Zur Quantifizierung des Befalls wurde ein DAS-ELISA optimiert, mit dessen Hilfe auch die Ausbreitung von L. maculans am Wurzelhals und an der Stängelbasis untersucht wurde. Eine systemische Verbreitung des Pilzes in der Pflanze war nicht zu beobachten. L. maculans breitete sich mit zunehmendem Befall auf- und abwärts am Stängelgrund- und im Wurzelhalsbereich, mit einem Maximum im Bereich von $5 \mathrm{~cm}$ um die Infektionsstelle herum, aus. Dieser Bereich wurde für die Befallsquantifizierung herangezogen.

Der Einfluss des Pilzbefalls auf die Kornertragsbildung wurde mit Hilfe von Analysen an Einzelpflanzen der anfälligen Sorte Cobra untersucht. Eine enge Korrelation wurde zwischen der Ertragsverminderung und dem Befall $(r=-0,7159 ; p=0,01)$ ermittelt. Die Ertragsverminderung bei einem starken Befall betrug 28,3\%, bei leichtem Befall lediglich 3,3\%.

Eindeutig pflanzenwachstumsfördernde Effekte konnten bei der Gießbehandlung mit Ps. fluorescens RII2 und Paenibacillus polymxa HA3e nicht festgestellt werden. Phytotoxische Wirkungen traten allerdings dann auf, wenn die Wurzeln der Rapskeimlinge für eine Stunde in eine $5 \times 10^{9} \mathrm{cfu} / \mathrm{ml}$ konzentrierte Suspension einer dieser beiden Antagonisten eingetaucht wurden.

HPLC-analytisch konnte für Ps. fluorescens RIl2 die Bildung der Antibiotika DAPG und Pyrrolnitrin sowie anhand colorimetrischer Tests auch HCN und IAA ( $>1 \mu \mathrm{g} / \mathrm{ml})$ nachgewiesen werden. Pyrrolnitrin zeigte eine fungizide Wirkung gegen L. maculans im Plättchentest bereits bei einer Konzentration von 2 ppm.

Cryorasterelektronenmikroskopisch waren Bakterien auf der Oberfläche von Wurzelhals und Stängelbasis der Rapspflanzen nach deren Behandlung mit einer Xanthan-Antagonistensuspension zu erkennen. Die geringen Populationsdichten könnte darauf hindeuten, dass sich Ps. fluorescens R2II und Paenibacillus polymxya HA3e bei geringen Feuchtigkeiten nur schwach auf der oberirdischen Pflanzenoberfläche etablieren können. 


\section{Literatur}

AHLERS, D. 1987: Untersuchungen über den Erreger der krankhaften Abreife an Winterraps. Gesunde Pflanzen 39: 375-383

Alabouvette, C. Lemanceau, P. \& SteinberG, C. 1993: Recent advances in the biological control of fusarium wilts. Pestic. Sci. 37: 365-373

Alabouvette, C. \& Brunin, B. 1970: Recherches sur la maladie du colza due à Leptosphaeria maculans (Desm.) Ces. Et de Not. I. Rôle des restes de culture dans la conservation et la dissémination du parasite. Ann. Phytopathol. 2: 463-475

AleXANDER, D. B. \& Zuberer, D. A. 1991: Use of chrome azurol S reagents to evaluate siderophore production by rhizosphere bacteria. Biol. Fertil. Soils 12: 39-45

ALLEN, J.D. \& SMITH, H.C. 1961: Drey-rot (Leptosphaeria maculans) of brassicas: Seed transmission and treatment. New Zeal. Journal of Agricultural Research 4: 676-685

ALPMANN, L. \& NÖLKENSMEIER, M. 1999: Grundlagen für hohe rapserträge bereits im Herbst legen. Innovation (3): 2-3

ALSTRÖM, S. 1991. Induction of disease resistance in common bean susceptible to halo blight bacterial pathogen after seed bacterization with rhizosphere pseudomonads. J. Gen. Appl. Microbiol. 37: 495-501

Amelung, D., Schulz, R.-R. \& DAebler, F. 1996: Einfluß der Fruchtfolge auf Rapskrankheiten. Raps 14: $52-55$

Andrade, D.E.G.T., Gomes, A.M.A., Silva, E.B., PeiXoto, A.R., Ferreira, A.S., MicherefF, S.J. und R.L.R. MARIANO 1994: Bean seed bacterization with Bacillus spp. and fluorescent pseudomonads for Rhizoctonia solani biocontrol. IN: Improving plant productivity with rhizosphere bacteria, Ryder, M.H., Stephens, P.M. und G.D. Bowen (eds.), Graphic Services, Adelaide: $77-79$

ANDREWS, J.H. 1992: Biological control in the phyllosphere. Ann. Rev. Phytopathol. 30: 603-635

ANNIS, S.L. \& GoODWIN, P.H. 1996: Comparison of cell wall-degrading enzymes produced by highly and weakly virulent isolates of Leptosphaeria maculans in cultures. Microbiol. Res. 151: 401-406.

Ansan-Melayah, D., Balesdent, M.-H., Delourme, R., Pilet, M.L., Tanguy, X., enard, M. \& ROUXEL, T. 1998: Genes for race-specific resistance against blackleg disease in Brassica napus L. Plant Breeding 117: 373-378.

Ash, C., Priest, F. G. \& Collins, M. D. 1993: Molecular identification of rRNA group 3 bacilli (Ash, Farrow, Wallbanks \& Collins) using a PCR probe test. Proposal for the reaction of a new genus Paenibacillus. Antonie Leeuwenhoek 64: 253-260.

ASKELAND, R.A. \& MORRISON, S.M. 1983: Cyanide production by Pseudomonas fluorescens and Pseudomonas aeruginosa. Appl. Environ. Microbiol. 45: 1802-1807.

ASMUS, E. \& GARSCHAGEN, H. 1953: Über die Verwendung der Barbitursäure für die photometrische Bestimmung von Cyanid und Rhodanid. Z. analyt. Chem. 138: 414-422

BADAWY, H., HOPPE, H.-H. \& KoCH, E. 1991: Differential reactions between the genus Brassica and aggressive single spore isolates of Leptosphaeria maculans. J. Phytopathol. 131: 109-119.

Bailey, D.M. \& Johnson, R.E. 1970: The synthesis of pyoluteorin. Tetrahedron-Lett. Pp. 3555-7

Bailey, D.M. \& Johnson-RE; Salvador-UJ 1973: Pyrrole antibacterial agents. 1. Compounds related to pyoluteorin. J. Med. Chem. 16: 1298-300

BAKER, R. 1968: Mechanisms of biological control of soil-borne pathogens. Ann. Rev. Phytopathol. 6: $263-294$ 
BAKeR, C.J., STAVELY, J.R. \& Mock, N. 1985: Biocontrol of bean rust by Bacillus subtilis under field conditions. Plant Dis. 69: 770-772.

BAKKER, A. W. \& SCHIPPERS, B. 1987: Microbial cyanide production in the Rhizosphere in relation to potato yield reduction and Pseudomonas spp.-mediated plant growth-stimulation. Soil Biol. Biochem. 19: 451-457.

Balesdent, M.-H., DesthieuX, I., Gall, C., Robin, P. \& Rouxel, T. 1995: Quantification of Leptosphaeria maculans growth in cotyledons of Brassica napus using ELISA. J. Phytopathol. 143: 65-73.

Balesdent, M.-H., JedryczKa, M., Jain, L., Mendes-Pereira, E., Bertrandy, J. \& RouXel, T. 1998: Conidia as a Substrate for Internal Transcribed Spacer-Based PCR Identification of Members of the Leptosphaeria maculans Species Complex. Am. Phytopath. Soc. 88: 1210-1217.

Ballinger, D.J., SAlisbury, P.A., Dennis, J.J., Kollmorgen, J.F. \& PotTer, T.D. 1988: Evaluation of fungicides, applied at sowing, for control of blackleg in rapeseed. Austr. J. Exp. Agric. 28: 511-515.

BANSAL, V.K., KHARBAndA, P.D., StRINGAM, G.R., Thiagarajah, M.R. \& TEWARI, J.P. 1994: A comparison of greenhouse and field screening methods for blackleg resistance in double haploid lines of Brassica napus. Plant Dis. 78: 276-281.

BARBETTI, M.J. 1975: Benomyl and carbendazim fail to provide effective control of blackleg in rape. Austr. Plant Path. Soc. Newsletter 4:11-12

BARBETTI, M.J. (1976): The role of pycnidiospores of Leptosphaeria maculans in spread of blackleg disease. Aust. J. Exp. Agric. Animal Hus. 16: 911-914.

Barbetti, M.J., Brown, A.G.P. \& Wood, P. 1977: Prospects for a successful rape crop. J. Agric. West. Austr. Series 4, 16: 7-10.

Barea, JM; Andrade, G; Bianciotto, V; Dowling, D; Lohrke, S; Bonfante, P; OGara, F; AzCONAGUILAR, C. 1998: Impact on arbuscular mycorrhiza formation of Pseudomonas strains used as inoculants for biocontrol of soil-borne fungal plant pathogens. Appl. Environ. Microbiol. 64: $2304-2307$.

BASHI, E. \& FOKKEMA, N.J. 1977: Environmental factors limiting growth of Sporobolomyces roseus, an antagonist of Cochliobolus sativus, on wheat leaves. Trans. Br. Mycol. Soc. 68: 17-25

BAteman, D. F., Jones, T. M. \& Yoder, O. C. 1973: Degradation of corn cell walls by extracellular enzymes produced by Helminthosporium maydis race T. Phytopathology 63: 1523-1529.

BERG, G. 1994: Charakterisierung der Rhizosphärenbakterien von Brassica napus L. (Raps) und ihrer antifungischen Wirkmechanismen gegen Verticillium dahliae Kleb. Dissertation, Universität Rostock.

BERG, G. 1996: Rhizobacteria of oilseed rape antagonistic to Verticillium dahliae var. longisporum STARK. Z PflKrankh. Pflschutz 103: 20-30.

BERG, G., KNAAPE, C., BALlin, G. UND SEIDEL, D. 1994: Biological control of Verticillium dahliae Kleb. by natural occurring rhizosphere bacteria. Arch. Phytopath. PflSchutz 29: 249-262.

Berger, F., Hong, L., White, D., Frazer, R. \& Leifert, C. 1996: Effect of pathogen inoculum, antagonist density, and plant species on biological control of Phytophthora and Pythium dampingoff by Bacillus subtilis Cot1 in high-humidity fogging glasshouses. Phytopathology 86: 428-433.

BERTRAM, H.-J. (1996): Zukunftsmärkte sichern. Raps 14: 140-142.

BIN, L., Knudson, G.R. \& Eschen, D. J. 1991: Influence of an antagonistic strain of Pseudomonas fluorescens on growth abd ability of Trichoderma harzianum to colonize sclerotia of Sclerotinia sclerotiorum in soil. Phytopathology 81: 994-1000. 
Bigirimana, J., De MeYer, G., Poppe, J., Elad, Y., Höfte, M. 1997: Induction of systemic resistance on bean (Phaseolus vulgaris) by Trichoderma harzianum. Med. Fac. Landbouwwet. Gent. In press

BLAKEMAN, J.P. und N.J. FoKKEMA 1982: Potential for biological control of plant diseases on the phylloplane. Ann. Rev. Phytopathol. 20: 167-192

Bloemberg, G. V., G. A. O'Toole, B. J. Lugtenberg, und R. Kolter. 1997. Green fluorescent protein as a marker for Pseudomonas spp. Appl. Environ. Microbiol. 63:4543-4551.

BLUMER, C. \& HAAS, D. 2000: Iron regulation of the henABC genes encoding hydrogen cyanide synthase depends on the anaerobic regulator ANR rather than on the global activator GacA in Pseudomonas fluorescens CHA0. Microbiology 146: 2417-2424.

BoEREMA, G.H. \& VAN KeSTEREN, H.A. 1964: The nomenclatue of two fungi paratizing Brassica. Persoonia 3: 17-28.

Bokor, A., Barbetti, M.J., Brown, A.G.P., MacNish, G.C. \& WoOd, P. 1975: Blackleg of rapeseed. J. Agric. Western Australia 16: 7-10.

BOLLER, T. 1982: Ethylene-induced biochemical defenses against pathogens. In: WARING, P. F. (ed.): Plant growth subsatnces. Acedemic Press, London, 303-312.

Bouma,T.J., Nielsen, K. L. \& KoUtSTAAL, B. 2000: Sample preparation and scanning protocol for computerised analysis of root length and diameter. Plant and Soil 218: 1-2, 185-196.

Bowers, J. H. \& PARKe, J. L. 1993: Colonization of pea (Pisum sativum L.) taproots by Pseudomonas fluorescens: Effect of soil temperature and bacterial motility. Soil Biol. Biochem. 25: 1693-1701.

BRANDL, M.T. \& Lindow, S. E. 1998: Contribution of Indole-3-Acetic Acid Production to the Epiphytic Fitness of Erwinia herbicola Appl Environ. Microbiol. 64: 3256-3263.

BRADFORD, M.M. 1976: A rapid and sensitive method for the quantitation of microgram quanties of protein utilising the principle of protein-dye binding. Anal. Biochem. 72: 248-254

BRISBANE, P.G., JANIK, L.J., TATE, M.E. und R.F.O. WARREN 1987: Revised structure for the phenazine antibiotic from Pseudomonas fluorescens 2-79 NRRL B-15132. Antimicrob. Agents Chemother. 31: 1967-1972

BRock, T.D. \& M.T. MADIGAN 1991: Biology of microorganisms, Prentice-Hall International, Inc., New Jersey

Broschewitz, B. \& SteINBACH, P. 1993: Einfluß stengelbewohnender tierischer Schaderreger auf den Befall von Winterraps mit Phoma lingam und Botrytis cinerea. Gesunde Pflanzen 45: 106110.

BROADBENT, P., BAKKER, K.F. \& WATERWORTH, Y. 1971: Bacteria and actinomycetes antagonistic to fungal roor pathogens in austrlian soils. Aust. J. biol. Sci. 24: 925-944.

BROWN, A.G.P., BARBETTI, M.J., WOOD, P. MCR. 1976: Effect of benomyl on blackleg disease of rape in western Australia. Austr. J. Exp. Agric. Animal Hus. 16: 276-279.

BRUNIN, B. 1972: Action en champ du bénomyl contre Leptosphaeria maculans (desm.) Ces. et de Not., agent de la nécrose du collet de colza. Phytiatrie-Phytopharmacie 21 : 143-150.

Buberl, C. 1992: Differenzierung quantitativer Resistenzeigenschaften bei Raps-Genotypen gegen Leptosphaeria maculans (Desm.) Ces. et de Not. Diss TU München-Weihenstephan.

Buchenauer, H. 1998: Biological control of soil-borne diseases by rhizobacteria. Z. PflKrankh. PflSchutz. 105: 329-348.

BUNDESSORTENAMT 1993-2000: Beschreibende Sortenliste für Getreide, Mais, Ölfrüchte und Hackfrüchte. Hrsg. Bundessortenamt - Strothe Verlag, Hannover. 
BurKheAD, K.D., SchisLer, D.A. und P.J. Slininger 1994: Pyrrolnitrin production by biological control agent Pseudomonas cepacia B37w in culture and in colonized wounds of potatoes. Appl. Environ. Microbiol. 60: 2031-2039.

Burr, T. J., Matheson, M. C. Smith, C. A., Corral-Garcia, M.R. \& Huang, T.-C. 1996: Effectiveness of bacteria and yeasts from apple orchards as biological control agents of apple scab. Biological Control 6: 151-157.

Busch, H. 1987: Resistenzzüchtung bei 00-Winterraps. Arbeitstagung 1987 der „Arbeitsgemeinschaft der Saatzuchtleiter" Irdning, Österreich, 101-113.

BUYER, J.S. \& LEONG, J. 1986: Iron transport-mediated antagonism between plant-growth-promoting and plant-deleterious Pseudomonas strains. J. biol. Chem. 261: 791-794

Buyer, J. S., Sikora, L. J. \& Chanley, R. L. 1989: A new growth medium for the study of siderophore-mediates interactions. Biol. Fertil. Soils 8: 97-101.

Callan, N.W., MAthre, D. E: \& Miller, J. B: 1990: Biopriming treatment for biological control of Pythium ultimum damping-off in sh2 sweet corn. Plant Dis. 74: 368-372.

CAllan, N. W., Mathre, D. E. \& Miller, J. B. 1991: Field performance of sweet corn seed bioprimed and coated with Pseudomonas fluorescens AB254. Hort. Science 26: 1163-1165.

CAMPBELL, R. 1994: Biological control of soil-borne diseases: some present problems and different approaches. Crop Protection 13: 4-13

CAMPBell, R. \& GREAVES, M. P. 1990: Anatomy and community structure in the rhizosphere. In: LyNCH, J. M. (ed.): The Rhizosphere. Wiley \& Sons, Chichester, England, pp. 11-34.

CAMpbell, R. \& Rovira, A. D. 1973: The study of he rhizosphere by scanning electron microscopy. Soil Biol. Biochem. 5: 747-752.

CARgeeg, L.A. \& Thurling, N. 1980: Contribution of host-pathogen interactions to the expression of the blackleg disease of spring rape (Brassica napus L.) caused by Leptosphaeria maculans (Desm.) Ces. Et de Not. Euphytica 29: 465-476.

CARMI, R. \& CAMELI, S. 1994: (+)-(S)-Dihydroaeruginoic acid, an inhibitor of Septoria tritici and other phytopathogenic fungi and bacteria, produced by Pseudomonas fluorescens. J. Nat. Prod. 57: $1200-1205$

CARTwRight, D.K. \& BENSON, D.M. 1995: Optimization of biological control of Rhizoctonia stem rot of Poinsettia by Paecilomyces lilacinus and Pseudomonas cepacia. Plant Dis. 79: 301-308

CARTwRight, D.K. W.S. Chilton \& BENSON, D.M. 1995: Pyrrolnitrin and phenazine production by Pseudomonas cepacia, strain 5.5B. a biocontrol agent of Rhizoctonia solani. Appl. Microbiol Biotechnol. 43: 211-216.

Casaz, P., Happela A., Keithanb, J., ReadC, D.L., Straind S.R. \& Levy, S.B. 2001: The Pseudomonas fluorescens transcription activator AdnA is required for adhesion and motility Microbiol. 147: 355-361.

CASPER, R. \& MENDGEN, K. 1979: Quantitative serological estimation of a hyperparasite: Detecton of Verticillium lecanii in yellow rust infected wheat leaves by ELISA. Phytopathol. Z- 94: 89-91.

CASPER, R. \& MEYER, S. 1981: Die Anwendung des ELISA-Verfahrens zum Nachweis pflanzenpathogener Viren. Nachrichtenbl. Deut. Pflanzenschutzd. 33: 49-54

CERNUSKO, R. 1996: Entwicklung und Erprobung enzymatischer und immunologischer Nachweismethoden für Verticillium dahliae Kleb. im Raps (Brassica napus L.). Dissertation, Universität Göttingen

Cernusko, R. Garbe, V. \& Wolf, G. 2000: Ergebnisse eines Monitorings zur Bedeutung des Auftretens von Verticillium und Phoma lingam an Winterraps in der Bundesrepublik Deutschland. (nicht veröffentlicht). 
CERNY, G. 1978: Studies of the aminopeptidase test for the distinction of gram-negative from grampositive bacteria. Eur. J. Appl. Microbiol. Biotechnol. 5: 113-122

Chang, C., Kwok, S.F., Bleecker, A.B. \& Meyerowitz, E.M. 1993 : Arabidopsis ethyleneresponse gene ETR1: similarity of product to two-component regulators. Science 262: 539-44

Chang, C.J., Floss, H.G., Hook, D.J., Mabe, J.A., Manni, P.E., Martin, L.L., SchröDer, K. \& SHIEH, T. 1981: The Biosynthesis of the Antibiotic Pyrrolnitrin by Pseudomonas aureofaciens", J. Antibiot. 34: 555.

CHANG, I. \& KOMMEDAHL, T. 1968: Biological control of seedling blight of corn by coating kernels with antagonisti microorganisms. Phytopathology 58: 1395-1401

Chet, I., Ordentlich, A., Shapira, R. \& OpPenheim, A. 1990: Mechanisms of biocontrol of soilborne plant pathogens by rhizobacteria. Plant and Soil 129: 85-92.

Chernin, L., Brandis, A., Ismailov, Z., Chet, I. 1996: Pyrrolnitrin Production by an Enterobacter agglomerans Strain with a Broad Spectrum of Antagonistic Activity Towards Fungal and Bacterial Phytopathogens CURR MICROBIOL. 32: 208-212

Chernin, L.S., De la Fuente, L., Sobolev, V., Haran, S., Vorgias, C.E., OpPenheim, A.B. \& CHET, I. 1997: Molecular cloning, structural analysis, and expression in Escherichia coli of a chitinase gene from Enterobacter agglomerans. Appl. Environ. Microbiol. 63: 834-839

Chernin, L., Ismailov, Z., Haran, S. \& Chet, I. 1995: Chtinolytic Enterobacter agglomerans antaginistic to fungal plant pathogens. Appl. Environ. Microbiol. 61: 1720-1726

Chèvre, A.M., Barret, P., Eber, F., Dupuy, P. Brun, H., TAnguy, X. \& Renard, M. 1997: Selection of stable Brassica napus-B.juncea recombinant lines resistant to blackleg (Leptosphaeria maculans). 1. Identification of molecular markers, chromosomal and genomic origin of the introgression. Theor. Appl. Genet. 95: 1104-1111.

Chin-A-Woeng, T. F. C., De Priester, W., van Der Bij, A. J. \& Lugten-Berg, B. J. 1997: Description of the colonization of a gnotobiotic tomato rhizo-sphere by Pseudomonas fluorescens biocontrol strain WCS365, using scan- ning electron microscopy. Mol. Plant-Microbe Interact. 10: 79-86.

CLARK, M.F. 1981: Immunosorbent assays in plant pathology. Ann. Rev. Phytopathol. 19: 83-106

CLARK, M.F. \& ADAMS, A.N. 1977: Characteristics of the microplate method of enzyme-linked immunosorbent assay for the detection of plant viruses. J. gen. Virol. 34: 475-483.

Cook, N., Silcock, D. J., Waterhouse, R. N., Prosser, J. I., Glover, L. A. \& Killham, K. 1993: Construction and detection of bioluminescent strains of Bacillus subtilis. J. Appl. Bacteriol. 75: 350-359.

COOK, R.J. \& BAKER, K.F. 1983: The nature and practice of biological control of plant pathogens. American Phytopathol. Society. St. Paul, Minnesota

COOK, R. J. \& RoviRA, A. D. 1976: The role of bacteria in the biological control of Gaeumannomyces graminis by suppressive soils. Soil Biol. Biochem. 8: 269-273.

COOPER, R.M. 1983: The mechanism and significance of enzymic degradation of host cell walls by parasites. In: CALLOW, J.A. (Eds.): Biochemical plant pathology. J. Wiley and Sons, New York, 101-135.

CoOPer, R.M., Longman, D., CAmpBell, A., Henry, M. \& Lees, P.E. 1988: Enzymic adaption of cereal pathogens to the monocotyledonous primary wall. Physiol. Mol. Plant Pathol. 32: 33-47.

COOPER, R.M. \& WOOD, R.K.S. 1973: Induction of synthesis of cell wall degrading enzymes in vascular wilt fungi. Nature 246: 309-311.

CORBELl, N \& LOPER, J. E. 1995: A global regulator of secondary metabolite production in Pseudomonas fluorescens Pf-5. J-Bacteriol. 177: 6230-6236 
Costin, J.D., KAPPNER, M. und W. SCHMIDT 1983: Differenzierung von Gram-positiven und Gramnegativen Bakterien mit dem L-Alanin-Aminopeptidase-Test. forum mikrobiologie 6: 351-353

CunNinghaM, G.H. 1927: Dry-rot of swedes and turnips: its causes and control. New Zealand Dept. Agric. Bull. 133: 1-51.

DAeBeleR, F. \& SeIDEL, D. 1989: Auswirkungen der Fruchtfolge auf Krankheitserreger des Winterrapses. Raps 7: 130.

DAHIYA, J.S.D., WoODS, D.L. \& TEWARI, J.P. 1988: Control of Rhizoctonia solani, causal agent of briwn girdling roor rot of rapeseed by Pseudomonas fluorescens. Bot. Bull. Acad. Sin. 29: $135-142$

DAVIES, J.M.L. 1986: Diseases of oilseed rape. In: Scarisbrick, D.H. \& Daniels, R.W. (eds.) Oilseed rape. London, UK: Collins, 195-236.

DAVISON, J. 1988: Plant benificial bacteria. Bio/Technology 6: 282-286.

DÉFAGO, G. \& HAAS, D. 1990: Pseudomonads as antagonists of soilborne plant pathogens: Modes of action and genetic analysis. In: BOOLAG, J.-M. \& STOTZKY, G. (eds.): Soil Biochemistry, Vol. 6, Marcel Dekker, New York und Basel, Seite 249-291.

DÉFAGO, G. 1993: 2,4-Diacetylphloroglucinol, a promising compound in biocontrol. Plant Pathol. 42: 311-312.

DELWICHE, P.A. 1980: Genetic aspects of blackleg (Leptosphaeria maculans) resistance in rapeseed (Brassica napus). Ph.D. Thesis, Univ. of Wisconsin, Madison, 144 pp.

DelWiche, P.A., \& WiLliams, P.H. 1979: Screening for resistance to blackleg of crucifers in the seedling stage. Cruciferae Newsletter 4: 24.

DE MEYER \& HÖFTE 1997 Salycilic acid produced by the rhizobacterium Pseudomonas aeruginosa 7NSK2 induces resistance to leaf infection by Botrytis cinerea in bean, Phytopathology 87: 588593.

Deuker-Isermeyer, B., BADAwY, H.M.A., \& HopPe, H.-H. 1990: Phoma: Sanfte und aggressive Formen schädigen den Raps. Pflanzenschutz-Praxis 3: 40-43.

DiePenBroch, W. 1999: Spezieller Pflanzenbau. 523 S. Ulmer, Stuttgart.

DOMSCH, K. H. \& GAMS, W. 1968: Die Bedeutung vorfruchtabhängiger Verschiebungen in der Bodenmikroflora. II.: Antagonistische Einflüsse auf pathogene Bodenpilze. Phytopathol. Zeitung 63: 165-176.

Dowling, D.N., Boesten,B., O'sullivan, D:J., Stephens, P., Morris, J. \& O'Gara, F. 1995: Genetically engineered fluorescent pseudomonads for improved biocontrol of plant pathognes. In: Hokkanen, H.M.T. \& Lynch, J.M. (eds.): Biological control: benifits and risks. Cambridge.

DuAmKhanmanee, R. 1996: Untersuchungen zur Sporulation und Überdauerung von Phoma lingam (Teleomorph: Leptosphaeria maculans) an zwei Standorten mit unterschiedlichem Befallsdruck. Dissertation, Universität-Geasmthochschule Kassel.

DufFY, B. K. \& DÉFAGO, G. 2000: Controlling Instability in gacS-gacA Regulatory Genes during Inoculant Production of Pseudomonas fluorescens Biocontrol Strains. Appl. Environ. Microbiol. 66: $3142-3150$

DuFFY, B.K. \& DEFAGO, G. 1999: Environmental factors modulating antibiotic and siderophore biosynthesis by Pseudomonas fluorescens biocontrol strains. Appl. Environ. Microbiol. 65: 242938

DufFY, B.K., Simon, A. \& Weller, D.M. 1996: Combination of Trichoderma koningii with fluorescent pseudomonads for control of take-all on wheat. Phytopathology 86: 188-194 
DuiJfF, B.J., AlabouvetTe, C., Lemanceau, P. 1996 : Involvement of induced systemic resistance in the control of fusar-ium wilt of tomato by Fusarium oxysporum strain FO47 and Pseudomonas fluorescens strain WCS417. IOBC/WPRS Bull. 19:120-241.

Dunne, C., Delany, I., Fenton, A., \& O'Gara, F. 1996: Mechanisms involved in biocontrol by microbial inoculants. Agronomie 16: 721-729

EASTON, C. \& RossalL, S. 1985: The production of certain cell wall-degrading enzymes by Leptosphaeria maculans in culture and in stem canker lesions of oilseed rape. Physiol. Plant Pathol. 26: 185-197.

Edwards, S. G., MCKAY, T. \& Seddon, B. 1994: Interaction of Bacillus Species with Phytopathogenic Fungi - Methods of Analysis and Manipulation for Biocontrol Purposes. In: Blakeman, J.O. \& Williamson, B. (eds.): Ecology of Plant Pathogens. CAB International, pp.101-118

ELAD, Y. \& BAKER, R. 1985: The role of competition for iron and carbon in suppresion of chlamydospore germination of Fuasrium spp. By Pseudomonas pp. Phytopathology 75: 10531059 .

ELAD, Y. \& CHET, I. 1987: Possible role of competition for nutrients in biocontrol of pythium damping-off by bacteria. The American Phytopath. Soc. 77: 190-195.

ELAD, Y. 1993: Introductory lecture: microbial suppresion of infection by foliar plant pathogens. IOBC/WPRS Bulletin 16: 3-7

ElandeR, R.P., Mabe, J.A., Hamill, R.H. \& Gorman, M. 1968: Metabolism of Tryptophans by Pseudomonas aureofaciens. VI. Production of pyrrolnitrin by selected Pseudomonas species. Appl. Microbiol. 16: $753-758$

Elsherif, M. \& GRossmanN, F. 1994: Comparative investigations on the antagonistic activity of fluorecent pseudomonads against Gaeumannomyces graminis var triticii in vitro and in vivo. Micribiol. Res. 149: 371-377.

Emmert, E.A.B., Milner, J.L., Lee, J.C., Pulvermacher, K.L., Olivares, H.A., Clardy, J., \& HANDElsman, J. 1998: Effect of Canavanine from Alfalfa Seeds on the Population Biology of Bacillus cereus. Appl. Environ. Microbiol. 64: 4683-4688.

Engvall, E. \& PerlmanN, P 1972: Enzyme-linked immunosorbent assay. III. Quantitation of specific antibodies by enzyme-labeled anti-immunoglobulin antigen-coated tubes. J. Immunol. 109: 129-135.

Eparvier, A., \& Alabouvette, C. 1994: Use of ELISA and GUS-transformed strains to study competition between pathogenic ans non-pathogenic Fusarium oxysporium for root colonizition. Biocontrol Sci. Technol. 4: 35-47.

EVANS, I.R. 1988: Blackleg of canola. Alberta Agriculture Agrifax, Agdex 149: 623-633.

FAWCETT, J.K. \& J. E. SCOTT (1960) J. CLIN. PATH. 13: 156

Fenton, A.M., Stephens, P.M., Crowley, J., O’CAllaghan, M. \& O’Gara, F. 1992: Exploitation of gene(s) involved in 2,4-diacetylphloroglucinol biosyn-thesis to confer a new biocontrol capability to a Pseudomonas strain. Appl. Environ. Microbiol. 58: 3873-3878.

FESER, M. 1992: Die Integration chemischer Pflanzenschutzmaßnahmen gegen Leptospaheria maculans (Desm.) Ces. et de Not. (Imperfektstadium Phoma lingam (Tode ex Fr.) Desm.), dem Erreger der Wurzehals- und Stengelfäule an Winterraps. Diss. TU München-Weihenstephan.

Fiddeman, P. J. \& RossaL, S. 1995: Selection of bacterial antagonists for the biological control of Rhizoctonia solani in oilseed rape (Brassica napus): Plant Pathol. 44: 695-703.

Fitt, B.D.L., Gladders, P. Turner, J.A., Sutherland, K.G. Welham, S.L.,\& Davies, J.M. 1997: Prospects for developing a forcasting scheme to optimise use of fungicides for disease control on winter oilseed rape in the UK. Aspects of Appl. Biol. 48: 135-142. 
Flemming, C. A., LeE, H. \& TRevors, J. T. 1994: Bioluminescent most-probable-number Method to enumerate lux-marked Pseudomonas aeruginosa UG2Lr in soil. Appl. Environ. Microbiol. 60: 3458-3461

FOCHEM, H. 1996: Einsatz von Pflanzenölen in der Oleochemie. Raps 14: 143-145.

FrAUEN, M. 1992: Raps: Resistenzzüchtung macht Fortschritte. Pflanzenschutz-Praxis 92: 29-31.

FRAVEL, D.R. 1988: Role of antibiosis in the biocontrol of plant diseases. Ann. Rev. Phytopathol. 26: $75-91$

FRIDLENDER, M., INBAR, J. \& I. CHET 1993: Biological control of soilborne plant pathogens by a 1,3$\beta$-glucanase-producing Pseudomonas cepacia. Soil Biol. Biochem. 25: 1211-1221

Friedrich, B., Hogrefe, C. \& SChlegel, H.G. 1981: Naturally occuring genetic transfer of hydrogen-oxidizing ability between strains of Alcaligenes eutrophus. J. Bacteriol. 147: 198-205

GABRIELSON, R.L. 1983: Blackleg disease of crucifers caused by Leptosphaeria maculans (Phoma lingam) and its control. Seed Sci. Technol. 11: 749-780.

Gabrielson, R.L., Mulanax, M.W., Matsuoka, K., Williams, P.H., Whiteaker, G.P. Maguire, D. 1977: Fungicidal erdiction of seedbone Phoma lingam on crucifers. Pl. Dis. Rep. 61: 118-121.

GAFFNEY, T. D., LAM, S. T., \& LIGON, J. 1994: Global regulation of expression of antifungal factors by a Pseudomonas fluorescens biological control strain. Mol Plant-Microbe Interact 7: 455-463.

Gall, C., Balesdent, M.-H., DesthieuX, Robin, P. \& RouXel, T. 1995: Polymorphism of Tox ${ }^{0}$ Leptosphaeria maculans isolates as revealed by soluble protein and isozyme electrophoresis. Mycol. Res. 99: 221-229.

Garbe, V. 2000: Investigations on fungicide application in oilseed rape in systems of integrated pest management. IOBC/WPRS Bulletin 23: 197-202.

GARBE, V. 1996: Krankheiten im Raps - Was tun? Raps 14: 156-159.

GARBE, V. 1994: Raps: Kosten sparen über die Sorte. DLG-Mitteilungen 7: 18-21.

Garbe, V., Beer, E., Broschewitz, B., Frosch, M., Kälberer, R., Lauenstein, G., Steck, U., STEINBACH, P. \& UlBER, B. 1994: Untersuchungen zur Bedeutung eines Schädlingsbefalls im Winterraps auf das Auftreten von Krankheiten. Mitt. a. d. Biol. Bundesanst. 301: 93.

GeELS, F. P. \& SCHIPPERS, B. 1983b: Reduction of yield depressions in high frequency potato cropping soil after seed tuber treatments with antagonistic fluorescent Pseudomonas spp. J. Phytopathol. 108: 207-214.

Geels, F.P., Lamers, J.G. Horkstra, O. \& Schippers, B. 1986: Potato plant response to seed tuber bacteriazation in the field in varous rotations. Neth. J. Pl. Path. 92: 257-272.

Gehmann, K., R. Neyfeler, A. Leadbeater, D. Nevill, And D. Sozzi. 1990: CGA173506: a new phenylpyrrole fungicide for broad-spectrum disease control. Proc. Brighton Crop Prot. Conf. Pests Dis. 2: 399-406.

Ghiglione, J.-F., Gourbiere, F., Potier P., Philippot, L. \& Lensi, R. 2000: Role of Respiratory Nitrate Reductase in Ability of Pseudomonas fluorescens YT101 To Colonize the Rhizosphere of Maize Appl. Environ. Microbiol. 66: 4012-4016

GlaDDERS, P. \& MUSA, T.M. 1979: The development of Leptosphaeria maculans in winter oilseed rape and its implication for disease control. Br. Crop Protection Conf. - Pests and Diseases 129136.

GlaDDERS, P. \& MUSA, T.M. (1980): Observations on the epidemiology of Leptosphaeria maculans stem canker in winter oilseed rape. Plant Pathol. 29: 28-37.

GLADDERS, P. \& SYMONDS, B.V. 1995: Occurrence of canker (Leptosphaeria maculans) in winter oilseed rape in eastern England, 1977-1993. IOBC/WPRS Bulletin 18: 1-11. 
GLADDERS, P., SYMONDS, B.V., HARDWICK \& SANFORD, C.E. 1998: Opportunities to control canker (Leptosphaeria maculans) in winter oilseed rape by improved spray timing. IOBC/WPRS Bulletin 21(5): 111-120.

Glandorf, D.C.M., VAn Der Sluis, I., Anderson, A.J., BAKKer, P.A.H.M. \& Schippers, B. 1994: Agglutination, adherence, and root colonization by fluorescent Pseudomonads. Appl. Environ. Microbiol. 60: 1726-1733.

GLICK, B.R. 1995: The enhancement of plant growth by free-living bacteria. Can. J. Microbiol. 41: 109-117

GLICKMANN, E. \& Y. DESSAUX 1995: a critical examination of the specificity of the Salkoski reagent for indolic compounds produced by phythopathogenic bacteria. Appl. Environ. Microbiol. 61: 793-796

GLADDERS, P. 1995: Canker on winter oilseed rape: occurrence in eastern England 1977-1995 and prospects for forcasting and control. Blackleg News 5: 7-10

Görlach, J., Volrath, S., Knauf-Beiter, G., Hengy, G., Beckhove, U., 1996: Ben-zothiadiazole, a novel class of inducers of systemic acquired resistance, activates gene expression and disease resistance in wheat. Plant Cell 8: 629-43

GotTLIEB, D. 1976: The production and role of antibiotics in soil. J. Antibiot. 987-1000.

GotTSCHALK, S. 1995: Isolierung und Charakterisierung mikrobieller Antagonisten des Erregers der Kraut- und Knollenfäule der Kartoffel (Solanum tuberosum L.) Phytophthora infestans (Mont.) de Bary. Diplomarbeit, Universität Göttingen

GREGERSEN, T. 1978: Rapid method for distinction of gram-negative from gram-positive bacteria. Europ. J. Appl. Microbiol. Biotechnol. 5: 123-127.

GREGERSEN, B. 1979: Rapid method for distinction of gram-negative from gram-positive bacteria. Europ. J. Appl. Microbiol. Biotechnol. 5: 123-127

Gugel, R.K., SÉGuin-Swartz, G. \& Petrie, G.A. 1990: Pathogenicity of three isolates of Leptosphaeria maculans on Brassica species and other crucifers. Can. J. Plant Pathol. 12: 75-82.

Gugel, R.K. \& PETRIE, G.A. 1992: History, occurrence, impact and control of blackleg of oilseed rape. Can. J. Plant Pathol. 14: 36-45.

GuRUsidDAiAh, S., Weller, D.M., SARKAR, A. \& COOK, R.J. 1986: Characterization of an antibiotic produced by a strain of Pseudomonas fluorescens inhibitory to Gaeumannomyces graminis var. tritici and Pythium spp. Appl. Environ. Microbiol. 29: 488-495

HALL, R. 1992: Epidemiology of blackleg of oilseed rape. Can. J. Plant Pathol. 14: 46-55.

HALL, R., PETERS, R.D. \& ASSABGUIR, R.A. 1993: Occurrence and impact of blackleg on oilseed rape in Ontario. Can. J. Plant Pathol. 15: 305-313.

HAmDan, H., Weller, D.M. und L.J. ThOMASHOW 1991: Relative importance of fluorescent siderophores and other factors in biological control of Gaeumannomyces graminis var. tritici by Pseudomonas fluorescens 2-79 and M4-80R. Appl. Environ. Microbiol. 57: 3270-3277

HAMmer, P.E., Hill, D.S., LAM, S.T., VAN PeÉ, K.-H. \& LigON, J.M. 1997: Four Genes from Pseudomonas fluorescens That Encode the Biosynthesis of Pyrrolnitrin. Appl. Environ. Microbiol. 63: $2147-2154$

HAMMOND, K.E., LEWIS, B.G. \& MusA, T. 1985: A systemic pathway in the infection of oilseed rape plants by Leptosphaeria maculans. Plant Pathol. 34: 357-365.

HAMMOND, K.E. \& LEWIS, B.G. 1986: Ultrastructure studies of the limitation of stem lesions by $L$. maculans on Brassica napus var. oleifera. Physiol. Mol. Plant Pathol. 28: 251-265.

HAMMOND, K.E. \& LEWIS, B.G. 1987: The establishment of systemic infection in leaves of oilseed rape by Leptosphaeria maculans. Plant Pathol. 36: 135-147. 
HAMMERSCHMIDT, R. \& KUC, J. 1995: Induced Resistance to Disease in Plants. Dor-drecht: Kluwer. $182 \mathrm{pp}$.

HARTLEB, H. \& WOlfF, C. 1998: Phoma-Spätbefall durch Triebrüßlerbekämpfung reduzieren. Raps 16: $26-31$.

HANSEN, M., L. KRAGELUND, O. NyBROE, AND J. SøRENSEN. 1997: Early colonization of barley roots by Pseudomonas fluorescens studied by immunofluorescence technique and confocal laser scanning microscopy. FEMS Microbiol. Ecol. 23: 353-360.

Hassett, D. J., Woodruff, W. A., Wozniak, D. J., Vasil, M. L., Cohen, M.S. \& OHMan, D.E. 1993: Cloning of sodA and sodB genes encoding manganese and iron superoxide dismutase in Pseudomonas aeruginosa: demonstration of increased manganese superoxide dismutase activity in alginate-producing bacteria. J. Bacteriol. 175: 7658-7665

HebBar, K.P., AtKInson, D., TUCKER, W. \& DART, P.J. 1992: Suppression of Fusarium moniliforme by maize root-associated Pseudomonas cepacia. Soil Biol. Biochem. 24: 1009-1020

Hemming, B. C. 1986: Microbial-iron interactions in the plant rhizosphere. An overview. J. Plant Nutr. 9: 505-521.

Hemming, B. C. 1990: Bacteria as antagonists in biological control of plant pathogens. In: Baker, R. R. \& Dunn, P. E. (eds.): New Directions in Biological Control: Alternativs for Suppressing Agricultural Pests and Diseases. Alan. R. Liss., New York, pp 223-242.

HENDERSON, M.P. 1918: The blackleg disease of cabbage caused by Phoma lingam (Tode) Desm. Phytopathology 8: 379-431

HEPPNER, C. \& HEITEFUß, R. 1996: Wenn der Raps zu früh abreift. DLG-Mitteilungen 12: 46-47

HERR, L.J. 1959: A method of assaying soil for numbers of actinomycetes antagonistic to fungal pathogens. Phytopathology 49: 270-273

HeSSENMÜlLER, A. und W. ZelLER 1996: Biologische Bekämpfung von bodenbürtigen Phytophthora-Arten an Erdbeere durch bakterielle Antagonisten: Antagonistische Wirkung und Kolonisierung der Rhizoplane. Z. PflKrankh. PflSchutz 103: 602-609

HeUPEL, M. 1992: Biologische Bekämpfung bodenbürtiger Wurzelbranderreger der Zuckerrübe (Beta vulgaris L. ssp. vulgaris var. altissima Doell) durch den Einsatz mikrobieller Antagonisten. Dissertation, Universität Göttingen

Hill, D. S., Stein, J. I., Torkewitz, N. R., Morse, A. M., Howell, C. R., Pachlatko, J. P., BECKER, J. O. \& LignON, J. M. 1994: Cloning of genes involved in the synthesis of pyrrolnitrin from Pseudomonas fluorescens and role of pyrrolnitrin synthesis in biological control of plant disease. Appl. Environ. Microbiol. 60: 78-85

Hill, C.B., XU, X.H. \& Williams, P.H. 1984: Correlation of virulence, growth rate, pigment production and allozyme banding patterns which differentiate virulent and avirulent Isolates of Leptosphaeria maculans. Cruciferae Newsl. 9: 79

HiLl, C.B. \& WiLliams, P.H. 1988: Leptosphaeria maculans, cause of blackleg of crucifers. In: WiLliams, P.H. \& INGRAM, D.S. (eds.): Adv. Plant. Pathol. 6: 169-174

Hoffland, E., Pieterse, C.M.J., BIK, L., VAN PELT, J.A. 1995: Induced systemic resistance in radish is not associated with accumulation of pathogenesis-related proteins. Physiol. Mol. Plant Pathol. 46: $309-20$

Hoffland, E., Hakulinen, J., Van Pelt, J.A. 1996: Comparison of systemic resistance induced by avirulent and non-pathogenic Pseudomonas species. Phytopathology 86: 757-62

HÖFLICH, G. 1989: Saatgutpillierung mit organischen Substanzen zur Beeinflussung der Mikroorganismenbesiedlung und Jugendentwicklung von Weizen. Zentralblatt Mikrobiologie 144: 59-63. 
HÖFLICH, G. \& RUPPEL, S. 1990: Saatgutpillierung bzw. Inkrustierung zur Verlängerung des Überlebens von Impforganismen am Samen und in der Rhizosphäre. Zentralblatt Mikrobiologie 145: 99-106

HOLL, F. B. 1992: Rhizosphere colonization and seedling growth promoting of lodgepole pine by Bacillus polymyxa. Can. J. Microbiol. 38: 303-308

Holt, J.G., KRIEG, N.R., SNEATH, P.H.A., StALEY, J.T. \& Williams, S.T. 1994: Bergey's manual of determinative bacteriology, Williams \& Wilkins, Baltimore, Maryland

Holtschulte, B. 1992: Untersuchungen zur Biologie und Bedeutung von Verticillium dahliae Kleb. und Leptosphaeria maculans (Desm.) Ces. et de Not. (Anamorph: Phoma lingam [Tode ex Fr.]) innerhalb des Erregerkomplexes der krankhaften Abreife von Raps. Dissertation, Universität Göttingen

Homma, Y., Hirayama, F., Konno, K., Skirahama, H. \& SuzUi, T. 1989: Production of antibiotics by Pseudomonas cepacia as an agent for biological control of soilborne plant pathogens. Soil Biol. Biochem. 21: 723-728

HORNIG, H. 1986: Krankhafte Abreife - Spätschäden durch Phoma lingam und/oder Verticillium dahliae. Raps 4: 83-85

Howell, C. R. \& STIPANOVIC, R. D. 1979: Control of Rhizoctonia solani on cotton seedlings with Pseudomonas fluorescens and with an antibiotic produced by the bacterium. Phytopathology 69: 480-482

Howell, C. R. \& StiPANOVIC, R. D. 1980: Suppression of Pythium ultimum-induced damping-off of cotton seedlings by Pseudomonas fluorescens and its antibiotic, Pyoluteorin. Phytopathology 70: $712-715$

Howell, C.R. BeIER, R.C. \& STIPANOVIC, R.D. 1988: Production of ammonia by Enteribacter cloacae and ist possible role in the biological control of Pythium preemergence damping-off by the bacterium. Phytopathology 78: 1075-1078

HowIE, W.J. \& SusLOW, T.V. 1991: Role of antibitic biosynthesis in the inhibition of Pythium ultimum in the cotton spermosphere and rhizosphere by Pseudomonas fluorescens. Mol. PlantMicrobe Interact. 4: 393-399

Huges, W. 1933: A study of Phoma lingam (Tode) Desm., and of the "Dry Rot" it causes, particularly in swede turnips. Scient. Proc., R.D.S., Vol. 20, No. 34.

HUMPHERSON-JONES, F.M. 1983: Pathogenicity studies on isolates of Leptosphaeria maculans from brassica seed production crops in south-east England. Ann. Appl. Biol. 103: 37-44

HUMPHERSON-JONES, F.M. 1985: The incidence of Alternaria spp. and Leptosphaeria maculans in commercial brassica seed in the United Kingdom. Plant Path. 34: 385-390

HUMPHERSON-JONES, F.M. 1986: The occurrence of virulent pathotypes of Leptosphaeria maculans in brassica seed crops in England. Plant Pathol. 35: 224-231

HUMPHERSON-JONES, F.M. \& BURCHILL, R.T. 1982: Chemical suppression of the sexual stage of Leptosphaeria maculans on oilseed rape and turnip seed crop straw. Ann. Appl. Biol. 100: 281288

Howie, W. J., COOK, R. J. \& Weller, D. M. 1987: Effects of soil matric potential and cell motility on wheat root colonization by fluorescent pseudomonads suppressive to take-all. Phytopathology 77: 286-292

Hwang, S. F., Chang, K. F., Howard, R. J., DeneKa, B. A. \& Turnbull, G. D. 1996: Decrease in incidence of Pythium damping-off of field pea by seed treatment with Bacillus spp. and metalaxyl. Z. PflKrankh. \& Pflschutz 103: 31-41 
HWANG, S.F. \& ChARKAVARTY, P. 1993: (1992???) Integrated biological and chemical control of Rhizoctonia root rot of field pea by Gliocladium virens and a fungicide. Z. PflKrankh. Pflschutz. 100: $308-316$.

INBAR, J. \& CHET, I. 1991: Evidence that chitinase produced by Aeromonas caviae is involved in the biological control of soil-borne plant pathogens by this bacterium. Soil Biol. Biochem. 23: 973978

JAHN, M. 1998: Das Anmeldverfahren Pflanzenstärkungsmittelund angemeldete Stärkungsmittel auf mikrobieller basis. Phytomedizin 28: 20-21.

JAHN, M. 2001: Die meisten Mittel erhöhen Widerstandsfähigkeit. Agarzeitung am 10. Feb. 2001.

JAMAUX, I. \& SPIRE, D. 1994: Development of a polyclonal antibody-based immunoassay for the early detection of Sclerotinia sclerotiorum in rapeseed petals. Plant Pathol. 43: 847-862

JANISIEWICZ, W.J. \& BORS, B. 1995: Development of a microbial community of bacterial and yeast antagonists to control wound-invading postharvest pathogens of fruits. Appl. Environ. Microbiol. 61: $3261-3267$

JANisiewicz, W., Yourman, L., RoITMAn, J. \& MAHONEY, N. 1991: Postharvest control of blue mold and gray mold of apples and pears by dip treatment with pyrrolnitrin, a metabolite of Pseudomonas cepacia. Plant Dis. 75: 490-494

JAYASWAL, R.K., FERNANDEZ, M.A. \& SCHROEDER, R.G. 1990: Isolation and characterization of a Pseudomonas strain that restricts growth of various phytopathogenic fungi. Appl. Environ. Microbiol. 56: 1053-1058

Jayaswal, R.K., Fernandez, M.A., Upadhyay, R.S., Visintin, L., KurZ, M., WebB, J. und K. RINEHART (1993): Antagonism of Pseudomonas cepacia against phytopathogenic fungi. Curr. Microbiol. 26: 17-22

JedryczKa, M., Rouxel, T., Balesdent, M.-H., Mendes-Pereira, E. \& Bertrandy, J. 1997: Molecular characterization of Phoma lingam isolates. Cereal Res. Communic. 25: 279-283

JOHNSON, L.F. 1954: Antibiosis in relation to Pythium root rot of sugarcane and corn. Phytopathology 44: 69-73.

JONES, R. W. \& PETTIT, R. E. 1987: Variation in sensitivity among anastomosis groups of Rhizoctonia solani to the antibiotic gliotoxin. Plant Dis. 71: 34-36.

Jongebloed, P.H.T., KeSel, G.J.T., MolhoeK, W.M.L., VAN DER Plas, C.H. \& Fokkema, N.J. 1993: Biological control of Phythophthora infestans with compost extracts and selected bacterial antagonists. IOBC/WPRS Bulletin 16: 16-20 (Bediedlung???)

KHAN, N.I. Filonow, A.B. \& Singleton, L.L. 1994: Clay granules bearing Actinoplanes spp. For the biocontrol of oomycetes fungi in soil. Phytopathology 84: 1136

Keel, C., Voisard, C., Berling, C.H., Kahr, G., \& Defago, G. 1989: Iron sufficiency, a prerequisite for the suppression of tabacco black root rot by Pseudomonas fluorescens strain CHA0 under gnotobiotic conditions. Phytopathology 79: 584-589

Keel, C., Weller, D.M., Natsch, A., Defago, G., Cook, R.J. \& Thomashow, L. 1996: Conservation of the 2,4-diacetylphloroglucinol biosynthesis locus among fluorescent Pseudomonas strains from diverse geographic locations. Appl. Environ. Microbiol. 62: 552-563

Keel, C., Wirthner, P., Oberhansli, T., Voisard, C., Burger, U. HAas, D. \& Defago, G. 1990: Pseudomonads as antagonists of plant pathogens in the rhizosphere: role of the antibiotic 2,4diacetylphloroglucinol in the suppression of black root rot of tobacco. Symbiosis 9: 1-3, 327-341.

Keel, C., Schnider, U., Mauerhofer, M., Voisard, C., Laville, J., Burger, U., Wirthner, P., HAAS, D. \& Defago, G. 1992: Suppresion of root diseases by Pseudomonas fluorescens CHA0: Importance of the bacterial secondary metabolite 2.4-diacetylphloroglucinol. Mol. Plant-Microb Interact. 5: 4-13 
KeEL, C., \& DÉFAGO, G.. 1997. Interactions between beneficial soil bacteria and root pathogens: mechanisms and ecological impact, p. 27-46. In A. C. Gange and V. K. Brown (ed.), Multitrophic interactions in terrestrial sys-tems. Blackwell Science, London, England.

KEMPF, H.-J. 1988: Biologische Bekämpfung von pflanzenpathogenen Pilzen, insbesondere Fusarium culmorum, durch Erwinia herbicola und andere mikrobielle Antagonisten. Dissertation, Universität Göttingen.

KEMPF, H.-J. \& WOLF, G. A. 1989: Erwinia herbicola as a biocontrol agent of Fusarium culmorum and Puccinia recondita f. sp. tritici on wheat. Phytopathology 79: 990-994.

KeRI, M., VAN DEN BERG, C.G.J., MC VETTY, P.B.E. \& RIMMER, S.R. 1997: Inheritance of Resistance to Leptosphaeria maculans in Brassica juncea. Phytopathology 87: 594-598.

Kessel, G.J.T., Jongebloed, P.H.J., Molhoek, W.M.L., VAN DeR Plas, C.H. und N.J. FoKkemA (1995): Biological control of Phytophthora infestans with bacterial antagonists. IN: 6th International Symposium on the Microbiology of Aerial Plant Surfaces 1995: 45

Kharbanda, P.D. Evans, I.R., Harrison, S., Slopek, S. Huang, H.C., Kaminsi, D., \& Tewari, J.P. 1989: Blackleg of canola survey in Alberta-1988. Can. Plant Dis. Sur. 69: 55-57

KHARBANDA, P.D. \& DAHIYA, J.S. 1990: A metabolite of Penicillium verrucosum inhibitory to growth of Leptosphaeria maculans and Rhizoctonia solani. Can. J. Plant Pathol. 12: 335 (Abstr.).

KHARBANDA, P.D. 1992: Performance of fungicides to control blackleg of canola. Can. J. Plant Pathol. 14: $169-176$.

KING, E.B. \& PARKE, J.L. 1996: Population density of the biocontrol agent Burkholderia cepacia AMMDR1 on four pea cultivars. Soil Biol. Biochem. 28: 307-312

KING, E.O., WARD, M.K. und D.E. RANEY 1954: Two simple media for the demonstration of pyocyanin and fluorescin. J. Lab. Clin. Med. 44: 301-307

KisaAlita, W. S., Slininger, P. J. \& Bothast, R. J. 1993: Defined media for optimal pyoverdine production by Pseudomonas fluorescens 2-79. Appl. Microbiol. Biotechnol. 39: 750-755

KLOEPPER, J.W. 1983: Effect of seed piece inoculation with plant growth-promoting rhizobacteria on populantions of Erwinia carotovora on potatos roots and in daughter tubers. Phythopathology 73: 217-219.

KLOEPPER, J.W. 1991: Development of in vivo assays for prescreening antagonists of Rhizoctonia solani on cotton. Phytopathology 81: 1006-1013

KlOEPPER, J.W., TUZUN, S., LIU, L., WEI, G. 1993: Plant growth-promoting rhizobac-teria as inducers of systemic disease re-sistance. In Pest Management: Biologi-cally Based Technologies, ed. RD Lums-den, JL Vaughn, pp. 156-65. Washington, DC: Am. Chem. Soc.

Kloepper, J. W. \& BeAUCHAMP, C. J. 1992: A review of issues related to measuring colonization of plant roots by bacteria. Can. J. Microbiol. 38: 1219-1232

Kloepper, J. W. \& SCHROTH, M. N. 1981: Relationship of in vitro antibiosis of plant growthpromoting rhizobacteria to plant growth and the displacement of root microflora. Phytopathology 71: 1020-1024

KNAPPE, C. 1994: Einsatz von Xanthomonas maltophilia zur biologischen Bekämpfung von Verticillium dahliae Kleb. und Rhizoctonia solani Kühn an Winterraps. Dissertation, Universität Rostock

KNOWLES, C.J. 1976: Microorganisms and Cyanide. Bacteriological Reviews 40: 652-680.

KNUDSEN, G.R. und H.W. SPURR 1987: Field persistance and efficacy of five bacterial preparations for control of peanut leaf spot. Plant Disease 71: 442-445 
KOCH, E. 1996: Wirkungsweise und Anwendungsmöglichkeiten mikrobieller Antagonisten von Pflanzenkrankheiten. Gesunde Pflanzen 48: 11-19

KocH, E. 1996a "Biological and integrated control of rot diseases in soilless cultures"- Bericht über die gemeinsame Arbeitstagung von IOBC/WPRS und EFPP. Nachrichtenbl. Deut. Pflanzenschutzd. 48: 85

Koch, E., BADAwY, H.M.A. \& HOPPE, H.-H. 1989: Differences between aggressive and nonaggressive single spore lines of Leptosphaeria maculans in cultural characteristics and phytotoxin production. J. Phytopathol. 124: 52-62.

KocH, E. \& HopPE, H.-H. 1988: Zur Verbreitung aggressiver und nichtaggressiver Stämme von Phoma lingam in der Bundesrepublik Deutschland. Raps 2: 74-77.

Koch, E., SONG, K., OSBORN, T.C. \& WiLliams, P.H. 1991: Relationship between pathogenicity and phylogeny based on Restriction Fragment Polymorphism in Leptosphaeria maculans. Mol. Plant Microbe Interact. 4: 341-349.

Kogure, K., U. Simidu, AND N. TAGA. 1979. A tentative direct microscopic method for counting living marine bacteria. Can. J. Microbiol. 25: 415-420

Kovacs, N. 1956: Identification of Pseudomonas pyocyaneae by the oxidase reaction. Nature 178: 703

KRAUS, J. \& LOPER, J.E. 1992: Lack of evidence for a role of antifungal metabolite production by Pseudomonas fluorescens Pf-5 in biological control of Pythium damping off of cucumber. Phytopathology 82: 264-271

KRÜGER, W. 1982: Die Wurzelhals- und Stengelfäule des Rapses, verursacht durch Phoma lingam (stat. gen. Leptosphaeria maculans), eine schwer bekämpfbare Krankheit., Z. Pflanzenkrankh. Pflanzensch. 89: 498-507

KRÜGER, W. 1979: Verbreitung der Wurzelhals- und Stengelfäule (verursacht durch Phoma lingam) bei Raps in der Bundesrepublik Deutschland. Nachrichtenbl. Deut. Pflanzenschutzd. 31: 145-148.

Kuswinanti, T. 1996: Die Population von Phoma lingam (Tode ex Fr.) Desm. (teleomorph: Leptosphaeria maculans (Desm.) Ces et Not.) dem Erreger der Wurzelhals- und Stengelfäule des Rapses: Virulenzunterschiede auf einem erweiterten Testsortiment, Kreuzungstypen, Physiologische Eigenschaften und Geographische Verbreitung. Dissertation, Universität Göttingen.

Kuswinanti, T., KoOPMANN, B. \& Hoppe, H.-H. 1999: Virulence patterns of aggressive isolates of Leptosphaeria maculans on an extended set of Brassica differentials. Z. Pflanzenkrankh. und Pflanzenschutz 106: 12-20

Kutcher, H.R., VAn DEN BerG, C.G.J. \& Rimmer, S.R. 1993: Variation in pathogenicity of Leptosphaeria maculans on Brassica spp. based on cotyledon and stem reactions. Can. J. Plant. Pathol. 15: 253-258

Lacosta, L. Louvet, J., Anselme, C. \& Alabuvette, C. 1969: Role de Phoma lingam (tode) Desm. Et de sa forme parfaite, Leptosphaeria maculans (desm.) Ces. et de Not. Dans les epidemies de necrose du collet de colza (Brassica napus L. var. oleifera Metzger). Comptes Rebdus Hebdomadaires des Seances de 1 ' Academie d’ Agriculture de France 55: 981-989

Lambert, B., Frederik, L., Van Rooyen, L., Gossele, F., Papon, Y. \& Swings, J. 1987: Rhizobacteria of maize and their antifungal activities. Appl. Environ. Microbiol. 53: 18661871

Laville, J., Voisard, C., Keel, C., Maurhofer, M., DÉfagO, G. \& HAAS, D. 1992: Global control in Pseudomonas fluorescens mediating antibiotic synthesis and suppression of black root rot of tobacco. Proc Natl Acad Sci USA 89: 1562-1566

Laville, J., Blumer, C., Von Schroetter, C., Gaia, V., Défago, G., Keel, C. \& HaAs, D. 1998: Characterization of the henABC gene cluster encoding hydrogen cyanide synthase and anaerobic 
regulation by ANR in the strictly aerobic biocontrol agent Pseudomonas fluorescens CHA0. J Bacteriol 180: $3187-3196$

LEBEN, C. 1964: Influence of bacteria isolated from healthy cucumber leaves on two leaf diseases of cucumber. Phytopathology 54: 405-408

LEBEN, C. 1965: Epiphytic microorganisms in relation to plant diseases. Ann. Rev. Phytopath. 3: 209-230

LEBEN, C. \& DAFT, J.D. 1965: Influence of an epiphytic bacterium on cucumber anthracnose, early blight of tomato, and northern leaf blight of corn. Phytopathology 55: 760-762.

LEE, Y.-S. 1991: Biologische Bekämpfung des Gerstenmehltaus (Erysiphe graminis DC f.sp. hordei Marchal): Isolierung, Charakterisierung und Einsatz antagonistischer Mikroorganismen und deren antimykotischer Wirkstoffe. Dissertation, Universität Göttingen

Leeman, M., Van Pelt, J. A., Hendrikx, M. J., Scheffer, R. J., Bakker, P. A. H. M. \& SCHIPPERS, B. 1995: Biocontrol of Fusarium wilt of radish in commercial greenhouse trials by seed treatment with Pseudomonas fluorescens strain WCS374. Phytopathology 85: 13011305 .

Leeman, M., Den Ouden, F.M., Van Pelt, J.A., Dirkx, F.P.M., SteiJl, H., 1996: Iron availability affects induction of systemic resistance to fusarium wilt of radish by Pseudomonas fluorescens. Phytopathology 86:149-55

Leifert, C. SigeE, D:C., StAnley, R. KNight, C. \& EPtON, H.A.S. 1993: Biocontrol of Botrytis cinerea and Alternaria brassicicola on dutch white cabbage by bacterial antagonists at cold storage temperature. Plant Pathol. 42: 270-279.

Leifert, C., Li, H., Chidburee, S., Hampson, S., Workman, S., Sigee, D., Epton, H. A. S. \& HARBOUR, A. 1995: Antibiotic production and biocontrol activity by Bacillus subtilis CL27 and Bacillus pumilis CL45. J. Appl. Bacteriol. 78: 97-108.

LEISINGER, T. \& R. MARGRAFF 1979: Secondary metabolites of the fluorescent pseudomonads. Microbiol. Rev. 43: 422-442

Lemanceau, P. \& Alabouvette, C. 1991: Biological control of Fusarium-diseases by fluorescent Pseudomonas and non-pathogenic Fusarium. Crop Protection 10: 279-285

LEONG, J. 1986: Siderophores: Their biochemistry and possible role in the biocontrol of plant pathogens. Ann. Rev. Phytopathol. 24: 187-209

LeVy, E., Eyal, Z., Carmely, S., Kashman, Y. \& I. CheT (1989): Suppression of Septoria tritici and Puccinia recondita of wheat by an antibiotic-producing fluorescent pseudomonad. Plant Pathol. 38: 564-570

LEWIS, J.A. \& PAPVIZAS, G.C. 1991: Biocontrol of plant diseases: the approach for tommorrow. Crop Protection 10: 95-105.

Lifshitz. R., Kloepper, J.W., Scher, F.M. Tipping, E.M. \& Laliberté: 1986: Nitrogen-fixing pseudomonads isolated from roots of plants grown in the Canadian controls and biological controls. Plant dis. 69: 431-434.

Ligon, M.J., Lam, S.T., Gaffney, T.D., Hill, D.S., Hammer, P.E. \& Torkewitz, N. 1996: Biocontrol: Genetic modifications for enhanced antifungal activity. In: Biology of plantmicrobe-interactions. Slacey, G., Mullin, B. \& Gresshof, P.M. (ed.) Minnesota: 457-462

LindBerg, G.D., LARKIn, J.M. \& Whaley, H.A. 1980: Production of tropolone by a Pseudomonas. J. Nat. Prod. 43: 592-594

LinDENBERG, H. 2001: Fuingizideinsatz in Winterraps. 19: 64-69.

LiU, L., KLOEPPER, W. \& TUZUN, S. 1995: Induction of systemic resistance in cucumber against bacterial angular leaf spot by plant growth-promoting rhizobacteria. The American Phytopath. Soc. 85: 843-847 
Loeffler, W., Tschen, J.S.-M., Vanittanakom, N., Kugler, M., Knorpp, E., Hsieh, T.-F. \& WU, T.-G. 1985: Antifungal effects of bacilysin and fengymycin from Bacillus subtilis F-29-3, a comparison with activities of other Bacillus antibiotics. J. Phytopathol. 115: 204-213

Lorito, M., Harmann, G.E., Hayes, C.K., Broadway, R.M. Tronsmo, A., Woo, S.L. \& DIPIETRO, A. 1993: Chitinolytic enzymes produced by Trichoderma harzianum: antifungal activity of purified endochitinase and chitibiosidase. Phytopathology 83: 302-307

Lorito, M., Woo, S.L., Fernandez, I.G., Colucci, G., Harman, G.E., Pintor-Toro, J.A., Filippone, E., Muccifora, S., LAWrence, C.B., ZoinA, A., TuZun, S, \& SCALA, F. 1998: Genes from mycoparasitic fungi as a source for improving plant resistance to fungal pathogens. Proc. Natl. Acad. Sci. USA 95: 7860-7865

LOPER, J.E. 1988: Role of fluorescent siderophore production in biological control of Pythium ultimum by a Pseudomonas fluorescens strain. Phytopathology 78: 166-172

LOPER, J.E. \& BUYER, J.S. 1991: Siderophores in microbial interactions on plant surfaces. Mol. PlantMicrobe Interactions 4: 5-13

LOPER, J. E., HAACK, C. \& SCHROTH, M.N. 1985: Population dynamics of soil pseudomonads in the rhizosphere of potato (Solanum tuberosum L.). Appl. Environ. Microbiol. 49: 416-422

LÜHS, W. \& FRIEDT, W. 1997: Wann ist mit ersten transgenen Rapssorten in Deutschland zu rechnen? Raps 15: 10-17

LUMSDEN, R.D., Lewis, J.A. \& Fravel, D.R. 1995: Formulation and delivery of biocontrol agents for use agaibst soilborne plant pathogens. In: Hall, F.R. \& barry, J.W. (eds.): Biorational pest control agents. Formulation and delivery. Washington

MAHUKU, G.S., GoODwIN, P.H. \& HALL, R. 1995: A competitive polymerase chain reaction to quantify DNA of Leptosphaeria maculans during blackleg development in oilseed rape. Mol. Plant Microbe Interact. 8: 761-767

Markellou, E., Malathrakis, N.E., Walker, R., Edwards, S.G., Powell, A.A. \& Seddon, B. 1995: Characterisation of bacterial antagonists to Botrytis cinerea from the biotic environment and its importance with respect to Bacillus species and biocontrol considerations. The Polish Phytopathological Society, pp. 385-389.

MARSCHNER, P. \& CROWLEY, D.E. 1996: Physiological activity of a bioluminescent Pseudomonas fluorescens (strain 2-79) in the rhizosphere of mycorrhizal and non-mycorrhizal pepper (Capsicum annuит L.). Soil Biol. Biochem. 28: 869-876

MAUCH, F., HADWIGER, L.A. \& Boller, T. 1988: Antifungal hydrolases in pea tissue. I. Purification and characterisation of two chitinases and two 1,3-3-glucanases differentially regulated during development and response to fungal infection. Plant Physiol. 87: 325-333.

MAURER, S. 1999: Isolierung von 1,3-ß-Glucanase und Chitinase produzierenden Bodenorganismen und Überprüfung ihrer antagonistischen Wirkung auf Rhizoctonia solani Kühn. Diplomarbeit, Universität Göttingen

Maurhofer, M., Hase, C. Meuwly, P. MétrauX, J.-P. \& Gefago. G. 1994: Induction of systemic resistance of tobacco to tobacco necrosis virus by the root-colonizing Pseudomonas fluorescens strain CHA0: Influence of the gacA gene and of pyoverdine production. Phytopathology 84: 139146

Maurhofer, M., Keel, C., HaAs, D. \& DÉfago, G. 1994: Pyoluteorin production by Pseudomonas fluorescens strain CHA0 is involved in the suppression of Pythium damping-off of cress but not of cucumber. Eur. J. Plant Pathol. 100: 221-232

Maurhofer, M., Schnider, U., KeEl, C., Voisard, C. HAAs, D. \& Defago, G. 1992: Influence of enhanced antibitic production in Pseudomonas fluorescens Strain CHA0 on ist disease suppressive capacity. Phytopathology 82: 190-195 
Maurhofer, M., Keel, C., HaAs, D. \& Defago, G. 1995: Influence of plant species on disease suppression by Pseudomonas fluorescens strain CHA0 with enhanced antibiotic production. Plant Pathol. 44: 40-50

Maurhofer, M., Keel, C., Schnider, U., Voisard, C., HaAs, D.\& DefagO, G. 1992: Influence of enhanced antibiotic production in Pseudomonas fluorescens strain CHA0 on its disease suppressive capacity. Phytopathology 82: 190-195

Mavrodi, D.V., KsenzenKo, V.N., Bonsall, R.F., CoOK, R.J., Boronin, A.M., \& ThOMASHOW, L.S. 1998: A Seven-Gene Locus for Synthesis of Phenazine-1-Carboxylic Acid by Pseudomonas fluorescens 2-79. J. Bacteriol. 180: 2541-2548

Mazzola, M., Fujimoto, D.K. \& CoOK, R.J. 1994: Differential sensitivity of Gaeumannomyces graminis populations to antibiotics produced by biocontrol fluorescent pseudomonads. Phytopathology 84: 1091

Mazzola, M., Fujimoto, D.K., Thomashow, L.S. \& CoOK, R.J. 1995: Variation in sensitivity of Gaeumannomyces graminis populations to antibiotics produced by fluorescent Pseudomonas spp. And effect on biological control oftake all of wheat. Appl. Environ. Microbiol. 61: 2554-2559

Mazzola, M., R. J. CoOK, L. S. Thomashow, D. M. Weller, \& Pierson, L. S. 1992: Contribution of phenazine antibiotic biosynthesis to the ecological competence of fluorescent pseudomonads in soil habitats. Appl. Environ. Microbiol. 58: 2616-2624

Mcclure, N.C., AhMadi, A. \& Clare, B.G. 1998: Construction of a Range of Derivatives of the Biological Control Strain Agrobacterium rhizogenes K84: a Study of Factors Involved in Biological Control of Crown Gall Disease. Appl. Environ. Microbiol. 64: 3977-3982

MCGEE, D.C. \& EMMETT, R.W. 1977: Blackleg (Leptosphaeia maculans (desm.)) Cs. et de Nort. of rapeseed in Victoria: Crop losses and factors which affect disease severity. Austr. J. Agric. Res. 28: $47-51$

MCGEE, D.C. \& PETRIE, G.A. 1978: Variability of Leptosphaeria maculans in relation to blackleg of oilseed rape. Phytopathology 68: 625-630

McGee, D.C. \& Petrie, G.A. 1979: Seasonal patterns of ascospore discharge by Leptosphaeria maculans in relation to blackleg of oilseed rape. Phytopathology 69: 586-589

MC Loughlin, T.J., QuinN, J.P., BetTermanN, A. \& Bookland, R. 1992: Pseudomonas cepacia suppression of sunflower wilt fungus and role of antifungal compounds in controlling the disease. Appl. Environ. Microbiol. 58: 1760-1763

MCQUILKEN, M.P., WHIPPS, R.C. \& COOKE, R.C. 1992: Use of oospore formulations of Pythium oligandrum for biological control of Pythium damping-off in cress. J. Phythopathology 135: 125134

MCQUILKEN, M.P., WHIPPS, R.C. \& LYNCH, J.M. 1993: Some effects of water extracts of composts on Botrytis cinerea. IOBC/WPRS Bulletin 16: 12-15

Mengistu, A., Hill, C.B. \& Williams, P.H. 1995: A toothpick Method for Mating Leptosphaeria maculans, the Causal Agent of Blackleg of Crucifers. Plant Dis. 79: 755-756

Mengistu, A., Rimmer, R.S. \& Williams, P.H. 1993: Protocols for in Vitro Sporulation, Ascospore Release, Sexual Mating and Fertility in Crosses of Leptosphaeria maculans. Plant Dis. 77: 538540

Merriman, P. R., Price, R. D., Kollmorgen, J. F., Piggott, T. \& Ridge, E. H. 1974: Effect of seed inoculation with Bacillus subtilis and Streptomyces griseus on the growth of cereals and carrots. Austr. J. Agric. Res. 25: 219-226

Mew, T.W., Rosales, A.M., Mannigeas, G.V., Telan, I.F., Xuan, T.H. 1994: Field evaluation of biological control agents against Rhizoctonia sheath blight of rice. Phythopathology 84: 1083 
Meyer, J.-M, Azelvandre, P. \& Georges, C. 1992: Iron metabolism in Pseodomonas: Salicylic acid, a siderophore of Pseudomonas fluorescens CHA0. Biofactors 4: 23-27

MeYer, J.M., Hohnadel, D. und F. HAlle 1989: Cepabactin from Pseudomonas cepacia, a new type of siderophore. J. Gen. Microbiol. 135: 1479-1487

MiLls, P. \& WoOD, R. 1984: The effects of polyacrylic acid on resistance of cucumber to Colletrihum lagenarium Phytopath. Z. 111: 209-216

Mitchell, R. \& AleXANDER, M. 1961: Chitin and the biological control of Fusarium diseases. Plant Dis. Reporter 45: 487-490

Mohamed, S. \& CAUNTER, I. G. 1995: Isolation and characterization of a Pseudomonas fluorescens strain suppressive to Bipolaris maydis. J. Phytopathol. 143: 111-114

Montesinos, E., BonaterRA, A., OPHIR, Y. \& BeER, S.V. 1996: Antagonism of selected bacterial strains to Stemphylium vesicarium and biological control of brown spot of pear under controlled environmental conditions. Phytopathology 86: 856-863.

MÜlLER, E. \& TOMASEVIC, G.S. 1957: Kulturversuche mit einigen Arten der Gattung Leptosphaeria Ces. et de Not. Phytopath. Z. 29 : 297-294

Morales, V.M, SÉGuin-Swartz, G. \& TAYLOR, J. 1993: Chromosome size polymorphism in Leptosphaeria maculans. Phytopathology 83: 503-509.

MuRRAY, T. \& SEDDON, B. 1986: Antibiotic-producing bacilli and biocontrol against fungal plant pathogens. J. Appl. Bacteriol. 61: 345-351

Natsch, A., Keel, C. \& Hebecker, N. 1998: Impact of Pseudomonas fluorescens strain CHA0 and a derivative with improved biocontrol activity on the culturable resident bacterial community on cucumber roots. FEMS-Microbiology-Ecology. 27: 365-380

NATHANIELS, N.Q.R. \& TAYLOR, G.S. 1983: Latent infection of winter oilseed rape by Leptosphaeria maculans. Plant Pathol. 32: 23-31.

NÄVEKE, R. \& TEPPER, K.P. 1979: Einführung in die mikrobiologischen Arbeitsmethoden, Guslav Fischer Verlag, Stuttgart

NDimande, B. 1976: Studies on Phoma lingam (Tode ex Fr.) Desm. and dry rot on oilseed rape, Brassica napus (L.) var. olerfera Metzger. Thesis Agric.Colege of Sweden, Uppsala, Sweden.

NEILL, J.C. 1929: Dry-rot of swedes. Some field observations an experiments on control. J. Agric. 39: $86-93$.

NeviLl, D., R. NYFELER, \& SozzI, D. 1988: CGA142705: a novel fungicide for seed treatment. Proc. Brighton Crop Prot. Conf. Pest Dis. 1: 65-72

NOGA, G.A., STINDT \& LENZ 1990: Auswirkungen von Tensidbehandlungen auf die Anfälligkeit von Phaseolus vulgaris L. und Brassica oleracea var. gongylodes L. gegenüber Botrytis cinerea. Gartenbauwissenschaft 55: 97-103

Normander, B. Hendriksen, N.B. \& Nybroe, O. 1999: Green Fluorescent Protein-Marked Pseudomonas fluorescens: Localization, Viability, and Activity in the Natural Barley Rhizosphere Appl. Environ. Microbiol. 65: 4646-4651

NowAK-ThOMPSON, B; CHANEY, N., WING, J.S., GOULD, S.J., LOPER, J.E. 1999: Characterization of the pyoluteorin biosynthetic gene cluster of Pseudomonas fluorescens Pf-5. J. Bacteriol. 181: 2166-74

O’Callaghan, K.J., Stone, P.J., Hu, X. GRifFiths, D.W, Davey, M.R., \& Cocking, E.C. 2000: Effects of Glucosinolates and Flavonoids on Colonization of the Roots of Brassica napus by Azorhizobium caulinodans ORS571 Appl. Enviiron. Microbiol. 66: 2185-2191

ORDEnTlich, A., ElaD, Y. \& ChET, I. 1988: The role of chitinase of Serratia marcescens for the control of Sclerotium rolfsii. Phytopathology 78: 84-88 
PAAN, A. S. 1988: Formulation useful in applying beneficial microorganisms to seed. Elsevier science Publishers 6: 276-279

PAN, S.Q., YE, X.S. \& KUĆ, J. 1991: Association of B-1,3-glucanase activity and isoform pattern with systemic resistance to blue mould in tobacco induced by stem injection with Peronospora tabacina or leaf inoculation with tobacco mosaic virus. Mol. Plant Pathol. 39: 25-39

PARK, D. 1960: Antagonism - the background to soil fungi. IN: The ecology of soil fungi, Parkinson, D. and WAID, J.S., (eds), Liverpool University Press, Liverpool, England, 148-159

PaUL, V.H. 1992: Krankheiten und Schädlinge des Rapses. Verlag Th. Mann, Gelsenkirchen-Buer.

Paul, V., Gerdiken, K.J. \& GÜnZelmann, A. 1991: Neue Erkenntnisse über die Reaktion von 00Sorten und die Wirkung von Fungiziden auf die Wurzelhals- und Stengelfäule des Winterrapses. Nachrichtenbl. Deut. Pflanzenschutzd. 43: 82-92

PAUlitz, T.C. AhMED, J.S. \& BAKER, R. 1990: Integration of Pythium nunn and Trichoderma harzianum isolate T-95 for the biological control of Pythium damping-off of cucumber. Plant and soil 121: 243-250

Pavlica, D.A., Hora, T.S., Bradshaw, J.J., Skogerboe, R.K. \& BaKer, R. 1978: Volatiles from soil influencing activities of soil fungi. Phytopathology 68: 758-765

VAN PÉE, K.-H. \& LIGON, J.M. 2000: Biosynthesis of pyrrolnitrin and other phenylpyrrole derivatives by bacteria Nat. Prod. Rep. 17: 157-164

Patel, A.V., MÜller, R. \& Vorlop, K.D. 1995: Einschlußimmobilisierung von biologischen Schädlingsbekämpfungsmitteln. Geunde Pflanzen 47: 167-174

PaVlica, D.A. Hora, T.S., Bradshaw, J.J. SKOgERBoe, R.K. \& BAKER, R. 1978: Volatiles from soil influencing activities of soil fungi. Phytopathology 68: 758-765.

PETRIE, G.A. 1979: Prevalence of a highly virulent strain of Leptosphaeria maculans (blackleg) in seed samples of rape and turnip rape produced on Western Canada in 1976 and 1977. Can. J. Plant Sci. 59: 899-901

PETRIE, G.A. 1994: Effects of temperature and moisture on the number, size and septation of ascospores produced by Leptosphaeria maculans (blackleg) on rapeseed stubble. Can. Plant Dis. Survey 74: $141-151$

Petrie, G.A. 1993b: Distribution of virulent blackleg on standing rapeseed/canola crops in Saskatchewan, 1982-1991. Can. Plant. Dis. Survey 73: 117-121

PETRIE, G.A. 1995: Effect of chemicals on ascospore production by Leptosphaeria maculans on blackleg-infected canola stubble in Saskatchewan. Can. Plant Dis. Surv. 75: 45-50

PetrIE, G.A. 1982: Blackleg of rapeseed (canola) caused by Leptosphaeria maculans: interactions of virulent strains and implications for biological control. Can. J. Plant Pathol. 4: 309 (Abstr.)

PETRIE, G.A. 1978: Occurrence of a highly virulent strain of blackleg (Leptosphaeria maculans) on rape in Saskatchewan (1975-77). Can. Plant. Dis. Survey 58: 21-25.

Petrie, G.A., Mortensen, K. \& Dueck, J. 1985: Blackleg and other diseases of rapeseed in Saskatchewan, 1978 to 1981. Can. Plant Dis. Surv. 65: 35-41.

PfÄHLER, B. 1998: Charakterisierung der Abwehrreaktionen von Rapspflanzen gegen Phoma lingam unter besonderer Berücksichtigung der Anreicherung von Phytoalexinen. Dissertation, Universität Göttingen.

PfEndeR, W.F., KRAUS, J. \& LOPER, J.E. 1993: A genomic region from Pseudomonas fluorescens Pf-5 required for pyrrolnitrin production and inhibition of Pyrenophora tritici-repentis in wheat straw. Phytopathology 83: 1223-1228.

PHILIPP, W.-D., 1988: Biologische Bekämpfung von Pflanzenkrankheiten. Verlag Eugen Ulmer, Stuttgart. 
Philipp, W.-D., Beuther, E., Hermann, D., Klinkert, F., Oberwalder, C., Schmidrke \& STRAUB, B. 1990: Zur Formulierung des Mehltauhyperparasiten Ampelomyces quisqualis Ces. Z. PflKrankh. PflSchutz 92: 120-132.

PhilipP, W.-D. \& Hellstern, A. 1986: Biologische Mehltaubekämpfung mit Ampelomyces quisqualis bei reduzierter Luftfeutigkeit. Z. PflKrankh. PflSchutz 93: 384-391

Philson, S.B. \& LlinAS, M. 1982: Siderochromes from Pseudomonas fluorescens. J. Biol. Chem. 257: $8081-8085$.

PIERSON, E.A. \& WELlER, D.M. 1993: The use of bacterial mixtures to improve the biological control of take-all of wheat. Phytopathology 83: 1365

Pierson, E.A. \& Weller, D.M. 1993: The use of mixtures of fluorescent pseuodomonads to suppress take-all and improve the growth of wheat. Phytopathology 84: 940-947

Pieterse, C.M.J., Van Wees, S.C.M., Hoffland, E., Van Pelt, J.A., Van Loon, L.C. 1996. Systemic resistance in Arabidop-sis induced by biocontrol bacteria is in-dependent of salicylic acid accumula-tion and pathogenesis-related gene ex-pression. Plant Cell 8: 1225-37

Pleban, S., InGEL, F. \& CHET, I. 1995: Control of Rhizoctonia solani and Sclerotium rolfsii in the greenhouse using endophytic Bacillus spp. Europ. J. Plant Pathol. 101: 665-672.

Plet, P E. \& ChOllet. R. 1970: Sur le dosage colorimétrique de I'acide indolylacétique. C. R. Acad. Sci. ser. D 271: 1675-1678

Plieske, J., Strussá, D. \& RobBelen, G. 1998: Inheritance of resistance derived from the B-genome of Brassica against Phoma lingam in rapeseed and the development of molecular markers. Theor. Appl. Genet. 97: 929-936

Plummer, K.M., Dunse, K. \& Howlett, B. 1994: Non-aggressive Strains of the Blackleg Fungus, Leptosphaeria maculans, are present in Australia and can be distinguished from Aggressive Strains by Molecular Analysis. Aust. J. Bot. 42: 1-8.

Powell, K.A., \& Jutsum, A.R. 1993: Technical and commercial aspects of biocontrol products. Pestic. Sci. 37: 315-321.

Press, C.M., Wilson, M., Tuzun, S., KloepPer, J.W. 1997: Salicylic acid produced by Serratia marcescens 90-166 is not the primary determinant of induced systemic resistance in cucumber or tobacco. Mol. Plant-Microbe Interact. 10: 761-68

RAAIJMAKERS, J. M., \& WELLER, D. M. 1998: Natural plant protection by 2,4-diacetylphloroglucinolproducing Pseudomonas spp. in take-all decline soil. Mol. Plant-Microbe Interact. 11: 144-152.

RAAiJMAKERS, J.M., BONSALl, R.F. \& WELlER, D.M. 1999: Effect of population density of Pseudomonas fluorescens on production of 2,4-diacetylphloroglucinol in the rhizosphere of wheat. Phytopathology 89: 470-475.

RAAiJMAKers, J. M., Weller, D. M. \& ThOMASHOW, L. S. 1997: Frequency of antibiotic-producing Pseudomonas spp. in natural environments. Appl. Environ. Microbiol. 63: 881-887.

RAuPACH, G.S., LiU, L., MurPhy, J.F., TuZun, S., KLOEPPER, J.W. 1996: Induced systemic resistance in cucumber and tomato against cucumber mosaic cucu-movirus using plant growth-promoting rhizobacteria (PGPR). Plant Dis. 80: 891-94

Rawlinson, C.J., Muthyalu, G. \& Caley, G.R. 1984: Fungicide effects on light leaf spot canker, cop growth and yield of winter oilseed rape. J. agric. Sci. Camb. 103: 613-628.

REMMELE, E. \& WidMANN, B. (1998): Schmierstoffe und Hydrauliköle auf Basis Rapsöl. Raps 16: 142-145.

RenwiCK, A., CAMPBell, R. \& COE, S. 1991: Assessment of in vivo screening systems for potential biocontrol agents of Gaeumannomyces graminis. Plant Pathol. 40: 524-532

REUTER, L.B. 1999: Der Markt für Raps-Speiseöl. Innovation (3): 26-27. 
Rothrock, C.S. \& GotTlieb, D. 1984: Role of antibiosis in antagonism of Streptomyces hygroscopicus var. geldanus to Rhizoctonia solani in soil. Can. J. Microbiol. 30: 1440-1447

RouXel, T., BALESDENT, M.-H., SÉGuin-SWARTZ. G. \& Gugel. R. 1995: How many pathogens cause blackleg of crucifers? Blackleg News 4: 1-7.

RovirA, A.D. \& CAMPBELL, R. 1975: A scanning electron microscope study of interactions between microorganisms and Gaeumannomyces graminis (Syn. Ophiobolus graminis) on wheat roots. Microb. Ecol. 3: 177-185.

Rovira, A. D., Newman, E. I., Bowen, H. J. \& CAMPBell, R. 1974: Quantitative assessment of the rhizoplane microflora by direct microscopy. Soil Biol. Biochem. 6: 211-216.

SAlisbury, P. \& BALlinger, D. 1993: Race variability in Leptosphaeria maculans. Blackleg News. 1: $3-4$.

Salisbury, P.A., Ballinger, D.J., Wratten, N., Plummer, K.M. \& Howlett, B.J. 1995: Blackleg disease on oilseed Brassica in Australia: a review. Aust. J. Exp. Agricultur, 35: 665672.

Sarniguet, A., Kraus, J., Henkels, M.D., Muehlchen, A. M. \& LoPer, J. 1995: The sigma factor sigma-s affects antibiotic production and biological control activity of Pseudomonas fluorescens Pf-5. Proc. Nat. Acad. Sci. USA 92: 12255-12259

SASSE, A. 1997: Untersuchungen zur biologischen Bekämpfung des Rapswelkeerregers (Verticillum dahliae Kleb.) durch den Einsatz mikrobieller Antagonisten. Dissertation Univ. Göttingen. $133 \mathrm{pp}$

SAUERMANN, W. 1993: Vorfruchteffekte von Winterraps. Raps 11: 118-120

SCHIPPERS, B., BAKKER, A.W. \& BAKKER, P.A.H.M. 1987: Interactions of deleterious and bebeficial rhizosphere microorganisms and the effect of cropping pratices. Annu. Rev. Phytopathol. 25: 339-358.

Schoemann, M., WebBer, J. \& Dickinson, D. 1994: A rapid method for screening potential biocontrol agents of wood decay. Eur. J. For. Path. 24: 154-159.

Shanahan, P., O'Sullivan, D.J., Simpson, P., GlenNON, J.D. \& O'GARA, F. 1992: Isolation of 2.4-diacetylphloroglucinol from a fluorescent Pseudomonad and investigation of physiological parameters influencing ist production. Appl. Environ. Microbiol. 58: 353-358.

SHIPTON, P. J. 1975: Take-all decline during cereal monoculture. In: Biology and Control of SoilBorne Plant Pathogens, BrueHL G.W. (ed.), pp. 137-44. St. Paul, Minn.: Am. Phytopathol. Soc. $216 \mathrm{pp}$

Sharifi-Tehrani, A., Zala, M., NATSCh, A., MoËNne-Loccoz, Y., \& DÉfaGO, G. 1998: Biocontrol of soil-borne fungal plant diseases by 2,4-diacetylphloroglucinol-producing fluorescent pseudomonads with different restriction profiles of amplified 16s rDNA. Eur. J. Plant Pathol. 104: 631-643

SCHLEIER, S., Voigt, K. \& Wöstemeyer, J. 1997: RAPD-based Molecular Diagnosis of Mixed Fungal Infections on Oilseed Rape (Brassica napus): Evidence for Genus- and Species-specific Sequences in the Fungal Genomes. J. Phytopathol. 145: 81-87

SCHMIDT, C. 1997: Untersuchungen zur biologischen bekämpfung von Eutypa lata (Pers.:Fr.) Tul. \& C.Tul., dem Erreger der Eutypiose der Weinrebe, durch mikrobielle Antagonisten. Dissertation, Uiversität Göttingen. 188pp.

SCHMiDT, C., LORENZ, D. \& G.A. WOLF 1997: Untersuchungen zur biologischen Bekämpfung der Eutypiose an Weinreben. Gesunde Pflanzen 49: 61-67

SchmiedeKnecht, G. Bochow, H. \& Junge, H. 1996: Biologischer Pflanzenschutz bei Kartoffeln. In: Mitteilungen aus der Biologischen Bundesanstalt für Land- und 
Forstwirtschaft: 50. Deutsche Pflanzenschutztagung in Münster, Laux, W. (Hrsg.). Parey, Berlin: 467

SCHMIEDL, J. \& KÖPPL, H. 1996: Lohnt sich der Fungizideinsatz im Raps? Raps 14: 17-19.

SChNider, U., Keel, C., Blumer, C., Troxler, J.. DÉFAGO, G. \& HAAS, D. 1995: Amplification of the housekeeping sigma factor in Pseudomonas fluorescens CHAO enhances antibiotic production and improves biocontrol abilities. J. Bacteriol. 177: 5387-5392

SCHÖNBECK, F., STEINER, U. \& KRASKA, T. 1993: Induzierte Resistenz: Kriterien, Mechanismen, Anwendung und beertung. Z. PflKrankh. PflSchutz 100: 541-557.

Schramm, H. 1989: Zur Epidemiologie von Leptosphaeria maculans (Desm.) Ces. et de Not. (Imperfektstadium Phoma lingam (Tode ex Fr.) Desm.), dem Erreger der Wurzelhals- und Stengelfäule an Winterraps als Grundlage eines integrierten Pflanzenschutzes. Diss. TU München-Weihenstephan.

SCHROTH, M. N. \& HANCOCK, J. F. 1982: Disease-suppressive soil and rootcolonizing bacteria. Science 216: 1376-1381.

Schulz, D. \& Wolf, G. 1998: Der Einfluss definierter Nährstoffgaben in einer Saatgutbehandlung auf die biologische Bekämpfung des Zuckerrübenpathogens Pythium ultimum durch Pseudomonas fluorescens B5. In: Mitteilungen aus der Biologischen Bundesanstalt für Landund Forstwirtschaft: 51. Deutsche Pflanzenschutztagung in Halle/Saale, Laux, W. (Hrsg.). Parey, Berlin: 76.

Schulz, D., Heupel, M. \& Wolf, G. A. 1994: Untersuchungen zu Mechanismen und Steuerungsfaktoren der antagonistischen Wirkung von Pseudomonas fluorescens B5 im System Beta vulgaris-Pythium ultimum. Mitt. Biol. Bundesanst. Land- und Forstwirtschaft 301: 354 .

SCHUSTER, W. SCHEIBERT-BÖHM, F. \& SCHLÖSSER, E. 1980: Untersuchungen zum Befall durch Phoma lingam (Tode ex. Fr.) Desm. bei Winterraps. Z. Acker- und Pflanzenbau 149: 433-446.

SCHWYNN, B. \& NeILANDS, J. B. 1987: Universal chemical assay for the detection and determination of siderophores. Anal. Biochem. 160: 47-56.

Simons, M., VAn der Bij, A. J., Brand, I., De Weger, L. A., Wijffelman, C. A. \& LUGTENBERG, B. J. 1996: Gnotobiotic system for studying rhizosphere colonization by plant growth-promoting Pseudomonas bacteria. Mol Plant-Microbe Interact 9: 600-607

SiKora, R. A., Bodenstein, F. \& Nicolay, R. 1990: Einfluß der Behandlung von Rübensaatgut mit Rhizosphärenbakterien auf den Befall durch Pilze der Gattung Pythium. I: Antagonistische Wirkung verschiedener Bakterienisolate gegenüber Pythium spp. J. Phytopathol. 129: 111-120

SJöDIN, C. \& GLIMELIUS, K. 1988: Screening for resistance to blackleg Phoma lingam (Tode ex Fr.) Desm. within Brassicaceae. J. Phytopathol. 123: 322-332

SLEESMAN, J.P. und C. LeBEN 1976: Microbial antagonists of Bipolaris maydis. Phytopathology 66: 1214-1218

SLININDER, P. J. \& JACKSON, M.A. 1992: Nutritional factors regulating growth and accumulation of phenazine 1-carboxylic acid by Pseudomonas fluorescens 2-79. Appl. Microbiol. Biotechnol. 37: 388-392.

SLINIGER, P.J. \& SHEA-WILBUR, M.A. 1995: Liquid-culture pH, temperature and carbon (not nitrogen) source regulate phenazine productivity of the take-all biocontrol agent Pseudomonas fluorescens. Appl. Microbiol. Biotechnol. 43: 794-800.

SMIRNOV, V. V., \& E. A. KipRIANOVA. 1990. In Bacteria of Pseudomonas genus, p. 100-111. Naukova Dumka, Kiev, Ukraine

SMith, H. C. 1956: Leptosphaeria napi, the perithecial form of Phoma lingam causing dry-rot disease of Brassicas. New. Zeal. Sci. Rev. 14: 116-117 
Smith, H.C. \& SutTon, B.C. 1964 Leptosphaeria maculans the ascogenous state of Phoma lingam. Trans. Brit. Mycol. Soc. 47: 159-165

SMith, K.P., HANDELSMAN, J. \& GOODMAN, R.M. 1999: Genetic basis in plants for interactions with disease-suppressive bacteria. Proc. Natl. Acad. Sci. USA 96: 4786-4790

Sock, J. \& Hoppe, H.-H. 1999: Pathogenicity of Sirodesmin-deficient Mutants of Phoma lingam. J. Phytopathol. 147: 169-173

Soledade-M; Pedras, C. \& Biesenthal-Corinne, J. 1998: Production of the host-selective phytotoxin phomalide by isolates of Leptosphaeria maculans and its correlation with sirodesmin PL production. Can. J. Microbiol. 44: 547-553

SOMDA, I., RENARD, M. \& BRUN, H. 1996: Morphology, pathogenicity and isozyme variation amongst French isolates of Leptosphaeria maculans recovered from Brassica juncea cv. Picra. Plant Pathol. 45: 1090-1098

SOMDA, I.,HARKOUS, S. \& BRUN, H. 1997: Bipolar heterothallism in B-group isolates of Leptosphaeria maculans. Plant Pathol. 46: 890-896

SPURR, H.W. 1990: The Phylloplane. In: Baker, R.R. \& Dunn, P.E. (eds.): New Directories in Biological Control. Alan R. Liss, Inc., New York, 271-278

Stanley, R., Brown, M., Poole, N. Rogerson, M., Sigee, D.C., Knight, C., Ivuin, C.C., Epton, H.A.S. \& LEIFERT, C.1994: Biocontrol of postharvest fungal diseases on dutch white cabbage by Pseudomonas and Serratia antagonists in storage trials. Plant Pathol. 43: 605-611

Sticher. L., MaUch-MAni, B., \& M'EtrauX, J.P. 1997: Systemic Acquired Resistance. Annu. Rev. Phytopathol.. 35: 235-270

Struss, D., Quiros, C.F., Plieske, J. \& RöbBelen, G. 1996: Construction of Brassica B genome synteny groups based on chromosomes extracted from three different sources by phenotypic, isozyme and molecular markers. Theor. Appl. Genet. 93: 1026-1032

Suslow, T. V. \& Schroth, M. N. 1981: Bacterial culture preservation in frozen and dry-film methylcellulose. Appl. Environ. Microbiol. 42: 872-877

TAKEDA, R. 1958 Pseudomonas pigments. I. Pyoluteorin, a new chlorin-containing pigment produced by Pseudomonas aeruginosa. Hako Kogaku Zasshi 36: 281-290

TANG, W.H. \& YANG, H.T. 1997: Research and application of biocontrol of plant diseases and PGPR in China. In: OGOSHI et al. (eds.) Plant Growth-Promoting Rhizobacteria -Present Status and Future, Prospects. pp. 2-9. Nakanishi Printing, Sapporo.

TANNEN, D. 1975: A test of a modified line intertest method of estimating root length J. Appl. Ecol.

TAYLOR, J.L., BORGMANN, I. \& SÉGUIN-SWARTZ, G. 1991: Electrophoretic karyotyping of Leptosphaeria maculans differentiates highly virulent from weakly virulent isolates. Appl. Environ. Microbiol. 59: 3681-3685

ThOMASHOW, L. S. \& WelleR, D. M. 1990: Role of antibiotics and siderophores in biocontrol of take-all disease of wheat. Plant and Soil 129: 93-99

Thomashow, L.S. \& WelleR, D.M. 1988: Role of a phenazine antibiotic from Pseudomonas fluorescens in biological control of Gaeumannomyces graminis var. tritici. J. Bacteriol. 170: 33993508

Thompson, D. C., Clarke, B. B. \& Kobayashi, D. Y. 1996: Evaluation of bacterial antagonists for reduction of summer patch symptoms in Kentucky bluegrass. Plant Dis. 80: 856-862.

THÜRWÄCHTER, F. 1995: Zum Auftreten und zur Bedeutung verschiedener Rapskrankheiten in Norddeutschland und zur Wirtschaftlichkeit von Fungizidmaßnahmen in Winterraps (Brassica napus L. var. oleifera). Gesunde Pflanzen, 47: 217-221. 
von Tiedemann, A., Hedke, K. \& Mögling, R. 2000: Biologische Bekämpfung der SclerotiniaWeißstängeligkeit. Raps 18: 10-13.

TILCHER, R 1996: Untersuchungen zur Biologischen Bekämpfung des Falschen Mehltaus der Weinrebe (Plasmopara viticola (Berk.\& Curt.) Berl.\& de Toni) durch bakterielle Antagonisten. Dissertation, Universität Göttingen

Troxler, J., Zala, M., Moënne-Loccoz, Y., Keel, C. \& Défago, G.. 1997: Predominance of nonculturable cells of the biocontrol strain Pseudomonas fluorescens CHA0 in the surface horizon of large outdoor lysimeters. Appl. Environ. Microbiol. 63: 3776-3782

Troxler, J., Berling, C.H., Möenne-Loccoz, Y., Keel, C., Défago G. 1997: Interactions be-tween the biocontrol agent Pseudomonas fluorescens CHA0 and Thielaviopsis ba-sicola in tobacco roots observed by immunofluorescence microscopy. Plant Pathol. 46: 62-71

TRAUTWEIN, E. \& ERBERSDOBLER, H.F. 1997: Rapssorten mit verändertem Fettsäure-muster - eine ernährungswissenschaftliche Betrachtung. Raps 15: 152-155

TURNER, J.T. \& BACKMAN, P.A. 1991: Factors relating to peanut yield increase after seed treatment with Bacillus subtilis. Plant Dis. 75: 347-353.

TURNER, J. M., \& MESSENGER, A. J. 1986: Occurrence, biochemistry and physiology of phenazine pigment production. Adv. Microb. Physiol. 27: 211-275

UlBER, B. 1994: Wirkung des kombinierten Befalls von Winterraps mit dem Großen Rapsstengelrüßler (Ceutorhynchus napi (GYLL.)) und dem Gefleckten Kohltriebrüßler (Ceutorhynchus pallidactylus (MRSH.)) auf den Phoma lingam-Befall und den Ertrag. Mitt. a.d. Biol. Bundesanst. 301: 96.

VAN Loon, L. C., BAKKer, P. A. H. M., \& C. Pieterse, M. J. 1998: Systemic resistance induced by rhizosphere bacteria. Annu. Rev. Phytopathol. 36: 453-83

VAN PEER, R. \& SCHIPPERS, B. 1992: Lipopolysaccharides of plant-growth promot-ing Pseudomonas sp. strain WCS417r induce resistance in carnation to fusarium wilt. Neth. J. Plant Pathol. 98:12939

VElAZHAHAN, R. SAMIYAPPAN, R. \& VidHYASEKARAN, P. 1999: Relationship between antagonistic activitie of Pseudomonas fluorescens isoltaes against Rhizoctonia solani and their production of lytic enzymes. Z. PflKrankh. PflSchutz 106: 244-250.

Visca, P., Ciervo, A., SANFILIPPO, V. und N. ORSI 1993: Iron-regulated salicylat synthesis by Pseudomonas spp. J. Gen. Microbiol. 139: 1995-2001

Voisard, C., Keel, C. HAas, D. \& Défago, G. 1989: Cyanide production by Pseudomonas fluorescens helps suppress black-root rot of tobacco under gnotobiotic conditions. EMBO J. 8: $351-358$

Volke, B. 1999: Leptosphaeria maculans, der Erreger der Wurzelhals- und Stengelfäule an Raps: Verbreitung verschiedener Pathogenitätsgruppen in Europa, Quantifizierung des Befalls und Schadwirkug im Freiland. Dissertation, Universität Göttingen

WALDOW, F. 1997: Entwicklung und Erprobung immunologischer Methoden zum Nachweis des Kohlhernieerregers Plasmodiophora brassicae (Woron.) für Phytohygieneprüfungen von Komposten. Dissertation, Universität Göttingen

WASTERNACK, C. \& PARTHIER, B. 1997: Jasmonate-signalled plant gene expression. Trends Plant Sci. 2: $302-307$

WeBer, E. \& BleiHOLDER, H. 1990: Erläuterungen zu den BBCH-Dezimal-Codes für die Entwicklungsstadien von Mais, Raps, Faba-Bohne, Sonnenblume und Erbse - mit Abbildungen. Gesunde Pflanzen, 42: 308-321 
WeI, G., Kloepper, J. W. \& TUZUn, S. 1991: Induction of systemic resistance of cucumber to Colletotrichum orbiculare by selected strains of plant growth-promoting rhizobacteria. Phytopathology 81: 1508-1512

WELLER, D.M. 1988: Biological control of soilborne plant pathogens in the rhizosphere with bacteria. Ann. Rev. Phytopathol. 26: 379-407

WELLER, D.M., THOMASHOW, L.S., \& COOK, R.J. 1995: Biological control of soil-borne pathogens of what: benefits, risks and current chanllenges. In: HOKKANEN, H.M.T. \& LYNCH, J.M. (eds.): Biological control: benefits and risks Cambridge

WILLIAMS, I.H. 1989: Pest incidence on single low and double low oilseed rape cultivars. Aspects of Appl. Biol. 23: 277-286

WiLliams, P.H. 1992: Biology of Leptosphaeria maculans. Can. J. Plant Pathol. 14: 30-35

WiLliams, R.H. \& FITT, B. 1999: Differentiating A and B groups of Leptosphaeria maculans, causal agent of stem canker (blackleg) of oilseed rape: a review. Plant Pathol.

WILlMS, H. 1990: Biologische Bekämpfung von Microdochium nivale (Fries.) comb. noV. (Syn. Gerlachia nivalis (Ces. ex Sacc.) W. Gams \& E. Müller) durch mikrobieller Antagonisten. Dissertation, Universität Göttingen.

WIRTH, S.J. \& WolF, G.A. 1990: Dye-labelled substrates for the assay and detection of chitinase and lysozyme activity. J. Microbiol. Methods 12: 197-205

Wissing, A.E., ViLlich, V. \& SiKORA, R. 1997: Vergleich von Biotestverfahren zur Ermittlung und Nutzng des antagonistischen Potentials gegen Phytopathogene im Bodenökosystem. Gesunde Pflanzen 49: 1-11

WODZINSKI, R.S., UMHOLTZ, T.E. RUNDLE, J.E. \& BEER, S.V. 1994: Mechanisms of inhibition of Erwinia amylovora by Erwinia herbicola in vitro and in vivo. J. Appl. Bacteriol. 76: 22-29

WOLF, G.A. 1994: Regulationsmechanismen bei der Epidemiologie von bodenbürtigen Pflanzenpathogenen. IN: Bodennutzung und Bodenfruchtbarkeit, Band 7: Dynamik und Regulation von Biozönosen im Agarökosystem, Bundesministerium für Ernährung, Landwirtschaft und Forsten (Hrsg.), Landwirtschaftsverlag, Münster-Hiltrup: 85-92

Wolf, G.A., KeMPF, H.-J., LEE, Y.-S. \& H. WILlms 1993 Charakterisierung und Einsatz antagonistischer Mikroorganismen und deren Sekundärmetabolite zur Bekämpfung phytopathogener Pilze. IN: Wege zu neuen Produkten und Verfahren der Biotechnologie, Anke, T. und U. Onken (Hrsg.), Dechema Monographien, Bd 129, VCH: 289-297

WOLF, G.A. KEMPF, H.J. \& FLIEßBACH, A. 1986: Untersuchungen zur antagonistischen Wirkung von Trichoderma spp. und Erwinia sp.. Mitt. a.d. Biol. Bundesanst. 232: 279

WOLF, G.A. \& WIRTH, S.J. 1990: Application of soluble chromogenic substrates for assays of polysaccharide endohydrolase activity. In: Methods in Phytobacteriology, (Klement, Z., Rudolph, K. \& Sands D.C. eds.), pp. 409-419, Akademial Kiado, Publishiing House of Hungarian academy of sciences, Budapest

WoOD, P. \& BARBETTI, M.J. 1977: A study on the inoculation of rape seedlings with ascospores and pycnidiospores of the blackleg disease causal agent Leptosphaeria maculans. J. Aust. Inst. Agric. Sci. 43: 79-80.

WÖPPEL, H.J. 1995: Ist der Einsatz von Fungiziden im Raps noch wirtschaftlich? Raps 13: 62-63.

WU, J. S. DUAN, Z.H., ZHANG, Y. 1998: Hochwertige Rapssorten und Anbautechnik zum Mehrertrag. Chinesischer Landwirtschsftlicher Verlag 171p.

Zehnder, G., Kloepper, J., TuZun, S., YAO, C., WeI, G. 1997: Insect feeding on cucumber mediated by rhizobacteria-induced plant resistance. Entomol. Exp. Appl. 83: 81-85 
ZHANG, S.A., XU, W.M., YAN, Z.N. \& MEI, R.H. 1996: Research and commercialization of yieldincreasing bacteria in China. In: Eds. TANG, W.H., COOK, R.J. \& ROVIRA, A.: Advances in Biological Control, China Agricultural University Press pp.47-53.

ZHOU, T, \& PAULITZ, T.C. 1994 : Induced resistance in the biocontrol of Pythium aphani-dermatum by Pseudomonas spp. on cucumber. J. Phytopathol. 142: 51-63 


\section{Danksagung}

Mein besonderer Dank gilt Herrn Prof. Dr. G. A. Wolf für die Überlassung des Themas, seine Diskussionsbereitschaft, viele wertvolle Anregungen und Ideen sowie sein ungebrochenes Interesse am Fortgang der Arbeit.

Herrn Prof. Gr. U. Eberhardt, Isotopenlaboratorium für biologische und medizinische Forschung der Universität Göttingen, danke ich für die freundliche Übernahme des Korreferates.

Mein herzlicher Dank gilt 'Xiao Lao Ban' Herrn Dr. Dietmar Schulz für seine kompetente fachliche Mitbetreuung, die Freundschaft und tatkräftige Unterstützung beim Zusammenschreiben der Arbeit.

Für die anregende Diskussion, das kritische Durchlesen des Manuskriptes und die Freundschaft danke ich Dr. Joachim Weinert, Dr. Robert Cernusko, Dr. Hanno Wolf und Herrn Roland Hartz.

Dr. Beate Volke danke ich für die Überlassung der Phoma-Isolate und die Beratung bei fachspezifischen Fragen zu Phoma lingam.

Shimin Tian, Li-Ling Chen und Sui Zhang danke ich für die großzügige Hilfe bei der Durchführung von Versuchen und das sorgfältige Durchlesen der Arbeit trotz vielfältiger eigener Arbeiten.

Frau Dr. Kuo-Sell und Herrn Dr. Sell sowie meinem ersten deutschen Freund Friedrich Sundmacher danke ich für die umfangreiche Hilfe während meines sechsjährigen Aufenthalts in Deutschland.

Den ,Wölfen', insbesondere Sabine Mauer, Dagmar Tacke, Petra Romanczuk, Ahmad Ghazvinizade danke ich für die freundliche Aufnahme und Hilfsbereitschaft.

Weiterhin bedanke ich mich bei:

Prof. Becker für die Bereitstellung des Versuchsaatgutes.

Dr. T. Heinrichs für die Durchführung der Cryo-Rasterelektronmikroskopie.

Dr. B. Koopmann und Bettina Schraut für die Unterstützung bei HPLC-Arbeiten.

Den Graduierten des Kollegs ,Landwirtschaft und Umwelt', insbesondere Gertrud Burghardt, Karin Reiter und Frieder Hamm für die Hilfe bei dienstlichen Aufgaben und Komi Egle für die Hilfe bei der Ermittlung der Wurzellänge.

Herrn Reindtke und Herrn Hodyl für die Hilfe bei der Durchführung von Versuchen.

Allen Institutsangehörigen für die angenehme Arbeitsatmosphäre.

Meiner Schwiegermutter danke ich für ihre liebevolle Betreuung unseres Sohnes während unserer härtesten Studienzeit in Deutschland.

Der Deutschen Forschungsgemeinschaft gilt mein Dank für die Unterstützung dieser Arbeit durch ein Doktorandenstipendium im Rahmen des Graduiertenkollegs ,Landwirtschaft und Umwelt'. 


\section{Lebenslauf}

Name:

Geburtsdatum:

Geburtsort:

Eltern:

Familienstand

$1975-1980$

$1980-1987$

$1987-1991$

$1995-1998$

seit 1998

$1991-1995$

$4 / 1995-9 / 1995$
Qinghua Zhao

19.10.1968

Huxian, Shaanxi, VR China

Junwen Zhao und Ehefrau Shulan Zhao († 1996)

verheiratet, ein Kind

\section{Schulausbildung}

Grundschule Zuan in Shaanxi, VR China

Gymnasium im Landkreis Huxian, Shaanxi, VR China Abschluß: Abitur

\section{Hochschulausbildung}

Studium der Agrarwissenschaften an der Northwestern Agricultural University, VR China

Abschluß: Diplom (B. sc. agr.)

Aufbaustudium am Forschungs- und Studienzentrum für Agrar- und Forstwissenschaften in den Tropen und Subtropen sowie Anfertigung der Magisterarbeit am Institut für Pflanzenpathologie und Pflanzenschutz der Universität Göttingen

Abschluß: Magister (M. sc. agr.)

Promotionsstudium und Anfertigung der Dissertation am Institut für Pflanzenpathologie und Pflanzenschutz der Universität Göttingen

\section{Berufstätigkeit}

Fachreferent für Prognose von Krankheiten und Schädlingen am Pflanzenschutzamt der Provinz Shaanxi, VR China

\section{Deutschkurs}

Deutschkurs an der Sprachschule Speak + Write in Marburg, Deutschland 